\title{
Socio-economic modelling of rabies control in Flores Island, Indonesia
}

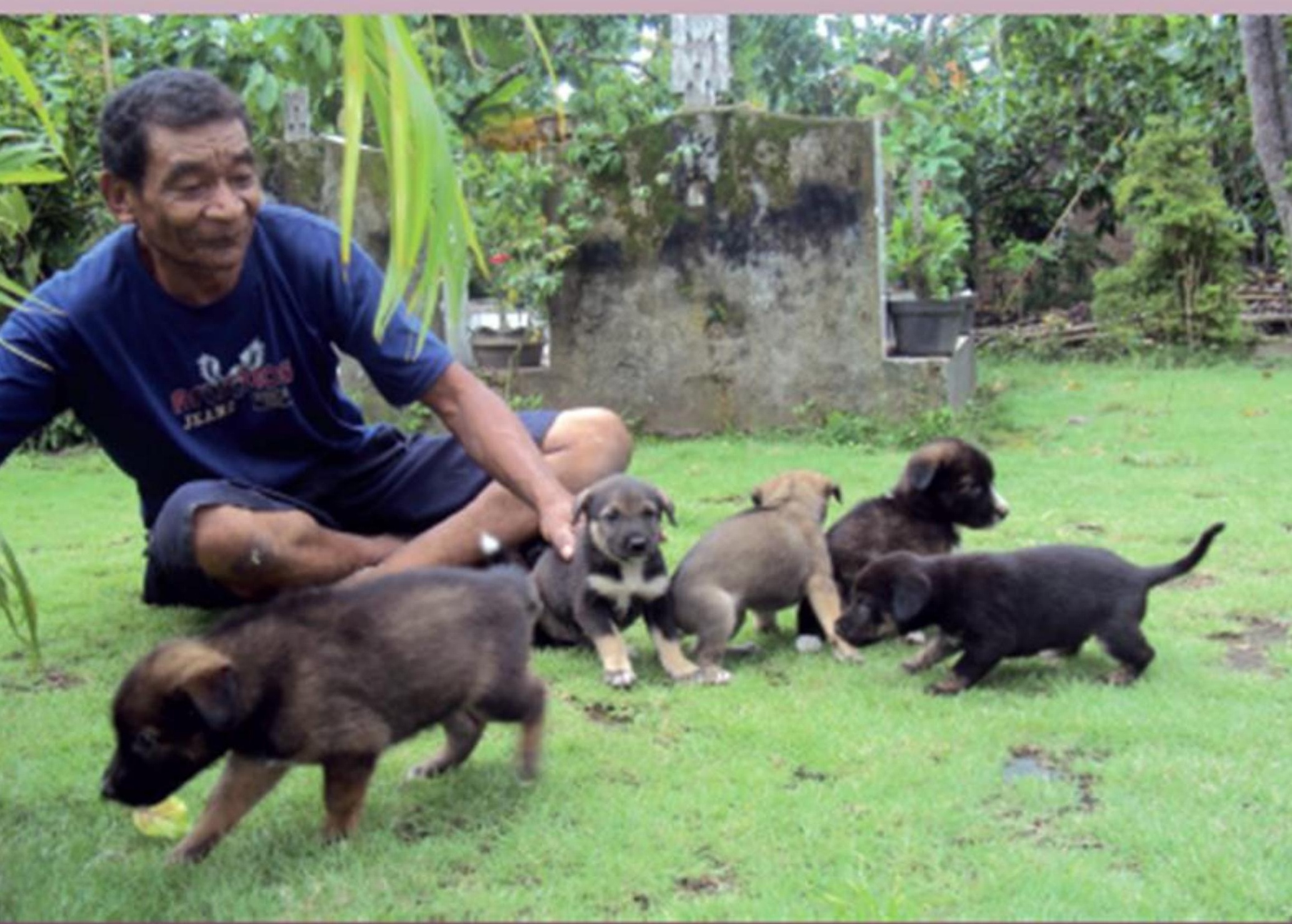





\section{Propositions}

1. The lack of infrastructure limits the success of rabies control in more remote areas of Flores Island.

(this thesis)

2. Improving rabies vaccination campaigns in Flores Island saves life years and is cheaper. (this thesis)

3. Separation between public health and veterinary budgets limits efficient decision making with regard to zoonoses.

4. Without knowledge on 'materials and methods', the 'conclusions' of a scientific paper cannot be interpreted correctly.

5. Corruption leads to poverty.

6. The main challenge of a modern city is to ensure that the basic needs of its people are fulfilled.

Propositions belonging to the thesis, entitled

Socio-economic modelling of rabies control in Flores Island, Indonesia

Ewaldus Wera

Wageningen, 4 April 2017 



\section{Socio-economic modelling of rabies control in Flores Island, Indonesia}




\section{Thesis committee}

\section{Promotor}

Prof. Dr H. Hogeveen

Personal chair at the Business Economics Group

Wageningen University \& Research

\section{Co-promotor}

Dr M.C.M. Mourits

Associate professor, Business Economics Group

Wageningen University \& Research

\section{Other members}

Prof. Dr M. Koelen, Wageningen University \& Research

Dr S. Durr, University of Bern, Switzerland

Dr B. Haesler, Royal Veterinary College, UK

Dr H.I.J. Roest, Wageningen University \& Research

This research was conducted under the auspices of the Graduate School Wageningen School of Social Sciences. 


\title{
Socio-economic modelling of rabies control in Flores Island, Indonesia
}

\section{Ewaldus Wera}

\author{
Thesis \\ submitted in fulfilment of the requirements for the degree of doctor \\ at Wageningen University \\ by the authority of the Rector Magnificus \\ Prof. Dr A.P.J. Mol, \\ in the presence of the \\ Thesis committee appointed by the Academic Board \\ to be defended in public \\ on Tuesday 4 April 2017 \\ at 1.30 p.m. in the Aula.
}


Ewaldus Wera

Socio-economic modelling of rabies control in Flores Island, Indonesia, 183 pages.

PHD thesis, Wageningen University, Wageningen, the Netherlands (2017)

With references, with summaries in English

ISBN 978-94-6343-058-6.

DOI http://dx.doi.org/10.18174/401889 


\section{Contents}

Abstract

Chapter 1

General introduction

Chapter 2

Costs of rabies control: An economic calculation

method applied to Flores Island

Chapter 3

Uptake of rabies control measures by dog owners in

Flores Island, Indonesia

Chapter 4

Intention of dog owners to participate in rabies control measures in Flores Island, Indonesia

Chapter 5

Cost-effectiveness of mass dog vaccination campaigns

against rabies in Flores Island, Indonesia

Chapter 6

Cost-effectiveness of mass dog rabies vaccination

strategies to reduce human health burden in Flores

Island, Indonesia

Chapter 7

General discussion

Summary

Acknowledgements

About the author 


\section{Abstract}

Rabies is a zoonotic viral disease that can cause encephalomyelitis both in animals and humans. Since its introduction in Flores Island, Indonesia in 1997, it has been a serious public health threat with significant economic consequences. To control the disease, annual dog vaccination campaigns have been implemented to vaccinate all dogs free of any charge. Nevertheless, the campaigns have not been successful in eliminating rabies from the island.

The main objective of this dissertation was to support future decisions on the control of rabies in Flores Island by providing insight into the role of socio-demographic and psychological factors of dog owners in the uptake of rabies control measures and by analyzing the costeffectiveness of alternative mass dog vaccination strategies.

By means of a cost accounting model, the costs of the currently applied rabies control measures in Flores Island were estimated at US\$1.12 million (range: US\$0.60-1.47 million) per year. The costs of culling roaming dogs resulted in the highest cost portion (39\%), followed by the costs of post-exposure treatment (35\%) and mass vaccination (24\%).

Risk factors associated with the uptake level of rabies control measures were analysed based upon an extensive survey among 450 dog-owners in the regencies of Sikka and Manggarai. Only $52 \%$ of these dog owners had at least one of their dogs vaccinated during the 2012 vaccination campaign. Vaccination uptake was significantly higher for dog owners who resided in Sikka, kept female dogs for breeding, had a monthly income of more than one million rupiah, and had easy access to their village.

A study based on the Theory of Planned Behaviour demonstrated that the actual intention of dog owners to participate in a free-of-charge vaccination campaign was high (> 90\%). The attitude item 'vaccinating dogs reduces rabies cases in humans', and the perceived behavioural control items 'availability of time' and 'ability to confine dogs' were shown to be significantly associated with this intention level. Relevant considerations to improve the participation level in future vaccination campaigns are therefore appropriate time management as well as the provision of skills to confine dogs during the vaccination.

The cost-effectiveness of different mass dog vaccination strategies was evaluated by means of a deterministic model simulating transmission of rabies virus through the dog population of one village. Annual vaccination using a short-acting vaccine at a coverage of $50 \%$ was far from being cost-effective, suggesting that the currently applied rabies control in Flores Island is not an efficient investment in reducing human rabies burden. An increased investment in either an increase in the current coverage or in a switch from the short-acting vaccine to the long-acting vaccine type would certainly pay off.

Keywords: Rabies, dog, Flores, economic impact, uptake, intention, cost-effectiveness, vaccination strategies. 
Chapter 1

General introduction 


\subsection{Background}

Rabies is a neglected tropical disease caused by a member of the lyssavirus genus in the Rhabdoviridae family (King and Turner, 1993; Wandeler and Bingham, 2000). Naturally, the virus circulates among animals such as dogs, cats, ferrets, fox, raccoon, mongooses, bats, and wolves (Randall et al., 2006; Green et al., 2011), but it can be spilled over to humans through these animals, particularly those of dogs (Jackson, 2007). The most frequent route by which the virus transmit to human is through an animal bite in which the virus in saliva is inoculated (Jackson, 2007). A human infection causes fatal encephalomyelitis (Wunner, 2005) which may be expressed by confusion, hallucination, aggressive behaviour, and extremely painful laryngeal spasms (Colville and Berryhill, 2007; Jackson, 2007). Once clinical signs appear, fatality rate is almost $100 \%$ (Briggs, 2007). Estimations on the global burden of rabies indicate a health impact of 61,000 human deaths/year, a loss of more than 3.7 million DALYs (disability adjusted life years)/year and about 8.6 billion USD of damage (Hampson et al., 2015). Approximately $45 \%$ of the these human death cases occur in the South East Asian region (WHO, 2012). Within this region, Indonesia has the fourth largest number of human rabies cases after India, Bangladesh and Myanmar (150-300 cases reported per year) (WHO, 2012). The true burden of disease is thought to be higher because of under-reporting and inadequate surveillance (Cleaveland et al., 2002).

\subsection{Problem definition}

Rabies has been endemic in Indonesia since 1989 (Ward, 2014). Since its introduction, rabies has been a serious public threat with significant economic consequences. The national strategic plan of Indonesia underscores the control of rabies as of main priority. The control is carried by the provision of human rabies vaccines and/or immunoglobulin, by vaccination of dogs, and by the controlling the dog population (e.g. by selected culling of free roaming dogs, sterilization of dogs, and regulations on the maximum number of dogs owned by a household) in all endemic areas, including Flores Island.

Flores Island is located in the Eastern part of Indonesia and covers 15,624 $\mathrm{km}^{2}$ (Wikipedia, 2013). The island is divided into eight regencies with a human population of more than 1.8 million (BPS, 2013) and a dog population over 0.2 million. Many of the rural areas on the island are only accessible by foot or with high-clearance vehicles, motor bikes or horses (Bingham, 2001). The main socio-economic activity is agriculture (e.g., production of coconut, corn, groundnut, cocoa, coffee, potato, and paddy) in which dogs are used to guard the crops (Hutabarat et al., 2003).

On Flores Island, the first cases of rabies in dogs were officially confirmed in 1998 in the regency of East Flores (Wera, 2001). Despite a total dog culling program in and around the affected villages (1998-1999), rabies spread to other regencies of the island. As rabies could be eliminated by routine dog vaccination programs (Jackson, 2011), a dog vaccination 
program was started in 2000, in which vaccination was combined with culling of dogs in infected villages, application of dog movement restrictions, and castration of male dogs to minimize the number of roaming dogs. Up until now, these programs have, however, not been successful in eliminating rabies from Flores Island. In the period of 1998-2012, 228 human rabies cases were reported (HDENT, 2012). In the current endemic situation, thousands of people are looking for post-exposure treatment (PET) every year resulting in large economic impacts for both the government and local communities.

For the last 13 years, the Indonesian government has recommended dog-owners to vaccinate their dogs annually. Moreover, the applied vaccination programs contained 'house to house' vaccination campaigns in an attempt to approach the dog owners directly. Nevertheless, the coverage of vaccinating dogs has been lower than the $70 \%$ recommended by WHO (WHO, 2005) to prevent rabies circulation among dogs, by ranging between 16-53\% (Siko, 2011). The decision of people to participate in certain behaviour can be explained by both sociodemographic and socio-psychological factors (Ajzen, 1991) as in the case of dog owners' decision to adopt a certain rabies control measure. Studies conducted in countries where rabies is endemic have identified for example dog's age (i.e. dogs younger than 12 months are less likely to be vaccinated) and employment status of dog owners (i.e. dog owners employed are more likely to vaccinate their dogs) as significant factors influencing vaccination coverage (Flores-Ibarra and Estrella-Valenzuela, 2004; Kongkaew et al., 2004; Suzuki et al., 2008; Davlin et al., 2012). However, none of these studies have focused on the situation of rabies in Flores Island, nor evaluated the impact on the uptake of vaccination of the socio-demographic or psychological factors of dog owners. An understanding of this impact is essential to support policy decisions about rabies control in the future.

Generally, mass vaccination of the dog population has been demonstrated as a cost-effective strategy to prevent rabies in the human population (Zinsstag et al., 2009, Fitzpatrick et al., 2014). Zinsstag et al. (2009) showed that a single vaccination campaign using long-acting vaccine with a coverage of $70 \%$ in combination with PET was more cost-effective than PET alone to prevent human rabies in an urban area of Chad. Fitzpatrick et al. (2014) demonstrated that a repeated annual dog vaccination campaign with a coverage of $25 \%-90 \%$ was a costeffective strategy to prevent human rabies in rural areas of Tanzania. The results of both studies indicate the feasibility of cost-effective vaccination campaigns, but are not representative enough for extrapolation to Flores Island. The dog population of Flores Island is characterized by a high turn-over rate $(>45 \%)$ (Siko, 2011) and most of the villages are located in remote areas with poor road infrastructure. These characteristics in combination with limited resources, reflected by an insufficient veterinary infrastructure for dog vaccination (Bingham, 2001), make it difficult to obtain high vaccination coverage and this has implications for the cost-effectiveness of mass vaccination programs. An evaluation of the 
cost-effectiveness of mass dog vaccination strategies directed to the situation of Flores Island is, therefore, of relevance to support sound decision making with respect to rabies control in the future.

\subsection{Objective}

The main objective of this dissertation was to support decision making on the control of rabies in Flores Island, Indonesia by providing insight into the role of socio-demographic and psychological factors of dog owners in the uptake of rabies control measures and analysing the cost-effectiveness of dog vaccination strategies. This objective was addressed by the following five sub-objectives:

1. To estimate the costs of rabies control measures currently applied in both dogs and humans.

2. To identify the role of socio-demographic factors of dog owners associated with the uptake of rabies control measures.

3. To identify the role of psychological factors of dog owners (attitude, subjective norm, and perceived behavioral control) in the intention to participate in future rabies control measures.

4. To evaluate the cost-effectiveness of different dog vaccination strategies in reducing dog rabies cases.

5. To evaluate the cost-effectiveness of different dog vaccination strategies in reducing human rabies cases.

\subsection{Outline of the dissertation}

This dissertation consists of seven chapters namely a general introduction (Chapter 1), five research chapters (Chapters 2-6), and a general discussion (Chapter 7) (Figure 1.1). Chapter 1 provides the general background, problem statement, objectives and outline of the dissertation. In Chapter 2 an integrated deterministic economic model is developed to calculate for the current situation of Flores Island the costs of rabies control measures, in dogs and humans. In this chapter the economic impact of rabies is evaluated for the public (Government) and private (dog owners and local community) sectors during 2000-2011.

In order to get more insight the motivation of dog owners to participate in rabies control, a survey is conducted to investigate the factors associated with the current uptake and future intention of dog owners to participate in rabies control measures (Chapters 3 and 4). Based on the insights obtained of Chapter 2, the epidemiological and economic impact of alternative dog rabies control measures has been evaluated (Chapters 5 and 6). Chapter 5 presents the development of a SEIVR (Susceptible, Exposed, Infectious, Vaccinated, and Immune) and an 
discounting cost model to estimate the cost-effectiveness, defined as the costs per dog rabies case averted, of vaccination strategies in dog population.

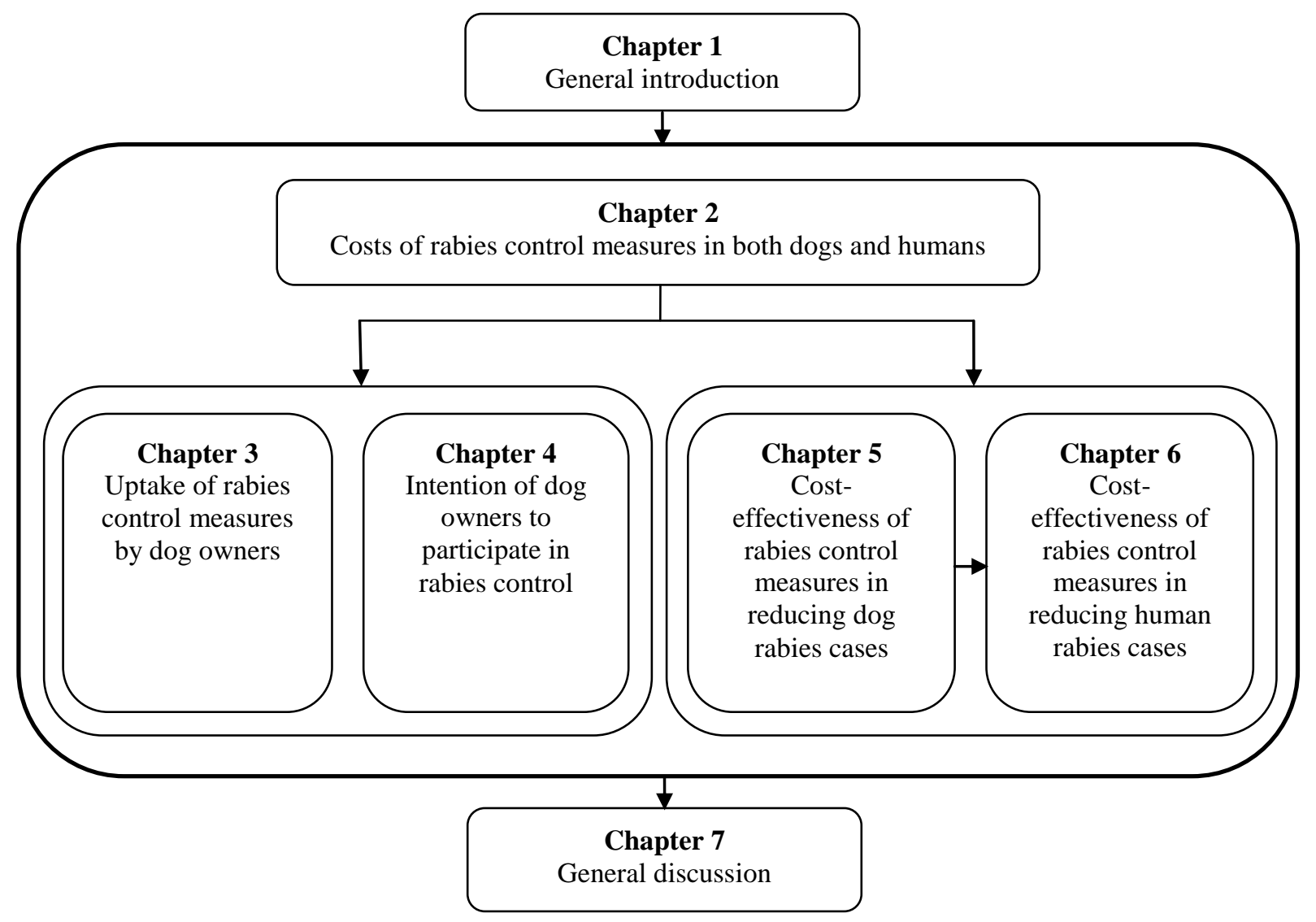

Figure 1.1 Structure of the dissertation

In order to fully appreciate the impact of rabies control measures on human health as part of the one-health approach, Chapter 6 provides a cost-effectiveness, defined as the costs per averted year of human life lost, of different vaccination strategies in dog population in combination with the required amount of human post exposure treatment. Finally, Chapter 7 synthesises the results of this dissertation and reflects the integrated research approach and methods applied. Chapter 7 also discusses the implications of the results for future rabies control in Flores Island and outlines the directions for future research. 


\section{References}

Ajzen, I., 1991. The theory of planned behavior. Organ. Behav. Hum. Decis. Process. 50, 179 - 211.

Bingham, G.M., Budke, C.M., Slater, M.R., 2010. Knowledge and perceptions of dog-associated zoonoses: Brazos County, Texas, USA. Prev. Vet. Med. 93, 211-221.

BPS, 2013. Population of Indonesia by village. Available at: http://bps.go.id/eng/download_file/Population_of_Indonesia_by_Village_2010.pdf (accessed on 20.06.13.).

Briggs, D.J., 2007. Human Rabies Vaccine In. Elsevier/Academic Rabies. 2nd ed. Amsterdam. The Netherlands.

Cleaveland, S., Fevre, E., Kaare, M., Coleman, P., 2002. Estimating human rabies mortality in the united republic of Tanzania from dog bite injuries. Bull. World Health Organ. 80, 304 - 310.

Colville, J.L., Berryhill, D.L., 2007. Handbook of zoonoses : identification and prevention. Mosby St. Louis. USA.

Davlin, S., Lapiz, S.M., Miranda, M.E., Murray, K., 2012. Factors Associated with Dog Rabies Vaccination in Bohol, Philippines: Results of a Cross-Sectional Cluster Survey Conducted Following the Island-Wide Rabies Elimination Campaign. Zoonoses Public Health 60, 494503.

Fitzpatrick MC, Hampson K, Cleaveland S, Mzimbiri I, Lankester F, Lembo T., Meyers, L.A., Paltiel, A.D., Galvani, A.P., 2014. Cost-effectiveness of canine vaccination to prevent human rabies in rural Tanzania. Ann. Intern. Med. 160, 91-100.

Flores-Ibarra, M., Estrella-Valenzuela, G., 2004. Canine ecology and socioeconomic factors associated with dogs unvaccinated against rabies in a Mexican city across the US-Mexico border. Prev. Vet. Med. 62, 79-87.

Green, A.L., Carpenter, L.R., Dunn, J.R., 2011. Rabies Epidemiology, Risk Assessment, and Pre- and Post-Exposure Vaccination. Vet. Clin. North Am. Exot. Anim. Pract. 14, 507-518.

Hampson, K., Coudeville, L., Lembo, T., Sambo, M., Kieffer, A., Attlan, M., et al. 2015. Estimating the global burden of endemic canine rabies. PLoS Negl. Trop. Dis. 9 (4), e0003709.

HDENT, 2012. Roadmap program pengendalian rabies pada hewan penular rabies dalam rangka provinsi Nusa Tenggara Timur bebas rabies. Workshop sehari dalam rangka peringatan rabies sedunia, 8 Oktober 2012. Maumere, Flores.

Hutabarat, T., Geong, M., Newsome, A., Ruben, A., Cutter, S., 2003. Rabies and dog ecology in Flores. Urban Animal Management Conference Proceedings. Australian Veterinary association, Australia. Pp. 7-14. Available at: http://www.fao.org/fileadmin/user_upload/animalwelfare/Willyanto_Indonesia_Flores_Cutter. pdf/ (accessed on 21.04.15.).

Jackson, A.C., 2007. Rabies in Human In. Elsevier/Academic Rabies. 2nd ed. Amsterdam. The Netherlands.

Jackson, A.C., 2011. Update on rabies. Res. Rep. Trop. Med. 2, 31-43.

King, A.A., Turner, G.S., 1993. Rabies: A review. J. Comp. Pathol. 108, 1-39. 
Kongkaew, W., Coleman, P., Pfeiffer, D.U., Antarasena, C., Thiptara, A., 2004. Vaccination coverage and epidemiological parameters of the owned-dog population in Thungsong District, Thailand. Prev. Vet. Med. 65, 105-115.

Randall, D.A., Marino, J., Haydon, D.T., Sillero-Zubiri, C., Knobel, D.L., Tallents, L.A., Macdonald, D.W., Laurenson, M.K., 2006. An integrated disease management strategy for the control of rabies in Ethiopian wolves. Biological Conservation. 131, 151-162.

Siko, M.M., 2011. Dog population dynamic and its impact to rabies vaccination coverage in rural and urban Sikka regency, East Nusa Tenggara province Period October 2009 - April 2010. Graduate School, Veterinary Faculty, Gadjah Mada university. Yogyakarta.

Suzuki, K., Pereira, J.A.C., Frías, L.A., López, R., Mutinelli, L.E., Pons, E.R., 2008. Rabiesvaccination Coverage and Profiles of the Owned-dog Population in Santa Cruz de la Sierra, Bolivia. Zoonoses Public Health 55, 177-183.

Wandeler, A.I., Bingham, J., 2000. Dogs and Rabies. In: Macpherson, C. N. L., Meslin, F. X. (Eds). Dogs, zoonoses, and public health. CABI Wallingford.

Ward, M.P., 2014. Rabies in the Dutch East Indies a century ago - A spatio-temporal case study in disease emergence. Prev. Vet. Med. 114, 11-20.

Wera, E, 2001. Epidemiologi dan usaha pemberantasan penyakit Rabies di Kabupaten Flores Timur, Provinsi Nusa Tenggara Timur periode November 1997- April 2000. Skripsi. Fakultas Kedokteran Hewan, Institut Pertanian Bogor. Available at: http://repositoryipbacid/bitstream/handle/123456789/21527/B01ewepdf;jsessionid=3C23983E 3FB5A771643967D5C4340EE2?sequence $=2$ (accessed 6.06.14.).

WHO, 2005. WHO expert Consultation on Rabies, first report. In: WHO Technical Report Series 931. World Health Organisation, Geneva, Switzerland.

WHO, 2012. Strategic framework for elimination human rabies transmitted by dogs in South-East Asia Region. World Health Organisation Regional Office for South-East Asia, India.

Wikipedia, 2013. Flores. Available at: http://en.wikipedia.org/wiki/Flores (accessed 20.06.13.).

Wunner, W.H., 2005. Rabies in the Americas. Virus Research 111, 1-4.

Zinsstag, J., S. Durr, M. Penny, R. Mindekem, F. Roth, S. Gonzalez, S. Naissengar and J. Hattendorf, 2009: Transmission dynamics and economics of rabies control in dogs and humans in an African city. Proc. Natl. Acad. Sci. USA. 106, 14996 - 15001. 
Chapter 1 
Chapter 2

Costs of rabies control: An economic calculation method applied to Flores Island

Ewaldus Wera, Annet G.J. Velthuis, Maria Geong, Henk Hogeveen

Published in PLoS One 8: e83654.

doi:10.1371/journal.pone.0083654.t002 


\begin{abstract}
Rabies is a zoonotic disease that, in most human cases, is fatal once clinical signs appear. The disease transmits to humans through an animal bite. Dogs are the main vector of rabies in humans on Flores Island, Indonesia, resulting in about 19 human deaths each year. Currently, rabies control measures on Flores Island include mass vaccination and culling of dogs, laboratory diagnostics of suspected rabid dogs, putting imported dogs in quarantine, and preand post-exposure treatment (PET) of humans. The objective of this study was to estimate the costs of the applied rabies control measures on Flores Island.

A deterministic economic model was developed to calculate the costs of the rabies control measures and their individual cost components from 2000 to 2011. The inputs for the economic model were obtained from: (i) relevant literature, (ii) available data on Flores Island, and (iii) experts such as responsible policy makers and veterinarians involved in rabies control measures in the past. As a result, the total costs of rabies control measures were estimated to be US\$1.12 million (range: US\$0.60-1.47 million) per year. The costs of culling roaming dogs were the highest portion, about $39 \%$ of the total costs, followed by PET (35\%), mass vaccination $(24 \%)$, pre-exposure treatment (1.4\%), and others (1.3\%) (dog-bite investigation, diagnostic testing of suspected rabid dogs, trace-back investigation of human contact with rabid dogs, and quarantine of imported dogs).

This study demonstrates that rabies has a large economic impact on the government and dog owners. Control of rabies by culling dogs is relatively costly for the dog owners in comparison with other control measures. Providing PET for humans is an effective way to prevent rabies, but is costly for government and does not provide a permanent solution to rabies in the future. The developed model can be used for future economic ex-ante and expost analyses on rabies control.
\end{abstract}




\subsection{Introduction}

Rabies is a zoonotic viral disease caused by a member of the Lyssavirus genus in the Rhabdoviridae family (King and Turner, 1993). The main transmission route to humans is through animal bites, especially those of dogs (Jackson, 2007). In humans, the virus infects the peripheral nerves and spreads to the brain (central nervous system), resulting in encephalomyelitis (Wunner, 2005) and hydrophobia, which is the most specific clinical sign of rabies (Jackson, 2007). Once clinical signs appear, fatality is almost 100\% (Briggs, 2007). The World Health Organization (WHO, 2005) estimated that 55,000 people die each year due to rabies around the world, with over $99 \%$ of these cases occurring in Africa and Asia (Briggs, 2010). In Indonesia, 150-300 fatal cases of human rabies are reported annually (Gongal and Wright, 2011), with approximately 19 on Flores Island (Windiyaningsih et al., 2004) where dogs are the principal reservoir for transmitting the virus to humans (Bingham, 2001).

Control of rabies in dogs is an important means to prevent rabies in humans. Possible control measures include mass vaccination of dogs, culling roaming dogs, quarantining imported dogs, and movement restrictions of dogs. Vaccination of dogs offers a safe and effective means to control rabies as has been reported for some endemic countries (Tierkel et al., 1950; Cleaveland et al., 2003; Belotto et al., 2005; Putra et al., 2013). The first successful example of a mass vaccination program in a dog population occurred in the city of Memphis and Shelby County, Tennessee in the United States in 1948 (Tierkel et al., 1950). The number of rabies cases in both animals and humans was reduced to zero (Tierkel et al., 1950). Success stories were also reported from Latin American countries, where mass vaccination of the dog population has led to reduction of rabies in humans (Belotto et al., 2005). More recently, mass vaccination of dogs in Tanzania (Cleaveland et al., 2003) and Bali Island, Indonesia (Putra et al., 2013) successfully decreased dog and human rabies cases. Other control measures than vaccination enabled the United Kingdom to become free of rabies in 1922. These measures included shooting stray dogs, strict muzzling of all pet dogs, and quarantining imported dogs (Carter, 1997; Muir and Roome, 2005). Measures to reduce the burden of rabies in humans include pre-exposure treatment (vaccination of human at risk before exposure) and postexposure treatment (wound cleaning, immunoglobulin injection, and series of vaccine injections after bitten by a suspected rabid dog) (Meltzer and Rupprecht, 1998).

Rabies is a costly disease (Meltzer and Rupprecht, 1998) mainly because of the costs of postexposure treatment (PET) in humans and vaccination programs in animals. PET in humans accounts for the highest proportion of the costs of rabies control measures. Knobel et al. (2005) reported that $83 \%$ (US\$485 million) of the total rabies control budget in Asia and Africa was allocated to PET. The costs of PET include costs for rabies immunoglobulin and vaccines and for physician and hospital services (Woodruff et al., 1991). Vaccination costs in 
animals vary among countries, depending on the epidemiological features of the disease. For example, the annual costs of animal rabies vaccination were estimated to be US\$5.5 million in Canada (Shwiff et al., 2011) and US\$ 4.1 million in the Philippines (Fishbein et al., 1991).

Located in eastern Indonesia, Flores Island is populated by over 1.8 million humans (BPS, 2013) and 236,500 dogs (as registered by the Husbandry Department of East Nusa Tenggara Province in 2011). The first officially confirmed case of rabies appeared in 1998 when dogs with the disease were imported from Sulawesi Island. The response was total culling of all dogs (Windiyaningsih et al., 2004; Hutabarat et al., 2003). Unfortunately, this control measure failed to stop the spread of the rabies virus. Therefore, in 2000, the Flores Island government implemented a combination of control measures, including mass vaccination of dogs, culling of roaming dogs, placing imported dogs in quarantine, and giving pre- and post-exposure treatment to humans. In addition, complementary control measures were applied, such as dog bite investigation, diagnostic testing of suspected rabid dogs, and trace-back of human contacts with rabid dogs.

Although there are some economic evaluations of rabies outbreaks published for South and South East Asia (Fishbein et al., 1991; Wilde et al., 1999; Goswami et al., 2005; Chulasugandha et al., 2006; Tenzin et al., 2012), none of these publications were dedicated to the situation of rabies in Indonesia and none of these publications described an integral economic evaluation of rabies control, taking into account the costs of control measures both in dogs and humans for different stakeholders (i.e. Animal Health Department, dog owners, dog-bite patients and Public Health Department). Therefore, this study sought to calculate the costs of the rabies control measures both in dogs and humans (with specified costs of rabies control measures for different stakeholders and the costs of culling roaming dogs) applied on Flores Island since 2000. The results of this study provide insights which are useful for decision makers who need to decide upon the rabies control programs in the future.

\subsection{Materials and methods}

An economic model was developed using Microsoft Excel 2010 to evaluate the costs of various rabies control measures and the distribution of the costs among the various stakeholders on Flores Island. The inputs for the economic model were obtained from: (i) relevant scientific literature, (ii) available data on Flores Island, and/or (iii) experts such as responsible policy makers and veterinarians involved in rabies control measures on Flores Island. The values of the input obtained from scientific literature were related to the indicated year of the described study or, if not present, to the year of publication. The cost in different years $\left(C_{y}\right)$ was compounded to $2011\left(C_{2011}\right)$ using the following formula: 


$$
C_{2011}=C_{y} \times(1+i)^{(2011-y)}
$$

Where, $i$ is the discount rate which was set at $6 \%$ (Kaare et al., 2009) and $y$ is the year in which the costs were made. Costs involved in each control measure were converted into US dollars, using the currency rate on January 31, 2012 which was US\$1 = Rp 9045 (http://www.bi.go.id). A sensitivity analysis was performed using add-in software TopRank 6.0 for Excel of Palisade Decision Tools to identify the inputs that were highly influential to the output. Furthermore, the costs of each measure were ranked based on their contribution to the total costs.

\subsubsection{Economic model}

A deterministic economic model was built to evaluate the total costs of control measures (TMC) applied both in dogs and humans:

$T M C=C M D+C M H$

Where, $C M D$ represents the costs of control measures in dogs, and $C M H$ represents the costs of control measures in humans.

\subsubsection{Control measures in dogs}

The total costs of rabies control measures in the dog population equal the sum of the costs of five control measures: (i) mass vaccination $(C M V)$, (ii) culling of roaming dogs $(C C D)$, (iii) dog-bite investigations $(C B I)$, (vi) diagnostic testing of suspected rabid dogs $(C D D)$, traceback investigation of human contacts with rabid dogs $(C T B)$ and (v) quarantining of imported dogs $(C Q D)$ :

$$
C M D=C M V+C C D+C B I+C D D+C T B+C Q D
$$

In the following paragraphs, each control measure in the dog population is explained and detailed economic calculations are given for each, including the inputs.

\section{Mass vaccination of dogs}

A rabies vaccination program that is free of charge and compulsory for all dog owners has been in effect in the Ende and Manggarai regencies of Flores Island since 2000 (Windiyaningsih et al., 2004). In 2001, the program was expanded to other regencies, namely, East Flores, Sikka, Nagakeo, East and West Manggarai. Several activities are involved to make the vaccination campaign operational, including organization, communication, and vaccination activities. 
The organizational activities include planning the campaign, recruitment and training of temporary vaccinators, and selection activities of the areas. The planning began with a meeting to determine the vaccinators, the budget, and the distribution of campaign information. The vaccinators were veterinary assistants graduated from an animal health and/or a husbandry study program at a university or senior high school. To increase vaccination coverage, a veterinarian occasionally trained local people and community nurses as temporary vaccinators, as in 2008. The Agricultural Department in each regency incurred the available budget for the campaign.

The communication activities included development and distribution of materials to inform the local community about the vaccination campaign and to stimulate dog owners to vaccinate their dogs. The campaign information was sent to the heads of the villages, religious leaders, and a radio station, and/or was broadcasted from a car with a loudspeaker once a week before the mass vaccination began. The head of each village was asked to encourage dog owners to bring their dogs to a designated place and/or to confine at home for the vaccinator. Religious leaders were asked to announce the campaign schedule in churches and mosques. The radio station was asked to make announcements on consecutive days before the campaign began. Additionally, leaflets and posters were distributed in public areas.

The vaccination activities included the vaccination of dogs and an educational program for the local community. On the day of the mass vaccination, vaccinators, veterinarians, and staff of the Regency Agricultural Department went to rural and urban areas to vaccinate dogs and to educate the local community to keep dogs under supervision. Vaccinations were delivered by subcutaneous administration and required a booster at three months to confer one year's protection (Knobel and Hiby, 2009). The vaccine used was Rabivet Supra ${ }^{\circledR}$ (Pusvetma, Surabaya, Indonesia). Sometimes, depending on the allocated budget, a vaccinated dog was collared with a wire collar and tag (Hutabarat et al., 2003). The total number of registered dogs vaccinated on the island was on average $53 \%$ (range: $23-82 \%$ ) of the total registered dog population during the vaccination campaign (Table 2.1).

The costs of mass vaccination $(C M V)$ include costs of the vaccine $\left(C_{v a}\right)$, costs of consumables, such as needles, syringes, etc. $\left(C_{m a}\right)$, costs of vaccinators $\left(C_{v t}\right)$, costs to train the temporary vaccinators $\left(C_{m t}\right)$, costs of the information campaign $\left(C_{i c}\right)$, capital costs $\left(C_{c c}\right)$, and opportunity costs for the time of the dog owners to catch and restrain their dogs for vaccination $\left(\mathrm{C}_{\mathrm{do}}\right)$ :

$C M V=C_{v a}+C_{m a}+C_{v t}+C_{m t}+C_{i c}+C_{c c}+C_{d o}$

$C_{v a}$ depends on the price of the vaccine per dose $\left(p_{v a}\right)$, costs of transportation of the vaccine from manufacturer to each regency $\left(t_{v a}\right)$, and the number of registered vaccinated dogs $\left(n_{v d}\right)$ : 


$$
C_{v a}=n_{v d} \times\left(p_{v a}+t_{v a}\right)
$$

$C_{m a}$ depends on the price of needles and syringes $\left(p_{s n}\right)$, ice bars $\left(p_{i b}\right)$, disinfectant swabs $\left(p_{d s}\right)$, the proportion dogs using collar after vaccination $\left(p r_{c l}\right)$, and the price of collar $\left(p_{c l}\right)$ :

$$
C_{m a}=n_{v d} \times\left(p_{s n}+\frac{p_{i b}}{n_{c a p v}}+p_{d s}+p r_{c l} \times p_{c l}\right)
$$

Where, $n_{\text {capv }}$ is the average number of registered dogs vaccinated by one vaccinator per day.

The vaccination of dogs was administered by a group of temporary vaccinators under close supervision of a veterinarian or public servant. Therefore, costs of vaccinators $\left(C_{v t}\right)$ consist of the costs for temporary vaccinators $\left(C_{t v}\right)$ and costs for public servants who supervise the vaccinators $\left(C_{s v}\right)$ :

$$
C_{v t}=C_{t v}+C_{s v}
$$

Where, $C_{t v}$ consists of the number of registered vaccinated dogs multiplied with the salary $\left(s_{t v}\right)$ and fuel costs (per day) for travelling $\left(f_{c m}\right)$ of the vaccinator per day :

$C_{t v}=n_{v d} \times\left(s_{t v}+\frac{f_{c m}}{n_{c a p v}}\right)$

$C_{s v}$ was calculated based on the number of vaccination days $\left(n_{v d a y s}\right)$, the costs per day per public servant or veterinarian $\left(c_{p s}\right)$ and the fuel costs for travelling $\left(f_{c m}\right)$ per day:

$$
C_{s v}=n_{v d a y s} \times\left(c_{p s}+f_{c m}\right)
$$

The number of vaccination days depends on the number of vaccinators who can be supervised by one public servant $\left(n_{v s}\right)$ :

$n_{v d a y s}=\frac{n_{v d}}{n_{\text {capv }}} \times \frac{1}{n_{v s}}$

$C_{m t}$ includes costs of meeting and training of temporary vaccinators while $C_{i c}$ includes costs of printing and distribution of the leaflets and posters, and the development and broadcast of the radio advertisements. $C_{m t}$ and $C_{i c}$ were not calculated, but were given as a fixed budget item reported by a government veterinarian responsible for the rabies control program (2012, personal communication). 
$C_{c c}$ includes the yearly depreciation costs for cool bags, refrigerators, motorcycles, and muzzles:

$C_{c c}=\left(\frac{\left(n_{c b} \times p_{c b}+n_{m c} \times p_{m c}+n_{r f} \times p_{r f}\right)}{l_{c m r} \times n_{d y}}+\frac{\left(n_{m z} \times p_{m z}\right)}{l_{m z} \times n_{d y}}\right) \times n_{v d a y s}$

Where $n_{c b}$ is the number of cool bags needed each year, $p_{c b}$ the price of a cool bag, $n_{m c}$ the number of motorcycles, $p_{m c}$ the price of a motorcycle, $n_{r f}$ the number of refrigerators, $p_{r f}$ the price of a refrigerator, $n_{m z}$ the number of muzzles, $p_{m z}$ the price of a muzzle, $l_{c m r}, l_{m z}$ the number of life years of capital goods (cool bags, motorcycles, and refrigerators) and muzzles (expected to be used in any diseases control programs), and $n_{d y}$ the number of days in a year. Note that $n_{c b}, n_{m c}, n_{r f}$, and, $n_{m z}$ increased with the number of new areas ${ }^{1}$ to be vaccinated (Windiyaningsih et al., 2004); however, for simplification, the average numbers for Flores Island were used for each year. We assumed the salvage value of capital goods and muzzles to be equal to zero.

$C_{d o}$ was calculated based on the opportunity cost for the dog owner's time to catch and restrain a $\operatorname{dog}\left(O_{d o}\right)$ and the number of vaccinated dogs:

$C_{d o}=O_{d o} \times n_{v d}$

$O_{d o}$ was based on the number of working hours lost per dog owner $\left(w_{h l}\right)$, the average daily wage of a dog owner $\left(d_{w}\right)$, and the number of hours work per day $\left(n_{h w}\right)$ :

$O_{d o}=w_{h l} \times \frac{d_{w}}{n_{h w}}$

As the vaccination campaign was conducted during working days when the children were at school, we assumed that all the handlers of dogs during the campaign were adult people.

The inputs used in the calculations for the costs of mass vaccination in dogs are presented in Table 2.2. The calculation of the mass vaccination campaign was based on a door-to-door approach as most vaccination programs in Flores Island were carried out as door-to-door campaigns (2013, Personal communication).

\footnotetext{
${ }^{1}$ An area is defined as a village in which a group of local community (75-500 households) live together.
} 


\section{Table 2.1}

Total number of registered $\operatorname{dogs}(n)$, vaccinated dogs $\left(n_{v d}\right)$, culled dogs $\left(n_{c d}\right)$, samples submitted $^{\left(n_{s s}\right)}$, and tested positive ${ }^{\left(n_{s p}\right)}$ in Flores Island from 2000 to 2011.

\begin{tabular}{rrrrrr}
\hline & \multicolumn{3}{c}{ Number of dogs } & \multicolumn{2}{c}{ Number of samples } \\
\cline { 2 - 6 } Year & Total $(n)$ & Vaccinated $\left(n_{v d}\right)$ & Culled $\left(n_{c d}\right)$ & Submitted $\left(n_{s s}\right)$ & Positive $\left(n_{s p}\right)$ \\
\hline 2000 & 213,004 & 49,632 & 27,050 & $1,935^{\text {a }}$ & 1,550 \\
2001 & 165,411 & 50,297 & 25,181 & $946^{\text {a }}$ & 760 \\
2002 & 165,411 & 79,058 & 25,297 & 279 & 219 \\
2003 & 169,035 & 126,343 & 4,312 & 31 & 13 \\
2004 & 207,099 & 168,921 & 9,988 & 30 & 13 \\
2005 & 250,372 & 172,763 & 14,697 & 26 & 7 \\
2006 & 260,269 & 142,903 & 16,183 & 12 & 9 \\
2007 & 201,322 & 78,086 & 22,603 & 10 & 9 \\
2008 & 236,378 & 146,155 & 12,836 & 3 & 2 \\
2009 & 257,841 & 158,086 & 5,436 & 7 & 3 \\
2010 & 233,739 & 130,637 & 234 & 28 & 15 \\
2011 & 236,447 & 78,231 & 106 & 39 & 28 \\
\hline
\end{tabular}

Source data: Husbandry Department of East Nusa Tenggara Province. These data were registered by each Regency Husbandry Department in Flores Island as part of vaccination campaign. In case the dog owners and their dogs were not present at time of registration, the dogs were not accounted for. For example in Sikka regency, the dogs of approximately $30 \%$ of the dog owners were not registered for this reason in 2012 (Personal communication, Dr. Sikko). As a result the registered number underestimates the actual size of the dog population.

${ }^{a}$ Windiyaningsih et al. (2004)

\section{Culling of roaming dogs}

According to (Bingham, 2001; Hutabarat et al., 2003), it is unlikely there are ownerless dogs in Flores Island. Majority of the dogs is unrestrained and allowed to roam freely, hence the term free-roaming dogs. The decision to cull roaming dogs was generally considered in one of the following three situations: (1) when the virus was newly introduced into an area, all dogs in that area would be culled; (2) when a dog was freely roaming in a public place regardless of its vaccination status; and (3) when an unvaccinated dog was freely roaming in a public place.

The diagnosis of whether the virus was newly introduced in an area was based on the occurrence of clinical signs in a human who lived in that area, accompanied by test results of suspected dogs in that area. In this case, the regency administrator released a warning regarding the rabies danger, usually followed by mass dog culling in that area. For example, when rabies was introduced to East Flores Regency in 1998 and to Ngada Regency in 2000, each regency administrator decided to cull all dogs throughout the regency (Wera, 2001). 
Culling any dog freely roaming in a public place, regardless of vaccination status, has been applied in Manggarai Regency (Manggarai Regency's law number 6, year 2003). Public places include roads, public parks, traditional markets, and open fields.

Culling unvaccinated dogs freely roaming in public places was initiated in Ngada Regency in 2001, and expanded into all other regencies on Flores Island except for Manggarai Regency. This program was not operating well because of a lack of regulation to force people to comply. The culling program was carried out in collaboration between government and local community, and was conducted within villages during the day light by shooting (generally by a team that formed by regency administrator) or by beating the dogs with a stick (by local community). The majority of the culling was carried out by the local community and dog owners themselves (Hutabarat et al., 2003). Since actual data is lacking, we assumed only $20 \%$ of the total culled dogs to be executed by a governmental team (based on the experiences of the local veterinarians involved) which included a public servant and police or army assistance.

The cost of culling roaming dogs $(C C D)$ includes private costs $(P C)$ and public (governmental) costs $(G C)$ :

$$
C C D=P C+G C
$$

$P C$ only depends on the number of $\operatorname{dogs}$ culled $\left(n_{c d}\right)$, the value of $\operatorname{dogs}\left(v_{c d}\right)$, and the proportion by which the dogs are culled by the local community $\left(p r_{c d o}\right)$, and the opportunity cost for their time investment to cull one $\operatorname{dog}\left(o_{c d}\right)$ :

$P C=n_{c d} \times\left(v_{c d}+p r_{c d o} \times o_{c d}\right)$

$G C$ includes the costs per day per governmental team culling dogs $\left(c_{p s}\right)$, the price of a bullet used to shoot a $\operatorname{dog}\left(p_{a m}\right)$, the fuel costs per day of the team $\left(f_{c m}\right)$, and the daily depreciation cost of the motorcycles needed to travel to the culling area $\left(d_{c m}\right)$ :

$G C=n_{c d} \times\left(1-p r_{c d o}\right) \times\left(p_{a m}+\frac{c_{p s}+f_{c m}+d_{c m}}{n_{c a p c d}}\right)$

$d_{c m}$ was calculated based on the number of motorcycles $\left(n_{m c}\right)$, the price of a motorcycle $\left(p_{m c}\right)$, and the number of life years of motorcycles $\left(l_{c m r}\right)$ :

$d_{c m}=\frac{n_{m c} \times p_{m c}}{l_{c m r} \times n_{d y}}$ 
Depreciation costs of guns and sticks were ignored since these were negligible. The guns were provided by police and army departments and were not special purchased for shooting dogs. The sticks were already available in the village.

The costs for an information campaign regarding culling dogs are included as an integral part of the campaign of the mass vaccination program. The inputs used in the calculations for the costs of culling control measures are presented in Table 2.2. In addition, the total number of dogs culled per year on Flores Island is shown in Table 2.1, which was on average 7\% (range: $0-15 \%$ ) of the total registered dog population during the vaccination campaign.

\section{Table 2.2}

Model inputs for the cost calculations of control measures in dogs (Prices expressed at level of 2011).

\begin{tabular}{|c|c|c|c|c|}
\hline Description & Variable & $\begin{array}{r}\text { Value } \\
(\mathrm{Rp}) \\
\end{array}$ & $\begin{array}{l}\text { Value } \\
\text { (US\$) }\end{array}$ & Unit \\
\hline \multicolumn{5}{|l|}{ Mass vaccination } \\
\hline Price of vaccine ${ }^{1}$ & $p_{v a}$ & $2,631^{\mathrm{a}}$ & 0.29 & Rp/dose \\
\hline $\begin{array}{l}\text { Transportation costs of vaccine from } \\
\text { manufacturer to each regency }\end{array}$ & $t_{v a}$ & $1,390^{\mathrm{b}}$ & 0.15 & $\mathrm{Rp} /$ dose \\
\hline Price of syringes and needles & $p_{s n}$ & $1,750^{\mathrm{b}}$ & 0.19 & $\mathrm{Rp} / \mathrm{dog}$ \\
\hline Ice bars & $p_{i b}$ & $3,000^{\mathrm{b}}$ & 0.33 & $\mathrm{Rp} /$ coolbag/day \\
\hline Vaccination capacity & $n_{\text {capv }}$ & $25^{\mathrm{c}}$ & & Dogs/vaccinator/day \\
\hline $\begin{array}{l}\text { Disinfectant swabs ( } 70 \% \text { ethanol or } \\
\text { alcohol) for cleaning the dog's skin }\end{array}$ & $p_{d s}$ & $200^{\mathrm{b}}$ & 0.02 & $\mathrm{Rp} / \mathrm{dog}$ \\
\hline $\begin{array}{l}\text { Proportion of vaccinated dogs using } \\
\text { collar }\end{array}$ & $p r_{c l}$ & $10 \%^{\mathrm{b}}$ & & \\
\hline Price of collar & $p_{c l}$ & $3,000^{\mathrm{b}}$ & 0.33 & Rp/piece \\
\hline Salary of temporary vaccinator & $s_{t v}$ & $2,500^{\mathrm{b}}$ & 0.28 & $\mathrm{Rp} /$ vaccinated dog \\
\hline $\begin{array}{l}\text { Transportation cost for people } \\
\text { involved in the rabies control }\end{array}$ & $f_{c m}$ & $9,000^{\mathrm{d}}$ & 1.00 & Rp/person/day \\
\hline Costs of public servant & $c_{p s}$ & $91,000^{\mathrm{e}}$ & 10.06 & Rp/person/day \\
\hline $\begin{array}{l}\text { The number of vaccinators that can } \\
\text { be supervised by one public servant }\end{array}$ & $n_{v s}$ & $10^{\mathrm{b}}$ & & vaccinators/supervisor \\
\hline Costs of training and meeting & $C_{m t}$ & $7,700,000^{\mathrm{b}}$ & 851.30 & Rp/year \\
\hline Campaign costs & $C_{i c}$ & $120,000,000^{\mathrm{b}}$ & 13,267 & Rp/year \\
\hline Cool bags & $n_{c b}$ & $27^{\mathrm{f}}$ & & Pieces \\
\hline Price cool bag & $p_{c b}$ & $253,170^{\mathrm{g}}$ & 27.99 & Rp/piece \\
\hline Motorcycles & $n_{m c}$ & $16^{\mathrm{f}}$ & & Pieces \\
\hline
\end{tabular}


Price motor cycle

Refrigerator

Price refrigerator

Muzzles

Price of muzzle

Life years of capital goods (cool bags, refrigerators and motorcycles)

Life years of muzzles

Number of days in one year

Working hours lost for a dog owner

Daily wage

Number hours work

\section{Culling of roaming dogs}

Value of $\operatorname{dogs}^{3}$

Proportion of dogs culled by local community or dog owners

Opportunity cost of time to cull dogs

for local community or dog owners

The number of dogs that can be

culled by a governmental team

Price of ammunition (bullet)

$$
\begin{aligned}
& p_{m c} \\
& n_{r f} \\
& p_{r f}
\end{aligned}
$$

$n_{m z}$

$p_{m z}$

$l_{c m r}$

$l_{m z}$

$n_{d y}$

$w_{h l}$

$d_{w}$

$n_{h w}$

$v_{c d}$

$p r_{c d o}$

$o_{c d}$

$n_{\text {capcd }}$

$p_{a m}$

$n_{b i}$

$c_{b i}$

$c_{\text {matbi }}$ $15,100,000^{\mathrm{h}}$

$8^{\mathrm{f}}$

$1,580,000^{\mathrm{h}}$

$27^{\mathrm{f}}$

$50,000^{\mathrm{h}}$

5.53

$5^{\mathrm{i}}$

$2^{\mathrm{b}}$

$365^{\mathrm{i}}$

$2^{\mathrm{j}}$

$39,000^{\mathrm{k}}$

$8^{\mathrm{i}}$

\subsection{1}

Rp/day

Hours/day

$278,923^{1}$

30.80

$80 \%$

$2,500^{\mathrm{m}}$

0.28

$40^{\mathrm{b}}$

$9,241^{\mathrm{n}}$

1.02

$1^{\circ}$

$191,000^{\mathrm{e}}$

21.12

Person/ case

Cost of the investigators

Material costs (gloves, scissors, and tweezers)

\section{Diagnostic testing of suspected rabid dogs}

Material costs (glycerin, formalin)

Laboratory costs

Packing

Shipping

Cost of collector sample

Correspondence of laboratory result $c_{\text {mat }}$

$c_{l a b}$

$c_{\text {pack }}$

$c_{\text {ship }}$

$c_{\text {coll }}$

$c_{\text {corr }}$ $5,000^{\mathrm{b}} \quad 0.55$

$20,000^{p}$

$10,000^{\mathrm{b}}$

1.11

$20,000^{\mathrm{b}}$

2.21

$15,000^{\mathrm{b}}$

1.66

$30,000^{\mathrm{i}}$
Rp/ sample

$\mathrm{Rp} /$ sample

$\mathrm{Rp} /$ sample

$\mathrm{Rp} /$ sample

$\mathrm{Rp} /$ sample

$\mathrm{Rp} /$ sample

$\mathrm{Rp} /$ sample

\section{Trace back investigation of human contacts with rabid dogs}

Number of people that are doing $n_{t b i}$ 
trace back investigation

Costs of investigator

$l_{t b}$

$191,000^{\mathrm{b}}$

21.12

$\mathrm{Rp} /$ day

\section{Quarantine}

Number of dog quarantined

Length of quarantine

Cost of quarantine facility

Cost of dog food

$\begin{array}{lrll}n_{q} & 4^{\mathrm{q}} & & \text { dogs per year } \\ l_{q} & 14^{\mathrm{r}} & & \text { days } \\ c_{q f} & 1,500^{\mathrm{a}} & 0.17 & \text { Rp/day } / \mathrm{dog} \\ c_{f d} & 5,000^{\mathrm{i}} & 0.55 & \mathrm{Rp} / \text { day } / \mathrm{dog}\end{array}$

The quarantine caretaker salary

$c_{c t}$

$2,500^{\mathrm{a}}$

0.28

$\mathrm{Rp} / \mathrm{day} / \mathrm{dog}$

Cost of veterinary inspection

$c_{v i}$

$7,500^{\mathrm{a}}$

$\mathrm{Rp} /$ period

Cost of administration (sertificate

document, ect)

$c_{a d}$

${ }^{a}$ Indonesian Agriculture Ministry (IAM) (2004)).

${ }^{\mathrm{b}}$ Public servants/veterinarians involved in rabies control measures in the past.

${ }^{\mathrm{c}}$ Vaccinators involved in the vaccination campaign.

${ }^{\mathrm{d}}$ Calculated: Multiplying by the average distance between the vaccination location and the Regency Agricultural Department (in average $100 \mathrm{~km}$, rate of fuel consumption (in average 1 litter per $50 \mathrm{~km}$ ) and market price of fuel per litter (Rp 4,500 per litter).

${ }^{\mathrm{e}}$ The real cost paid to a public servant (Rp 100,000 per person per day) minus his/her transportation cost (Rp 9,000 per person per day).

${ }^{\mathrm{f}}$ Average number based on data from Husbandry Department of Sikka and Ngada regencies.

${ }^{g}$ http://www.igloo-store.com/detail/IGL+DUO+STCOOL+G (accessed 24 June 2013).

${ }^{\mathrm{h}}$ Market price in Flores by asking the seller in the shopping center.

${ }^{\mathrm{i}}$ Assumption based on the author knowledge.

${ }^{\mathrm{j}}$ Dog owners participated in the vaccination program.

${ }^{\mathrm{k}}$ BPS (Indonesian Statistics) ( 2012).

${ }^{1}$ Calculated based on the average value of dogs year 2003, Rp 175,000 per dog (Hutabarat et al.,2003)

${ }^{\mathrm{m}}$ Calculated based on the daily wage and the number of dog culled per day per person (approximately 16 dogs per day per person).

${ }^{\mathrm{n}}$ Michell and Kanowski (2003).

${ }^{\circ}$ Husbandry Department of Sikka Regency.

${ }^{\mathrm{p}}$ Center of Disease Investigation, Maros.

${ }^{\mathrm{q}}$ Ende Regency quarantine.

${ }^{\mathrm{r}}$ Indonesian quarantine (IQ) (2008).

\section{Dog-bite investigation}

When a bite from a suspected rapid dog was reported, the veterinary authority (investigators) gathered information from the victim and the dog owner. Officially, the veterinary authority would capture and quarantine the dog for 10 days, but usually the owner or the victim's family already had killed the dog. In this context, the veterinary authority would collect a brain sample or a head of dog to be sent to the central laboratory in Maros, Sulawesi.

$C B I$ includes costs of the investigators who were involved in the investigation of the biting case $\left(c_{b i}\right)$, costs of materials, such as gloves, scissors, and tweezers $\left(c_{\text {matbi }}\right)$, and costs of transportation for the investigators $\left(d_{c m}\right.$ and $\left.f_{c m}\right)$ : 


$$
C B I=n_{s s} \times n_{b i} \times\left(c_{b i}+c_{m a t b i}+d_{c m}+f_{c m}\right)
$$

Where, $n_{s s}$ is the number of samples submitted and $n_{b i}$ the number of investigators involved in the investigation. The diagnostic costs are explained in the following paragraph. The inputs for this calculation are given in Table 2.2, and the number of dogs investigated in Table 2.1.

\section{Diagnostic testing of suspected rabies dogs}

Diagnostic testing is an integral part of the control program to obtain accurate incidence data. Therefore, all suspected rabies cases in dogs should be confirmed by clinical samples that are tested at a diagnostic laboratory (Childs et al., 2007) using fluorescent antibody test (Whitfield et al., 2001). In total 2,988 samples from suspected rabid dogs from Flores Island were sent to the laboratory in Maros, South Sulawesi for rabies testing from 2000 to 2011. These samples came from dogs that bit humans, as mentioned in the dog bite investigation activity. All samples were sent by postal services, and results were sent by postal service to the Animal Health director in Jakarta, the head of the animal husbandry of East Nusa Tenggara Province (in Kupang), and the head of the Regency Agricultural Department in Flores Island.

The total costs of testing suspected rabies dogs depend on the number of samples submitted, transported, and tested and the corresponding cost of the results:

$$
C D D=n_{s s} \times\left(c_{\text {mat }}+c_{\text {lab }}+c_{\text {pack }}+c_{\text {ship }}+c_{\text {coll }}+c_{\text {corr }}\right)
$$

Where, $n_{s s}$ is the number of samples submitted to the laboratory, $c_{m a t}$ the costs of materials, such as glycerin and formalin, $c_{l a b}$ the laboratory costs, $c_{\text {pack }}$ the costs for packing the samples; $c_{\text {ship }}$ the shipping costs, $c_{\text {coll }}$ the costs for collection of samples (or sampling activity), and $c_{\text {corr }}$ the cost for correspondence of laboratory results.

The inputs of these calculations are listed in Table 2.2. The number of samples tested in 2000 and 2001 was high, relative to later years because there were severe outbreaks in Ngada and Manggarai Regencies with more than 1,894 and 712 bite cases in 2000 and 2001, respectively.

\section{Trace back investigation of human contacts with rabid dogs}

When a brain sample of a suspected dog tested was positive for rabies, the authorities attempted to trace all persons who may have had contact with the dog. Anyone bitten by the dog was vaccinated.

The costs for tracing back the human contacts of rabid dogs $(C T B)$ include transportation costs of the person doing the work $\left(d_{c m}\right.$ and $\left.f_{c m}\right)$ and the labor costs of this person $\left(l_{t b}\right)$ : 


$$
C T B=n_{s p} \times n_{t b i} \times\left(l_{t b}+d_{c m}+f_{c m}\right)
$$

Approximately, $80 \%$ of the brain samples tested in the laboratory tested positive for rabies. We assumed that all dogs testing positive $\left(n_{s p}\right)$ were traced back so that the people who may have had contact with these dogs were investigated. The inputs for this calculation can be found in Table 2.2.

\section{Quarantine of imported animals}

The Indonesian government applies a quarantine program of minimal 14-days to prevent reintroduction of rabies through the import of vectors such as dogs, cats, and monkeys to Flores Island.

The quarantine costs $(C Q D)$ are described as:

$$
C Q D=n_{q} \times\left(l_{q} \times\left(c_{q f}+c_{f d}+c_{c t}\right)+c_{v i}+c_{a d}\right)
$$

Where $n_{q}$ represents the number of dogs quarantined, $l_{q}$ the length of the quarantine period, $c_{q f}$ the cost of quarantine facility per day, $c_{f d}$ the cost of dog food per day, $c_{c t}$ the caretaker salary per dog per day, $c_{v i}$ the costs of veterinary inspection per dog per period quarantine, and $c_{a d}$ the costs of quarantine administration or document per dog per period quarantine. The input values can be found in Table 2.2.

\subsubsection{Control measures in humans}

The total costs of rabies control measures in humans equal the sum of the pre-exposure treatment costs $\left(C_{p r e}\right)$ and the PET costs $\left(C_{P E T}\right)$ :

$$
C M H=C_{p r e}+C_{P E T}
$$

Each control measure in humans is explained below and a detailed economic calculation is given, including the inputs.

\section{Pre-exposure treatment in humans}

Pre-exposure treatment is effective to prevent rabies in persons who have a high risk of contact with the virus, such as veterinarians, veterinary assistants, laboratory workers and public servants involved in the rabies control program (WHO, 2005). The treatment consists of three doses of a rabies vaccine $\left(\right.$ Verorab $^{\circledR}$ ), which is administered prior to the person's exposure to a suspected rabid dog. The vaccine is administered intramuscularly or intradermally on days 0,7 , and 21 or 28 (WHO, 2005). If the serological status is below 0.5 $\mathrm{IU} / \mathrm{ml}$, a booster after one year is recommended. 
$C_{p r e}$ depends on the number of people at risk that received pre-exposure treatment $\left(n_{\text {pre }}\right)$, the number of doses of vaccine for pre-exposure treatment $\left(n_{d p r e}\right)$, costs of the vaccine $\left(c_{v a c}\right)$, costs of materials such as needles, syringes, and disinfectant swabs (70\% ethanol or alcohol) $\left(c_{n s}\right)$, physician costs $\left(c_{p}\right)$ and transportation costs to take high-risk people to and from a hospital to receive the vaccination $\left(c_{t p r e}\right)$ :

$$
C_{\text {pre }}=n_{\text {pre }} \times n_{d p r e} \times\left(c_{v a c}+c_{n s}+c_{p}+c_{t p r e}\right)
$$

We assumed that there were no opportunity costs for the public servants who received preexposure treatment, since expected time needed to provide a vaccination was less than 1 hour per person. The input values of pre-exposure treatment are given in Table 2.2.

\section{Post-exposure treatment in humans}

Post-exposure treatment, which is given to persons bitten by a suspected rabid animal, consists of wound cleaning, one dose of immunoglobulin, and four (Zagreb schedule) or five doses (Essen schedule) of vaccine (Manning, 2008).

The wound should be cleaned with soap for 15 minutes and antiseptic should be used to reduce the contamination from microorganisms (Linscott, 2012). Proper wound cleaning can remove the virus before it spreads to the nervous system, and consequently, the probability of human infection may be reduced (Kaplan et al., 1962). In addition, wound cleaning is sometimes the most feasible option for bitten persons in remote areas; Flores Island has only five regency hospitals that provide vaccine and immunoglobulin treatments, and these may be too far for some individuals to travel.

A rabies immunoglobulin injection around the wound is an essential part of the PET because it neutralizes the virus before it invades the nervous system (Jackson et al., 2003). Human rabies immunoglobulin (HRIG) is administered only once (at the beginning of anti-rabies prophylaxis) to previously unvaccinated persons to provide neutralizing antibodies immediately (Manning, 2008). This treatment is highly recommended for those with severe wounds (WHO, 2005).

Vaccination of persons bitten by a suspected dog aims to prevent clinical signs of rabies, and delay contributes to post-exposure treatment failure ( $\mathrm{Si}$ et al., 2008). Therefore, the vaccination should be applied immediately after exposure (WHO, 2005).

The Indonesian Health Ministry (IHM) (2000) recommended using the Zagreb schedule for post-exposure treatment, with four doses injected intramuscularly in three visits on days 0,7 , and 21. On the first visit (day 0), a patient is injected with two doses of vaccine. Then, additional doses are applied on days 7 and 21. The vaccine used in Flores Island was a rabies vaccine produced on Vero cells $\left(\right.$ Verorab $\left.^{\circledR}\right)$. 
$C_{P E T}$ depends on the costs of wound cleaning $\left(C_{w c}\right)$, immunoglobulin injection $\left(C_{r i}\right)$, and a series of vaccine injections $\left(C_{r v}\right)$ :

$C_{P E T}=C_{w c}+C_{r i}+C_{r v}$

$C_{w c}$ consists of costs of water $\left(c_{w t}\right)$, soap $\left(c_{s o}\right)$, and antiseptic $\left(c_{a n}\right)$ multiplied by the number of persons bitten by a suspected dog $\left(n_{\text {bite }}\right)$ :

$$
C_{w c}=n_{b i t e} \times\left(c_{w t}+c_{s o}+c_{a n}\right)
$$

We assumed that all people bitten by suspected rabid dogs cleaned their wound with water and soap for 15 minutes in line with the general recommendation.

The costs related to rabies immunoglobulin injection $\left(c_{r i}\right)$ are costs of immunoglobulin $\left(p_{r i}\right)$, needles, syringes, and disinfectant swabs $\left(c_{n s}\right)$ :

$$
C_{r i}=p r_{r i} \times n_{p e t} \times\left(p_{r i}+c_{n s}\right)
$$

Where, $p r_{r i}$ is the proportion of people who received rabies immunoglobulin, and $n_{p e t}$ the number of people who received rabies vaccine after exposure to a suspected rabid dog. We assumed no additional costs for transport and physicians since the immunoglobulin injection was performed along with the first injection of vaccine series.

The factors associated with the costs of vaccine injection $\left(c_{r v}\right)$ are the cost of vaccine $\left(c_{v a c}\right)$, costs of needles, syringes, and disinfectant swabs $\left(c_{n s}\right)$, physicians' fees $\left(c_{p}\right)$, and the number of doses of vaccine for PET $\left(n_{d p e t}\right)$, proportion of adult people received PET $\left(p r_{a d u}\right)$, transportation costs $\left(c_{t}\right)$ to and from medical center for each dose of vaccine for 2 persons as we assumed that all patients were accompanied by one person.

$C_{r v}=n_{p e t} \times\left(n_{d p e t} \times\left(c_{v a c}+c_{n s}\right)+n_{v i} \times\left(c_{p}+2 c_{t}\right)+\left(1+p r_{a d u}\right) \times o_{c}\right)$

Where, $o_{c}$ is the opportunity costs of the time of adult patients and one additional person who accompanies the patient to receive a treatment from a nurse or physician. The opportunity costs were calculated based on the daily wage $\left(d_{w}\right)$ and the number of loss working time during the vaccine series $\left(l_{w t}\right)$ :

$o_{c}=d_{w} \times l_{w t}$

Table 2.3 shows the number of humans bitten by suspected dogs and the number of persons receiving PET. All other inputs are shown in Table 2.4. 


\section{Table 2.3}

The number of bitten human by rabies suspected dogs and post exposure treatments (PET) in Flores Island during $2000-2011$.

\begin{tabular}{lrrr}
\hline Year & Bite cases $\left(n_{\text {bite }}\right)$ & PET $\left(n_{p e t}\right)$ & Percentage of PET $(\%)$ \\
\hline $2000^{\mathrm{a}}$ & 2,560 & 1,821 & 71 \\
$2001^{\mathrm{a}}$ & 1,143 & 419 & 37 \\
$2002^{\mathrm{a}}$ & 718 & 710 & 99 \\
2003 & 967 & 840 & 87 \\
2004 & 1,222 & 1,061 & 87 \\
2005 & 3,073 & 2,668 & 87 \\
2006 & 2,231 & 2,164 & 97 \\
2007 & 3,261 & 3,020 & 93 \\
2008 & 3,448 & 3,011 & 87 \\
2009 & 3,764 & 3,248 & 86 \\
2010 & 4,888 & 3,743 & 77 \\
2011 & 3,563 & 2,889 & 81 \\
\hline
\end{tabular}

Source data: Human Health Department of East Nusa Tenggara Province

${ }^{a}$ Windiyaningsih et al (2004)

\subsubsection{Distribution of costs}

This study not only studied the total societal costs of rabies in Flores Island, it also evaluated the distribution of rabies control costs in terms of private and public costs (Kayali et al., 2006). Public costs are those that the Animal Health and Public Health departments incur, which are included in the local and/or national budgets. Private costs are those that dog owners and those exposed to the rabies virus incur. The costs for dog owners include the loss of the value of dogs due to culling measures and income loss (opportunity costs) due to time lost while bringing dogs to be vaccinated and/or to catch their dogs. For exposed patients, costs include the opportunity costs for the patient and anyone accompanying the patient to get treatment and their transportation costs to a medical center for each treatment. Detailed components of public and private costs are shown in Table 2.5.

\subsubsection{Sensitivity analysis}

A sensitivity analysis was performed to identify those input parameters (Table 2.2) that are highly influential to the costs of control measures. The sensitivity was based on a univariate analysis in which each parameter was increased and reduced by $10 \%$ of the default input values, as the others were held constant. The results of each change in parameter were compared with the results of the model outcome in the default situation to assess the impact of each parameter on the costs of rabies control measures. 


\section{Table 2.4}

Model inputs for the cost calculations of control measures in humans.

\begin{tabular}{|c|c|c|c|c|}
\hline Description & Variable & $\begin{array}{l}\text { Value } \\
(\mathrm{Rp})\end{array}$ & $\begin{array}{l}\text { Value } \\
\text { (US\$) }\end{array}$ & Unit \\
\hline \multirow{2}{*}{$\begin{array}{l}\text { Number of people received pre-exposure } \\
\text { treatment } \\
\text { Number of doses of vaccine for pre- } \\
\text { exposure treatment }\end{array}$} & $n_{\text {pre }}$ & \multicolumn{2}{|l|}{$150^{\mathrm{a}}$} & Person/year \\
\hline & $n_{d p r e}$ & \multicolumn{2}{|l|}{$3^{b}$} & Doses/patient \\
\hline Cost of vaccine & $c_{v a c}$ & $250,000^{\mathrm{a}}$ & 27.64 & $\mathrm{Rp} /$ dose \\
\hline Costs of needle, syringe and swab & $c_{n s}$ & $1,950^{\mathrm{a}}$ & 0.22 & Rp/patient \\
\hline \multirow{2}{*}{$\begin{array}{l}\text { Cost for Physician } \\
\text { Transportation cost of people received } \\
\text { pre-exposure treatment* }\end{array}$} & $c_{p}$ & $50,000^{\mathrm{a}}$ & 5.53 & Rp/Patient \\
\hline & $c_{\text {tpre }}$ & $6,000^{\mathrm{a}}$ & 0.66 & \multirow{2}{*}{$\begin{array}{l}\mathrm{Rp} / \text { visiting } \\
\mathrm{Rp} / \text { per } 30 \\
\text { liter/patient }\end{array}$} \\
\hline Cost of water & $c_{w t}$ & $563^{\mathrm{c}}$ & 0.06 & \\
\hline Cost of soap & $c_{s o}$ & $2,000^{\mathrm{d}}$ & 0.22 & Rp/patient \\
\hline \multirow{2}{*}{$\begin{array}{l}\text { cost of antiseptic } \\
\text { Proportion of human received } \\
\text { immunoglobulin }\end{array}$} & $c_{a n}$ & $3,000^{\mathrm{d}}$ & 0.33 & Rp/patient \\
\hline & $p r_{r i}$ & $0.01^{\mathrm{e}}$ & & \\
\hline \multirow{2}{*}{$\begin{array}{l}\text { Price of Immunoglobulin } \\
\text { Number of doses of vaccine for post- } \\
\text { exposure treatment }\end{array}$} & $p_{r i}$ & $1,550,000^{\mathrm{a}}$ & 171.37 & $\mathrm{Rp} /$ dose \\
\hline & $n_{\text {dpet }}$ & $4^{\mathrm{b}}$ & & doses/patient \\
\hline $\begin{array}{l}\text { Number of visits for receiving } \\
\text { vaccination post-exposure treatment }\end{array}$ & $n_{v i}$ & $3^{\mathrm{b}}$ & & visit \\
\hline $\begin{array}{l}\text { Transportation cost of people received } \\
\text { vaccination post-exposure treatment } * *\end{array}$ & $c_{t}$ & $40,000^{\mathrm{f}}$ & 4.42 & $\mathrm{Rp} /$ visit \\
\hline Daily wage & $d_{w}$ & $39,000^{\mathrm{g}}$ & 4.31 & Rp/day \\
\hline Loss of working time for patient & $l_{w t}$ & $3^{\mathrm{h}}$ & & day \\
\hline Proportion of adult people received PET & $p r_{a d u}$ & 0.60 & & \\
\hline
\end{tabular}

${ }^{\mathrm{a}}$ Public servants/veterinarians/internist involved in rabies control measures in the past.

${ }^{\mathrm{b}}$ WHO ( 2005).

${ }^{c}$ Market price of water in Kupang was approximately Rp 75,000 per 4,000 liter (Rp 18.75 per liter). We assumed that a patient will use the water about 2 litre per minute, so for 15 minutes wound cleaning (as recommended by WHO ( 2005) and IHM (2000)) the water needed was about 30 litre. Thus the price of water equal Rp 563 (Rp 18.75 x 30) per patient.

${ }^{\mathrm{d}}$ Assumption based on the market price in Flores in October 2011.

${ }^{\mathrm{e}}$ Bingham ( 2001).

${ }^{\mathrm{f}}$ Patients received immunoglobulin injection, and series of vaccine injections.

${ }^{\mathrm{g}}$ BPS ( 2012).

${ }^{\mathrm{h}}$ Loss of working time for patient was set 3 days to visit the hospital 3 times to get PET.

*Transportation cost within the city since the people received pre-exposure treatment are public servants that working and living in the city.

**Transportation cost from rural areas. 


\section{Table 2.5}

The components of public and private costs of rabies control measures for different stakeholders.

Stakeholders Component

\begin{tabular}{ll}
\hline 1. Agricultural Department & 1. Mass vaccination \\
& 2. Culling of roaming dogs \\
Public costs & 3. Dog-bite investigation \\
& 4. Diagnostic testing of suspected rabid dogs \\
& 5. Trace back investigation of human contacts \\
& 6. Quarantine
\end{tabular}

$\begin{array}{ll}\text { 2. Public Health Department } & \text { 1. Human rabies vaccines } \\ \text { 2. Immunoglobulin } \\ \text { 3. Syringe and needles }\end{array}$

3. Dog owners

Private costs
1. The lost value of dogs due culling control measure

2. Opportunity cost for the owner of vaccinated dogs

3. Opportunity cost for the dog owners for their time investment to cull dogs

$\begin{aligned} \text { 4. Dog-bite patients } & \text { 1. } \\ & \text { Opportunity cost for: } \\ & \bullet \text { Patients } \\ & \bullet \text { Caretakers }\end{aligned}$

2. Transportation of patients and caretaker

\subsection{Results}

\subsubsection{Total costs of control measures}

Total costs of rabies control measures during the study period (2000-2011) were estimated to be US\$13.40 million, with an average of US\$1.12 million (range: US\$0.60-1.47 million) per year. The costs of control measures in dogs were about $28 \%$ higher than in humans. When ranked individually, regardless of control measures in dogs or humans, the costs of culling dogs were the highest, accounting for $39 \%$ of the total costs, followed by post-exposure treatment $(35 \%)$, mass vaccination (24\%), pre-exposure treatment $(1.4 \%)$, and others $(1.3 \%)$ (dog-bite investigation, diagnostic testing of suspected rabid dogs, trace-back investigation of human contact with rabid dogs, and quarantine of imported dogs) (Tables 6 and 7).

The total costs of control measures fluctuated during 2000-2006, and tended to decrease in the last five years of the study period (Figure 2.1). The costs seemed to depend on the priority 
of rabies control measures applied. For example, in the first three years (2000-2002), the control program focused more on culling dogs, which is costly. Approximately $14 \%$ of the total dog population was culled at that time (Table 2.1). During 2008-2011, PET in humans dominated, at $41 \%$ to $71 \%$ of the total costs. In this context, the high proportion of PET costs in the total probably indicated not only a priority but also an increase in bite cases, and consequently, more PET.

\subsubsection{Costs of control measures in dogs}

Total costs of rabies control measures in dogs during the study period were estimated at US $\$ 8.58$ million, with an average of US\$0.72 million (range: US\$0.19-1.08 million) per year (Table 2.6). Culling roaming dogs was the most costly measure, accounting for $60 \%$ of the annual costs of control measures among dogs, followed by mass vaccination of dogs (38\%), bite investigation (1\%), trace back investigation $(0.7 \%)$, and diagnostic testing $(0.4 \%)$. The quarantine of imported dogs accounted for almost nothing in total costs, a finding that could be underestimated because we assumed that the costs of quarantine remained the same throughout the study period.

\section{Table 2.6}

Cost of Rabies control measures in dogs in Flores Island from 2000 to 2011.

\begin{tabular}{|c|c|c|c|c|c|c|c|}
\hline \multirow[b]{2}{*}{ Year } & \multicolumn{6}{|c|}{ Costs of Rabies control measures in dogs (x 1000 US\$) } & \multirow{2}{*}{ Total } \\
\hline & $\begin{array}{c}\text { Mass } \\
\text { vaccination } \\
\text { dogs }\end{array}$ & $\begin{array}{l}\text { Culling } \\
\text { dogs }\end{array}$ & $\begin{array}{c}\text { Bite } \\
\text { inves- } \\
\text { tigation }\end{array}$ & $\begin{array}{l}\text { Diagnostic } \\
\text { testing }\end{array}$ & $\begin{array}{c}\text { Trace back } \\
\text { investigation }\end{array}$ & Quarantine* & \\
\hline 2000 & 123.76 & 856.35 & 45.57 & 20.32 & 34.27 & 0.06 & $1,080.33$ \\
\hline 2001 & 125.23 & 797.18 & 22.28 & 9.94 & 16.80 & 0.06 & 971.49 \\
\hline 2002 & 188.76 & 800.15 & 6.57 & 2.93 & 4.84 & 0.06 & $1,004.02$ \\
\hline 2003 & 293.22 & 136.51 & 0.73 & 0.33 & 0.29 & 0.06 & 431.13 \\
\hline 2004 & 387.27 & 316.20 & 0.71 & 0.32 & 0.29 & 0.06 & 704.84 \\
\hline 2005 & 395.76 & 465.28 & 0.61 & 0.27 & 0.15 & 0.06 & 862.14 \\
\hline 2006 & 329.80 & 512.32 & 0.28 & 0.13 & 0.20 & 0.06 & 842.79 \\
\hline 2007 & 186.61 & 715.57 & 0.24 & 0.11 & 0.20 & 0.06 & 902.78 \\
\hline 2008 & 336.98 & 406.36 & 0.07 & 0.03 & 0.04 & 0.06 & 743.55 \\
\hline 2009 & 363.34 & 172.09 & 0.16 & 0.07 & 0.07 & 0.06 & 535.80 \\
\hline 2010 & 302.70 & 7.41 & 0.66 & 0.29 & 0.33 & 0.06 & 311.46 \\
\hline 2011 & 186.93 & 3.36 & 0.92 & 0.41 & 0.62 & 0.06 & 192.30 \\
\hline Total & $3,220.36$ & $5,189.47$ & 78.79 & 35.14 & 58.11 & 0.75 & $8,582.62$ \\
\hline
\end{tabular}

The annual costs of mass vaccination of dogs were approximately US $\$ 268,360$ (range: US\$123,760-395,760), with a mean of US\$2.49 per vaccinated dog. The price of vaccine contributed only $18 \%$ of the total vaccination costs of dogs. Other components were 
vaccinators, supervisors, meeting and training of temporary vaccinators, the information campaign, capital, and the opportunity costs of dog owners. In addition, the costs of mass vaccination of dogs increased from US\$123,760 in 2000 to US\$395,760 in 2005, and then fluctuated until 2011. This pattern indicates the government's performance or commitment to control rabies through mass vaccination of dogs. Because of Indonesia's autonomy system, the local governments of regencies provide budgets for vaccination control measures in dogs. Therefore, budget decisions regarding vaccination of dogs varied among Flores Island's eight regencies, and the number of dogs vaccinated in each regency was not the same each year, depending upon budget allocations. Even when the central government (Agriculture Ministry of Indonesia) provides vaccines for dogs, regency budgets for training and hiring temporary vaccinators may determine the final vaccination coverage. This problem might contribute to the declining vaccination coverage in the last three years of the study period (2009-2011). Vaccination costs in 2011 were estimated to be two times lower than those in 2005 (Figure 2.1 ), as the vaccination coverage of registered dogs in 2011 (33\%) was lower than in 2005 (69\%) (Table 2.1).

Total costs of culling dogs were approximately US\$5.2 million, with average annual costs about US\$432,460 (range: US\$3,360-856,350). The average costs per dog culled was estimated to be US\$31.70. A large portion of these costs originated from the lost value of the dogs for the dog owners, which accounted for almost $100 \%$ of the total costs. Note that the annual costs of culling dogs were highest in the first year of the study period and then tended to fluctuate until reaching their lowest value in 2011 (Figure 2.1), which was about US\$3,360.

The annual costs of diagnostic testing of suspected rabid dogs were calculated to be US\$ 2,930 (range: US\$30.00-20,320.00). The mean diagnostic costs per sample were estimated to be US\$10.50. Interestingly, 53\% of these costs were for shipping specimens to the rabies diagnostic laboratory and to correspondence of the diagnostic results. Specimens were sent to Maros, Sulawesi because there is no veterinary rabies diagnostic facility on Flores Island.

\subsubsection{Costs of control measures in humans}

The total costs of rabies control measures in humans were estimated to be US\$4.82 million, with the largest portion being the PET costs. The pre-exposure treatment contributed only $3.8 \%$ of the total costs (Table 2.7). These costs were assumed to be constant every year since the number of people at high risk was stable over the years. 


\section{Table 2.7}

Cost of Rabies control measures in humans.

\begin{tabular}{cccccc}
\hline \multirow{2}{*}{ Year } & \multicolumn{2}{c}{ Costs of control measures in humans (x 1000 US\$) } & \multirow{2}{*}{ Total } \\
\cline { 2 - 4 } & $\begin{array}{c}\text { Pre- } \\
\text { exposure* }\end{array}$ & $\begin{array}{c}\text { Wound } \\
\text { cleaning }\end{array}$ & $\begin{array}{c}\text { Post-exposure treatment } \\
\text { immunoglobulin }\end{array}$ & $\begin{array}{c}\text { Human } \\
\text { rabies vaccine }\end{array}$ & \\
\hline 2000 & 15.32 & 1.50 & 3.63 & 370.89 & 391.34 \\
2001 & 15.32 & 0.32 & 0.77 & 78.35 & 94.75 \\
2002 & 15.32 & 0.62 & 1.50 & 153.50 & 170.94 \\
2003 & 15.32 & 0.59 & 1.44 & 147.11 & 164.46 \\
2004 & 15.32 & 0.75 & 1.82 & 185.90 & 203.79 \\
2005 & 15.32 & 1.89 & 4.58 & 467.49 & 489.28 \\
2006 & 15.32 & 1.37 & 3.71 & 379.21 & 399.61 \\
2007 & 15.32 & 2.01 & 5.18 & 529.21 & 551.72 \\
2008 & 15.32 & 2.12 & 5.17 & 527.63 & 550.24 \\
2009 & 15.32 & 2.31 & 5.57 & 569.16 & 592.37 \\
2010 & 15.32 & 3.01 & 6.42 & 655.90 & 680.65 \\
2011 & 15.32 & 2.19 & 4.96 & 506.25 & 528.72 \\
\hline Total & 183.85 & 18.68 & 44.75 & $4,570.60$ & $4,817.89$ \\
\hline
\end{tabular}

* We assumed that the costs of pre-exposure treatment were the same over time.

This assumption is based on the costs of pre-exposure treatment control measure in 2011.

The annual costs of the PET were estimated to be US\$386,170 (range: US\$79,430-665,330), with most of the expenses related with the costs of a series of vaccine injections (99\%). The costs of PET for the first year of the study period were higher than for the next four years, because of a huge outbreak of rabies and a high number of people being bitten by suspected rabid dogs. The outbreak could be attributed to the higher number of roaming dogs. In 2001, the number of dogs decreased as a result of the culling control measure in 2000. The PET costs tended to increase, starting in 2001 (US\$79,430) until 2010 (US\$665,330) (Figure 2.1). The total costs of PET in 2010 were 8.4 times higher than those in 2001.

\subsubsection{Distribution of costs}

Of the total costs of rabies control measures, public costs were higher (US\$6.8 million) than private costs (US\$6.6 million). The majority of public costs $(71 \%)$ were incurred by the Public Health Department, which provided human vaccine and immunoglobulin for free to the local community. In addition, the annual proportion of public costs allocated by the government increased over time, with exception of 2000 (Figure 2.2). This increase reflects the fact that the number of people getting PET increased over the years. When the costs incurred by each stakeholder group during the study period were ranked, the total costs for dog owners was the highest portion, or about $49 \%$ of the total societal costs, followed by costs 
incurred by the Public Health Department (36\%), the Agricultural Department (15\%), and patients (0.2\%) (Figure 2.2).

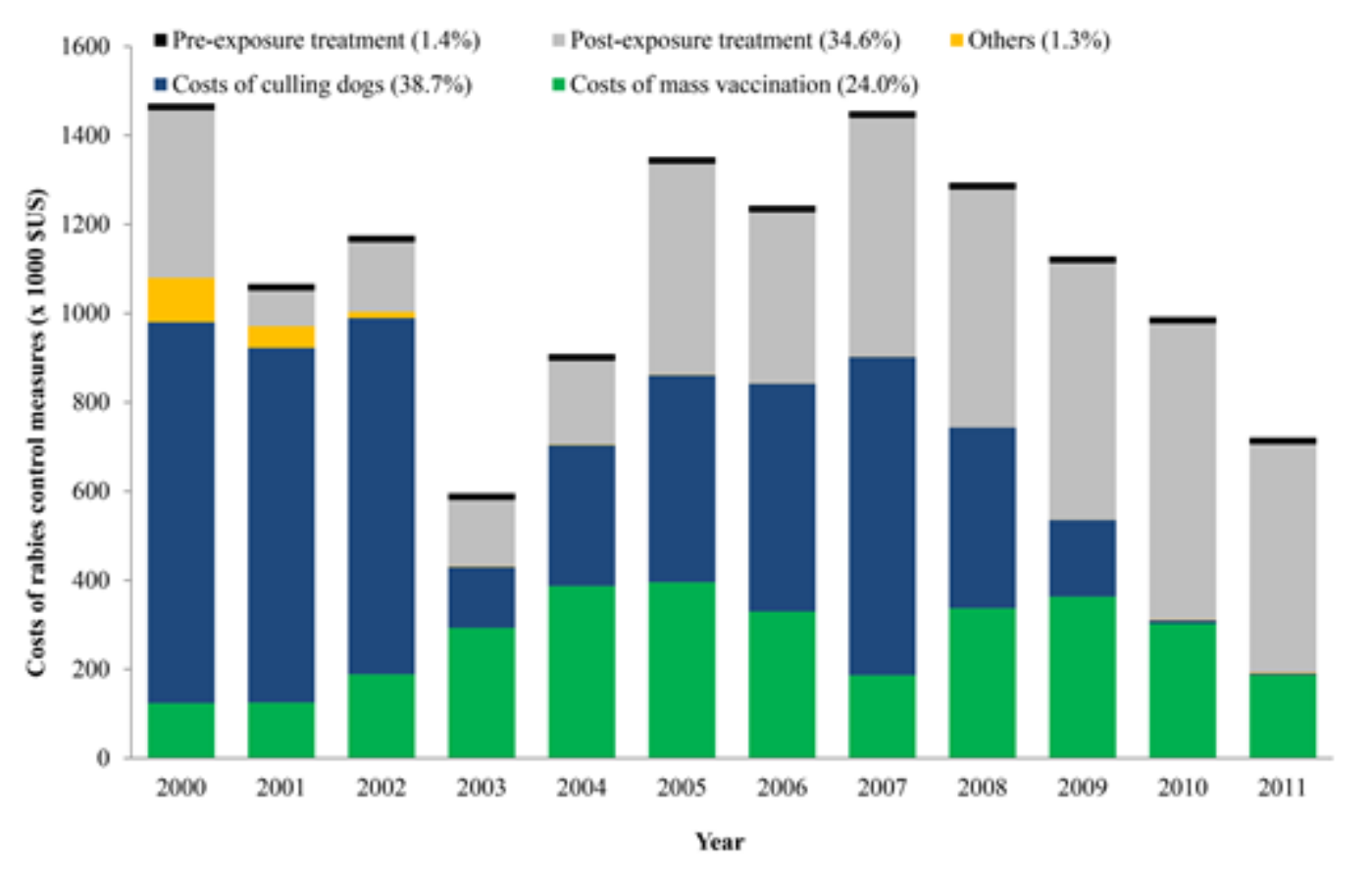

Figure 2.1 Distribution of costs by control measures and year in Flores Island.

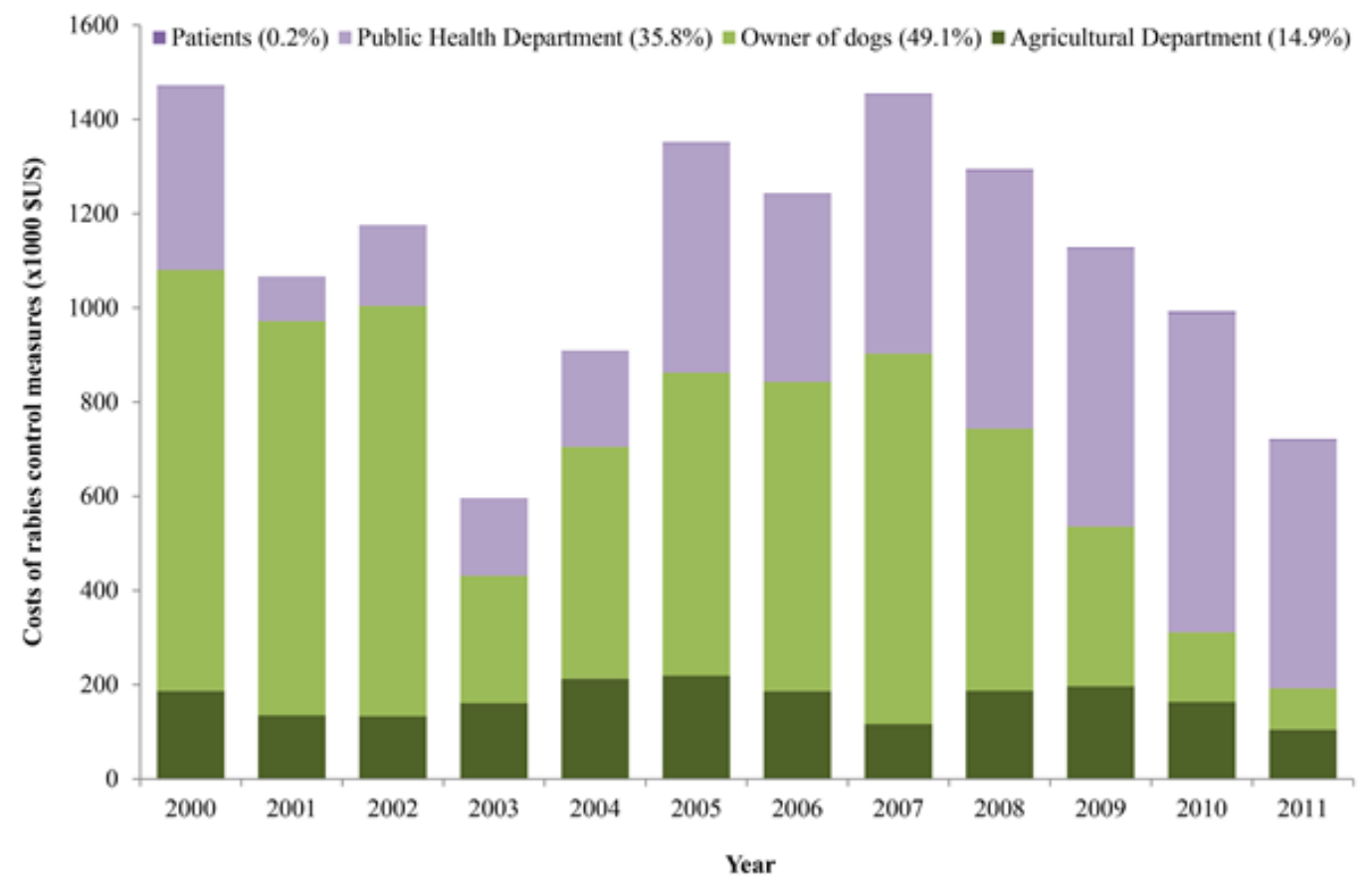

Figure 2.2 Distribution of Rabies control costs over different stakeholders and year in Flores Island. 


\subsubsection{Sensitivity analysis}

The total costs of rabies control measures were most sensitive to the dog value. An increase or decrease of the dog value by $10 \%$ resulted in a $4 \%$ change in total costs. Other input parameters that influenced the total costs in our analysis were the price of human rabies vaccine and the number of vaccine doses in humans; a $10 \%$ increase or decrease in these parameters, resulted in both cases in a $2 \%$ change in total costs. Other inputs contributed to changes in the default total costs of less than $2 \%$.

\subsection{Discussion}

A deterministic economic model was developed to evaluate the costs of rabies control on Flores Island during 2000-2011. With this model, we calculated the total costs of rabies control measures as they were carried out on Flores Island, by integrating available epidemiological and economic data, scientific literature, and information from experts in rabies control measures. The results are an estimation because some inputs (price of vaccine, immunoglobulin) were uncertain in the analysis. The described analysis is an ex-post analysis. However, the developed calculation model is set up in such a way that it can be used to predict the costs of future rabies control programs (ex-ante analysis), not only for Flores Island but also for other regions or countries.

Some limitations of this study may have led to over- or under-estimation of the total costs of control measures. For example, the costs of control measures in humans might have been overestimated because we assumed all people were injected with four doses, despite the fact that the dog-bite patients might receive fewer than four doses in reality. Moreover, the epidemiological surveillance and research costs were not considered in the analysis because of a lack of data. Also, the costs for diseased livestock and human patient cases were not included, which may have led to an under-estimation of the costs of rabies. In none of the regencies in Flores cases of rabies in livestock have been reported, although the Husbandry Department of East Nusa Tenggara province provides the livestock owners a format to report any rabies cases in the livestock. So this omission is, most probably not related with a large under-estimation of the costs of rabies. However, no data were available on the number of patients that were hospitalized due to rabies. Unfortunately, therefore, we were not able to make an estimation of the costs for human patients. Despite these limitations, the estimate made in this study illustrates the economic burden of rabies control measures for all stakeholders on Flores Island, Indonesia as realistic as possible. Our results show that the costs of culling roaming dogs were the highest portion $(39 \%)$ of the total costs, with average costs per dog culled at US\$31.70. This finding contrasts with other studies that found the highest portion of costs were for PET (Knobel et al., 2005; Recuenco et al., 2007; Voelker, 2007; Tenzin et al., 2010). Knobel et al. (2005) studied the economic burden of rabies at the 
regional level in Asia and Africa and found that the highest portion (83\%) of the total control budget was allocated to PET. The World Health Organization, as cited by Voelker (2007), estimated the costs of rabies in Asia to be about US\$560 million every year, with the largest portion spent on PET. The proportion of costs of culling roaming dogs in Asia and Africa was lower than in our findings, with the average cost per dog culled at US\$5 (Knobel et al., 2005). The difference is due to the value of dogs, which their analysis ignored. In our analysis, the largest part of the costs of culling dogs was the value of the dogs. Ignoring the value of dogs would significantly reduce the contribution of the costs of culling dogs to only $1.6 \%$ of the total estimated costs.

The second largest costs for rabies control measures were those of PET, an average of US\$178 per patient. The expensive human rabies vaccine and/or immunoglobulin (Wilde et al., 1999) and the high number of the dog-bite patients receiving PET (Kamoltham et al., 2003) contributed to the high PET costs in this study. Our findings were a little bit higher than those in Thailand (Chulasugandha et al., 2006), but lower than those in the United States (Meltzer and Rupprecht, 1998). In Thailand, the costs of PET were estimated to be US\$135154 per patient (Chulasugandha et al., 2006), while the costs in the United States were estimated to be US\$1,707 per patient (Meltzer and Rupprecht, 1998). This disparity is caused by differences in prices of human vaccine, immunoglobulin, transportation costs, labor costs, scheduled vaccine, and the type of vaccine used. For example, in the United States, human diploid cell vaccine was used with a cost range of US\$80-483 per dose (Kreindel et al., 1998), while purified chick embryo rabies vaccine was used in Thailand, with a cost range of US\$13-14 per dose (Chulasugandha et al., 2006).

This study also found that the annual costs of PET increased in the last seven years of the study period, which reflects the increased number of dog-bite patients who received PET (Figure 2.2) as the vaccine became more widely available. PET for humans is an effective but costly way to prevent clinical problems with rabies but does not provide a permanent solution to rabies in the future. The costs of PET (US\$178 per patient) equals approximately 41 times the daily wage of people in Flores Island. This finding is higher than in Asia (US\$49.41 equivalent to 14 times daily wage) and Africa (US\$39.5721 equivalent to 21 times daily wage) (Knobel et al., 2005).

The current control measures in the dog populations were not successful in reducing the number of human bite cases by suspected rabid dogs and rabies as such is still endemic in Flores Island. Some explanations that may contribute to this situation; (1) there was no islandwide dog vaccination campaign as, for instance, carried out on Bali Island (Putra et al., 2013) due to lack of resources; (2) the locally produced killed rabies vaccine has a relatively low duration of immunity and booster vaccination is recommended at three months, but rarely implemented (Scott-Orr et al., 2009); (3) in addition, the actual number of dogs in Flores 
Island is unknown. The number of dogs in this study is based on the administration record of Animal Husbandry Department East Nusa Tenggara Province. These registered data were submitted annually by eight Regency Husbandry Department in Flores Island. These data underestimate the actual number of dogs present since the data are based on the recording during the vaccination campaign. In case the dog owners and their dogs were not at home at the moment of the vaccination campaign, the dogs were not registered (Dr. Siko, Personal communication). Therefore, the vaccination coverage level of $>70 \%$ during the year 20042006 as indicated by Table 2.1 was overestimated.

Furthermore, of the total dogs registered, the percentage of vaccinated dogs was less than $100 \%$. There are two possible reasons that could explain this situation as described in detail by (Kayali et al., 2003; Kongkaew et al., 2004; Suzuki et al., 2008; Davlin and VonVille, 2012; Putra et al., 2013). The first reason is related to the young age of the dogs at the time of the vaccination campaign. Generally it is recommended by vaccine manufacturers not to vaccinate dogs which are younger than 3 months of age. The proportion of this cohort of young dogs could reach up to $39 \%$ of the total population dogs (Davlin and VonVille, 2012). The second reason is related to the inaccessibility of free roaming dogs as in the case of Bali Island, Indonesia (Putra et al., 2013), which might be due to a lack of willingness by the dog owners to participate in the vaccination program.

The culling program of dogs in infected areas failed to prevent the virus spreading throughout the island since not all local people were willing to participate in culling dogs. Only a few local people (approximately 5-10 people in each village) joined as volunteers in the culling of dog procedure.

The annual total costs of control measures in humans increased over the years, a finding that contrasts with other studies in different countries. In many countries, rabies control measures in dogs have substantially reduced the costs of PET in humans because fewer people seek PET (Glosser et al., 1970; Cleaveland et al., 2003). Glosser et al. (1970) reported that an increased number of vaccinated dogs, combined with culling stray dogs decreased the number of people bitten by a suspected rabid dog, resulting in reduced numbers of people getting vaccine or immunoglobulin anti-rabies by $91 \%$ (from 1,116 in 1966 to 170 in 1968). In addition, Cleaveland et at. (2003) studied a rabies vaccination campaign of dogs in rural Africa and found that vaccination coverage of $60-70 \%$ of the dog population significantly reduced the PET in humans. This would imply that rabies control in the dog population significantly contributes to a reduction of the economic burden caused by expensive PET.

This is the first study to consider the value of culled dogs in rabies control. This factor was included because dogs have an economic value and are culturally very important for the local society (Wera, 2001; Windiyaningsih et al., 2004; Hutabarat et al., 2003). Dog meat is a popular menu item in certain traditional events. Besides being a source of protein, dogs also 
guard property and chase away wild animals (wild pigs, mice, and monkeys) that destroy farmers' crops. As a consequence good guard dogs are highly priced at the traditional markets (Hutabarat et al., 2003).

Therefore, culling as a control measure might be less acceptable for a local community because of ethical, social, and economic reasons. In this context, the World Organization for Animal Health (Vallat, 2011) does not recommend culling dogs as priority in control and eradication of rabies. There is no evidence that culling dogs alone significantly contributes to a reduction of the spread of rabies (WHO, 2005). Therefore, the local government of Flores Island reduced the culling of dogs over the years, which lowered the annual costs of that control measure.

Our results demonstrate that the rabies control measures were costly to society. Optimization of the current control measures could reduce the economic burden of rabies in the future. An economic study that weighed the trade-off between controlling rabies in dogs and PET in humans is needed to determine if more control among dogs would be cost beneficial. This study's results could provide baseline data for additional effectiveness studies.

\subsection{Conclusion}

This study shows a generic and transparent way to calculate the societal costs of rabies in a certain region. Rabies has a large economic impact on government and the dog owners of Flores Island. Control of rabies by culling dogs is relatively costly for the dog owners in comparison with other control measures. Providing PET is an effective way to prevent rabies casualties in humans, but is costly for the government, without providing a permanent solution for rabies control in the future. The developed model can be used for future economic ex-ante and ex-post analyses on rabies control.

\section{Acknowledgements}

The authors would like to acknowledge Maria Margaretha Siko, DVM, MSc, Simon Nany, DVM, MSc, Herlina Modesta, DVM, Paulus Jadu, DVM, Kristo Hemo, DVM, Severinus Jani Hadir, SST, Tati Gantir, Spt, Dr. Asep Purnama, Spd, Christina Br Tarigan, SKM and Yosef Kupertino, S.Si for providing the model inputs in this paper. 


\section{References}

Belotto, A., Leanes, L.F., Schneider, M.C., Tamayo, H., Correa, E., 2005. Overview of rabies in the Americas. Virus Research 111, 5-12.

Bingham, J., 2001. Rabies on Flores Island, Indonesia: is eradication possible in the near future? In: Doddet, B., Meslin, F.X. (Eds), 2001. Rabies Control in Asia. John Libbey Eurotext, Paris, pp. 148-155.

BPS, 2013. Population of Indonesia by village. Available at: http://bps.go.id/eng/download_file/Population_of_Indonesia_by_Village_2010.pdf (accessed on 20.06.13.).

BPS, 2012. The growth of farmer terms of trade, producer prices of unhusked rice and labour wage. Press release No. 18/03/Th.XV, March 1st, 2012; http://dds.bps.go.id/eng/brs_file/eng-ntp02mar12.pdf (accessed on 2.08.12.).

Briggs, D.J., 2007. Human Rabies Vaccine In. Elsevier/Academic Rabies. 2nd ed. Amsterdam. The Netherlands.

Briggs, D.J., 2010. Reducing the global burden of rabies. Int. Health 2, 161-162.

Carter, H.E., 1997. Britain Should Immediately Alter its Quarantine Rules for the Control of Rabies. Rev. Med. Virol. 7, 13-15.

Childs, J.E., Krebs, J.W., Real, L.A., Gordon, E.R., 2007. Animal-based national surveillance for zoonotic disease: Quality, limitations, and implications of a model system for monitoring rabies. Prev. Vet. Med. 78, 246-261.

Chulasugandha, P., Khawplod, P., Havanond, P., Wilde, H., 2006. Cost comparison of rabies preexposure vaccination with post-exposure treatment in Thai children. Vaccine 24, 1478-1482.

Cleaveland, S., Kaare, M., Tiringa, P., Mlengeya, T., Barrat, J., 2003. A dog rabies vaccination campaign in rural Africa: impact on the incidence of dog rabies and human dog-bite injuries. Vaccine 21, 1965-1973.

Davlin, S.L., VonVille, H.M., 2012. Canine rabies vaccination and domestic dog population characteristics in the developing world: A systematic review. Vaccine 30, 3492-3502.

Fishbein, D.B., Miranda, N.J., Merrill, P., Camba, R.A., Meltzer, M., Carlos, E.T., Bautista, C.F., Sopungco, P.V., Mangahas, L.C., Hernandez, L.M., Leoncio, M.M., Mercado, D., Gregorio, S., Salva, E., Dobbins, J.G., Winkler, W.G., 1991. Rabies control in the Republic of the Philippines: benefits and costs of elimination. Vaccine 9, 581-587.

Glosser, J.W., Hutchins.Lr, Rich, A.B., Huffaker, R.H., Parker, R.L., 1970. Rabies in El-Paso, Texas, before and after Institution of a new rabies control program. Journal of the American Veterinary Medical Association 157, 820-\&.

Gongal, G., Wright, A.E., 2011. Human Rabies in the WHO Southeast Asia Region: Forward Steps for Elimination. Advances in Preventive Medicine.

Goswami, A., Plun-Favreau, J., Nicoloyannis, N., Sampath, G., Siddiqui, M.N., Zinsou, J.-A., 2005. The real cost of rabies post-exposure treatments. Vaccine 23, 2970-2976.

Green, A.L., Carpenter, L.R., Dunn, J.R., 2011. Rabies Epidemiology, Risk Assessment, and Pre- and Post-Exposure Vaccination. Veterinary Clinics of North America - Exotic Animal Practice 14, 507-518. 
Hutabarat, T., Geong, M., Newsome, A., Ruben, A., Cutter, S., 2003. Rabies and dog ecology in Flores. Urban Animal Management Conference Proceedings. ACIAR. Australia.

IAM, 2004. Peraturan Pemerintah Republik Indonesia Nomor 7 tahun 2004 Tentang Perubahan atas Peraturan Pemerintah Nomor 49 Tahun 2002 Tentang Tarif atas jenis penerimaan negara bukan pajak yang berlaku pada departemen pertanian.

IHM, 2000. Petunjuk perencanaan dan penatalaksanaan kasus gigitan hewan tersangka/rabies di Indonesia. Jakarta. Cetakan VI.

IQ, 2008. Petunjuk teknis persyaratan dan tindakan karantina terhadap lalu lintas pemasukan hewan penular rabies (anjing, kucing, kera, dan sebangsanya): Lampiran keputusan kepala badan karantina pertanian no. 344.b/kpts/PD.670.370/L/12/06, tanggal 13 desember 2008.

Jackson, A.C., 2007. Rabies in Human In. Elsevier/Academic Rabies. 2nd ed. Amsterdam. The Netherlands.

Jackson, A.C., Warrell, M.J., Rupprecht, C.E., Ertl, H.C.J., Dietzschold, B., O'Reilly, M., Leach, R.P., Fu, Z.F., Wunner, W.H., Bleck, T.P., Wilde, H., 2003. Management of rabies in humans. Clin. Infect. Dis. 36, 60-63.

Kaare, M., Lembo, T., Hampson, K., Ernest, E., Estes, A., Mentzel, C., Cleaveland, S., 2009. Rabies control in rural Africa: Evaluating strategies for effective domestic dog vaccination. Vaccine $27,152-160$.

Kamoltham, T., Singhsa, J., Promsaranee, U., Sonthon, P., Mathean, P., Thinyounyong, W., 2003. Elimination of human rabies in a canine endemic province in Thailand: five-year programme. Bull. World Health Organ. 81, 375-381.

Kaplan, M.M., Cohen, D., Koprowski, H., Dean, D., Ferrigan, L., 1962. Studies on the Local Treatment of Wounds for the Prevention of Rabies. Bull. World Health Organ. 26, 765-775.

Kayali, U., Mindekem, R., Hutton, G., Ndoutamia, A.G., Zinsstag, J., 2006. Cost-description of a pilot parenteral vaccination campaign against rabies in dogs in N'Djamena, Chad (vol 11, pg 1058, 2006). Trop. Med. Int. Health 11, 1482-1482.

Kayali, U., Mindekem, R., Yemadji, N., Vounatsou, P., Kaninga, Y., Ndoutamia, A.G., Zinsstag, J., 2003. Coverage of pilot parenteral vaccination campaign against canine rabies in N'Djamena, Chad. Bull. World Health Organ. 81, 739-744.

King, A.A., Turner, G.S., 1993. RABIES - A REVIEW. J. Comp. Pathol. 108, 1-39.

Knobel, D.L., Cleaveland, S., Coleman, P.G., Fevre, E.M., Meltzer, M.I., Miranda, M.E.G., Shaw, A., Zinsstag, J., Meslin, F.X., 2005. Re-evaluating the burden of rabies in Africa and Asia. Bull. World Health Organ. 83, 360-368.

Knobel, D.L., Hiby, E., 2009. Bali rabies control report and recommendations. WSPA, UK.

Kongkaew, W., Coleman, P., Pfeiffer, D.U., Antarasena, C., Thiptara, A., 2004. Vaccination coverage and epidemiological parameters of the owned-dog population in Thungsong District, Thailand. Prev. Vet. Med. 65, 105-115.

Kreindel, S.M., McGuill, M., Meltzer, M., Rupprecht, C., DeMaria, A., 1998. The cost of rabies postexposure prophylaxis: One state's experience. Public Health Reports 113, 247-251.

Linscott, A.J., 2012. Rabies. Clin. Microbiol. Newsl. 34, 177-180.

Manning, S.E., Charles E. Rupprecht, C.E., Fishbein, D., Hanlon, C.A., Lumlertdacha, M., Guerra, M., Meltzer, M.I, Dhankhar, P., Vaidya, S.A., Jenkins,S.R., Sun, B., Hull, H.F., 2008. Human 
rabies prevention-United states, 2008. Available at: https://www.cdc.gov/MMWr/preview/mmwrhtml/rr5703a1.htm (accessed on 2.08.12.).

Meltzer, M.I., Rupprecht, C.E., 1998. A Review of the Economics of the Prevention and Control of Rabies: Part 1: Global Impact and Rabies in Humans. PharmacoEconomics 14, 365-383.

Mitchell, J., Kanowski, A., 2003. Best practice wild pig management in the Burdekin River catchment. Bureau of Rural Sciences, Australian Government, Publishing Service, Canberra, Australia.

Muir, P., Roome, A., 2005. Indigenous rabies in the UK. The Lancet 365, 2175.

Putra, A.A.G., Hampson, K., Girardi, J., Hiby, E., Knobel, D., Wayan Mardiana, I., Townsend, S., Scott-Orr, H., 2013. Response to a rabies epidemic, Bali, Indonesia, 2008-2011. Emerg. Infect. Dis. 19, 648-651.

Recuenco, S., Cherry, B., Eidson, M., 2007. Potential cost savings with terrestrial rabies control. BMC Public Health 7, 47.

Scott-Orr, H., Bingham, J., Saunders, G., Dibia, I.N., Putra, A.A.G., Geong, M., 2009. Potential Eradication of Rabies from Flores in Indonesia. Proceedings of the 12th Symposium of the International Society for Veterinary Epidemiology and Economics, Durban, South Africa.

Shwiff, S.A., Nunan, C.P., Kirkpatrick, K.N., Shwiff, S.S., 2011. A Retrospective Economic Analysis of the Ontario Red Fox Oral Rabies Vaccination Programme. Zoonoses Public Health 58, 169177.

Si, H., Guo, Z.M., Hao, Y.T., Liu, Y.G., Zhang, D.M., Rao, S.Q., Lu, J.H., 2008. Rabies trend in China (1990-2007) and post-exposure prophylaxis in the Guangdong province. BMC Infect. Dis. 8.

Suzuki, K., Pereira, J.A.C., Frías, L.A., López, R., Mutinelli, L.E., Pons, E.R., 2008. Rabiesvaccination Coverage and Profiles of the Owned-dog Population in Santa Cruz de la Sierra, Bolivia. Zoonoses Public Health 55, 177-183.

Tenzin, Sharma, B., Dhand, N.K., Timsina, N., Ward, M.P., 2010. Re-emergence of rabies in Chhukha district, Bhutan, 2008. Emerg. Infect. Dis. 16, 1925-1930.

Tenzin, Wangdi, K., Ward, M.P., 2012. Human and animal rabies prevention and control cost in Bhutan, 2001-2008: The cost-benefit of dog rabies elimination. Vaccine 31, 260-271.

Tierkel, E.S., Graves, L.M., Tuggle, H.G., Wadley, S.L., 1950. Effective Control of an Outbreak of Rabies in Memphis and Shelby County, Tennessee. American Journal of Public Health and the Nations Health 40, 1084-1088.

Voelker, R., 2007. Global effort takes aim at rabies. J. Am. Med. Assoc. 298, 1749-1750.

Wera, E., 2001. Epidemiologi dan usaha pemberantasan penyakit Rabies di Kabupaten Flores Timur, Provinsi Nusa Tenggara Timur periode November 1997- April 2000. Skripsi. Fakultas Kedokteran Hewan, Institut Pertanian Bogor.

Whitfield, S.G., Fekadu, M., Shaddock, J.H., Niezgoda, M., Warner, C.K., Messenger, S.L., 2001. A comparative study of the fluorescent antibody test for rabies diagnosis in fresh and formalinfixed brain tissue specimens. J. Virol. Methods 95, 145-151.

WHO, 2005. WHO expert Consultation on Rabies, first report. In: WHO Technical Report Series 931. World Health Organisation, Geneva, Switzerland.

Wilde, H., Tipkong, P., Khawplod, P., 1999. Economic Issues in Post-exposure Rabies Treatment. J. Travel Med. 6, 238-242. 
Windiyaningsih, C., Wilde, H., Meslin, F.X., Suroso, T., Widarso, H.S., 2004. The rabies epidemic on Flores Island, Indonesia (1998-2003). J. Med. Assoc. Thai. 87, 1389-1393.

Woodruff, B.A., Jones, J.L., Eng, T.R., 1991. Human exposure to rabies from pet wild raccoons in South-Carolina and West-Virginia, 1987 through 1988. Am. J. Public Health 81, 1328-1330.

Wunner, W.H., 2005. Rabies in the Americas. Virus Research 111, 1-4. 
Chapter 3

\section{Uptake of rabies control measures by dog owners in Flores Island, Indonesia}

Ewaldus Wera, Monique C. M. Mourits, Henk Hogeveen

Published in PLoS Neglected Diseases 9: e0003589

doi:10.1371/journal.pntd.0003589 


\begin{abstract}
Rabies has been a serious public health threat in Flores Island, Indonesia since it was introduced in 1997. To control the disease, annual dog vaccination campaigns have been implemented to vaccinate all dogs free of charge. Nevertheless, the uptake rate of the vaccination campaigns has been low. The objective of this paper is to identify risk factors associated with the uptake of rabies control measures by individual dog owners in Flores Island. A total of $450 \mathrm{dog}$ owners from 44 randomly selected villages in the Sikka and Manggarai regencies were interviewed regarding their socio-demographic factors, knowledge of rabies, and their uptake of rabies control measures. The majority of dog owners surveyed (>90\%) knew that rabies is a fatal disease and that it can be prevented. Moreover, $68 \%$ of the dog owners had a high level of knowledge about available rabies control measures. Fifty-two percent of the dog owners had had at least one of their dogs vaccinated during the 2012 vaccination campaign. Vaccination uptake was significantly higher for dog owners who resided in Sikka, kept female dogs for breeding, had an income of more than one million Rupiah, and had easy access to their village. The most important reasons not to join the vaccination campaign were lack of information about the vaccination campaign schedule (40\%) and difficulty to catch the dog during the vaccination campaign (37\%). Dog owners in Flores Island had a high level of knowledge of rabies and its control, but this was not associated with uptake of the 2012 vaccination campaign. Geographical accessibility was one of the important factors influencing the vaccination uptake among dog owners. Targeted distribution of information on vaccination schedules and methods to catch and restrain dogs in those villages with poor accessibility may increase vaccination uptake in the future.
\end{abstract}




\subsection{Introduction}

Rabies still poses a significant health problem in many countries of the world, despite it being a vaccine-preventable disease in dogs and humans (WHO, 2005). Approximately 55,000 people around the world die each year due to rabies, with $45 \%$ of these cases occurring in the South East Asian region (WHO, 2012). Within this region, Indonesia has the fourth largest number of human rabies cases after India, Bangladesh and Myanmar, with 150-300 cases reported per year (WHO, 2012).

The first occurrence of rabies in Indonesia was reported in 1889 (Ward, 2014). Since its introduction, rabies has posed a serious public health threat with significant economic consequences to society (Wera et al., 2013). The national strategic plan of Indonesia emphasizes the control of rabies as a policy priority, aiming for eradication by the year 2020 .

Flores Island is located in the eastern part of Indonesia and covers an area of $15,624 \mathrm{~km}^{2}$. The island is divided into eight regencies, with a human population of more than 1.8 million (BPS, 2013) and a dog population greater than 0.2 million (Wera et al., 2013). Many of the rural areas on the island are only accessible by foot or with high-clearance vehicles, motor bikes, or horses (Bingham, 2001). The main socio-economic activity on the island is agriculture (production of coconut, corn, groundnut, cocoa, coffee, potato, and paddy), in which dogs are used to guard the crops (Hutabarat et al., 2003). Most dogs are owned and roam freely day and night. Although Indonesia is predominantly Muslim (practicing the Islamic principles in which it is prohibited to eat dog meat or to keep dogs inside the house), the majority of people in Flores are Catholic. Dogs have a high cultural and economic value in Flores Island, as they provide a source of animal protein in addition to their guarding capacities. Dog meat is a popular menu item in certain traditional ceremonies of the island (Hutabarat et al., 2003).

On Flores Island, the first cases of dog rabies were officially confirmed in April 1998 in the regency of East Flores (Wera, 2001). The introduction of the disease was traced back to three suspected rabid dogs that were brought from Buton Island by a fisherman in September 1997 (Wera, 2001). Despite the initial control measures applied, which entailed the culling of the entire dog population in and around the affected villages (1998-1999), rabies spread to other regencies of the island (Windiyaningsih et al., 2004). In response, the Flores Island government have implemented a comprehensive control campaign since 2000. This control campaign is based on a combination of control measures, including mass vaccination of dogs, culling of roaming dogs, placing imported dogs in quarantine, and giving pre- and postexposure treatment to humans. Complementary control measures include investigation of dog bites, diagnostic testing of suspected rabid dogs, and tracing of human contacts with rabid dogs. However, this campaign has not yet been successful in eliminating rabies from Flores Island. 
Thousands of people bitten by dogs are looking for post-exposure treatment each year, resulting in a large economic cost for both government and local communities. The annual cost of rabies control efforts in Flores Island has been estimated to exceed US\$ 1.0 million (Wera et al., 2013). The impact on public health is difficult to measure. Until 2012, 96 human cases of rabies were officially registered by the Public Health Department, with the highest number of cases in Manggarai regency (27 cases), followed by Sikka (22 cases), Ngada (16 cases), West Manggarai (11 cases), East Manggarai (8 cases), East Flores (6 cases), Nagakeo (4 cases), and Ende ( 2 cases) . However, these numbers do not reflect the real human rabies burden in Flores, as the data only capture the number of rabies patients who visited hospitals or public health centers during the period that rabies was clinically manifest. The number of human cases reported by the Husbandry Department of East Nusa Tenggara Province was more than two times higher (228 cases) (HDENT, 2012) than the 96 cases officially recorded by the Public Health Department .

During the last thirteen years, the regencies on Flores Island have implemented annual dog vaccination campaigns using Rabivet Supra 92 (Wera et al., 2013). Although vaccination is compulsory for all dogs (Manggarai Regency Law, number 6, year 2003), it is difficult to enforce due to the absence of a proper registration system and the lack of resources to catch and restrain dogs. Vaccination is therefore only feasible with the support of the dog owner, who presents and restrains the dogs for vaccination. To increase vaccination coverage, regencies have offered dog owners the vaccination of their dogs for free. Moreover, the vaccine has been delivered using a 'house-to-house' approach, undertaken by the local authority (Wera et al., 2013) to directly persuade dog owners to vaccinate their dogs. The 'house to house' vaccination approach is a method in which the vaccination teams visit the dog owners at their own homes. As the vaccination team are not equipped to handle roaming dogs, dog owners need to catch and restrain their dogs themselves. Because the dogs in Flores Island are not used to being restrained, it is expected that 'house-to-house' vaccination campaigns result in a higher vaccination coverage than central point vaccination campaigns (Kaare et al., 2009). Moreover, 'house-to-house' campaigns put more social pressure on dog owners to vaccinate than central point campaigns. Nevertheless, the uptake rate of the dog vaccination measure has been low, with an average vaccination coverage of around $53 \%$ of the registered dogs during the 2000-2011 vaccination campaigns (Wera et al., 2013). This value is lower than the $70 \%$ coverage of the complete dog population, which is recommended to maintain the control of rabies between annual vaccination campaigns (WHO, 2005).

Although there are publications describing the uptake of dog vaccination campaigns in developing countries (Robinson et al., 1996; Matter et al., 2000; Kayali et al., 2003; Kongkaew et al., 2004; Suzuki et al., 2008; Durr et al., 2009; Kaare et al., 2009), none of these studies have focused on the situation of rabies in Flores Island, nor evaluated the impact on the uptake of vaccination of the socio-demographic characteristics of dog owners and their 
knowledge of rabies. An understanding of this impact is essential to support policy decisions about rabies control in the future. The objective of this paper is to identify risk factors associated with the uptake of rabies control measures by dog owners in Flores Island, Indonesia. This is achieved by undertaking an extensive survey among dog owners in the regencies of Sikka and Manggarai. Risk factors concern socio-demographic factors and the level of rabies knowledge of dog owners. Special emphasis is given to risk factors associated with the uptake of the vaccination campaign in 2012.

\subsection{Materials and methods}

\subsubsection{Study area}

An extensive survey was conducted among dog owners in the regencies of Sikka and Manggarai during January and February 2013. The regencies were selected because of the high prevalence of human rabies and the control legislation in place. Sikka relies on the national rabies control campaign, whereas Manggarai has a local control legislation in place (Wera et al., 2013). Based on this local legislation, Manggarai has been applying additional control measures (such as culling) alongside the nationally recommended vaccination control campaign. The regencies have similar sized populations, 300,301 inhabitants in Sikka and 292,037 inhabitants in Manggarai (census data of 2010) (BPS, 2013). There are no officially registered data available on the number of villages and the number of households owning dogs, nor on the size of the dog population. During the 'house-to-house' rabies vaccination campaign in 2012, 351 villages in Sikka and 162 villages in Manggarai were involved. All households in these villages were visited by the local authorities to vaccinate the dogs for free. Given the number of dogs registered during this vaccination campaign, the number of dogs is estimated at 37,000 in Sikka and 6,675 in Manggarai. The difference in the number of dogs per regency is a result of the culling measures that were implemented in Manggarai.

\subsubsection{Sample size and design}

The minimum sample size required to estimate the proportion of dog owners vaccinating their dogs was based on the conservative assumption that $50 \%$ of dog owners vaccinated at least one of their $\operatorname{dogs}\left(p_{\exp }\right)$, with a $5 \%$ error in estimate $(d)$ and a $95 \%$ confidence interval. Given the standard power calculation:

$n=\frac{1.96^{2} \times p_{\exp } \times\left(1-p_{\exp }\right)}{d^{2}}$

the required sample was a minimum of 385 dog owners. The sample size was increased to 450 dog owners to account for incomplete interviews, with 300 dog owners sampled in Sikka and 150 in Manggarai. The relative size of the samples in Sikka and Manggarai reflected the difference in the number of villages involved in the 2012 vaccination campaign, which was 351 villages in Sikka and 162 villages in Manggarai. 
Dog owners were selected from the villages included in the 2012 vaccination campaign. A random order of villages for the survey was obtained for each regency by randomly ranking the villages involved in the 2012 vaccination campaign. Subsequently, villages were visited in the order of this ranking until the predefined sample sizes (300 dog owners in Sikka and 150 dog owners in Manggarai) were reached. A total of 44 villages were visited, with 27 villages in Sikka and 17 villages in Manggarai. The following process was carried out in each of the 44 villages in the survey. Firstly, the village leader was approached to inform him about the study and to seek permission to carry out the study in his village. Subsequently, 7 to $15 \mathrm{dog}$ owners (respondents) aged 18 years or older were selected per village. The number of dog owners to be interviewed was predefined for each village and proportional to the number of dog owners involved in the rabies vaccination campaign of 2012. Due to the lack of registration data on households, the first respondent in each village was chosen by chance by spinning a pen at the center of the village (Kongkaew et al., 2004). The direction of the pen tip determined the first household/respondent to be interviewed. In case there were no dogs or adult persons present in the house, the next household was selected (Thomas et al., 2013). Subsequent respondents were selected from the closest neighboring households that owned dogs.

The questionnaire interviews were conducted by two survey teams (one team per regency) assisted by local people with knowledge of the local languages (Sikka, Lio, and Manggarai) as well as Bahasa Indonesia. Prior to each individual interview, the purpose of the survey was explained to the respondents. A verbal informed consent (permission to carry out the interview) was obtained from the dog owners before the interview was conducted. The interviews generally took place between 8 a.m. and 6 p.m., from Mondays to Saturdays. When there were not enough participants available in a village due to the absence of dog owners, the interviews were subsequently administrated in the early morning or evening of the next day. Daily evening briefings among the survey team members ensured interview consistency. Obtained data were entered in Data Editor of SPSS software version 19.

\subsubsection{Questionnaire design}

The questionnaire was designed after an extensive literature review of previous survey studies, which focused on either the level of rabies knowledge or the uptake of rabies control measures in dogs and humans (Kongkaew et al., 2004; Suzuki et al., 2008; Lunney et al., 2012; Tenzin et al., 2012).

The questionaire contained open and closed questions, which were divided into four sections: (1) socio-demographics of dog owners, (2) knowledge of rabies and its control measures (3) uptake of rabies control measures, and (4) reasons for joining or not joining the rabies vaccination campaign of 2012. 
1) Socio-demographics: Questions on the socio-demographics of dog owners covered personal characteristics, characteristics of the household, characteristics of the dogs and reasons for keeping them, and one characteristic of the village. Personal characteristics included gender, age, education level, occupation, income, and religion. Characteristics of the household included the size of the household and presence of children in the household. Characteristics of the dogs included whether female for breeding or male dogs were kept, reasons for keeping dogs, and the economic value of dogs. The characteristic of the village concerned the accessibility of the village. This was assessed for each village according to the type of road infrastructure between the village and the main road. Three categories were used to stratify accessibility. Villages located along the provincial road connecting West to East Flores Island were categorized as villages with 'good accessibility', as these villages have easy access to frequent public transportation. Villages located more than $3 \mathrm{~km}$ from the main road, which have less frequent access to public transportation, were categorized as villages with 'average accessibility'. Villages that can only be reached by foot or motorcycle, which have no public transportation facility, were categorized as villages with 'poor accessibility'.

2) Knowledge of the risk, prevention in humans, and control of rabies: The knowledge of the dog owners about the risk of rabies to humans was assessed using the following two 'yes' or 'no' questions, as modified from Tenzin et al. (2012): (1) “do you know that rabies is a fatal disease in humans?" and (2) "do you know that rabies in humans can be prevented?". To assess the level of knowledge of rabies control measures, a subsequent question was posed to those dog owners who responded positively to the second question: "which measures are known to you in order to prevent rabies in humans?". The intention of this question was to evaluate the level of knowledge about the range of control measures that could prevent rabies in humans. This knowledge does not necessarily reflect an understanding of the efficacy of the control measures. The respondents' answers to the question were classified as either correct or incorrect based on scientific evidence (Kunda John et al., 2008; Zingg and Siegrist, 2012). Answers were considered scientifically correct if the control measures mentioned by the respondents were in line with those recommended by the WHO (WHO, 2002, 2005) and OIE (Vallat, 2011). These recommendations consist of: (1) vaccination injections before exposure (pre-exposure treatment), (2) cleaning wound after being bitten, (3) injection of human rabies vaccines and/or immunoglobulin after exposure (post-exposure treatment), (4) vaccination of dogs, (5) dog movement restrictions, and (6) leashing of dogs. Each corresponding answer was given a score of 1 . Answers that were not based on scientific evidence (e.g., prayer and traditional medicine) were given a score of 0 . In addition, as culling of dogs is a control measure within Manggarai regency law (number 6, year 2003), an additional score of 1 was given to those respondents who reported culling as a control measure. Within Mangarai regency law, this culling refers to the culling of dogs that are aggressive and tend to bite and culling of roaming dogs in newly infected villages and public 
areas regardless of their health status. The total score per respondent (range of 0-7) was subsequently categorized into a binary variable, by defining one category to indicate total scores lower than the median score of all answers and another category to indicate total scores equal to or higher than the overall median score (Tenzin et al., 2012).

3) Uptake of rabies control measures: To obtain information about the uptake of rabies control measures, dog owners were asked about the measures they had adopted during the period 1999-2012. With respect to the control measures in dogs, dog owners were specifically questioned about the uptake of vaccination and culling. In addition, the uptake of a complementary rabies control measure was also specified, namely castration of male dogs as part of dog-population management. We did not consider the option to sterilize female dogs, assuming that very few female dogs will be sterilized due to the lack of animal health facilities and the costs involved.

Concerning the control measures in humans, dog owners who indicated that they had experienced a bite incident in their family were asked about their uptake of post-exposure treatments (wound cleaning, rabies immunoglobulin injection, and series of rabies vaccine injections). The uptake items were recorded into dichotomous variables for subsequent data analysis $(1=$ 'Uptake' and $0=$ 'No uptake').

4) Reasons for (not) joining the rabies vaccination campaign of 2012: In the final item, motives for joining or not joining the 2012 dog vaccination campaign were explored with open questions. The question about the motives for joining was posed to the dog owners who had vaccinated their dogs, allowing them to mention multiple reasons. The question about motives for not joining was posed to those who had not vaccinated their dogs and allowed them to indicate only the main reason.

The questionnaire was developed in English and translated to Bahasa Indonesia. It was pretested by a focus group, consisting of 4 veterinarians, 4 veterinarian assistants/vaccinators, a husbandry officer of the Animal Health and Husbandry Department of Sikka, and by five pilot interviews (Tenzin et al., 2012) with dog owners from a village in Sikka. The final questionnaire was revised based on the pre-test and pilot interviews to improve clarity and interpretation (Tenzin et al., 2012). An interview took approximately 45 minutes to complete the questionnaire.

\subsubsection{Statistical analysis}

Descriptive statistics were used to summarize the dog owners' responses for each of the four survey items. Differences in the proportions of dog owners with knowledge of rabies (yes/no), knowledge of control measures (high/low), and uptake of the 2012 vaccination campaign (yes/no) were tested using the Chi-square test. The associations of the socio-demographic factors with the levels of knowledge (i.e. about the risk of the disease, prevention in humans, 
and control measures) and the uptake of the 2012 vaccination campaign were assessed using univariable logistic regression analyses. The effect of the knowledge level of dog owners on the uptake of the 2012 dog vaccination campaign was also explored using an univariable logistic regression analysis. Four multivariable logistic regression analyses were conducted to determine the independent contribution of each of these variables to the outcome (e.g. uptake of the 2012 dog vaccination campaign) after adjusting for other variables (Katz, 2003; Wakkee et al., 2014). All independent variables, which had p-values of less than 0.25 in the univariable analyses were subsequently included in the initial models for the multivariable analyses (Noordhuizen et al., 2001). Prior to the multivariable analyses, Spearman's rank correlation coefficient $(\rho)$ was calculated to check for multicollinearity between the independent variables selected from the univariable analyses. Multicollinearity was considered to be present at $\rho>0.7$. The final multivariable logistic models were derived by backward stepwise elimination of variables with a p-value greater than 0.05 . The HosmerLemeshow goodness-of-fit test was performed to determine the fit of the final models with the data (Noordhuizen et al., 2001).

The multivariable models are represented by the logit formula:

$\ln \left(\frac{v}{1-v}\right)=\beta_{0}+\beta_{1} x_{1}+\beta_{2} x_{2}+\ldots . .+\beta_{p} x_{p}$,

where $\ln \left(\frac{v}{1-v}\right)$ is the $\log$ of the odds of the outcomes (i.e., having knowledge about rabies and the risk it poses for humans or not, having a high or low level of knowledge about rabies control measures, and having participated in the 2012 vaccination campaign or not, represented by $(v)$ and $(1-v)$, respectively), $\beta_{0}$ is the estimated intercept, and $\beta_{(1)}, \ldots, \beta_{(p)}$ represent the regression coefficients of each independent variable included in the model. Exponentiation of these regression coefficients $\left(e^{\beta_{(1) \ldots} \beta_{(p)}}\right)$ gives the odds ratios (OR) for each independent variable. SPSS version 19 was used for the analysis of all the data.

\subsection{Results}

\subsubsection{Socio-demographic characteristics of the dog owners}

A total of 463 households were visited. Of these households, 5 dog owners (in Sikka) refused to be interviewed and 8 dog owners ( 3 in Sikka and 5 in Manggarai) were not at home during the time of the interviews. The socio-demographic characteristics of the 450 respondents are shown in Table 3.1. The majority of the respondents was male (67\%), aged between 18-45 years $(56 \%)$, and had children in the household (84\%). Most respondents were farmers $(79 \%)$ and of catholic religion (99\%). Of the 450 respondents, almost $50 \%$ had attended or graduated 
from elementary school. The median numbers of humans and dogs per household were 5.0 humans (mean 5.3; range: 1-11) and $2.0 \mathrm{dogs}$ (mean 2.2; range: 1-12). The majority of dog owners $(68 \%)$ indicated that they kept dogs to guard their house and property, and to chase away wild animals that destroy their crops.

\subsubsection{Knowledge of the risk, prevention in humans, and control of rabies}

The majority of the dog owners surveyed in Sikka and Manggarai regencies agreed with the statement that "rabies is a fatal disease in humans" (92\%). Agreement with this statement was significantly different $(\mathrm{p}<0.05)$ for regency, income, presence of children in the household, primary function of dogs, and economic value of dogs (Table 3.1).

Four hundred and three dog owners (90\%) agreed with the statement "rabies in humans can be prevented". Agreement was significantly different $(\mathrm{p}<0.05)$ for regency, education level of dog owners, having a family member previously bitten by dogs, having female dogs for breeding, primary function of dogs, and economic value of dogs (Table 3.1). The preventive measures that were most frequently known by the dog owners, who agreed with the statement that rabies in humans can be prevented $(n=403)$, were vaccination and/or immunoglobulin injection (81\%) and wound cleaning (79\%) (Figure 3.1). Other indicated control measures included dog vaccination (77\%), leashing of dogs (36\%), traditional treatment $(31 \%)$, and prayer $(15 \%)$. The total number of scientifically correct measures indicated per dog owner varied between 0 and 6 , with a median of 3 . The majority of the dog owners (68\%) mentioned 3 or more measures, indicating a relatively high level of knowledge about rabies control measures (Table 3.1). Only four respondents (1\%) indicated traditional treatment and prayer as the only means to prevent rabies in humans. The level of knowledge of control measures differed significantly $(\mathrm{p}<0.05)$ by income, religion, number of people per household, and primary function of dogs. The level of knowledge was not significantly different between regencies $(\mathrm{p}>0.05)$. 


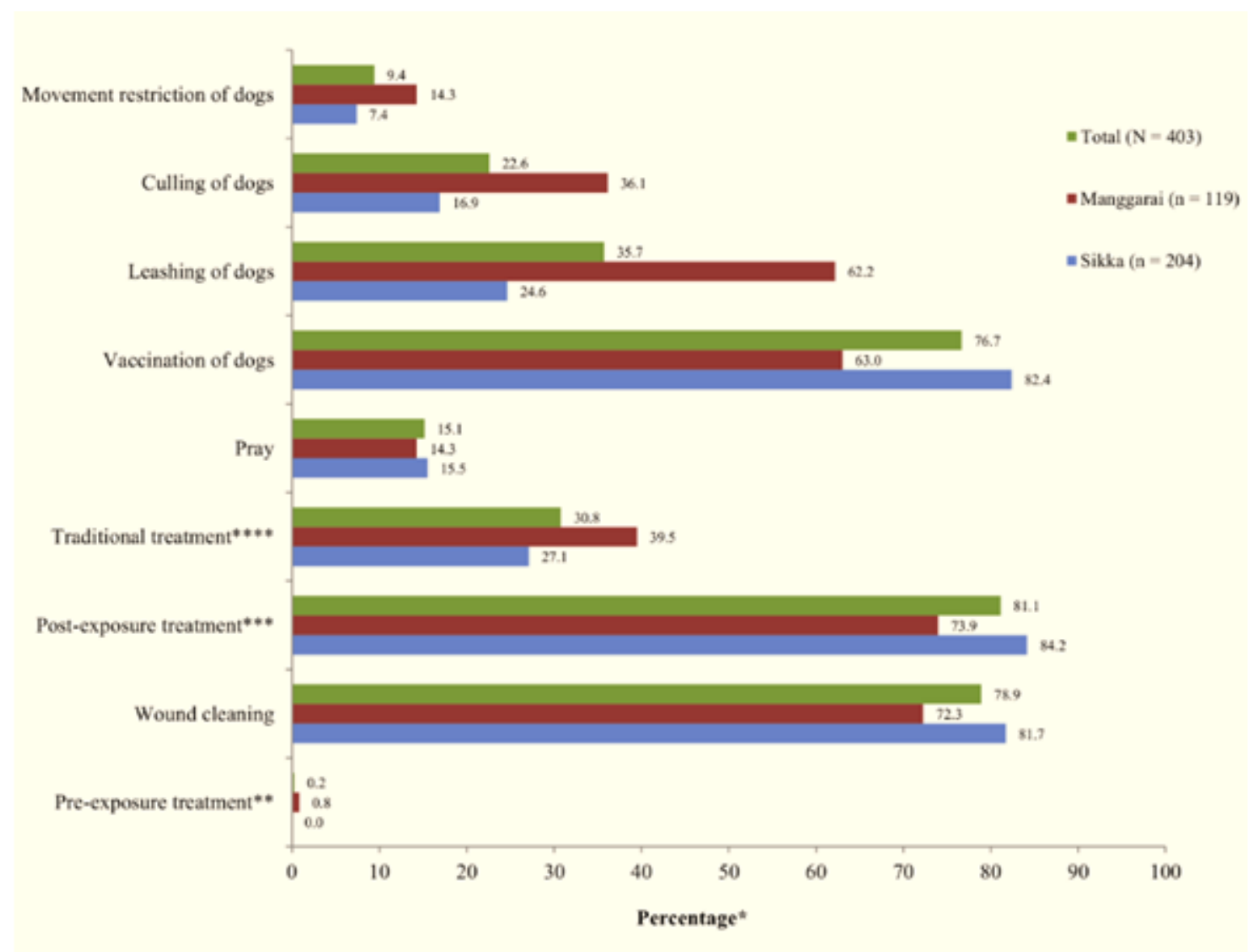

Figure 3.1 Rabies control measures known by dog owners who agreed with the statement that "rabies in humans can be prevented" $(\mathrm{N}=403)$. *Dog owners were allowed to provide more than one response; therefore, percentages of reasons do not sum to $100 \%$; **A series of vaccination injections before exposure; ***A series of vaccination injections and/or immunoglobulin injection after exposure; $* * * *$ Treatment relying on healers, herbs, etc. 


\section{Table 3.1}

Distribution of socio-demographic characteristics of the surveyed dog owners in Flores Island in relation to their knowledge of rabies and its control and their uptake of the 2012 vaccination campaign. Differences were tested with a Chi square test.

\begin{tabular}{|c|c|c|c|c|c|c|c|c|c|c|c|c|}
\hline \multirow[t]{3}{*}{ Variables } & \multicolumn{3}{|c|}{$\begin{array}{l}\text { Rabies is a fatal disease } \\
\text { in humans }(\mathrm{N}=450)\end{array}$} & \multicolumn{3}{|c|}{$\begin{array}{l}\text { Rabies in humans can be } \\
\text { prevented }(\mathrm{N}=450)\end{array}$} & \multicolumn{3}{|c|}{$\begin{array}{l}\text { Knowledge of rabies } \\
\text { control measures }(\mathrm{N}=403)^{*}\end{array}$} & \multicolumn{3}{|c|}{$\begin{array}{l}\text { Uptake } 2012 \text { vaccination campaign } \\
(\mathrm{N}=450)\end{array}$} \\
\hline & Yes & No & & Yes & No & & High & Low & & Yes & No & \\
\hline & $\mathbf{n}$ & $\mathbf{n}$ & p-value & $\mathbf{n}$ & $\mathbf{n}$ & p-value & $\mathbf{n}$ & $\mathbf{n}$ & p-value & $\mathbf{n}$ & $\mathbf{n}$ & p-value \\
\hline Regency: & & & 0.000 & & & 0.000 & & & 0.141 & & & 0.000 \\
\hline Sikka & 289 & 11 & & 284 & 16 & & 198 & 86 & & 189 & 111 & \\
\hline Manggarai & 126 & 24 & & 119 & 31 & & 74 & 45 & & 45 & 105 & \\
\hline Gender: & & & 0.096 & & & 0.153 & & & 0.619 & & & 0.030 \\
\hline Male & 275 & 28 & & 267 & 36 & & 178 & 89 & & 147 & 156 & \\
\hline Female & 140 & 7 & & 136 & 11 & & 94 & 42 & & 87 & 60 & \\
\hline Age: & & & 0.570 & & & 0.303 & & & 0.925 & & & 0.850 \\
\hline $18-45$ years & 234 & 18 & & 229 & 23 & & 155 & 74 & & 132 & 120 & \\
\hline$>45$ years & 181 & 17 & & 174 & 24 & & 117 & 57 & & 102 & 96 & \\
\hline Highest education : & & & 0.160 & & & 0.001 & & & 0.851 & & & 0.720 \\
\hline None & 38 & 7 & & 33 & 12 & & 21 & 12 & & 20 & 25 & \\
\hline Elementary school & 206 & 18 & & 201 & 23 & & 139 & 62 & & 117 & 107 & \\
\hline Junior high school & 77 & 5 & & 76 & 6 & & 49 & 27 & & 45 & 37 & \\
\hline Senior high school/University & 94 & 5 & & 93 & 6 & & 63 & 30 & & 52 & 47 & \\
\hline Occupation: & & & $0.940 * *$ & & & $0.647 * *$ & & & 0.967 & & & 0.190 \\
\hline Farmer & 327 & 29 & & 316 & 40 & & 214 & 102 & & 179 & 177 & \\
\hline Public service & 20 & 1 & & 20 & 1 & & 13 & 7 & & 10 & 11 & \\
\hline Others & 68 & 5 & & 67 & 6 & & 45 & 22 & & 45 & 28 & \\
\hline $\begin{array}{l}\text { Monthly income of dog owners } \\
\left.\text { (in Rupiah }(\mathrm{Rp})^{1}\right)^{* * *} \text { : }\end{array}$ & & & $0.006 * *$ & & & 0.129 & & & 0.024 & & & 0.020 \\
\hline$<500,000$ & 227 & 10 & & 212 & 25 & & 148 & 64 & & 137 & 100 & \\
\hline $500,000-1,000,000$ & 131 & 13 & & 133 & 11 & & 80 & 53 & & 62 & 82 & \\
\hline
\end{tabular}




\begin{tabular}{|c|c|c|c|c|c|c|c|c|c|c|c|c|}
\hline$>1,000,000$ & 55 & 10 & & 54 & 11 & & 43 & 11 & & 33 & 32 & \\
\hline Religion ${ }^{2}$ : & & & $1.000 * *$ & & & $1.000 * *$ & & & $.000 * *$ & & & $0.677 * *$ \\
\hline Islam & 2 & 0 & & 2 & & & 2 & 0 & & 1 & 1 & \\
\hline Protestant & 4 & 0 & & 4 & & & 3 & 1 & & 1 & 3 & \\
\hline Catholic & 409 & 35 & & 397 & 47 & & 267 & 130 & & 232 & 212 & \\
\hline $\begin{array}{l}\text { Number of people } \\
\text { per household: }\end{array}$ & & & 0.607 & & & 0.982 & & & 0.022 & & & 0.848 \\
\hline$\leq$ Two & 31 & 1 & & 28 & 4 & & 16 & 12 & & 17 & 15 & \\
\hline Three & 42 & 3 & & 40 & 5 & & 23 & 17 & & 20 & 25 & \\
\hline Four & 68 & 8 & & 69 & 7 & & 45 & 24 & & 42 & 34 & \\
\hline Five & 98 & 6 & & 94 & 10 & & 76 & 18 & & 54 & 50 & \\
\hline$\geq \operatorname{Six}$ & 176 & 17 & & 172 & 21 & & 112 & 60 & & 101 & 92 & \\
\hline Having children in the household: & & & 0.029 & & & 0.307 & & & 0.308 & & & 0.590 \\
\hline Yes & 345 & 34 & & 337 & 42 & & 231 & 106 & & 195 & 184 & \\
\hline No & 70 & 1 & & 66 & 5 & & 41 & 25 & & 39 & 32 & \\
\hline $\begin{array}{l}\text { Having family member previously } \\
\text { bitten by dogs: }\end{array}$ & & & 0.396 & & & 0.040 & & & 0.923 & & & 0.684 \\
\hline Yes & 84 & 5 & & 85 & 4 & & 57 & 28 & & 48 & 41 & \\
\hline No & 331 & 30 & & 318 & 43 & & 215 & 103 & & 186 & 175 & \\
\hline Having female dogs for breeding ${ }^{3}$ : & & & 0.506 & & & 0.001 & & & 0.341 & & & 0.000 \\
\hline Yes & 214 & 16 & & 217 & 13 & & 142 & 75 & & 145 & 85 & \\
\hline No & 201 & 19 & & 186 & 34 & & 130 & 56 & & 89 & 131 & \\
\hline Having male dogs: & & & 0.099 & & & 0.609 & & & 0.626 & & & 0.130 \\
\hline Yes & 237 & 25 & & 233 & 29 & & 155 & 78 & & 144 & 118 & \\
\hline No & 178 & 10 & & 170 & 18 & & 117 & 53 & & 90 & 98 & \\
\hline Primary function of dogs: & & & $0.024 * *$ & & & $0.031 * *$ & & & 0.018 & & & 0.060 \\
\hline Economy & 89 & 6 & & 87 & 8 & & 60 & 27 & & 13 & 14 & \\
\hline Source of protein & 19 & 3 & & 17 & 5 & & 12 & 5 & & 45 & 50 & \\
\hline Guard of house/property & 238 & 15 & & 233 & 20 & & 167 & 66 & & 8 & 14 & \\
\hline $\begin{array}{l}\text { Hunter (chase away) wild } \\
\text { animals }\end{array}$ & 43 & 10 & & 43 & 10 & & 23 & 20 & & 146 & 107 & \\
\hline
\end{tabular}




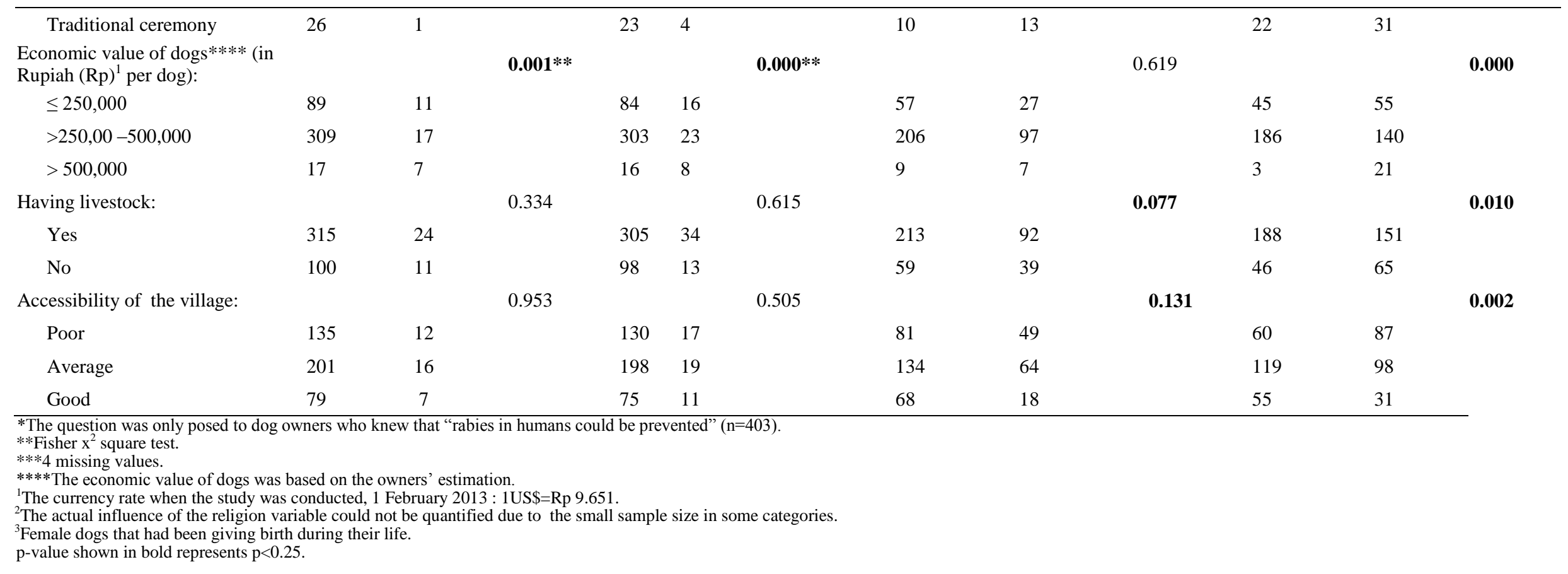




\subsubsection{Factors related to knowledge of the risk, prevention, and control of rabies}

The factors regency, having male dogs, and economic value of dogs were significantly related with knowledge of the risk of rabies in humans (Table 3.2). Dog owners living in Sikka were more aware about the risk of rabies in humans $(\mathrm{OR}=5.55 ; 95 \% \mathrm{CI}=2.33-13.18)$ compared to dog owners living in Manggarai. Dog owners having male dogs had lower odds of having knowledge of the risk of rabies in humans $(\mathrm{OR}=0.41 ; 95 \% \mathrm{CI}=0.18-0.96)$ compared to their counterparts. Dog owners who kept dogs with an average economic value between $\mathrm{Rp} 250,000$ and $\mathrm{Rp500,000} \mathrm{per} \mathrm{dog} \mathrm{were} \mathrm{more} \mathrm{likely} \mathrm{(} \mathrm{OR}=2.74 ; 95 \% \mathrm{CI}=1.14-6.59)$ to have knowledge of the risk of rabies in humans compared to a value of less than Rp250,000 per dog. The final model had a good fit with the data (Hosmer-Lemeshow goodness-of-fit test p-value was 0.76) and no multicollinearity was found between the independent variables (highest Spearman's rank correlation coefficient ( $\rho$ ) was 0.36).

\section{Table 3.2}

Determinants of knowledge about the risk of rabies to human health (rabies is a fatal disease in humans (yes/no)) in the logistic multivariable regression model $(\mathrm{n}=446)$.

\begin{tabular}{lll}
\hline Variables & OR $(\mathbf{9 5 \%} \mathbf{C I})$ & p-value \\
\hline Regency: & & \\
$\quad$ Manggarai & 1.00 & \\
$\quad$ Sikka & $5.55(2.33-13.18)$ & 0.000 \\
Having male dog: & 1.00 & \\
$\quad$ No & $0.41(0.18-0.96)$ & 0.040 \\
$\quad$ Yes & & \\
Economic value of dogs* (in Rupiah(Rp) ${ }^{1}$ per dog): & 1.00 & \\
$\quad \leq 250,000$ & $2.74(1.14-6.59)$ & 0.024 \\
$>250,000-500,000$ & $0.60(0.18-2.07)$ & 0.419 \\
$>500,000$ & & \\
\hline
\end{tabular}

$\mathrm{OR}=$ Odds ratio $; \mathrm{CI}=$ Confidence interval.

*The economic value of dogs was based on the owners' estimation.

${ }^{1}$ The currency rate when the study was conducted, 1 February $2013: 1$ US $\$=$ Rp 9,651.

The Hosmer-Lemeshow goodness-of-fit test p-value for this model was 0.76 .

Knowledge of the prevention of rabies in humans was significantly associated with regency, economic value of dogs, and education level (Table 3.3). The odds of having knowledge of rabies prevention were higher among dog owners living in Sikka $(\mathrm{OR}=3.44 ; 95 \% \mathrm{CI}=1.68$ - 7.05), having a high educational level $(\mathrm{OR}=4.64$; $95 \% \mathrm{CI}=1.50-14.33)$, and having dogs with an average economic value between $\mathrm{Rp} 250,000$ and $\mathrm{Rp500,000} \mathrm{per} \mathrm{dog} \mathrm{(OR} \mathrm{=} \mathrm{2.94;}$ $95 \% \mathrm{CI}=1.40-6.16)$ compared to a value of $\leq \mathrm{Rp} 250,000$ per dog. The Hosmer-Lemeshow goodness-of-fit test p-value for this model was 0.48 , which indicates an adequate fit of the model to the data. There was no multicollinearity between the independent variables (the highest Spearman's rank correlation coefficient $(\rho)$ was 0.53 ). 


\section{Table 3.3}

Determinants of knowledge about rabies prevention (rabies in humans can be prevented $($ yes/no $))$ in the logistic multivariable regression model $(\mathrm{n}=446)$.

\begin{tabular}{lll}
\hline Variables & OR $(\mathbf{9 5 \%}$ CI $)$ & p-value \\
\hline Regency: & & \\
$\quad$ Manggarai & 1.00 & \\
$\quad$ Sikka & $3.44(1.68-7.05)$ & 0.001 \\
Education: & 1.00 & \\
$\quad$ None & $2.17(0.92-5.17)$ & 0.079 \\
Elementary school & $3.37(1.08-10.51)$ & 0.036 \\
$\quad$ Junior high school & $4.64(1.50-14.33)$ & 0.008 \\
$\quad$ Senior high school/University & & \\
Economic value of dogs* (in Rupiah(Rp) ${ }^{1}$ per & 1.00 & \\
dog): & $2.94(1.40-6.16)$ & 0.004 \\
$\quad \leq 250,000$ & $0.94(0.30-2.96)$ & 0.910 \\
$\quad>250,000-500,000$ & & \\
$>500,000$ & & \\
\hline
\end{tabular}

$\mathrm{OR}=$ Odds ratio; $\mathrm{CI}=$ Confidence interval.

*The economic value of dogs was based on the owners' estimation.

${ }^{1}$ The currency rate when the study was conducted, 1 February $2013: 1$ US $\$=R p$ 9,651.

The Hosmer-Lemeshow goodness-of-fit test p-value for this model was 0.48 .

The results of the logistic multivariable regression analysis (Table 3.4) on the level of knowledge of rabies control measures showed a significant association with the following factors: primary function of dogs, the level of dog owners' income, and the geographical accessibility of the village. The odds of having a high level of knowledge of rabies control measures was higher in the following situations: for dog owners who lived in villages with good accessibility ( $\mathrm{OR}=2.14 ; 95 \% \mathrm{CI}=1.07-4.27)$ compared to poor accessibility, for $\mathrm{dog}$ owners who kept dogs as a source of income (economy) $(\mathrm{OR}=3.18 ; 95 \% \mathrm{CI}=1.20-8.44)$ or as a guard of the house or property $(\mathrm{OR}=3.44 ; 95 \% \mathrm{CI}=1.39-8.51)$ compared to the function of traditional ceremony, and for dog owners who had an income of more than $\mathrm{Rp} 1,000,000(\mathrm{OR}=3.02 ; 95 \% \mathrm{CI}=1.36-6.71)$ compared to an income of Rp500,000 1,000,000. The model fitted the data well (the Hosmer-Lemeshow goodness-of-fit test p-value was 0.80 ) and no multicollinearity was found between independent variables (the highest $\rho$ was 0.37$)$. 


\section{Table 3.4}

Determinants of the level of knowledge of rabies control measures (high $>=3$ measures $/$ low $<3$ measures $)$ in the logistic multivariable regression model $(\mathrm{n}=399)$.

\begin{tabular}{llc}
\hline Variables & OR $(\mathbf{9 5 \%} \mathbf{C I})$ & p-value \\
\hline Primary function of dogs: & 1.0 & \\
Traditional ceremony & $3.18(1.20-8.44)$ & 0.020 \\
Economy & $3.60(0.84-15.38)$ & 0.084 \\
Source of protein & $3.44(1.39-8.51)$ & 0.007 \\
Guard of house/property & $1.65(0.57-4.78)$ & 0.353 \\
Hunter/chaser of wild animals & & \\
Monthly income of dog owners* (in & $1.61(0.98-2.66)$ & 0.063 \\
Rupiah $\left.(\text { Rp })^{1}\right):$ & 1.00 & \\
$<500,000$ & $3.02(1.36-6.71)$ & 0.007 \\
$500,000-1,000,000$ & & \\
$>1,000,000$ & 1.00 & 0.227 \\
Geographical accessibility of the village: & $1.36(0.82-2.27)$ & 0.031 \\
Poor & $2.14(1.07-4.27)$ & \\
Average & & \\
Good & & \\
\hline OR = Odds ratio; CI = Confidence interval. & \\
*4 missing values. & \\
'The currency rate when the study was conducted, 1 February $2013: 1 \mathrm{US} \$=\mathrm{Rp} 9,651$. & \\
The Hosmer-Lemeshow goodness-of-fit test p-value for this model was 0.80. &
\end{tabular}

\subsubsection{Uptake of control measures}

\subsubsection{Control measures in dogs}

Respondents' uptake of rabies control measures during the last fourteen years (1999 - 2012) are shown in Table 3.5. Fifty-six percent of respondents reported that at least one of their dogs had been vaccinated during the last fourteen years, the majority of which (92\%) had had their dogs vaccinated during the 2012 campaign. Regarding culling as a control measure, $33 \%$ of the dog owners reported that at least one of their dogs had been culled during the last fourteen years. The majority of the culling was carried out in 1999 (45\%) and 2010 (25\%). Only $1 \%$ of the respondents reported that at least one of their dogs had been culled in 2012. Most often, these dogs were culled after having bitten someone or showing unusual behavior. In total, $12 \%$ of the dog owners had castrated at least one of their dogs. The main purpose given by the dog owners for castration was to keep the dogs close to home (prevent roaming away) in their function as guard of the house and property or as hunter to chase away wildlife. Castration of male dogs was carried out by the dog owners themselves or by their family.

The uptake of vaccination and culling differed among regencies. The proportion of dog owners who had vaccinated their dogs was significantly $(\mathrm{p}<0.001)$ higher in Sikka $(65 \%)$ than 
in Manggarai (39\%) (Table 3.5). In contrast, the proportion of dog owners that had culled their dogs was significantly higher in Manggarai $(45 \%)$ than in Sikka $(27 \%)(\mathrm{p}<0.001)$.

\section{Table 3.5}

Uptake of rabies control measures to reduce human rabies cases in Sikka and Manggarai regencies during the period 1999-2012.

\begin{tabular}{|c|c|c|c|}
\hline $\begin{array}{l}\text { I. Rabies control measures in } \\
\text { dogs }\end{array}$ & $\begin{array}{l}\text { Sikka }(n=300) \\
\text { n }(\%)\end{array}$ & $\begin{array}{l}\text { Manggarai }(\mathrm{n}=150) \\
\mathrm{n}(\%)\end{array}$ & $\begin{array}{l}\text { Total }(\mathrm{N}=450) \\
\mathrm{n}(\%)\end{array}$ \\
\hline a. Dog vaccination & $196(65.3)$ & $58(38.7)$ & $254(56.4)$ \\
\hline b. Culling of dogs & $82(27.3)$ & $68(45.3)$ & $150(33.3)$ \\
\hline c. Castration of male dogs & $34(11.3)$ & $19(12.7)$ & $53(11.8)$ \\
\hline $\begin{array}{l}\text { II. Rabies control measures in } \\
\text { humans }\end{array}$ & $\begin{array}{l}\text { Sikka }(\mathrm{n}=67) \\
\text { n }(\%)\end{array}$ & $\begin{array}{l}\text { Manggarai }(n=22) \\
\text { n }(\%)\end{array}$ & $\begin{array}{l}\text { Total }(\mathrm{N}=89 *) \\
\text { n }(\%)\end{array}$ \\
\hline a. Wound cleaning & $59(88.1)$ & $16(72.7)$ & $75(88.3)$ \\
\hline $\begin{array}{l}\text { b. Vaccine and/or } \\
\text { immunoglobulin injection }\end{array}$ & $35(52.2)$ & $15(68.2)$ & $50(56.2)$ \\
\hline
\end{tabular}

*Number of dog owners that experienced a dog bite among one of their family members.

\subsubsection{Control measures in humans}

Of the 450 dog owners interviewed, 89 (20\%) reported that at least one of their family members had been bitten by a suspected rabid dog during the last fourteen years. Of these 89 bite cases, $75(84 \%)$ cleaned the wound, and $50(56 \%)$ received vaccination. The level of uptake of these measures did not differ between regencies ( $p>0.05$ ). Approximately $87 \%$ of the reported bite cases occurred during the period 2009-2012, of which $34 \%$ in 2012 alone.

\subsubsection{Uptake of the 2012 vaccination campaign}

During the 2012 vaccination campaign, 52\% (234/450) of the dog owners had vaccinated at least one of their dogs (Table 3.1). This uptake proportion was significantly higher in Sikka $(63 \% ; 189 / 300)$ than in Manggarai $(30 \% ; 45 / 150)(\mathrm{p}<0.001)$. The proportion of vaccination uptake was also significantly higher for owners of female dogs $(59 \% ; 87 / 147)$ than male dogs $(49 \% ; 147 / 303)(\mathrm{p}<0.05)$. The vaccination uptake was significantly associated with the knowledge of the dog owners about rabies $(p<0.001)$ and its control measures $(p<0.05)$ (Table 3.6). The proportion of dog owners who had vaccinated dogs was higher for those who considered rabies a fatal disease $(54 \% ; 225 / 415)$ than for those who did not $(26 \% ; 9 / 35)$. Similarly, dog owners with a high level of knowledge of rabies control measures (59\%; $161 / 272)$ tended to vaccinate their dogs compared to their counterparts $(46 \% ; 60 / 131)$. We found no significant association of vaccination uptake with the age and education level of the dog owner, presence of children in the household, or having male dogs (Table 3.1). 


\subsubsection{Multivariable model for the 2012 vaccination uptake}

Of the 13 independent variables that had an association (p-value less than 0.25) with the uptake of the 2012 vaccination campaign in the univariable analyses (Table 3.1 and Table 3.6), only five variables were retained in the final multivariable model. Regency, having female dogs for breeding, economic value of dogs, income of dog owners, and accessibility of the village were significantly associated with the uptake of vaccination (Table 3.7). Dog owners from Sikka were more likely to vaccinate their dogs $(\mathrm{OR}=4.07 ; 95 \% \mathrm{CI}=2.30$ 7.20) than those from Manggarai. The dog owners who held female dogs for breeding had significantly higher odds to vaccinate their $\operatorname{dogs}(\mathrm{OR}=2.07 ; 95 \% \mathrm{CI}=1.31-3.27)$ compared with those who did not.

\section{Table 3.6}

Rabies knowledge of surveyed dog owners in Flores Island in relation to their uptake of the 2012 vaccination campaign. Differences were tested with a Chi square test.

\begin{tabular}{llll}
\hline Variables & \multicolumn{3}{l}{ Uptake 2012 vaccination campaign (N=450) } \\
\cline { 2 - 4 } & $\begin{array}{l}\text { Yes } \\
\text { N }\end{array}$ & $\begin{array}{l}\text { No } \\
\text { p-value }\end{array}$ \\
\hline $\begin{array}{l}\text { Knew that rabies is a fatal disease in } \\
\text { humans: }\end{array}$ & 225 & 190 & 0.001 \\
$\quad$ Yes & 9 & 26 & \\
$\quad$ No & & & 0.000 \\
Knew that rabies in humans can be & & & \\
prevented: & 221 & 182 & 0.010 \\
$\quad$ Yes & 13 & 34 & \\
$\quad$ No & & & \\
$\begin{array}{l}\text { Knowledge level of rabies control } \\
\text { measures*: }\end{array}$ & 161 & 111 & \\
$\quad$ High & 60 & 71 & \\
Low & *The question was posed only to dog owners who knew that "rabies in humans can be prevented" (n=403).
\end{tabular}

Similarly, the dog owners who owned dogs with an economic value ranging between Rp250,000 - 500,000 tended to vaccinate their dogs $(\mathrm{OR}=2.38 ; 95 \% \mathrm{CI}=1.36-4.17)$ compared with owners who valued their dogs at less than or equal to Rp250,000. Moreover, the uptake of vaccination was higher if the dog owners had a monthly income of more than 1 million Rupiah $(\mathrm{OR}=2.39 ; 95 \% \mathrm{CI}=1.10-5.20)$ and lived in a village with a good accessibility $(\mathrm{OR}=3.84 ; 95 \% \mathrm{CI}=1.92-7.67)$ compared with those having a yearly income less than Rp500,000 and who lived in a village with poor accessibility. The HosmerLemeshow goodness-of-fit test $\mathrm{p}$-value for this model was 0.85 , which indicates the model fitted the data well. There was no multicollinearity between independent variables (the highest Spearman's rank correlation coefficient ( $\rho$ ) was 0.49). 


\section{Table 3.7}

Determinants of the uptake of the 2012 vaccination campaign (yes/no) in the logistic multivariable regression model $(n=399)$

\begin{tabular}{lll}
\hline Variables & OR $(\mathbf{9 5 \%} \mathbf{C I})$ & p-value \\
\hline Regency: & & \\
$\quad$ Manggarai & 1.00 & 0.000 \\
$\quad$ Sikka & $4.07(2.30-7.20)$ & \\
Having female dogs for breeding*: & 1.00 & 0.002 \\
$\quad$ No & $2.07(1.31-3.27)$ & \\
$\quad$ Yes & & \\
Economic value of dogs** (in Rupiah(Rp) ${ }^{1}$ per & 1.00 & 0.002 \\
dog): & $2.38(1.36-4.17)$ & 0.191 \\
$\quad \leq 250,000$ & $0.24(0.03-2.04)$ & \\
$\quad>250,000-500,000$ & & 0.434 \\
$>500,000$ & 1.00 & 0.028 \\
Monthly income of dog owners*** (in & $0.81(0.47-1.39)$ & \\
Rupiah(Rp) $\left.{ }^{1}\right):$ & $2.39(1.10-5.20)$ & \\
$\quad<500,000$ & & 0.022 \\
$500,000-1,000,000$ & 1.00 & 0.000 \\
$>1,000,000$ & $1.80(1.09-2.97)$ & \\
Geographical accessibility of the village: & $3.84(1.92-7.67)$ & \\
Poor &
\end{tabular}

$\mathrm{OR}=$ Odds ratio; $\mathrm{CI}=$ Confidence interval.

*Female dogs that had been giving birth during their life.

**The economic value of dogs was based on the owners' estimation.

$* * * 4$ missing values.

${ }^{1}$ The currency rate when the study was conducted, 1 February $2013: 1$ US $\$=\operatorname{Rp} 9,651$.

The Hosmer-Lemeshow goodness-of-fit test p-value for this model was 0.85 .

\subsubsection{Motivation to adopt the vaccination control campaign}

Reasons for having their dogs vaccinated against rabies in 2012 were given by the $234 \mathrm{dog}$ owners who indicated that at least one of their dogs was vaccinated during this vaccination campaign. The most common reasons for the dog owners to vaccinate their dogs were to protect their own health and that of their family (97\%) and to protect the children in their community (77\%) (Figure 3.2). For those dog owners who had not vaccinated their dogs (216 of 450 dog owners), the most important reasons for not joining were the lack of information about the schedule of the vaccination campaign (40\%) and the difficulty to catch their dogs during the vaccination campaign (37\%) (Figure 3.3). Other reasons, of minor importance, included the lack of belief in the vaccine efficacy (13\%), and the young age of the dog at the time of the vaccination campaign $(6 \%)$. 


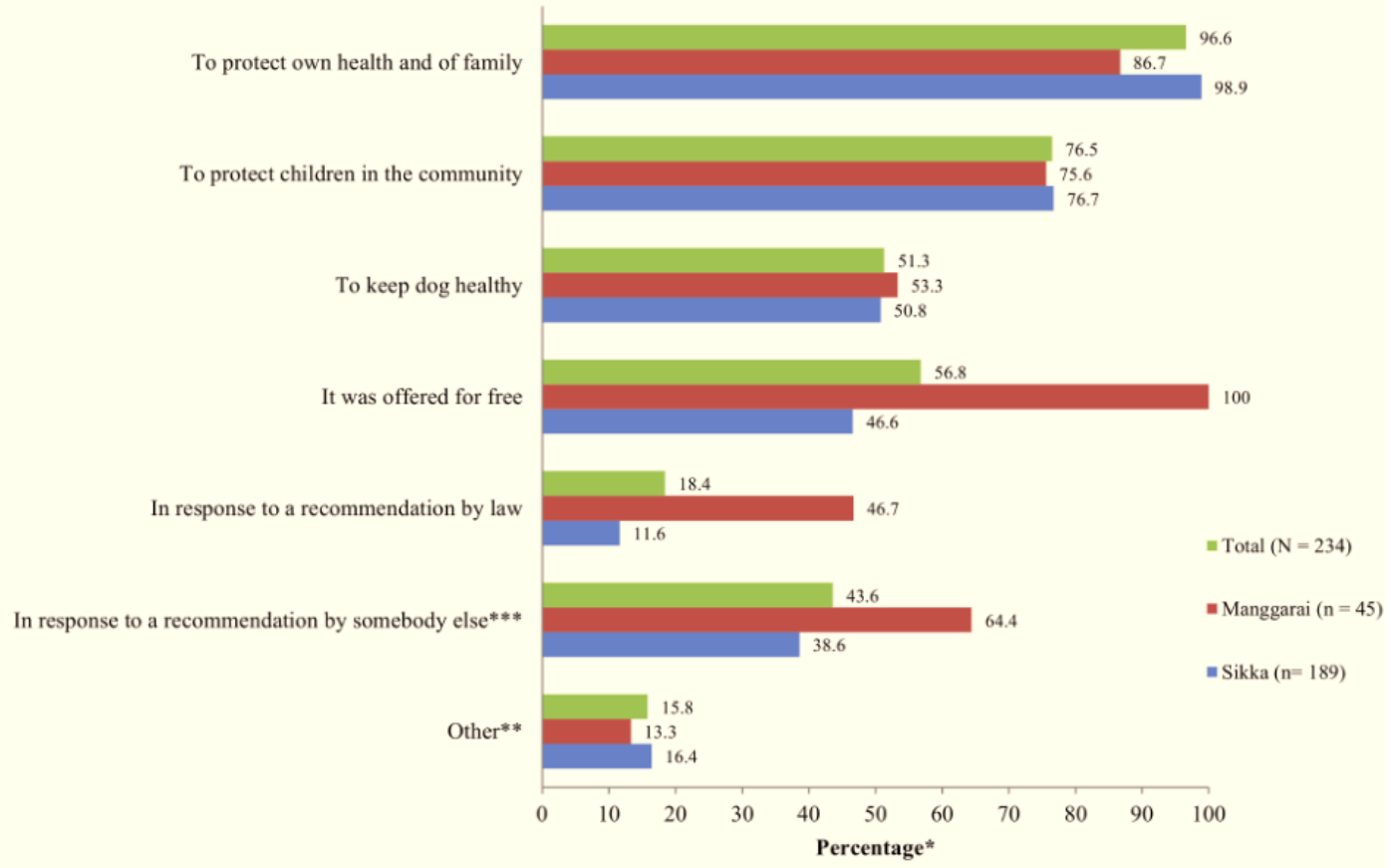

Figure 3.2 Reasons for joining the vaccination campaign of 2012. *Dog owners were allowed to provide more than one response; therefore, percentages of reasons do not sum to $100 \%$; **To support the government's campaign or in response to the fact that vaccinators were visiting at home; ***Neighbor, relative, family, and village leaders.

\subsection{Discussion}

The knowledge of dog owners in Flores Island about the risk of rabies to human health and about the possibilities to prevent the disease was generally high. This positive result might have been overestimated or biased due to the structure of the questions posed ("do you know that rabies is a fatal disease" and "do you know that rabies in humans can be prevented"). However, given the dog owners' prompt responses on the subsequent open questions, e.g., "which control measures are known to you in order to prevent rabies in humans", to which all dog owners provided a response, we expect that the structure of the questions did not influence the result substantially. This high knowledge level is comparable with findings of other studies conducted in South East Asian countries (Ramos and Bravo, 2004; Sharma, 2005; Tenzin et al., 2012). The high level of knowledge about the risk of rabies and its control might be due to the long history of rabies in these countries and the frequent coverage of human rabies cases by the mass media.

Vaccination of dogs against the rabies virus offers a safe and effective means to prevent rabies infection in humans (Linscott, 2012). Vaccination coverage should be at least 70\% (WHO, 2005) to maintain the control of rabies between annual vaccination campaigns. Mass vaccination of dogs ( $70 \%$ of the estimated total number of dogs) in Bali Island, Indonesia, 
successfully decreased the human rabies incidence on that island by 74\% (Putra et al., 2013). In our study, around 52\% of the dog owners had vaccinated at least one of their dogs in 2012. Real vaccination coverage (number of dogs vaccinated divided by the size of the total dog population) will be lower than the estimated 52\%, as most households own multiple dogs, which makes it hard to handle them all at a single time during a vaccination campaign. The Sikka Regency estimated the vaccination coverage during the 2012 campaign to be around $58 \%$. This recorded coverage rate, however, overestimated the real coverage as it did not account for the dogs and their owners that were not at home during the 'house-to-house' campaign. These non-registered dogs were estimated to represent approximately $30 \%$ of the total dog population (Wera et al., 2013). These findings indicate that the real rate of vaccination coverage for the dog population in Flores Island is still far below the WHO recommended coverage of $70 \%$ (WHO, 2005). A targeted vaccination coverage of $70 \%$ is very important to maintain the overall herd immunity between campaigns above the threshold immunity coverage (e.g. 20-45\%; (Hampson et al., 2009)). This is especially relevant for Flores Island, where the dog population is characterized by a high turn-over rate $(>45 \%)$ (Siko, 2011) and the vaccine used has a short duration of immunity. High quality, cell-culture vaccines are recommended for rabies control, such as Rabisin, which was used to effectively reduce the prevalence of dog and human rabies in Bali (Putra et al., 2013).

Relatively more dog owners in Sikka vaccinated their dogs than in Manggarai, whereas in Manggarai the proportion of dog owners that had culled dogs was higher than in Sikka. This difference reflects the different approaches used by the regencies to implement control measures. The animal health authority of Sikka has focused on vaccination of dogs as the main approach to control rabies in the regency, which is in line with the national campaign. Whereas the authority in Manggarai implemented culling of roaming dogs as an additional control measure alongside the national campaign. In 2010, for example, Manggarai conducted mass culling of 2,440 dogs ( $24 \%$ of the estimated total number of dogs in the regency), which were free roaming in the public area, regardless of the vaccination status of these dogs (FHDM, 2011). As a consequence, the size of the dog population in Manggarai reduced considerably (Wera et al., 2013). The number of registered dogs during the vaccination campaign of 2012 was six times lower than in Sikka, even though the size of the human population in both regencies was comparable. A positive impact of culling is the removal of all potentially exposed dogs in infected villages, thereby reducing the transmission of rabies between dogs and decreasing the risk of rabies for humans (Wera, 2001). The culling of free roaming dogs was, however, less acceptable for the local community in comparison to the vaccination campaign (Wera et al., 2013). This resulted in unintended negative consequences (Knobel et al., 2013) in which the dog owners hid or moved their dogs to another village during the incubation phase of rabies (Beran, 1982; Hutabarat et al., 2003). In this context, the OIE and other international animal health related organizations (e.g. WHO, WSAVA, and 
GARC) do not recommend culling as a rabies control measure (Vallat, 2011; WHO, 2013; GARC, 2015; WSAVA, 2015). Culling (i.e. the killing of dogs regardless of their health status) is not effective in controlling rabies (Morters et al., 2013) and can be counterproductive (GARC, 2015), as previously vaccinated dogs may also be culled.

The difference in vaccination uptake between the regencies might also be due to the intensity of local community support for the control campaign (Fishbein et al., 1992). Religious and village leaders in Sikka participated actively in encouraging dog owners to vaccinate their dogs, whereas this was not the case in Manggarai. The encouragement of community leaders may have stimulated dog owners to increase their efforts to catch and restrain the dog to be vaccinated. In addition, the vaccination campaign in Sikka coincided with the national celebration of World Rabies Day on $8^{\text {th }}$ October 2012 in Maumere. During this celebration, religious and village leaders were invited to join the event to share experiences on rabies control measures in their villages. Our findings suggest that the involvement of local communities in rabies control activities can be important to implement rabies control measures successfully in a regency. Moreover, a good collaboration among sectors, such as public health and veterinary authorities, is also important, as was reported from Latin America (WHO, 2005).

Theoretical and empirical evidence suggests that reducing population density through sterilization, which includes castration of male dogs, does not reduce disease transmission (Hampson et al., 2009; Morters et al., 2013). There is limited, equivocal empirical evidence that in open, dynamic populations mass sterilization extends vaccination by reducing the number of new susceptible dogs entering the population through reducing local births (Totton et al., 2010; Jackson, 2013; Morters et al., 2014). Nonetheless, castration of males has been encouraged by the local authority since 2000 , as a method to limit the number of free roaming dogs within villages in Flores and restrict male dog behavior (such as dispersal and fighting) that facilitates the spread of rabies (WHO, 2005). Humane dog population management, which includes sterilization and the provision of basic dog health care, is currently recommended as a supplementary measure to mass vaccination programs (WHO, 2013b), and for this reason we have estimated the prevalence of castration. Only $12 \%$ of dog owners reported that at least one of their male dogs had been castrated during the period 1999-2000. This low uptake might be due to the lack of skill to castrate dogs as castration of male dogs was carried out by the dog owners themselves or by their family. Another reason could be attributed to the dog owners' preference, especially those who keep female dogs for breeding, to have a male dog without castration. 


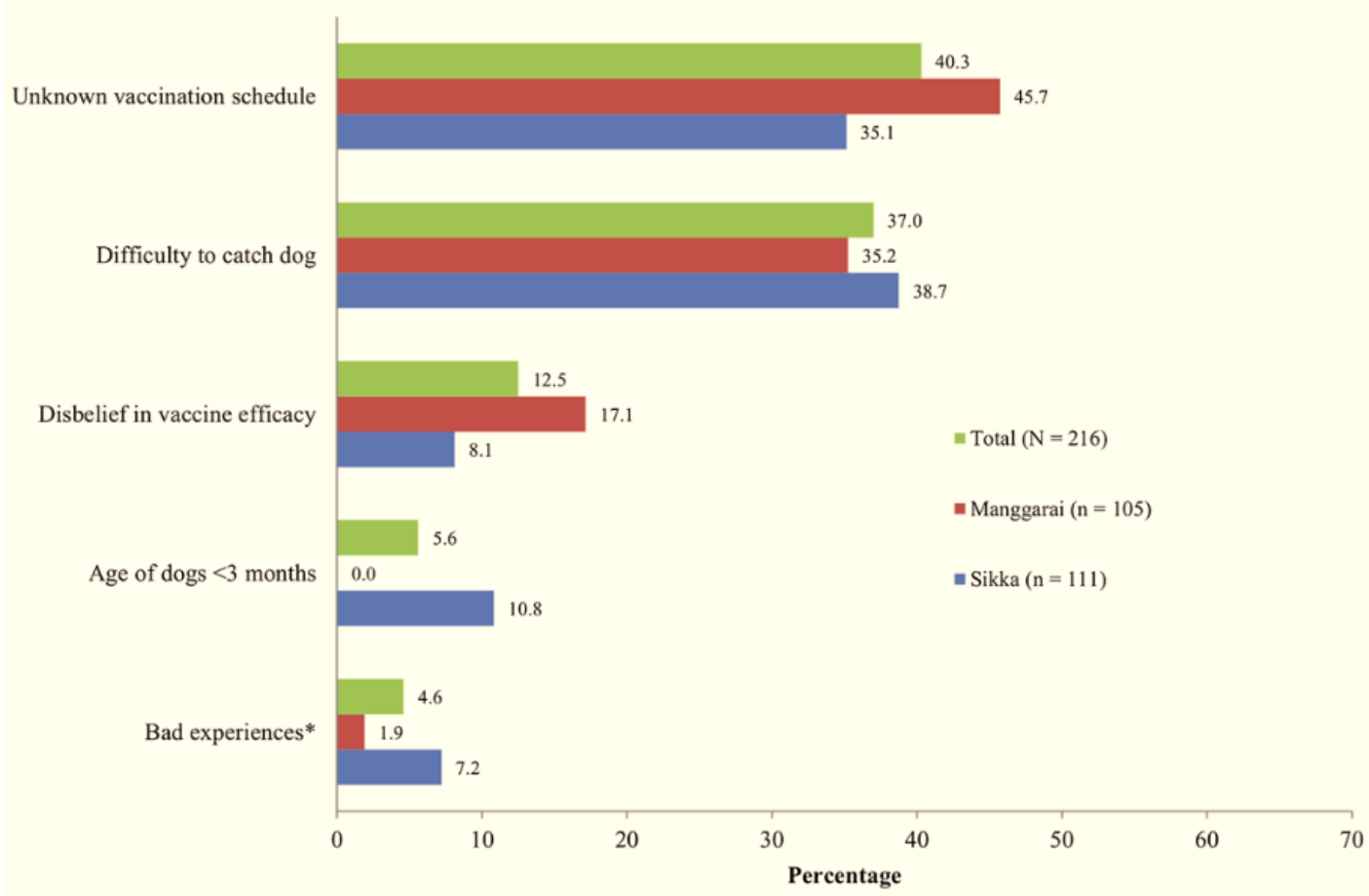

Figure 3.3 Main reason for not joining the vaccination campaign of 2012. *Bad experiences with earlier vaccinations reflected by the perception that it made the dogs less aggressive or less fertile or that it eventuated in the death of the dogs.

Dog owners, both in Sikka and Manggarai, had a high level of knowledge about the preventive measures to be taken after being bitten by a suspected rabid dog. However, a high level of knowledge of rabies and its prevention does not guarantee a high uptake of proper treatment after exposure. In our study, less than $60 \%$ of patients (89 reported bite cases in humans) went to the medical center to seek proper medical treatment, even though the majority of the community knew that rabies in humans is fatal and can be prevented by a series of vaccine injections after exposure. Most of the people in Flores Island that died after being bitten by a rabid dog did not receive any post exposure treatment (Purnama, personal communication, 2014). In addition to the level of knowledge, socio-economic factors such as income level and distance to the nearest rabies-treatment center can contribute significantly to the decision to adopt the appropriate treatment (Fang et al., 2010). People living in rural areas, far from any rabies-treatment center, may not have access to prompt and appropriate treatment (Fang et al., 2010). Even if the treatment is provided for free ${ }^{2}$, costs associated with travel to and from the rabies-treatment center and income loss during the treatment (Knobel et al., 2005) could prevent dog-bite victims from seeking medical care.

The distribution of reported control measures in dogs and bite cases in humans over the previous fourteen years may have been influenced by recall bias, reflecting the extensive time

\footnotetext{
${ }^{2}$ The direct medical costs (e.g. cost of human rabies vaccines and physician costs) are paid by the individual Regency Governments of Flores Island
} 
frame posed in the research questions. However, the results give an overview of the uptake of rabies control measures over the previous fourteen years and could be used for better planning of rabies control in the future.

In the univariable analysis, knowledge of rabies and its control measures was significantly associated with the 2012 vaccination uptake by dog owners. However, in the multivariable analysis this association was no longer significant. This indicates that the level of rabies knowledge did not have a direct effect on the uptake of the 2012 vaccination campaign. An important factor associated with vaccination uptake was the accessibility of the village. Uptake of the vaccination campaign was four times more likely for dog owners living in a village with good infrastructure than for those living in more remote villages with a poor road infrastructure. This is an interesting finding, as this factor has not been studied before. The accessibility of a village might be related to the transfer of knowledge from animal health authorities (especially the distribution of vaccination schedule information). Informal discussions during the survey with dog owners in the less accessible villages revealed that many of these dog owners became aware of the vaccination campaign only on the day it was conducted. This is in line with our survey results, which showed that one of the main reasons for not joining the vaccination campaign was the lack of information about the vaccination campaign. As a consequence, dog owners were not at home when the vaccinators arrived. This corresponds with the study results of Durr et al (2009), in which 26\% of the surveyed dog owners did not join the vaccination campaign as they were not aware of the time schedule. In Flores Island, it is common practice for the notification letter about the vaccination schedule to be sent to the village leader through public transportation. Given the poor accessibility of the more remote villages due to natural barriers, (especially in the rainy season, September-April) these notifications do not always reach the villages on time. As a result, dog owners in less accessible villages are less informed about the vaccination campaign. This finding suggests that targeted distribution of vaccination campaign information within these villages is an effective and practical way to increase the uptake of rabies vaccination in the future. Effective channels for the distribution of information about the vaccination schedule, prior to the visit of the vaccination team, could be through elementary school teachers (Bogel and Joshi, 1990), and church and village leaders.

The second important reason given by dog owners for not joining the vaccination campaign was the inability to handle and restrain their dogs $(37 \%)$. This reason was given more frequently in our study than reported in studies from other endemic rabies countries (Kongkaew et al., 2004; Suzuki et al., 2008; Belsare and Gompper, 2013). The difference could be due a different relationship between humans and dogs in those countries. Dogs in Flores are never restricted and roam freely within the village, so the interaction between owners and their dogs is very low. Dogs in Flores Island have a primary function as guard 
dogs. This type of dog is more aggressive and difficult to handle compared with companion dogs. This suggests that educating the vaccinators and dog owners about dog behavior and the safe handling of dogs might improve vaccination coverage whilst limiting the risk of being bitten. Alternatively, training teams of government dog catchers, similar to Bali (Putra et al., 2013), may be required to increase vaccination coverage if owners are unable to catch and restrain their dogs.

Our study highlighted the association between keeping female dogs for breeding and the uptake of vaccination. The dog owners who had female dogs for breeding purposes were more likely to join the vaccination campaign. The perceived value of the dog may have increased the dog owners' effort to catch and restrain the dog to be vaccinated. Other reasons that might have contributed to this association are related to the relatively longer life span and lower turn-over rate of female dogs. In the event of a traditional ceremony in which dog meat is needed, dog owners in Flores prefer to cull male dogs and keep female dogs for breeding. A reproductive female can produce puppies until the age of 11 years (reproductive lifespan) (Gsell et al., 2012). Therefore, dog owners get more benefit from vaccinating reproductive female dogs.

Furthermore, our study found that dog owners who valued their dogs at less than Rp250,000 were less likely to join the vaccination campaign compared to dog owners with dogs valued between Rp250,000 and Rp500,000. This result might be due to the age of the dogs. The majority of the dogs valued at less than Rp250,000 were younger than one year old. It is well documented that dogs younger than one year are less likely to be vaccinated by their dog owners (Flores-Ibarra and Estrella-Valenzuela, 2004; Suzuki et al., 2008; Kaare et al., 2009; Davlin et al., 2012), putting this cohort at a higher risk for contracting rabies (Mitmoonpitak et al., 1997). This is the result of a common perception that this cohort is too young to be vaccinated (Flores-Ibarra and Estrella-Valenzuela, 2004; Kongkaew et al., 2004). Vaccine manufacturers indicate that rabies vaccine can be effectively administered to dogs at as early as 3 months of age. Therefore, the vaccination campaign in the future should place additional emphasis on this unvaccinated cohort of dogs, aged between 3 and 12 months. In addition, community education efforts should be focused on dog owners who have a female dog for breeding, encouraging them to vaccinate their young dogs before selling them. Dog owners with a high income (more than 1 million Rupiah per year) had a higher probability of having their dogs vaccinated than dog owners with lower income levels. This finding is similar to the result of a study by Beran (1982). It is common practice in Flores Island for people with a good income to hire other adults (particularly from their family) to take care of their children and home. As a consequence, there will always be an adult person present at the home to handle the dogs during vaccination. This may explain our finding that dog owners with a higher income were more likely to vaccinate their dogs. 


\subsection{Conclusions}

The level of knowledge of dog owners in Flores Island about rabies and its control measures was high, but not associated with the uptake of the vaccination campaign of 2012. Overall, the uptake rate of the 2012 vaccination campaign was relatively low (52\%) and differed between regencies. Geographical accessibility is one of the important predictors of vaccination uptake among dog owners. Targeted interventions in those villages with poor accessibility may increase the vaccination uptake in the future. These interventions should include: (1) an effective system for distributing information so that dog owners are provided with timely information on the vaccination schedule, for instance through elementary school teachers, and church and village leaders; and (2) the provision of dog owners and vaccinators with a technique or skill to catch and restrain dogs.

\section{Acknowledgements}

The authors would like to acknowledge the following people for their comments on earlier drafts of the questionnaire: Maria Geong (Husbandry Department of East Nusa Tenggara Province), Vitalis Kanisius, Maria Margaretha Siko, Elfrida Carvallo, Quartus Keupung, Yersi Bura, Rina Sari, Satri Meo, Elias M. Nong (Husbandry and Animal Health Department of Sikka), Yoseph Mantara, Teddy Geong, Daniel Dan, and Severinus Jani Hadir (Fisheries and Husbandry Department of Manggarai. Petrus Malo Bulu (Murdoch University, Australia) is acknowledged for his useful comments on the translation of the questionnaire. The authors thank the dog owners and village leaders from Sikka and Manggarai for their participation in this study, and the people involved in the administration of the survey: Gregorius M. Dewa, Yohanis Sena, Yohanes Bajo, Servasius N. Roga, Servulus Bura (Husbandry and Animal Health Department of Sikka), Eduardus Adu Kanisius Batung and Yohanes T Panggul. 


\section{References}

Belsare, A.V., Gompper, M.E., 2013. Assessing demographic and epidemiologic parameters of rural dog populations in India during mass vaccination campaigns. Prev. Vet. Med.111, 139-146.

Beran, G.W., 1982. Ecology of dogs in the central Philippines in relation to rabies control efforts. Comp. Immunol. Microbiol. Infect. Dis. 5, 265-270.

Bingham, G.M., Budke, C.M., Slater, M.R., 2010. Knowledge and perceptions of dog-associated zoonoses: Brazos County, Texas, USA. Prev. Vet. Med. 93, 211-221.

Bingham, J., 2001. Rabies on Flores Island, Indonesia: is eradication possible in the near future? In: Doddet. B., Meslin, F.X. (Eds.), Rabies Control in Asia. John Libbey Eurotext. Paris. pp. 148 -155 .

Bogel, K., Joshi, D.D., 1990. Accessibility of dog populations for rabies control in Kathmandu valley, Nepal. Bull. World Health Organ. 68, 611-617.

BPS, 2013. Population of Indonesia by village. Available at: http://bps.go.id/eng/download file/Population of Indonesia by Village 2010.pdf (accessed on 20.06.13.).

Davlin, S., Lapiz, S.M., Miranda, M.E., Murray, K., 2012. Factors Associated with Dog Rabies Vaccination in Bohol, Philippines: Results of a Cross-Sectional Cluster Survey Conducted Following the Island-Wide Rabies Elimination Campaign. Zoonoses Public Health 60, 494503.

Durr, S., Mindekem, R., Kaninga, Y., Moto, D.D., Meltzer, M.I., et al., 2009. Effectiveness of dog rabies vaccination programmes: Comparison of owner-charged and free vaccination campaigns. Epidemiol. Infect. 137, 1558-1567.

Fang, L.X., Ping, F., Ping, D.Y., Hui, B.G., Yan, Y.X., 2010. Socioeconomic status is a critical risk factor for human rabies post-exposure prophylaxis. Vaccine 28, 6847-6851.

FHDM, 2011. Evaluasi kegiatan penanggulangan rabies tahun 2010 dan kegiatan penanggulangan rabies tahun 2011 di Kabupaten Manggarai. Rapat Komite Pemberantasan Rabies FloresLembata dan Workshop pengendalian zoonosis, 3-5 Oktober 2011. Maumere, Flores.

Fishbein, D.B., Frontini, M.G., Dobbins, J.G., Collins, E.F., Huerta, G.Q., et al., 1992. Prevention of canine rabies in rural Mexico: An epidemiologic study of vaccination campaigns. Am. J. Trop. Med. Hyg. 47, 317-327.

Flores-Ibarra M, Estrella-Valenzuela G., 2004. Canine ecology and socioeconomic factors associated with dogs unvaccinated against rabies in a Mexican city across the US-Mexico border. Prev. Vet. Med. 62, 79-87.

GARC, 2013. GARC joins effort to control rabies in Indonesia. Available at: http://rabiesalliance.org/media/press/garc-joins-effort-to-control-rabies-in-indonesia (accessed on 15.04.14.).

GARC, 2015. Should dogs be removed as part of rabies vaccination campaign? Available at: http://caninerabiesblueprint.org/5-4-15-Should-dogs-be-removed-as (accessed on 11.01.15.).

Gsell, A.S., Knobel, D.L, Kazwala, R.R., Vounatsou, P., Zinsstag, J., 2012. Domestic dog demographic structure and dynamics relevant to rabies control planning in urban areas in Africa: The case of Iringa, Tanzania. BMC Vet. Res. 8, 1-10. 
Hampson, K., Dushoff, J., Cleaveland, S., Haydon, D.T., Kaare, M., et al., 2009. Transmission dynamics and prospects for the elimination of canine rabies. PLoS Biol. 7, 462 - 471.

HDENT, 2012. Roadmap program pengendalian rabies pada hewan penular rabies dalam rangka provinsi Nusa Tenggara Timur bebas rabies. Workshop sehari dalam rangka peringatan rabies sedunia, 8 Oktober 2012. Maumere, Flores.

Hutabarat T, Geong M, Newsome A, Ruben A, Cutter S., 2003. Rabies and dog ecology in Flores. Urban Animal Management Conference Proceedings. ACIAR. Australia.

Jackson AC, 2013. Rabies: Scientific basis of the disease and its management; Jackson AC. (Ed.). Academic Press. San Diego, United States.

Kaare, M., Lembo, T., Hampson, K., Ernest, E., Estes, A., et al.,2009. Rabies contro 1 in rural Africa: evaluating strategies for effective domestic dog vaccination. Vaccine 27, 152 - 160.

Katz, M.H., 2003. Multivariable Analysis: A Primer for Readers of Medical Research. Ann. Intern. Med. 138, 644-650.

Kayali, U., Mindekem, R., Yemadji, N., Vounatsou, P., Kaninga, Y., et al., 2003. Coverage of pilot parenteral vaccination campaign against canine rabies in N'Djamena, Chad. Bull. World Health Organ. 81, 739-744.

Knobel, D.L., Cleaveland, S., Coleman, P.G., Fevre, E.M., Meltzer, M.I., et al., 2005. Re-evaluating the burden of rabies in Africa and Asia. Bull. World Health Organ. 83, 360-368.

Knobel, D.L., Lembo, T., Morters, M., Townsend, S.E., Cleaveland, S., et al., 2013. Dog Rabies and Its Control. Rabies: Elsevier Inc. pp. 591-615.

Kongkaew, W., Coleman, P., Pfeiffer, D.U., Antarasena, C., Thiptara, A., 2004. Vaccination coverage and epidemiological parameters of the owned-dog population in Thungsong District, Thailand. Prev. Vet. Med. 65, 105-115.

Kunda, J., Rudovic, K., Mfinanga, G.S., 2008. Knowledge of causes, clinical features and diagnosis of common zoonoses among medical practitioners in Tanzania. BMC Infect. Dis. 8,162.

Linscott, A.J., 2012. Rabies. Clin. Microbiol. Newsl. 34, 177-180.

Lunney, M., Fèvre, S.J.S., Stiles, E., Ly, S., San, S., et al., 2012. Knowledge, attitudes and practices of rabies prevention and dog bite injuries in urban and peri-urban provinces in Cambodia, 2009. Int. Health 4, 4-9.

Matter, H.C., Wandeler, A.I., Neuenschwander, B.E., Harischandra, L.P.A., Meslin, F.X., 2000. Study of the dog population and the rabies control activities in the Mirigama area of Sri Lanka. Acta Trop. 75, 95-108.

Mitmoonpitak, C., Wilde, H., Tepsumetanon, W., 1997. Current Status of Animal Rabies in Thailand. J. Vet. Med. Sci. 59, 457-460.

Morters, M.K., McKinley, T.J., Restif, O., Conlan, A.J.K., Cleaveland, S., et al., 2014. The demography of free-roaming dog populations and applications to disease and population control. J. Appl. Ecol. 51, 1096-1106.

Morters, M.K., Restif, O., Hampson, K., Cleaveland, S., Wood, J.L.N., et al., 2013. Evidence-based control of canine rabies: a critical review of population density reduction. J. Anim. Ecol. 82, 614.

Noordhuizen, J.P.T.M, Frankena, K., Thrusfield, M.V., Graat, E.A.M., 2001. Application of quantitative methods in veterinary epidemiology. Wageningen Press. The Netherlands. 
PHDENT, 2012. Roadmap program pengendalian rabies pada manusia menuju provinsi Nusa Tenggara Timur bebas rabies 2017. Workshop sehari dalam rangka peringatan rabies sedunia, 8 Oktober 2012. Maumere, Flores.

Putra, A.A.G., Hampson, K., Girardi, J., Hiby, E., Knobel, D., et al., 2013. Response to a rabies epidemic, Bali, Indonesia, 2008-2011. Emerg. Infect. Dis. 19, 648-651.

Ramos M, Bravo L., 2004. Knowledge, attitudes and practices of the community regarding animal bites and rabies. PIDSP Journal 8, 24-32.

Robinson LE, Miranda ME, Miranda NL, Childs JE., 1996. Evaluation of a canine rabies vaccination campaign and characterization of owned-dog populations in the Philippines. Southeast Asian J. Trop. Med. Public Health 27, 250-256.

Sharma M., 2005. Knowledge and attitude of dog owner's towards the dog anti-rabies vaccination. J. Nepal Health Res. Counc. 1, 11-15.

Siko MM., 2011. Dog population dynamic and its impact to rabies vaccination coverage in rural and urban Sikka regency, East Nusa Tenggara province Period October 2009 - April 2010. Graduate School, Veterinary Faculty, Gadjah Mada university Yogyakarta.

Suzuki K, Pereira JAC, Frías LA, López R, Mutinelli LE, et al., 2008. Rabies-vaccination Coverage and Profiles of the Owned-dog Population in Santa Cruz de la Sierra, Bolivia. Zoonoses Public Health 55, 177-183.

Tenzin, Dhand NK, Rai BD, Changlo, Tenzin S, et al., 2012. Community-based study on knowledge, attitudes and perception of rabies in Gelephu, south-central Bhutan. Int. Health 4, 210-219.

Thomas D, Delgado A, Louison B, Lefrancois T, Shaw J., 2013. Examining dog owners' beliefs regarding rabies vaccination during government-funded vaccine clinics in Grenada to improve vaccine coverage rates. Prev. Vet. Med. 110, 563-569.

Totton, S.C, Wandeler, A.I, Zinsstag, J., Bauch, C.T., Ribblw, C.S., et al., 2010. Stray dog population demographics in Jodhpur, India following a population control / rabies vaccination program. Prev. Vet. Med. 97, 51-57.

Vallat, B., 2011. The OIE's commitment to fight rabies worldwide. Rabies: a priority for humans and animals. OIE Bull 3, 1-2.

Wakkee, M., Hollestein, L.M., Tamar, N., 2014. Multivariable Analysis. J. Invest. Dermat. 134, e20.

Ward, M.P., 2014. Rabies in the Dutch East Indies a century ago - A spatio-temporal case study in disease emergence. Prev. Vet. Med. 114, 11-20.

Wera, E, 2001. Epidemiologi dan usaha pemberantasan penyakit Rabies di Kabupaten Flores Timur, Provinsi Nusa Tenggara Timur periode November 1997- April 2000. Skripsi. Fakultas Kedokteran Hewan, Institut Pertanian Bogor. Available at: http://repositoryipbacid/bitstream/handle/123456789/21527/B01ewepdf;jsessionid=3C23983E 3FB5A771643967D5C4340EE2? sequence $=2$ (accessed on 6.06.14.).

Wera, E., Velthuis, A.G., Geong, M., Hogeveen, H., 2013. Costs of Rabies Control: An Economic Calculation Method Applied to Flores Island. PLoS ONE 8, e83654.

WHO, 2002. Strategies for the control and Elimination of rabies in Asia. Report of a WHO International Consultation, Department of Communicable Diseases Surveillance and Response Geneva, Switzerland. 
WHO, 2005. WHO expert Consultation on Rabies, first report. In: WHO Technical Report Series 931. World Health Organisation, Geneva, Switzerland.

WHO, 2012. Strategic framework for elimination human rabies transmitted by dogs in South-East Asia Region. World Health Organisation Regional Office for South-East Asia, India.

WHO, 2013. WHO Expert Consultation on Rabies. Second report. WHO technical report series 982. World Health Organisation, Geneva, Switzerland.

Wikipedia, 2013. Flores. Available at: http://en.wikipedia.org/wiki/Flores (accessed on 20.06.13.).

Windiyaningsih, C., Wilde, H., Meslin, F.X., Suroso, T., Widarso, H.S., 2004. The rabies epidemic on Flores Island, Indonesia, 1998-2003. J. Med. Assoc. Thai. 87, 1389-1393.

WSAVA, 2015. OIE-WSAVA Joint Statement on Control of Canine Rabies. Available at: http://www.wsava.org/sites/default/files/OIE-

WSAVA\%20Joint\%20Statement\%20November\%202013_final-1.pdf (accessed on 11.01.15.).

Zingg, A., Siegrist, M., 2012. Measuring people's knowledge about vaccination: Developing a onedimensional scale. Vaccine 30, 3771-3777. 
Chapter 3 
Chapter 4

Intention of dog owners to participate in rabies control measures in Flores Island, Indonesia

Ewaldus Wera, Monique C.M. Mourits, Henk Hogeveen

Published in Preventive Veterinary Medicine

doi:10.1016/j.prevetmed.2016.01.029 


\section{Abstract}

The success of a rabies control strategy depends on the commitment and collaboration of dog owners. In this study the theory of planned behaviour (TPB) was used to identify the factors, which are associated with the intention of dog owners to participate in rabies control measures in the Manggarai and Sikka regencies of Flores Island, Indonesia. Questionnaires were administered to 450 dog owners from 44 randomly selected villages in the two regencies. Ninety-six percent of the dog owners intended to participate in a free-of-charge vaccination campaign. The intention decreased to $24 \%$ when dog owners were asked to pay a vaccination fee equal to the market price of the vaccine (Rp 18.000 per dose=US\$2). Approximately $81 \%$ of the dog owners intended to keep their dogs inside their house or to leash them day and night during a period of at least three months in case of an incidence of rabies in the dog population within their village. Only $40 \%$ intended to cull their dogs in case of a rabies incident within their village. Using multivariable logistic regression analysis, the attitude item 'vaccinating dogs reduces rabies cases in humans', and the perceived behavioural control items 'availability of time' and 'ability to confine dogs' were shown to be significantly associated with the intention to participate in a free-of-charge vaccination campaign. The attitude item 'culling dogs reduces rabies cases in humans' was significantly associated with the intention to participate in a culling measure. The attitude item 'leashing of dogs reduces human rabies cases' and perceived behavioural controls 'availability of time' and 'money to buy a leash' were associated with the intention to leash dogs during a rabies outbreak. As the attitude variables were often significantly associated with intention to participate in a rabies control measure, an educational rabies campaign focusing on the benefit of rabies control measures is expected to increase the intention of dog owners to participate in future rabies control measures. The significant association between perceived behavioural controls and intention to participate points to other relevant policy interventions. Providing dog owners with a technique or skill to confine their dogs and creating a subsidy program for the vaccine and leash costs, by involving non-governmental organisations or charitable organisations, may be useful policy interventions. Moreover appropriate time management, such as implementing vaccination campaigns during the weekend, could increase the intention to participate in vaccination campaigns, by relaxing the constraints on the availability of dog owners' time. 


\subsection{Introduction}

Rabies is a viral disease that can cause encephalomyelitis in both animals and humans (Wunner, 2007). Rabies has a case fatality rate of almost $100 \%$, the highest of any infectious human disease (WHO, 2013). Rabies is recently estimated as causing 59,000 human death cases worldwide (Hampson et al., 2015). Most of these cases occur in Asian and African countries (Hampson et al., 2015). In these countries, domestic dogs are the main transmitters of the rabies virus to humans (Nicholson, 1990; Knobel et al., 2013). Rabies control measures targeted at the dog population could, therefore, be effective in preventing rabies infections in both dogs and humans. Control measures targeted at the dog population have been recommended by the World Health Organization (WHO) (WHO, 2013) and World Organisation for Animal Health (OIE) (Vallat, 2011). These measures include mass vaccination of dogs, euthanasia of infectious dogs and dog management actions, such as birth control and leashing or keeping dogs inside the house area.

Rabies has been endemic in Flores Island since its introduction in 1997. There is no integrated island-wide vaccination campaign (e.g. the timing of the mass vaccination campaigns is not uniform throughout Flores) due to a lack of financial resources between regencies. Each of the 8 regencies within Flores Island has implemented its own policy for eliminating rabies. For instance, East Flores, Sikka and Ngada regencies implemented mass culling of dogs during previous outbreaks of rabies, whereas Ende and Manggarai regencies focused on mass vaccination of dogs.

The mass culling measures on Flores Island resulted in the death of over 280,000 dogs between 1997 and October 2000 (Bingham, 2001). Many of these dogs were not infected. As a result of increased public concern about the killing of healthy dogs, mass culling has been banned as a measure in current control. Since 2001, all regencies in Flores Island have implemented a rabies control strategy, which consists of annual mass vaccination of dogs, culling of roaming dogs that are aggressive and tend to bite people, quarantine of dogs imported from outside the island, investigation of dog bites, diagnostic testing of suspected rabid dogs, tracing of human contacts with rabid dogs, and post-exposure treatment (a series of vaccine injections after exposure) for humans bitten by suspected rabid dogs. These control measures are in line with the national recommendations for rabies control in Indonesia (IAM, 1997; IHM, 2000).

The success of a rabies control strategy depends on the commitment and collaboration of the stakeholders involved (Lapiz et al., 2012; Putra et al., 2013). Stakeholders include animal health and public health authorities, non-governmental organisations and the local community, especially dog owners. In Flores Island, efforts to increase the uptake of the annual dog vaccination campaign have been made by providing vaccination free-of-charge and by applying a 'house-to-house' vaccination approach. However, the realised vaccination 
coverage (53\%) is still lower than the $70 \%$, which is recommended by the WHO (Wera et al., 2013). Studies conducted in countries where rabies is endemic have identified dog's age (i.e. dogs younger than 12 months are less likely to be vaccinated) and employment status of dog owners (i.e. dog owners employed are more likely to vaccinate their dogs) as significant factors influencing vaccination coverage (Flores-Ibarra and Estrella-Valenzuela, 2004; Kongkaew et al., 2004; Suzuki et al., 2008; Davlin et al., 2012). Studies in endemic areas have shown that lack of information about the vaccination schedule, lack of financial resources to pay the vaccination fee and difficulty to catch dogs are the most important reasons for dog owners not to join a vaccination campaign (Robinson et al., 1996; Matter et al., 2000; Kayali et al., 2003; Durr et al., 2009; Bardosh et al., 2014; Wera et al., 2015). However, all of these studies were primarily aimed at assessing the socio-demographic risk factors related to the uptake of rabies vaccination by dog owners. The decision to adopt a rabies control measure cannot be explained by socio-demographic factors alone, as sociopsychological factors also influence the uptake of a certain behaviour (Ajzen, 1991). As the intention 'to adopt' is the best predictor of actual behaviour (Ajzen, 1991), more insight is needed in the psychological factors of dog owners that influence the intention to participate in rabies control measures.

The theory of planned behaviour (TPB) (Ajzen, 1991) is a framework that is widely used to obtain insight in the psychological factors that influence intentions. There are several applications of the TPB in veterinary science. For example, Bruijnis et al. (2013) used the TPB as a theoretical framework to explain dairy farmers' intention to improve dairy cow foot health; Delgado et al. (2012) applied the TPB to study cattle producers' intention to participate in foot-and-mouth disease detection and control; and Lind et al. (2012) used it to study farmers' intention regarding the treatment of mild clinical mastitis. To our knowledge, only Thomas et al. (2013) have used the TPB as a theoretical framework to explore the socialpsychological factors influencing the intention of dog owners with regard to rabies control. This study showed that almost all dog owners in Grenada, West Indies, had the intention to vaccinate their dogs as they believed that vaccination was an effective way to protect their dogs from rabies. However, this study only considered the dog owners' intention to participate in a free-of-charge vaccination campaign. For developing countries with limited financial resources, insight is also needed in other rabies control measures, such as charged vaccination, culling of dogs in infected villages and confining dogs during the outbreak. These insights are needed to support the development of future policies to reduce human rabies cases.

The first objective of this study was to use the TPB as a theoretical framework to determine the intention of dog owners in Flores Island to participate in different rabies control measures and identify their attitudes, subjective norms and perceived behavioural controls in relation to 
these measures. The second objective was to estimate the influence of these psychological factors on the intention of dog owners to participate in different rabies control measures.

\subsection{Materials and Methods}

\subsubsection{Theoretical framework}

In this study, the evaluation of psychological factors influencing the intention to participate in rabies control measures was based on the TPB as proposed by Ajzen (1991). According to the TPB, the intention to perform a behaviour is determined by three conceptually independent psychological factors: (1) attitude, (2) subjective norm, and (3) perceived behavioural control (Ajzen, 1991) (Figure 4.1).

In our study, attitude is defined as the perception of dog owners about three aspects: the risk of rabies, the possibility of transmission from dogs to humans, and the benefit of control measures in reducing human rabies cases. A positive attitude indicates for instance that dog owners believe that a particular control measure is beneficial in reducing human rabies cases; this positive attitude may be a reason to participate in the rabies control measure.

Subjective norm reflects the perception of dog owners about social pressure or social opinion to adopt a certain rabies control measure. The opinions of family members, neighbours, animal and public health authorities, and local community could influence the decision of the dog owner to participate in a certain rabies control measure.

Perceived behavioural control concerns the dog owners' beliefs about their resources and ability to perform a certain rabies control measure, such as time, money, and ability to catch and restrain dogs. The beliefs of dog owners about their resources could influence their intention to participate in a rabies control measure. 


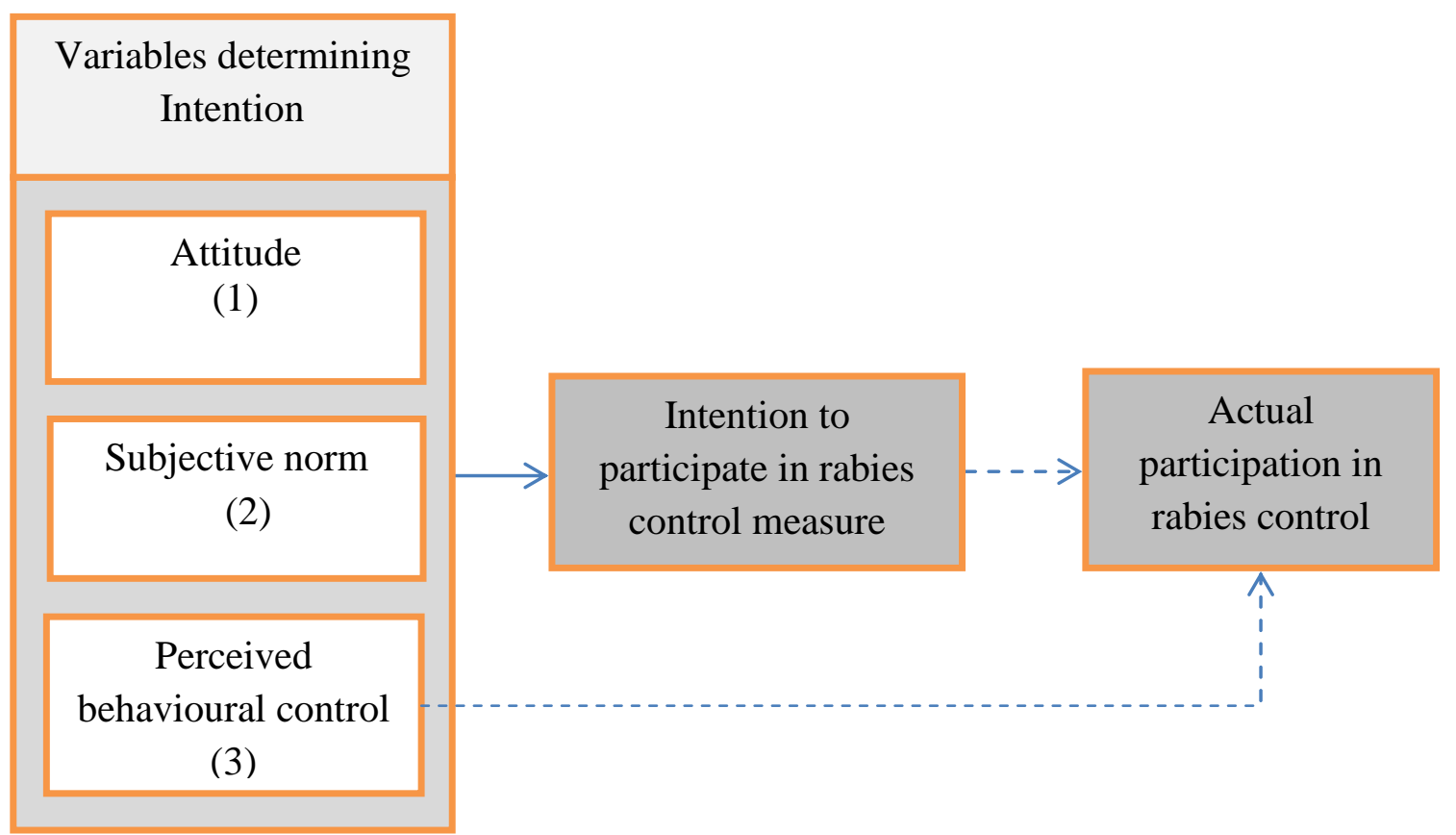

Figure 4.1. Framework for the intention to participate in rabies control measures (adapted from Ajzen, 1991). Dotted line indicates factors, which are not examined in this article.

\subsubsection{Rabies control measures}

In the present study the intention of dog owners is explored towards the following control measures: 1) free-of-charge vaccination, 2) charged vaccination, 3) culling of dogs in case of an incidence of rabies in the dog population within the village (termed 'culling' in this paper), and 4) permanently leashing of dogs or keeping them inside for at least three months in case of an incidence of rabies in the dog population within the village (termed 'leashing' in this paper).

The 'free-of-charge vaccination' measure represents the main rabies control measure as currently applied in Flores Island, in which the direct costs related to the vaccination campaigns are incurred by the government. The vaccination campaigns have been delivered using a 'house-to-house' approach, undertaken by the local animal health authorities. Most dogs in Flores are unrestricted and roam freely within the village. As local authorities are not equipped to handle roaming dogs, dog owners need to catch and restrain their dogs themselves to have them vaccinated. The 'charged vaccination' measure is based on the assumption that local governments might not always have enough budget to subsidise the vaccine costs. For this measure it is assumed that the costs of vaccine application are paid by the government but that the vaccine cost (Rp 18.000 per dose; 1US\$=Rp 9.651, the currency rate when the study was conducted, 1 February 2013) is paid by the dog owners. The 'culling' 
and 'leashing' control measures are based on past experience (Wera et al., 2013), in which local governments carried out mass culling of roaming dogs in infected villages or asked dog owners to leash their dogs to prevent rabies cases in humans.

\subsubsection{Questionnaire design}

Based on the TPB framework a questionnaire was designed using the format of statements to elicit the level of intention for each control measure and to measure the psychological factors explaining this intention, i.e. attitude, subjective norm, and perceived behavioural control (Table 4.1). Respondents were asked to state their response to each statement using a fivepoint Likert scale ( $1=$ strongly disagree, $2=$ disagree, $3=$ neutral, $4=$ agree, $5=$ strongly agree $)$.

The level of intention to participate in a control measure was assessed by one statement (variables I1-I4 in Table 4.1) posed for each of the defined control measures.

Psychological variables are either elicited directly or derived from dog owners' beliefs, which underlie the factors (Läpple and Kelley, 2013). In this study we used direct measures, similar to Thomas et al. (2013). Each of the three conceptually independent psychological model constructs was measured using a specific set of rating scale statements. Attitude was measured by three statements (variables A1-A3 in Table 4.1) describing an outcome for human rabies cases related to the three control measures: vaccination, culling and leashing. No differentiation was made between free-of-charge and charged vaccination for this factor. For example, the attitude towards vaccination was measured by the statement 'vaccination of dogs reduces rabies cases in humans'. The attitude towards culling of dogs was assessed by the statement 'culling of dogs reduces rabies cases in humans'. In addition to the three control-specific attitude statements, additional statements (variables A4-A6 in Table 4.1) were included to capture the general attitudes towards the risk of rabies to human health, dogs as main transmitter of rabies, and current rabies control, following the approach of Tenzin et al. (2012) and Thomas et al. (2013).

The subjective norm was assessed with a statement about the importance of the opinion of eight groups of people (named as 'important others') in deciding to participate in rabies control measures (variables SN1-SN8 in Table 4.1). The following groups of people were seen as 'important others' in this study: family living inside the home, neighbours, family living outside the home, the veterinarian, local human medical caretakers (e.g. nurses, physicians), government, village leaders and religious leaders.

The perceived behavioural control was measured by six statements related to the availability of time, money, and the ability to handle dogs (variables PBC1-PBC6 in Table 4.1). The availability of time (variable PBC1 in Table 4.1) was treated as an independent variable influencing the intention to vaccinate (free-of-charge or charged) (variables I1-I2 in Table 4.1). 


\section{Table 4.1}

Variables and corresponding statements for the components of the Theory of Planned Behaviour (TPB).

\begin{tabular}{ll}
\hline TPB Variables & Statement items $^{\mathrm{a}}$ \\
\hline Intention (I): & This year, I will vaccinate my dog if the government provides the \\
& vaccine free of charge \\
& This year, I will vaccinate my dog if the government provides the \\
I2 & vaccine at market price (Rp 18,000 per dose) \\
& I will cull my dog without compensation if there is a rabies case in \\
I3 & the dog population in my village \\
& I will keep my dogs inside my house or leash the dogs for at least \\
& three months if there is a rabies case in the dog population in my \\
& village
\end{tabular}

Attitude (A):

$\mathrm{A} 1^{\mathrm{c}}$

A2

A3

A4

A5

A6
Vaccination of dogs reduces rabies cases in humans

Culling of dogs reduces rabies cases in humans

Keeping dogs inside the home or leashing dogs during the outbreak reduces rabies cases in humans

Rabies is a threat for human health, therefore it should be controlled Rabies is transmitted by dogs, therefore it should be controlled I support the current rabies control measures ${ }^{\mathrm{d}}$ to reduce rabies cases in humans

\section{Subjective norm $(\mathbf{S N})^{\mathrm{e}}$ :}

The opinion of ... influence(s) my decision to participate in the rabies control measures

SN1

Family living in the same house

SN2

Neighbours

SN3

Family living outside the house

SN4

SN5

SN6

Veterinarian

SN7

Head of village

SN8

Leader of religion

Perceived behavioural control (PBC):

$\mathrm{PBC}^{\mathrm{c}}$

$\mathrm{PBC} 2^{\mathrm{e}}$

$\mathrm{PBC} 3^{\mathrm{f}}$
I do have time to vaccinate my dog

I do have the ability/skill to confine and tie up my dog

I do have time to leash my dog 


\begin{tabular}{ll}
\hline PBC4 & I do have money to pay the vaccination fee \\
PBC5 & I do have money to buy a new dog \\
PBC6 & I do have money to buy a leash
\end{tabular}

\footnotetext{
${ }^{\mathrm{a}}$ The items were measured using a five-point Likert scale ( $1=$ strongly disagree to $5=$ strongly agree).

b "Vaccine free of charge" means no charge at all.

${ }^{\mathrm{c}}$ Treated as independent variables for I1 and I2.

${ }^{\mathrm{d}}$ Annual dog vaccination campaigns and post exposure treatment after being bitten by a suspected rabid dog.

${ }^{\mathrm{e}}$ Treated as independent variables for I1, I2, I3 and I4.

${ }^{\mathrm{f}}$ Treated as independent variables for I1, I2 and I4.

A4, A5 and A6 are not part of the original TPB and are treated as independent variables for I1, I2, I3, and I4.
}

The availability of money was related to the intention of charged vaccination, culling, and leashing (variables I2, I3, I4 in Table 4.1). The ability to handle dogs was treated as an independent variable influencing the intention to participate in any of the evaluated measures (variables I1-I4 in Table 4.1).

Socio-demographic variables of dog owners such as gender, age, education status, parent status and occupation status were documented using closed ended questions (Table 4.2).

The questionnaire was developed in English and translated to Bahasa Indonesia and then pretested by a focus group and five pilot interviews with dog owners (Wera et al., 2015). The final questionnaire was revised based on the findings of the pre-test to improve clarity and interpretation.

\subsubsection{Sampling design}

This study was conducted in Manggarai and Sikka regencies. These regencies were selected because of the high incidence of rabies cases in humans (PHDENT, 2012). As the same questionnaire was used to study the proportion of dog owners vaccinating their dogs (see Wera et al., 2015) a target sample size of 385 was calculated based on the assumption there is an infinite dog owners population and the conservative assumption that $50 \%$ of dog owners vaccinated at least one of their dogs, with a $5 \%$ error in estimate and a $95 \%$ confidence interval. The sample size was increased to $450 \mathrm{dog}$ owners to account for incomplete interviews, with 300 dog owners sampled in Sikka and 150 in Manggarai. More dog owners were selected from Sikka than from Manggarai reflecting the difference in the number of villages per regency that was involved in the 2012 vaccination campaign; viz. 351 villages in Sikka and 162 villages in Manggarai. As there are no officially registered data available on the number of villages and the number of households owning dogs, a random order of villages was obtained for each regency by randomly ranking the villages that were involved in the 2012 vaccination campaign. Subsequently, villages were visited in the order of this ranking until the predefined sample size was reached. A total of 44 villages were visited, with 27 villages in Sikka and 17 villages in Manggarai. The number of dog owners to be interviewed was predefined for each village and proportional to the number of dog owners involved in the 
rabies vaccination campaign of 2012. On average, 10 (7-15) dog owners were interviewed per village. Due to the lack of a proper dog registration system, the first dog owners visited within a village were chosen randomly by spinning a pen at the center of the village. The closest neighbour with dogs was subsequently chosen as the next participant. The questionnaire interviews were conducted from January to March 2013 by two survey teams (one team per regency) assisted by local people with knowledge of the local languages (Sikka, Lio, and Manggarai) as well as Bahasa Indonesia. A total of 463 households were visited to obtain the predefined sample size of 450 responses. Of these households, five dog owners (in Sikka) refused to be interviewed and eight dog owners (three in Sikka and five in Manggarai) were not at home during the time of the interviews. The sampling design has been described in more detail in Wera et al. (2015).

\subsubsection{Statistical analysis}

A descriptive analysis was performed on the demographic data, the intention to participate in the four control measures and the individual items measuring the three conceptually independent TPB variables (attitude, subjective norm, and perceived behavioural control). Cronbach's alpha was used to check the internal consistency among the items which were used to measure the psychological variables. The TPB variables were considered to have an internal consistency among its items if Cronbach's alpha was $>0.70$ (Field, 2013). In case of internal consistency, the scores of the underlying items were averaged to obtain a single direct measure of the corresponding variable (Cammock et al., 2009). This aggregated variable or latent variable was used in subsequent regression analyses. For variables with inconsistent item scales (Cronbach's alpha $<0.70$ ), the individual items underlying the TPB variable were analysed separately. Data of all the latent variables and items were skewed and therefore a logistic regression analysis was used to assess the factors that were associated with intention.

For the logistic regression analyses, the responses 'agree' and 'strongly agree' of the fivepoint Likert scale were considered to indicate a high level of intention, and the responses 'neutral', 'disagree' and 'strongly disagree' were considered to indicate a low level of intention (Lau et al., 2010). Similarly, for the three latent variables and/or items that were analysed as predictors of intention, scores less than four were classified as 'negative or low attitude/subjective norm/perceived behavioural control', whereas scores four and five were classified as 'positive or high attitude/subjective norm/perceived behavioural control' (Lau et al., 2010).

As a first step in the logistic regression analyses, an univariable analysis was carried out to examine the association of each independent variable with the intention variable. Independent variables with a p-value less than 0.25 were selected for inclusion in the multivariable analysis (Noordhuizen et al., 2001). Prior to conducting the multivariable analyses, Spearman rank correlation coefficients $(\rho)$ were calculated to identify the presence of multicollinearity 
between the independent variables. No high levels of multicollinearity were observed between independent variables; all the correlation coefficients $(\rho)$ were less than 0.8 (Field, 2013). Therefore all the independent variables were retained for the multivariable analyses.

Besides the multivariable logistic regression on the association of intention as dependent variable and the psychological factors as predictors, a subsequent multivariable logistic regression was performed to study the effect of socio-demographic characteristics on the TPB concepts by using the psychological variables that were found significantly associated with intentions as dependent variables and the evaluated socio-demographic variables (Table 4.2) as predictors. For this analysis the same explorative univariable analysis was performed as described above.

For both multivariable logistic regression analyses, a backward stepwise procedure was applied in which variables with a p-value of $>0.05$ were excluded one-by-one in each step. The Hosmer-Lemeshow goodness-of-fit test was performed to determine the suitability of the final models with the data. The final models were considered a good fit of the data if the $\mathrm{p}$ value of the test was greater than 0.05 (Field, 2013). The standardised residuals, leverage values and delta-betas were checked; there was no evidence of unusual influence of any observation on the model predictions (Field, 2013). The accuracy of the model prediction of socio-demographic characteristics on the psychological variables was evaluated by checking the presence of potential confounding and interaction between independent variables. An independent variable act as confounder for other independent variables if the odd ratio of other variables changes by $30 \%$ or higher when the confounder was removed from the model (Dohoo et al, 2003). The interaction was significant if the p-value of interaction between independent variables was less than 0.05 (Dohoo et al, 2003). We did not consider the present of any potential interactions and potential confounding variables for models predicting intention as it was based on the TPB. All statistical analyses were performed using SPSS version 19.

\subsection{Results}

\subsubsection{Respondent characteristics}

In total, 450 dog owners in Sikka and Manggarai regencies were interviewed about their intentions to participate in rabies control measures and their relevant attitudes, subjective norms and perceived behavioural controls. Table 4.2 provides a general overview of the respondents' socio-demographic characteristics (see also Wera et al., 2015). The median number of humans (children included) and dogs (puppies included) in each household interviewed was 5 humans (mean 5.3; range: 1-11) and 2 dogs (mean 2.2; range: 1-12). The majority of dog owners $(70 \%)$ indicated that they kept dogs either to guard their house/property or to chase away wild animals that destroy their crops. 


\section{Table 4.2}

Socio-demographic characteristics of dog owners surveyed in Flores, Indonesia $(n=450)$.

\section{Frequency (n)}

Percentage $(\%)$

Gender:

Female

Male

Age:

$\geq 18-45$

$>45$

Highest education level:

None

Elementary school

Junior high school

Senior high school

University

Having children:

Yes

No

Occupation:

Farmer $^{\mathrm{a}}$

Public service

Driver

Others $^{\mathrm{b}}$

Monthly income of dog owners (in Rupiah $\left.(\mathrm{Rp})^{\mathrm{c}}\right)^{\mathrm{d}}$ :

$\begin{array}{lrr}<500.000 & 237 & 52.7 \\ 500.000-1.000 .000 & 144 & 32.0 \\ >1.000 .000 & 65 & 14.4\end{array}$

Religion:

Islam

Protestant

Catholic

${ }^{a}$ Farmer is defined as a person who grows crops such as rice, coconut, coffee, etc.

b Other occupations like driver, carpenter, entrepreneur.

${ }^{c}$ The currency rate when the study was conducted, 1 February $2013: 1$ US $\$=R p 9.651$.

${ }^{\mathrm{d}}$ The data for monthly income of dog owners had 4 missing values. 


\subsubsection{Intention to participate in the rabies control measures}

The intention of dog owners to participate in the rabies control measures differed across the four control measures (Table 4.3). Ninety-six percent of dog owners had a positive intention (response 'agree' or 'strongly agree') to participate in the free-of-charge vaccination campaign. This positive intention decreased to around $24 \%$ when dog owners would have to pay a vaccination fee equal to the market price of the vaccine. Approximately $81 \%$ of $\mathrm{dog}$ owners stated a positive intention to leash their dogs in case of a rabies outbreak within their village. Only $40 \%$ intended to cull their dogs in case of a rabies outbreak within their village.

\section{Table 4.3}

Intention of dog owners surveyed in Flores to participate in rabies control measures $(n=450)$.

\begin{tabular}{|c|c|c|c|c|c|c|}
\hline \multirow[b]{2}{*}{ Statements } & 1 & 2 & 3 & 4 & 5 & \multirow[b]{2}{*}{$\begin{array}{l}\text { Positive } \\
\text { responses } \\
(\%)^{\mathrm{a}}\end{array}$} \\
\hline & $\begin{array}{l}\text { Strongly } \\
\text { disagree } \\
(\%)\end{array}$ & $\begin{array}{l}\text { Disagree } \\
(\%)\end{array}$ & $\begin{array}{l}\text { Neutral } \\
(\%)\end{array}$ & $\begin{array}{l}\text { Agree } \\
(\%)\end{array}$ & $\begin{array}{l}\text { Strongly } \\
\text { agree } \\
(\%)\end{array}$ & \\
\hline $\begin{array}{l}\text { I1. This year, I will vaccinate my dog if the } \\
\text { government provides the vaccine free of } \\
\text { charge }\end{array}$ & 0.9 & 1.3 & 1.8 & 40.0 & 56.0 & 96.0 \\
\hline $\begin{array}{l}\text { I2. This year, I will vaccinate my dog if the } \\
\text { government provides the vaccine at } \\
\text { market price (Rp } 18,000 \text { per dose) }\end{array}$ & 40.4 & 28.2 & 7.1 & 20.7 & 3.6 & 24.3 \\
\hline $\begin{array}{l}\text { I3. I will cull my dog without compensation } \\
\text { if there is a rabies case in the dog } \\
\text { population in my village }\end{array}$ & 30.0 & 25.8 & 4.0 & 32.2 & 8.0 & 40.2 \\
\hline $\begin{array}{l}\text { I4. I will keep my dogs inside my house or } \\
\text { leash the dogs for at least three months if } \\
\text { there is a rabies case in the dog population } \\
\text { in my village }\end{array}$ & 4.4 & 11.6 & 3.3 & 53.3 & 27.3 & 80.6 \\
\hline
\end{tabular}

\subsubsection{Physiological variables in relation to rabies control}

\subsubsection{Attitude}

In general, dog owners had a positive attitude towards the rabies control measures related to vaccination and leashing but a negative attitude towards culling of dogs (Table 4.4). The majority of dog owners agreed or strongly agreed that vaccination of dogs (97\%) and leashing of dogs $(82 \%)$ could reduce the number of rabies cases in humans. In contrast, approximately $50 \%$ of the dog owners disagreed or strongly disagreed with the statement that culling of dogs 
could reduce the number of rabies cases in humans. Almost all dog owners agreed that rabies represents a threat to human health (95\%), that the virus is transmitted by dogs $(92 \%)$ and that the disease, therefore, should be controlled in dogs. In addition, almost all dog owners (98\%) indicated that they support the current rabies control measures to reduce rabies cases in humans.

\subsubsection{Subjective norm}

Overall, dog owners indicated that the opinions of family living in the same house, neighbours, family living outside the house, the veterinarian, head of village, leader of religion, leader of government and local human medical caretakers (e.g. nurses, physicians) were of high importance in influencing their decision to participate in rabies control measures (Table 4.4). The majority of dog owners perceived the opinion of the veterinarian (67\%) and local human medical caretakers $(48 \%)$ as very important (Table 4.4$)$.

\subsubsection{Perceived behavioural control}

The questionnaire revealed that although the majority of dog owners (96\%) believed that they have time to vaccinate their dogs, they do not have the money to pay for it (64\%) (Table 4.4). The majority of dog owners believed that they do have the ability/skill to handle/confine dogs $(90 \%)$ and money to buy a leash (84\%) (Table 4.4).

\subsubsection{Physiological factors associated with intention to participate in rabies control measures}

In the multivariable regression model, the latent variable for attitude, and the perceived behavioural control items time to vaccinate and ability to confine dogs were significantly associated with a positive intention to participate in the free-of-charge vaccination campaign (Table 4.5).

Dog owners who had a positive attitude towards rabies control measures were more likely to have a positive intention to participate in the vaccination campaign (OR 8.18; 95\%CI 2.6425.36) compared to dog owners who had a negative attitude towards rabies control measures. Dog owners who agreed or strongly agreed with the statement 'I do have time to vaccinate my dog' were more likely to have a positive intention to participate in the vaccination campaign (OR 7.10; 95\%CI 1.90-26.54) compared with dog owners who were neutral, disagreed or strongly disagreed with this statement. Furthermore, having the ability to confine dogs made a significant positive contribution to positive intention to participate in the vaccination campaign (OR 6.33; 95\%CI 1.94-20.61). For charged vaccination, money availability and time to leash dogs are significant barriers for dog owners (Table 4.6). The odds of having a positive intention to participate in the charged vaccination campaign were significantly higher for those dog owners who agreed or strongly agreed with the statements 'I do have money to 
pay vaccination fee' (OR 15.45; 95\%CI 9.10-26.21) and 'I do have time to leash my dogs' (OR 2.48; 95\%CI 1.13-5.13) compared with dog owners who were neutral, disagreed or strongly disagreed with these statements. The perception of dog owners about the benefit of culling as a measure to reduce rabies cases in humans was significantly associated with the intention to participate in the culling measure (Table 4.7). Dog owners who agreed or strongly agreed with the attitude statement 'Culling of dogs reduces rabies cases in humans' were more likely to participate in the culling measure (OR 3.24; 95\%CI 2.18-4.83) compared to their counterparts. The ability to handle dogs and having money to buy a new dog were not significantly related to the intention to participate in the culling measure, but these factors were kept in the model as the corresponding p-values were close to 0.05 . Finally, the attitude item about leashing dogs reducing human rabies cases and perceived behavioural control items (having time and money to buy a leash) were significantly associated with the intention to leash dogs or to keep dogs inside the house for at least three months in case of an incidence of rabies in the dog population in the village (Table 4.8).

Dog owners who agreed or strongly agreed with the statement 'Keeping dogs inside the house or leashing dogs during the outbreak reduces rabies cases in humans' were more likely to have a positive intention to these measures (OR 2.21; 95\% CI 1.23-3.97) compared with dog owners who were neutral, disagreed or strongly disagreed with this statement. Similarly, dog owners who had a high perceived behavioural control were more likely to have a positive intention to leash or keep dogs inside the house (OR 5.94; 95\%CI 3.47-10.19) compared to their counterparts. 


\section{Table 4.4}

Attitude (A), Subjective norm (SN) and Perceived behavioural control (PBC) in relation to rabies control measures $(\mathrm{n}=450$ dog owners surveyed in Flores).

\begin{tabular}{|c|c|c|c|c|c|c|}
\hline \multirow[b]{2}{*}{ Attitude statements } & 1 & 2 & 3 & 4 & 5 & \multirow{2}{*}{$\begin{array}{l}\text { High } \\
\text { responses } \\
(\%)^{\mathrm{a}}\end{array}$} \\
\hline & $\begin{array}{l}\text { Strongly } \\
\text { disagree } \\
(\%)\end{array}$ & $\begin{array}{l}\text { Disagree } \\
(\%)\end{array}$ & $\begin{array}{l}\text { Neutral } \\
(\%)\end{array}$ & $\begin{array}{l}\text { Agree } \\
(\%)\end{array}$ & $\begin{array}{l}\text { Strongly } \\
\text { agree }(\%)\end{array}$ & \\
\hline $\begin{array}{l}\text { A1. Vaccination of dogs reduces rabies } \\
\text { cases in humans }\end{array}$ & 0.7 & 0.9 & 1.1 & 64.4 & 32.9 & 97.3 \\
\hline $\begin{array}{l}\text { A2. Culling of dogs reduces rabies cases in } \\
\text { humans }\end{array}$ & 24.7 & 24.7 & 4.9 & 33.1 & 12.7 & 45.8 \\
\hline $\begin{array}{l}\text { A3. Keeping dogs inside the home or } \\
\text { leashing dogs during the outbreak } \\
\text { reduces rabies cases in humans }\end{array}$ & 5.1 & 7.3 & 6.0 & 64.0 & 17.6 & 81.6 \\
\hline $\begin{array}{l}\text { A4. Rabies is a threat for human health, } \\
\text { therefore it should be controlled }\end{array}$ & 0.7 & 1.1 & 2.9 & 65.1 & 30.2 & 95.3 \\
\hline $\begin{array}{l}\text { A5. Rabies is transmitted by dogs, } \\
\text { therefore it should be controlled }\end{array}$ & 0.7 & 2.7 & 4.4 & 61.6 & 30.7 & 92.3 \\
\hline $\begin{array}{l}\text { A6. I support the current rabies control } \\
\text { measures }{ }^{b} \text { to reduce rabies cases in } \\
\text { humans }\end{array}$ & 0.2 & 0.9 & 0.9 & 64.7 & 33.3 & 98.0 \\
\hline $\begin{array}{l}\text { Subjective norm statements } \\
\text { The opinion of ... influence }(\text { s) my decision } \\
\text { to participate in the rabies control } \\
\text { measures }\end{array}$ & $\begin{array}{l}\text { Very un- } \\
\text { important } \\
\quad(\%)\end{array}$ & $\begin{array}{l}\text { Unim- } \\
\text { portant } \\
(\%)\end{array}$ & $\begin{array}{l}\text { Neutral } \\
(\%)\end{array}$ & $\begin{array}{l}\text { Im- } \\
\text { portant } \\
(\%)\end{array}$ & $\begin{array}{l}\text { Very } \\
\text { important } \\
(\%)\end{array}$ & $\begin{array}{l}\text { High } \\
\text { responses } \\
(\%)^{\mathrm{a}}\end{array}$ \\
\hline SN1. Family living in the same house & 0.0 & 0.2 & 2.4 & 57.3 & 40.0 & 97.3 \\
\hline SN2. Neighbours & 2.0 & 3.3 & 11.6 & 71.6 & 11.6 & 83.2 \\
\hline SN3. Family living outside the house & 1.6 & 9.8 & 17.1 & 60.4 & 11.1 & 71.5 \\
\hline SN4. Veterinarian & 0.0 & 0.9 & 2.7 & 29.3 & 67.1 & 96.4 \\
\hline SN5. Head of village & 1.1 & 3.1 & 18.9 & 60.9 & 16.0 & 76.9 \\
\hline SN6. Leader of religion & 0.4 & 0.2 & 2.4 & 69.6 & 27.3 & 96.9 \\
\hline SN7. Government & 0.4 & 1.3 & 4.7 & 67.1 & 26.4 & 93.5 \\
\hline $\begin{array}{l}\text { Perceived behavioural control } \\
\text { statements }\end{array}$ & $\begin{array}{l}\text { Strongly } \\
\text { disagree } \\
(\%)\end{array}$ & $\begin{array}{l}\text { Disagree } \\
(\%)\end{array}$ & $\begin{array}{l}\text { Neutral } \\
(\%)\end{array}$ & $\begin{array}{l}\text { Agree } \\
(\%)\end{array}$ & $\begin{array}{l}\text { Strongly } \\
\text { agree }(\%)\end{array}$ & $\begin{array}{l}\text { High } \\
\text { responses } \\
(\%)^{\mathrm{a}}\end{array}$ \\
\hline PBC1. I do have time to vaccinate my dog & 0.9 & 1.1 & 1.6 & 69.1 & 27.3 & 96.4 \\
\hline $\begin{array}{l}\text { PBC2. I do have the ability/skill to confine } \\
\text { and tie up my dog }\end{array}$ & 2.9 & 6.2 & 0.9 & 75.6 & 14.4 & 90.0 \\
\hline PBC3. I do have time to leash my dog & 5.1 & 7.1 & 2.9 & 72.9 & 12.0 & 84.9 \\
\hline $\begin{array}{l}\text { PBC4. I do have money to pay the } \\
\text { vaccination fee }\end{array}$ & 37.8 & 26.2 & 4.9 & 25.6 & 5.6 & 31.2 \\
\hline PBC5. I do have money to buy a new dog & 28.7 & 16.4 & 13.6 & 34.9 & 6.4 & 41.3 \\
\hline PBC6. I do have money to buy a leash & 8.0 & 6.2 & 2.2 & 74.4 & 9.1 & 83.5 \\
\hline
\end{tabular}

${ }^{a}$ Cumulative percentage of responses with scores 4 (agree/important) and 5 (strongly agree/very important) for each attitude item.

${ }^{\mathrm{b}}$ Annual dog vaccination campaigns and post exposure treatment after being bitten by a suspected rabid dog. 


\section{Table 4.5}

Determinants of positive intention to participate in the free-of-charge dog vaccination campaign ( $\mathrm{n}=450)$ ('This year, I will vaccinate my dog if the government provides the vaccine free of charge').

\begin{tabular}{|c|c|c|c|c|c|c|}
\hline \multirow[t]{2}{*}{ Variables } & \multicolumn{3}{|c|}{ Univariable Model } & \multicolumn{3}{|c|}{ Multivariable Model } \\
\hline & OR & $95 \% \mathrm{CI}$ & P-value & OR & $95 \% \mathrm{CI}$ & P-value \\
\hline \multicolumn{7}{|l|}{ I. Attitude $(\mathrm{A})^{\mathrm{a}}$} \\
\hline Low & 1.00 & & & 1.00 & & \\
\hline $\operatorname{High}^{\mathrm{b}}$ & 9.80 & $3.68-26.10$ & $<0.001$ & 8.18 & $2.64-25.36$ & $<0.001$ \\
\hline \multicolumn{7}{|l|}{ II. Subjective norm $(\mathrm{SN})^{\mathrm{c}}$} \\
\hline Low & 1.00 & & & & & \\
\hline $\operatorname{High}^{\mathrm{b}}$ & 2.07 & $0.76-5.68$ & 0.157 & & & \\
\hline \multicolumn{7}{|l|}{$\begin{array}{l}\text { III. Perceived behavioural control (PBC) }{ }^{\mathrm{d}} \\
\text { a. I do have time to vaccinate my dog } \\
(\mathrm{PBC} 1)\end{array}$} \\
\hline Strongly disagree/disagree/neutral & 1.00 & & & 1.00 & & \\
\hline \multicolumn{7}{|l|}{$\begin{array}{l}\text { b. I do have the ability/skill to confine } \\
\text { and tie up my dog (PBC2) }\end{array}$} \\
\hline Strongly disagree/disagree/neutral & 1.00 & & & 1.00 & & \\
\hline Agree/strongly agree & 6.59 & $2.42-18.01$ & $<0.001$ & 6.33 & $1.94-20.61$ & 0.002 \\
\hline \multicolumn{7}{|l|}{$\begin{array}{l}\text { c. I do have time to leash my dog } \\
\text { (PBC3) }\end{array}$} \\
\hline Strongly disagree/disagree/neutral & 1.00 & & & & & \\
\hline Agree/strongly agree & 3.87 & $1.45-10.37$ & 0.007 & & & \\
\hline
\end{tabular}

$\mathrm{OR}=$ Odds ratio; $\mathrm{CI}=$ Confidence interval.

a Average of 4 attitude items: (1) 'Vaccination of dogs reduces rabies cases in humans'; (2) 'Rabies is a threat for human health, therefore it should be controlled'; (3) 'Rabies is transmitted by dogs, therefore it should be controlled'; (4) 'I support the current rabies control measures to reduce rabies cases in humans'; Cronbach's alpha was 0.78.

${ }^{\mathrm{b}}$ Average of the items equal or higher than 4 .

${ }^{c}$ Average of 8 subjective norm items: 'The opinion of ... influence(s) my decision to participate in the rabies control measures: (1) Family living in the same house; (2) Neighbours; (3) Family living outside the house; (4) Veterinarian; (5) Head of village; (6) Leader of religion; (7) Government; (8) Local human medical caretakers (nurse, physicians)'; Cronbach's alpha was 0.74 .

d The Cronbach's alpha of average of 3 perceived behavioural control items was 0.48 .

$\mathrm{p}$-value shown in bold represents $\mathrm{p}<0.25$; these variables were used in the subsequent multivariable logistic regression analysis.

The Hosmer-Lemeshow goodness-of-fit test p-value: 0.42 . 


\section{Table 4.6}

Determinants of positive intention to participate in the charged dog vaccination campaign $(n=450)$ ('This year, I will vaccinate my dog if the government provides the vaccine at market price (Rp 18,000 per dose)').

\begin{tabular}{|c|c|c|c|c|c|c|}
\hline \multirow[t]{2}{*}{ Variables } & \multicolumn{3}{|c|}{ Univariable Model } & \multicolumn{3}{|c|}{ Multivariable Model } \\
\hline & $\overline{\mathrm{OR}}$ & $95 \% \mathrm{CI}$ & $\mathrm{P}$-value & $\overline{\mathrm{OR}}$ & $95 \% \mathrm{CI}$ & P-value \\
\hline \multicolumn{7}{|l|}{ I. Attitude $(\mathrm{A})^{\mathrm{a}}$} \\
\hline Low & 1.00 & & & & & \\
\hline $\operatorname{High}^{\mathrm{b}}$ & 0.98 & $0.49-1.96$ & 0.963 & & & \\
\hline \multicolumn{7}{|l|}{ II. Subjective norm $(\mathrm{SN})^{\mathrm{c}}$} \\
\hline Low & 1.00 & & & & & \\
\hline $\operatorname{High}^{2}$ & 1.95 & $1.05-3.60$ & 0.034 & & & \\
\hline \multirow{2}{*}{\multicolumn{7}{|c|}{$\begin{array}{l}\text { III. Perceived behavioural control }(\mathrm{PBC})^{\mathrm{d}} \\
\text { a. I do have time to vaccinate my dog } \\
\text { (PBC1) }\end{array}$}} \\
\hline & & & & & & \\
\hline Strongly disagree/disagree/neutral & 1.00 & & & & & \\
\hline Agree/strongly agree & 2.29 & $0.51-10.24$ & 0.278 & & & \\
\hline \multicolumn{7}{|l|}{$\begin{array}{l}\text { b. I do have the ability/skill to confine } \\
\text { and tie up my } \operatorname{dog}(\mathrm{PBC} 2)\end{array}$} \\
\hline Strongly disagree/disagree/neutral & 1.00 & & & & & \\
\hline Agree/strongly agree & 1.31 & $0.61-2.82$ & 0.487 & & & \\
\hline \multicolumn{7}{|l|}{$\begin{array}{l}\text { c. I do have time to leash my dog } \\
\text { (PBC3) }\end{array}$} \\
\hline Strongly disagree/disagree/neutral & 1.00 & & & 1.00 & & \\
\hline Agree/strongly agree & 1.79 & $0.90-3.55$ & 0.096 & 2.48 & $1.13-5.13$ & 0.023 \\
\hline \multicolumn{7}{|l|}{$\begin{array}{l}\text { d. I do have money to pay the vaccination } \\
\text { fee (PBC4) }\end{array}$} \\
\hline Strongly disagree/disagree/neutral & 1.00 & & & 1.00 & & \\
\hline Agree/strongly agree & 14.82 & $8.82-24.89$ & $<0.001$ & 15.45 & $9.10-26.21$ & $<0.001$ \\
\hline
\end{tabular}

$\mathrm{OR}=$ Odds ratio; $\mathrm{CI}=$ Confidence interval.

a Average of 4 attitude items: (1) 'Vaccination of dogs reduces rabies cases in humans'; (2) 'Rabies is a threat for human health, therefore it should be controlled'; (3) 'Rabies is transmitted by dogs, therefore it should be controlled'; (4) 'I support the current rabies control measures to reduce rabies cases in humans'; Cronbach's alpha was 0.78 .

${ }^{\mathrm{b}}$ Average of the items equal or higher than 4.

c Average of 8 subjective norm items: 'The opinion of ... influence(s) my decision to participate in the rabies control measures: (1) Family living in the same house; (2) Neighbours; (3) Family living outside the house; (4) Veterinarian; (5) Head of village; (6) Leader of religion; (7) Government; (8) Local human medical caretakers (nurse, physicians)'; Cronbach's alpha was 0.74 .

${ }^{\mathrm{d}}$ The Cronbach's alpha of average of 4 perceived behaviour control items was 0.29 .

p-value shown in bold represents $\mathrm{p}<0.25$; these variables were used in the subsequent multivariable logistic regression analysis.

The Hosmer-Lemeshow goodness-of-fit test p-value: 0.56 . 


\section{Table 4.7}

Determinants of positive intention to participate in the dog culling control measure $(n=450)$ ('I will cull my dog without compensation if there is a rabies case in the dog population in my village').

\begin{tabular}{|c|c|c|c|c|c|c|}
\hline \multirow[t]{2}{*}{ Variables } & \multicolumn{3}{|c|}{ Univariable Model } & \multicolumn{3}{|c|}{ Multivariable Model } \\
\hline & $\overline{\mathrm{OR}}$ & $95 \% \mathrm{CI}$ & P-value & $\overline{\mathrm{OR}}$ & $95 \% \mathrm{CI}$ & P-value \\
\hline \multicolumn{7}{|l|}{ I. Attitude $(\mathrm{A})^{\mathrm{a}}$ : } \\
\hline \multicolumn{7}{|l|}{$\begin{array}{l}\text { a. Culling of dogs reduces rabies cases } \\
\text { in humans (A2) }\end{array}$} \\
\hline Strongly disagree/disagree/neutral & 1.00 & & & 1.00 & & \\
\hline Agree/strongly agree & 3.41 & $2.30-5.06$ & $<0.001$ & 3.24 & $2.18-4.83$ & $<0.001$ \\
\hline \multicolumn{7}{|l|}{$\begin{array}{l}\text { b. Rabies is a threat for human health, } \\
\text { therefore it should be controlled (A4) }\end{array}$} \\
\hline Strongly disagree/disagree/neutral & 1.00 & & & & & \\
\hline Agree/strongly agree & 0.73 & $0.30-1.75$ & 0.148 & & & \\
\hline \multicolumn{7}{|l|}{$\begin{array}{l}\text { c. Rabies is transmitted by dogs, } \\
\text { therefore it should be controlled (A5) }\end{array}$} \\
\hline Strongly disagree/disagree/neutral & 1.00 & & & & & \\
\hline Agree/strongly agree & 0.69 & $0.35-1.38$ & 0.296 & & & \\
\hline \multicolumn{7}{|l|}{$\begin{array}{l}\text { d. I support the current rabies control } \\
\text { measures to reduce rabies cases in } \\
\text { humans (A6) }\end{array}$} \\
\hline Strongly disagree/disagree/neutral & 1.00 & & & & & \\
\hline Agree/strongly agree & 2.39 & $0.49-11.64$ & 0.280 & & & \\
\hline \multicolumn{7}{|l|}{ II. Subjective Norm $(\mathrm{SN})^{\mathrm{b}}$ : } \\
\hline Low & 1.00 & & & & & \\
\hline $\operatorname{High}^{\mathrm{c}}$ & 1.99 & $1.20-3.30$ & 0.008 & & & \\
\hline \multicolumn{7}{|l|}{$\begin{array}{l}\text { III. Perceived behaviour control }(\mathrm{PBC})^{\mathrm{d}} \text { : } \\
\text { a. I do have ability/skill to confine and } \\
\text { tie up my } \operatorname{dog}(\mathrm{PBC} 2)\end{array}$} \\
\hline Strongly disagree/disagree/neutral & 1.00 & & & 1.00 & & \\
\hline Agree/strongly agree & 2.24 & $1.10-4.54$ & 0.026 & 2.04 & $0.98-4.27$ & 0.059 \\
\hline \multicolumn{7}{|l|}{$\begin{array}{l}\text { b. I do have money to buy a new dog } \\
\text { (PBC5) }\end{array}$} \\
\hline Strongly disagree/disagree/neutral & 1.00 & & & 1.00 & & \\
\hline Agree/strongly agree & 14.82 & $8.82-24.89$ & $<0.001$ & 1.48 & $0.99-2.21$ & 0.057 \\
\hline
\end{tabular}

$\mathrm{OR}=$ Odds ratio; $\mathrm{CI}=$ Confidence interval.

${ }^{a}$ The Cronbach's alpha of average of 4 attitude items was 0.43 .

b Average of 8 subjective norm items: 'The opinion of ... influence(s) my decision to participate in the rabies control measures: (1) Family living in the same house; (2) Neighbours; (3) Family living outside the house; (4) Veterinarian; (5) Head of village; (6) Leader of religion; (7) Government; (8) Local human medical caretakers (nurse, physicians)'; Cronbach's alpha was 0.74 .

${ }^{c}$ Average of the items equal or higher than 4.

${ }^{\mathrm{d}}$ The Cronbach's alpha of average of 2 perceived behavioural control items was 0.05 .

$\mathrm{p}$-value shown in bold represents $\mathrm{p}<0.25$; these variables were used in the subsequent multivariable logistic regression analysis.

The Hosmer-Lemeshow goodness-of-fit test p-value: 0.64. 


\section{Table 4.8}

Determinants of positive intention to keep dogs inside the house or leash them $(n=450)$ ('I will keep my dogs inside my house or to leash the dogs for at least three months if there is a rabies case in the dog population in my village').

\begin{tabular}{|c|c|c|c|c|c|c|}
\hline \multirow[t]{2}{*}{ Variables } & \multicolumn{3}{|c|}{ Univariable Model } & \multicolumn{3}{|c|}{ Multivariable Model } \\
\hline & OR & $95 \% \mathrm{CI}$ & $\mathrm{P}$-value & OR & $95 \%$ CI & P-value \\
\hline
\end{tabular}

I. Attitude $(\mathrm{A})^{\mathrm{a}}$ :

a. Keeping dogs inside the home or leashing dogs during the outbreak reduces rabies cases in humans (A3)

Strongly disagree/disagree/neutral 1.00 1.00

Agree/strongly agree

$3.83 \quad 2.26-6.47$

$<0.001$

$2.21 \quad 1.23-3.97$

0.008

b. Rabies is a threat for human health, therefore it should be controlled (A4)

Strongly disagree/disagree/neutral

Agree/strongly agree

1.00

$0.43 \quad 0.10-1.86 \quad 0.257$

c. Rabies is transmitted by dogs, therefore it should be controlled (A5)

Strongly disagree/disagree/neutral

Agree/strongly agree

$0.68 \quad 0.26-1.80 \quad 0.434$

d. I support the current rabies control measures to reduce rabies cases in humans (A6)

Strongly disagree/disagree/neutral

Agree/strongly agree

$2.13 \quad 0.52-1.87$

0.293

II. Subjective norm $(\mathrm{SN})^{\text {b }}$ :

Low

1.00

$\operatorname{High}^{\mathrm{c}}$

$1.85 \quad 1.08-3.16$

0.025

III. Perceived behavioural control (PBC) ${ }^{\mathrm{d}}$ :

\begin{tabular}{llllllll} 
Low & 1.00 & \multicolumn{7}{c}{1.00} & \\
High $^{\text {c }}$ & 7.36 & $4.40-12.31$ & $<\mathbf{0 . 0 0 1}$ & 5.94 & $3.47-10.19$ & $<0.001$ \\
\hline
\end{tabular}

$\mathrm{OR}=$ Odds ratio; $\mathrm{CI}=$ Confidence interval.

a The Cronbach's alpha of average of 4 item attitudes was 0.60 .

b Average of 8 subjective norm items: The opinion of ... influence(s) my decision to participate in the rabies control measures: (1) Family living in the same house; (2) Neighbours; (3) Family living outside the house; (4) Veterinarian; (5) Head of village; (6) Leader of religion; (7) Government; (8) Local human medical caretakers (nurse, physicians)'; Cronbach's alpha was 0.74 .

${ }^{c}$ Average of the items equal or higher than 4.

d Average of 3 perceived behavioural control items: (1) 'I do have the ability/skill to confine and tie up my dog'; (2) 'I do have time to leash my dog'; (3) 'I do have money to buy a leash'; Cronbach's alpha was 0.71.

$\mathrm{p}$-value shown in bold represents $\mathrm{p}<0.25$; these variables were used in the subsequent multivariable logistic regression analysis.

The Hosmer-Lemeshow goodness-of-fit test p-value: 0.85 . 


\subsubsection{Socio-demographic characteristics associated with psychological factors that significantly influence intention to participate in rabies vaccination control measures}

The level of positive attitude towards rabies control by free-of-charge vaccination was in turn significantly influenced by the socio-demographic variables income and education status (Table 4.9). The odds of having a high level of positive attitude was higher in dog owners with an monthly income less than Rp500,000 (OR 2.60; 95\%CI 1.33 - 5.08) and a high educational level (OR 7.07; 95\%CI 2.19 - 22.79) compared to those with, respectively, incomes of more than Rp1,000,000 and no formal education. The perception of having time to participate in a free-of-charge vaccination campaign (PBC1) was associated with dog owners' type of occupation (Table 4.9). Dog owners with occupations other than farmer or servant in public service perceived their availability of time to participate higher (OR 3.64; $95 \%$ CI 1.28 - 10.34) than dog owners with the occupation of farmer or servant in public service. Occupation also influenced the dog owners' perceptions on their ability to confine dogs (PCB2) (Table 4.9). Beside occupation, this perception was also significantly associated with gender. Male dog owners perceived their ability to confine dogs higher (OR 2.61; $95 \%$ CI 1.38 - 4.92) than female owners.

The intention to participate in the charged vaccination campaign was significantly influenced by the perceived behavioural control items PCB3 and PCB4 (Table 4.6). The response level on the statement "I do have time to leash my dog (PBC3)" was significantly associated with gender (males resulting in higher odds (OR 1.71; 95\%CI $1.00-2.93$ ) than females) and occupation status (occupation status 'other' resulting in higher odds (OR 4.02; 95\%CI 1.40 11.51 than famer status ). Furthermore, the perception of having money to pay the vaccination fee (PC4) was significantly related with income, occupation and education level (Table 4.9). The perception of having money was higher in dog owners with a monthly income $>\mathrm{Rp}$ $1,000,000$ (OR 2.53; 95\%CI 1.26 - 5.08) and an occupation in the public service (OR 4.22; 95\%CI 1.19 - 14.94) or 'other sector' (OR 1.93; 95\%CI 1.02 - 3.67) compared to those with a monthly income between Rp 500,000-1,000,000 per month and an occupation as farmer. Dog owners with an education at the level of elementary school (OR 0.50; 95\%CI 0.27 0.93 ) or junior high school (OR 0.32; 95\%CI $0.15-0.68$ ) were less likely to perceive that they have money to pay for the vaccination fee in comparison to those with the highest level of education.

Although intention to participate in a culling measure was significantly associated with the physiological factors A2, PBC2 and PBC3 (Table 4.7), only attitude item A2 was significantly influenced by the evaluated socio-demographic variables (Table 4.9). Dog owners with a high income (> 1,000,000 Rp per month) tended to have a higher positive attitude response to this measure (OR 2.23; 95\%CI 1.15 - 4.31) than those with a lower 
income, as well as dog owners with an occupation outside farming or public services ((OR 1.81 ; $95 \%$ CI 1.06 - 3.08) compared to farmers.

With respect to the intention to keep the dogs inside or to leash them only the response on the latent variable $\mathrm{PBC}$ was significantly influenced by socio-demographic characteristics, although the intention was also influenced by A3 (Table 4.8). Male dog owners indicated a higher perceived behavioural control level (OR 2.12; 95\%CI 1.36 - 3.29) than female dog owners, as well as dog owners with an occupation different from farmer or public servant ('others') (OR 2.29; CI 95\% 1.17 - 4.50) compared to farmers. 


\section{Table 4.9}

Multi variable regression results indicating the effect of socio-demographic characteristics on the response level of the psychological variables that were significantly associated with intentions to implement rabies control measures.

\begin{tabular}{|c|c|c|}
\hline & OR $(95 \% \mathrm{CI})$ & p-value \\
\hline \multicolumn{3}{|c|}{$\begin{array}{l}\text { Variables associated with intention to } \\
\text { participate in free-of-charge vaccination } \\
\text { campaign }\end{array}$} \\
\hline \multicolumn{3}{|l|}{ Attitude (A) $\left(0.98^{a}\right)(\mathrm{N}=446)$} \\
\hline \multicolumn{3}{|l|}{ Highest education level: } \\
\hline None & 1.00 & \\
\hline Elementary school & $3.08(1.29-7.36)$ & 0.011 \\
\hline Junior high school & $2.30(0.86-6.13)$ & 0.096 \\
\hline Senior high school/University & $7.07(2.19-22.79)$ & 0.001 \\
\hline \multicolumn{3}{|c|}{ Monthly income of dog owners $\left(\mathrm{Rp}^{\mathrm{b}}\right)$ : } \\
\hline$<500,000$ & $2.60(1.33-5.08)$ & 0.005 \\
\hline $500,000-1,000,000$ & 1.00 & \\
\hline$>1,000,000$ & $1.55(0.59-4.08)$ & 0.371 \\
\hline \multicolumn{3}{|c|}{$\begin{array}{l}\text { I do have time to vaccinate my dog (PBC1) } \\
\left(\mathbf{1 . 0 0}^{\mathrm{a}}\right)(\mathrm{N}=\mathbf{4 5 0})\end{array}$} \\
\hline \multicolumn{3}{|l|}{ Occupation: } \\
\hline Farmer & 1.00 & \\
\hline Public service & $2.00(0.45-8.82)$ & 0.358 \\
\hline Others & $3.64(1.28-10.34)$ & 0.015 \\
\hline \multicolumn{3}{|c|}{$\begin{array}{l}\text { I do have the ability/skill to confine and tie up } \\
\text { my } \operatorname{dog}(\mathrm{PBC})\left(0.58^{\mathrm{a}}\right)(\mathrm{N}=\mathbf{4 5 0})\end{array}$} \\
\hline \multicolumn{3}{|l|}{ Gender: } \\
\hline Female & 1.00 & \\
\hline Male & $2.61(1.38-4.92)$ & 0.003 \\
\hline \multicolumn{3}{|l|}{ Occupation: } \\
\hline Farmer & 1.00 & \\
\hline Public service & $0.32(0.11-0.93)$ & 0.037 \\
\hline Others & $1.76(0.66-4.72)$ & 0.262 \\
\hline \multicolumn{3}{|c|}{$\begin{array}{l}\text { Variables associated with intention to } \\
\text { participate in charged vaccination campaign }\end{array}$} \\
\hline \multicolumn{3}{|c|}{$\begin{array}{l}\text { I do have time to leash my dog }(\mathrm{PBC})\left(0^{-98^{\mathrm{a}}}\right) \\
(\mathrm{N}=450)\end{array}$} \\
\hline \multicolumn{3}{|l|}{ Gender: } \\
\hline Female & 1.00 & \\
\hline Male & $1.71(1.00-2.93)$ & 0.050 \\
\hline \multicolumn{3}{|l|}{ Occupation: } \\
\hline Farmer & 1.00 & \\
\hline Public service & $1.94(0.44-8.58)$ & 0.383 \\
\hline Others & $4.02(1.40-11.51)$ & 0.010 \\
\hline \multicolumn{3}{|c|}{$\begin{array}{l}\text { I do have money to pay the vaccination fee } \\
(\text { PBC4 })\left(0.87^{\mathrm{a}}\right)(\mathrm{N}=\mathbf{4 4 6})\end{array}$} \\
\hline Monthly income of dog owners & & \\
\hline
\end{tabular}




\begin{tabular}{lll}
\hline$<500,000$ & $0.84(0.51-1.37)$ & 0.477 \\
$500,000-1,000,000$ & 1.00 & \\
$\quad>1,000,000$ & $2.53(1.26-5.08)$ & 0.009 \\
Occupation: & 1.00 & \\
$\quad$ Farmer & $4.22(1.19-14.94)$ & 0.026 \\
$\quad$ Public service & $1.93(1.02-3.67)$ & 0.044 \\
$\quad$ Others & & \\
Highest education level: & $0.47(0.19-1.13)$ & 0.093 \\
$\quad$ None & $0.50(0.27-0.93)$ & 0.028 \\
$\quad$ Elementary school & $0.32(0.15-0.68)$ & 0.003 \\
$\quad$ Junior high school & 1.00 & \\
$\quad$ Senior high school/University & & \\
\hline
\end{tabular}

Variables associated with intention to participate in the dog culling measure

\section{Culling of dogs reduces rabies cases in humans}

(A2) $\left(0.54^{\mathrm{a}}\right)(\mathrm{N}=446)$

Monthly income of dog owners $\left(\mathrm{Rp}^{\mathrm{b}}\right)$ :
$<500,000$
$1.49(0.97-2.29)$
0.068
$500,000-1,000,000$
1.00
$>1,000,000$
$2.23(1.15-4.31)$
0.017

Occupation:

Farmer $\quad 1.00$

$\begin{array}{lll}\text { Public service } & 0.81(0.30-2.19) & 0.680\end{array}$

Others

$1.810(1.06-3.08)$

0.029

Variables associated with intention to

participate to keep dogs inside the house or

to leash them ${ }^{c}$

Perceived behavioural control (PBC) $\left(0.51^{\mathrm{a}}\right)$

( $\mathbf{N}=\mathbf{4 5 0})$

Gender:

Female

1.00

Male

$2.12(1.36-3.29)$

0.001

Occupation:

Farmer $\quad 1.00$

$\begin{array}{lll}\text { Public service } & 0.74(0.29-1.90) & 0.528\end{array}$

Others

$2.29(1.17-4.50)$

0.016

$\mathrm{OR}=$ Odds ratio CI $=$ Confidence interval.

${ }^{a}$ The Hosmer-Lemeshow goodness-of-fit test p-value.

${ }^{\mathrm{b}} 1 \mathrm{US} \$=\mathrm{Rp} 9,651$.

${ }^{c}$ The significant variable A3 was not significantly influenced by the evaluated socio-demographic characteristics. 


\subsection{Discussion}

Our research shows that the majority of dog owners (96\%) intended to participate in the rabies vaccination campaign if the government would provide the vaccine free of charge. This finding is similar to the study of Thomas et al. (2013) in Grenada, South America, where almost $100 \%$ of dog owners intended to vaccinate their dogs. A high level of intention does not guarantee a high level of actual behaviour as intention is not the only factor that determines the behaviour to adopt a measure. A previous study (Wera et al., 2015) revealed that despite the vaccination campaign free of charge, the realized uptake of vaccination by dog owners in Flores Island in 2012 was only 52\%. Lack of information regarding the vaccination campaign schedule was indicated as the main reason for dog owners not to participate in the campaign (Wera et al., 2015). Knowing that the intention of dog owners to participate is high it can be deduced that an improvement of the communication system on the vaccination schedule is a realistic option to improve future uptake.

The intention to participate in a free-of-charge dog vaccination campaign was positively associated with the ability to confine and handle dogs. Previous studies of Matter et al. (2000) and Davlin et al. (2012), which explored the association of the ability to confine dogs with the vaccination uptake rate support our findings. In both studies, it was found that confined dogs have a higher chance to be vaccinated compared with free roaming dogs. We hypothesise that a higher perceived ability to confine or handle dogs is related to a higher intention to have dogs vaccinated. A retrospective study (Wera et al., 2015) found that one of the main reasons given by dog owners for not vaccinating their dogs was that they had difficulty in handling their dogs during the vaccination campaign. Female dog owners as well as dog owners working as a public servant perceived their ability to confine dogs lower than their counterparts (Table 4.9). A possible reason might be a lower degree of relationship between these type of owners and their dogs. Dogs in Flores Island, as is also observed in other developing countries (Butler, 2000; Ratsitorahina et al., 2009), have a primary function as guard-dogs (Wera et al., 2015). This type of dog is more aggressive and difficult to handle compared with companion dogs. This finding suggest that targeted intervention programs towards these dog owners regarding the handling of dogs could improve the effectiveness of rabies control in the future.

Dog owners who perceived that they did not have enough time to vaccinate their dogs had a lower intention to vaccinate than their counterparts. Perception on the availability of time was lowest for dog owners with the occupation of farmer. This might be due to the fact that famers and their dogs are usually in the field during daylight hours from Monday to Saturday. Wera et al. (2015) found in a retrospective study that the majority of dog owners that had not vaccinated their dogs were not at home during the vaccination campaign because it was carried out during daylight hours. Therefore, appropriate time management may help to 
increase the vaccination coverage in the future. A vaccination campaign during the weekend could increase the vaccination coverage; many school children and dog owners are then able to handle their dogs to be vaccinated, as reported in Lusaka, Zambia ${ }^{3}$ and in Nairobi, Kenya (Perry et al., 1995).

In addition to perceived behavioural control (ability to confine dogs and having time to participate in the vaccination campaign), attitudes about the risk of rabies in humans, the transmission of rabies from dogs to humans and the benefit of vaccinating dogs in reducing rabies cases in humans were of significance in explaining the intention to participate in the free-of-charge vaccination campaign. Dog owners that had a positive attitude towards rabies control were more likely to have a high intention to vaccinate their dogs. This could be explained by the fact that the belief that dogs transmit the rabies virus to humans and the belief that rabies is a threat for human health could both be reasons for owners to have their dogs vaccinated. A perceived positive benefit of rabies vaccination for dogs could also encourage owners to have their dogs vaccinated as reported by Rohlf et al. (2012). In this study, a positive attitude towards vaccination was higher in dog owners with a low income and in dog owners with a high educational level. For the low income dog owners this perception could be driven by the dog owners' attitude in avoiding the risk of rabies and consequently the relatively high costs of post exposure treatments following dog-bite injuries, which equal approximately 41 times the daily wage of people in Flores (178US\$ per patient) (Wera et al., 2013). Dog owners with a high educational level are considered to be better informed on the actual risk of rabies. We expected in advance that education variable as a confounder for income level. However, our analyses indicated that there is no evidence the present of confounder in the model. When Education variable was removed from the model the OR (odd ratio) for income variable changes very little (increase 1.6\%; from 2.53 to 2.57). Similarly, there is no evidence for the presence of interaction effect on the model.

Sustainability of a rabies vaccination campaign in an area with a large dog population, such as Flores Island (Wera et al., 2013), requires a major investment of time and money (Meslin and Briggs, 2013). A financial contribution of dog owners could support the sustainability of the campaign (Meslin and Briggs, 2013). However, this study showed that the intention to vaccinate dogs decreased substantially if dog owners would be charged a fee for the vaccine. Only $24 \%$ of the dog owners had the intention to participate in a vaccination campaign at a charge equal to the current vaccine market price in Flores $(\mathrm{Rp} 18,000$ per dose $=\$ 2$ per vaccinated dog). The low level of intention was associated with the perception of dog owners on their ability to pay; dog owners who perceived to have money tended to have a higher intention to participate in the charged vaccination campaign. This perception was higher for dog owners with a higher income which is understandable considering the relatively high

\footnotetext{
${ }^{3}$ http://caninerabiesblueprint.org/An-example-of-the-use-of
} 
vaccine cost to in comparison to the average income level. More than $50 \%$ of the respondents indicated to live on incomes just over $\$ 1$ per day (Table 4.2). The intention may increase

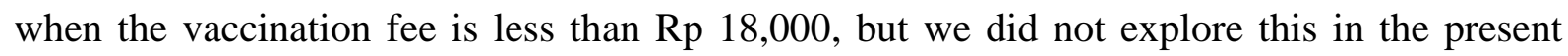
study. Exploration of the dog owners' willingness to pay is very important to find the maximum cost that dog owners are willing to pay to reach the recommended coverage of $70 \%$ of the total dog population, which is recommended to block virus transmission among dogs and ultimately prevent rabies in humans (WHO, 2013; Coleman and Dye, 1996). In general, low participation levels in charged vaccination campaigns are common in undeveloped countries, where income is low and dog health is not a main priority for their owners. In these countries, vaccine costs have been long recognised as a main driver of vaccination behaviour (Mindekem et al., 2005; Durr et al., 2009; Jibat et al., 2015); charging dog owners will generally limit their participation in a vaccination campaign. As a consequence, the vaccination coverage will not reach the target of $70 \%$ of the total dog population (WHO, 2013; Coleman and Dye, 1996). Involving non-governmental organisations or charitable organisations may reduce these budget constraint faced by governments in endemic undeveloped countries. For example, inter-sectoral funding allowed the local government of Bali Island to vaccinate their dog population with a coverage of $70 \%$ (Putra et al., 2013).

Besides income level, the perception on having money available to pay for the vaccination was also higher in dog owners with a higher education level and in dog owners with an occupation which is better paid than that of being a farmer. Although these three sociodemographics are related to each other, no high levels of multicollinearity were observed (correlation coefficients were less than 0.8), explaining the inclusion of all three characteristics in the related multivariable model.

Transmission of rabies among dogs or from dogs to humans is considered to be high if the density of dogs and their contact rates are high (Kitala et al., 2000), like in Flores Island. Therefore, keeping dogs under the supervision of dog owners during an outbreak is important to reduce the risk of rabies, both in humans and dogs. In this study we found that the majority $(81 \%)$ of dog owners intended to participate in the leashing control measure. This intention was significantly related to the belief that leashing of dogs reduces rabies cases in humans, the financial ability to buy a leash, and the availability of time to take care of the dogs during the leashing period. This suggests that efforts to educate dog owners about the benefit of leashing dogs and subsidy programmes for dog owners who are not able to buy a leash might increase the intention of dog owners to keep their dogs under their supervision or to leash their dogs during future outbreaks.

In case of coordination problems or lack of vaccination resources, the culling control measure is applied during an outbreak of rabies. The findings of this study indicate that culling of dogs was less acceptable to dog owners than leashing of dogs. The majority (60\%) of the dog 
owners did not intend to cull their dogs if there was an incidence of rabies in the dog population in their village. Culling of dogs is costly for dog owners as dogs have an economic value to them (Wera et al., 2013). In Flores dogs are widely acknowledged as the guard of farmers' crops (Bingham, 2001; Wera, 2001; Scott-Orr et et al., 2009; Hutabarat et al., 2003). This economic motivation is also supported by the finding that the attitude towards this control measure was more positive in dog owners with a higher income level and in dog owners with a higher paid occupation (driver, carpenter, and entrepreneur) (Table 9). Another reason for the low intention to participate in the culling measure might be related to the high cultural value of dogs to the local community (Wera et al., 2013)).

Although the subjective norm was not significantly associated with the intention to participate in rabies control, the descriptive analysis highlighted the role of the formal information channels by the veterinarian and local human medical caretakers (e.g. nurses, physicians) as well as the role of informal information channels by the religious leaders and village leaders in influencing dog owners to participate in rabies control measures. Veterinarians and human medical caretakers are often recognised as the principal source of advice or trusted information in the decision making on disease control (Heffernan et al., 2008; Schemann et al., 2012; Alarcon et al., 2014). However, due to the limited capacity of the formal channels, an effective option for a broader dissemination of information on rabies control could be the involvement of these informal channels, given the fact that more than $75 \%$ of the dog owners perceived the opinion of these informal channels as important in influencing their final decision to join a rabies control measure.

\subsection{Conclusion}

Dog owners' attitude and their perceived behavioural control were shown to be significantly associated with the intention to participate in the free-of-charge vaccination campaign. The intention to participate in the charged vaccination campaign was mainly explained by the dog owners' financial resources. The dog owners' attitude that culling reduces rabies cases in humans was significantly associated with the intention to participate in the culling measure. Dog owners' attitude that leashing dogs reduces human rabies cases and the perceived behavioural control items availability of time and money to buy a leash were significantly related to the intention to leash dogs or to keep dogs inside the house area during a rabies outbreak. As the attitude variables were often significant, an educational campaign focusing on the benefit of rabies control measures is expected to increase the intention of dog owners to participate in rabies control measures in the future. The perceived behavioural controls that were significantly related to intention also provide guidance for appropriate policy interventions. Providing dog owners with a technique or skill to confine their dogs and creating a subsidy program for the vaccine and leash costs, perhaps by involving nongovernmental organisations or charitable organisations, could also improve the intention to 
participate in the vaccination and leashing measures. Moreover appropriate time management, such as implementing vaccination campaigns during the weekend, could increase the vaccination intention by relaxing the constraints on the availability of dog owners' time.

\section{Acknowledgements}

The authors would like to acknowledge Directorate General of Human Resource for Science, Technology and Higher Education of Indonesia for funding this research. The authors also thank the enumerators for their help in distributing of the questionnaire. 


\section{References}

Ajzen, I., 1991. The theory of planned behavior. Organ. Behav. Hum. Decis. Process. 50, 179 - 211.

Alarcon, P., Wieland, B., Mateus, A.L.P., Dewberry, C., 2014. Pig farmers' perceptions, attitudes, influences and management of information in the decision-making process for disease control. Prev. Vet. Med. 116, 223-242.

Bardosh, K., Sambo, M., Sikana, L., Hampson, K., Welburn, S.C., 2014. Eliminating Rabies in Tanzania? Local Understandings and Responses to Mass Dog Vaccination in Kilombero and Ulanga Districts. PLoS Negl. Trop. Dis. 8 (6), e2935.

Bingham, J., 2001. Rabies on Flores Island, Indonesia: is eradication possible in the near future? In: Doddet. B., Meslin, F.X. (Eds.), Rabies Control in Asia. John Libbey Eurotext. Paris. pp. 148 -155 .

Bruijnis, M., Hogeveen, H., Garforth, C., Stassen, E., 2013. Dairy farmers' attitudes and intentions towards improving dairy cow foot health. Livest. Sci. 155, 103-113.

Butler, J., 2000. Demography and dog-human relationships of the dog population in Zimbabwean communal lands. Vet. Rec. 147, 442 - 446.

Cammock, T., Carragher, N., Prentice, G., 2009. Undergraduate intentions to apply to the Northern Ireland Civil Service: The application of a theory of planned behaviour model. Eur. J. Soc. Psychol. 39, 401-414.

Coleman, P.G., Dye, C., 1996. Immunization coverage required to prevent outbreaks of dog rabies. Vaccine 14, 185-186.

Davlin, S., Lapiz, S.M., Miranda, M.E., Murray, K., 2012. Factors associated with dog rabies vaccination in Bohol, Philippines: Results of a cross-sectional cluster survey conducted following the island-wide rabies elimination campaign. Zoonoses Public Health. 60, 494-503.

Delgado, A.H., Norby, B., Dean, W.R., McIntosh, W.A., Scott, H.M., 2012. Utilizing qualitative methods in survey design: Examining Texas cattle producers' intent to participate in foot-andmouth disease detection and control. Prev. Vet. Med. 103, 120-135.

Durr, S., Mindekem, R., Kaninga, Y., Moto, D.D., Meltzer, M.I., Vounatsou, P., Zinsstag, J., 2009. Effectiveness of dog rabies vaccination programmes: Comparison of owner-charged and free vaccination campaigns. Epidemiol. Infect. 137, 1558-1567.

Dohoo, I., Martin, W., Stryhn, H., 2003. Veterinary Epidemiologic Research. AVC Inc, Canada.

Field, A., 2013. Discovering Statistics using IBM SPSS Statistics. Sage, London.

Flores-Ibarra, M., Estrella-Valenzuela, G., 2004. Canine ecology and socioeconomic factors associated with dogs unvaccinated against rabies in a Mexican city across the US-Mexico border. Prev. Vet. Med. 62, 79-87.

Hampson, K., Coudeville, L., Lembo, T., Sambo, M., Kieffer, A., Attlan, M., et al. 2015. Estimating the global burden of endemic canine rabies. PLoS Negl. Trop. Dis. 9 (4), e0003709.

Heffernan, C., Nielsen, L., Thomson, K., Gunn, G., 2008. An exploration of the drivers to bio-security collective action among a sample of UK cattle and sheep farmers. Prev. Vet. Med. 87, 358372.

Hutabarat, T., Geong, M., Newsome, A., Ruben, A., Cutter, S., 2003. Rabies and dog ecology in Flores. Urban Animal Management Conference Proceedings. Australian Veterinary 
association, Australia. Pp. 7-14. Available at:

http://www.fao.org/fileadmin/user_upload/animalwelfare/Willyanto_Indonesia_Flores_Cutter. pdf/ (accessed on 21.0415.).

IAM, 1997. Pedoman teknis pemberantasan penyakit rabies. Direktorat Kesehatan Hewan, Direktorat Jenderal Peternakan Departemen Pertanian, Jakarta.

IHM, 2000. Petunjuk perencanaan dan penatalaksanaan kasus gigitan hewan tersangka/rabies di Indonesia. Departemen Kesehatan, Jakarta.

Jibat, T., Hogeveen, H., Mourits, M.C., 2015. Review on dog rabies vaccination coverage in Africa: a question of dog accessibility or cost recovery? PLoS Negl. Trop. Dis. 9(2), e0003447.

Kayali, U., Mindekem, R., Yemadji, N., Vounatsou, P., Kaninga, Y., Ndoutamia, A.G., Zinsstag, J., 2003. Coverage of pilot parenteral vaccination campaign against canine rabies in N'Djamena, Chad. Bull. World Health Organ. 81, 739-744.

Kitala, P.M., McDermott, J.J., Kyule, M.N., Gathuma, J.M., 2000. Community-based active surveillance for rabies in Machakos District, Kenya. Prev. Vet. Med. 44, 73-85.

Knobel, D.L., Lembo, T., Morters, M., Townsend, S.E., Cleaveland, S., Hampson, K., 2013. Dog Rabies and Its Control. Rabies. Elsevier Inc., Amsterdam , pp. 591-615.

Kongkaew, W., Coleman, P., Pfeiffer, D.U., Antarasena, C., Thiptara, A., 2004. Vaccination coverage and epidemiological parameters of the owned-dog population in Thungsong District, Thailand. Prev. Vet. Med. 65, 105-115.

Lapiz, S.M.D., Miranda, M.E.G., Garcia, R.G., Daguro, L.I., Paman, M.D., Madrinan, F.P., Rances, P.A., Briggs, D.J., 2012. Implementation of an intersectoral program to eliminate human and canine rabies: the Bohol Rabies Prevention and Elimination Project. PLoS Negl. Trop. Dis. 6 (12), e1891.

Läpple, D., Kelley, H., 2013. Understanding the uptake of organic farming: Accounting for heterogeneities among Irish farmers. Ecol. Econ. 88, 11-19.

Lau, J.T.F., Yeung, N.C.Y., Choi, K.C., Cheng, M.Y.M., Tsui, H.Y., Griffiths, S., 2010. Factors in association with acceptability of $\mathrm{A} / \mathrm{H} 1 \mathrm{~N} 1$ vaccination during the influenza $\mathrm{A} / \mathrm{H} 1 \mathrm{~N} 1$ pandemic phase in the Hong Kong general population. Vaccine. 28, 4632-4637.

Lind, A.-K., Thomsen, P., Rintakoski, S., Espetvedt, M., Wolff, C., Houe, H., 2012. The association between farmers' participation in herd health programmes and their behaviour concerning treatment of mild clinical mastitis. Acta Vet. Scand. 54, 1-9.

Matter, H.C., Wandeler, A.I., Neuenschwander, B.E., Harischandra, L.P.A., Meslin, F.X., 2000. Study of the dog population and the rabies control activities in the Mirigama area of Sri Lanka. Acta Trop. 75, 95-108.

Meslin, F.X., Briggs, D.J., 2013. Eliminating canine rabies, the principal source of human infection: What will it take? Antiviral Res. 98, 291-296.

Mindekem, R., Kayali, U., Yemadji, N., Ndoutamia, A.G., Zinsstag, J., 2005. Impact of canine demography on rabies transmission in N'djamena, Chad. Med. Trop. (Mars) 65, 53-58.

Nicholson, K.G., 1990. Rabies. Lancet. 335, 1201-1202.

Noordhuizen, J.P.T.M., Frankena, K., Thrusfield, M.V., Graat, E.A.M., 2001. Application of quantitative methods in veterinary epidemiology. Wageningen Press, The Netherlands. 
PHDENT, 2012. Roadmap program pengendalian rabies pada manusia menuju provinsi Nusa Tenggara Timur bebas rabies 2017. Makalah Workshop sehari dalam rangka peringatan rabies sedunia, 2012 Oct 8, Maumere, Flores.

Perry, B., Kyendo, T., Mbugua, S., Price, J., Varma, S., 1995. Increasing rabies vaccination coverage in urban dog-populations of high human-population density suburbs - a case-study in Nairobi, Kenya. Prev. Vet. Med. 22, 137 - 142.

Putra, A.A.G., Hampson, K., Girardi, J., Hiby, E., Knobel, D., Wayan Mardiana, I., Townsend, S., Scott-Orr, H., 2013. Response to a rabies epidemic, Bali, Indonesia, 2008-2011. Emerg. Infect. Dis. 19, 648-651.

Ratsitorahina, M., Rasambainarivo, J.H., Raharimanana, S., Rakotonandrasana, H., Andriamiarisoa, M.P., Rakalomanana, F.A., Richard, V., 2009. Dog ecology and demography in Antananarivo, 2007. BMC Vet. Res. 5, 1-7.

Robinson, L.E., Miranda, M.E., Miranda, N.L., Childs, J.E., 1996. Evaluation of a canine rabies vaccination campaign and characterization of owned-dog populations in the Philippines. Southeast Asian J. Trop. Med. Public Health 27, 250-256.

Rohlf, V.I., Bennett, P.C., Toukhsati, S., Coleman, G., 2012. Beliefs underlying dog owners' health care behaviors: Results from a large, self-selected, internet sample. Anthrozoos 25, 171-185.

Schemann, K., Firestone, S.M., Taylor, M.R., Toribio, J.A.L.M.L., Ward, M.P., Dhand, N.K., 2012. Horse owners'/managers' perceptions about effectiveness of biosecurity measures based on their experiences during the 2007 equine influenza outbreak in Australia. Prev. Vet. Med. 106, 97-107.

Scott-Orr, H., Bingham, J., Saunders, G., Dibia, I.N., Putra, A.A.G., Geong, M., 2009. Potential Eradication of Rabies from Flores in Indonesia. Proceedings of the 12th Symposium of the International Society for Veterinary Epidemiology and Economics, Durban, South Africa.

Suzuki, K., Pereira, J.A.C., Frías, L.A., López, R., Mutinelli, L.E., Pons, E.R., 2008. Rabiesvaccination coverage and Profiles of the owned-dog population in Santa Cruz de la Sierra Bolivia. Zoonoses Public Health 55, 177-183.

Takahashi-Omoe, H., Omoe, K., Okabe, N., 2008. Regulatory systems for prevention and control of rabies, Japan. Emerg. Infect. Dis. 14, 1368-1374.

Tenzin, Dhand, N.K., Rai, B.D., Changlo, Tenzin, S., Tsheten, K., Ugyen, P., Singye, K., Ward, M.P., 2012. Community-based study on knowledge, attitudes and perception of rabies in Gelephu, south-central Bhutan. Int. Health 4, 210-219.

Thomas, D., Delgado, A., Louison, B., Lefrancois, T., Shaw, J., 2013. Examining dog owners' beliefs regarding rabies vaccination during government-funded vaccine clinics in Grenada to improve vaccine coverage rates. Prev. Vet. Med. 110, 563-569.

Vallat, B., 2011. The OIE's commitment to fight rabies worldwide. Rabies: a priority for humans and animals. OIE Bull. 3, 1-2.

Wera, E, 2001. Epidemiologi dan usaha pemberantasan penyakit Rabies di Kabupaten Flores Timur, Provinsi Nusa Tenggara Timur periode November 1997- April 2000. Skripsi. Fakultas Kedokteran Hewan, Institut Pertanian Bogor. Available at: http://repositoryipbacid/bitstream/handle/123456789/21527/B01ewepdf;jsessionid=3C23983E 3FB5A771643967D5C4340EE2?sequence $=2$ (accessed 6.06.14.). 
Wera, E., Mourits, M.C.M., Hogeveen, H., 2015. Uptake of rabies control measures by dog owners in Flores Island, Indonesia. PLoS Negl. Trop. Dis. 9 (3), e0003589.

Wera, E., Velthuis, A.G., Geong, M., Hogeveen, H., 2013. Costs of Rabies Control: An Economic Calculation Method Applied to Flores Island. PLoS ONE 8 (12), e83654.

WHO, 2013. WHO Expert Consultation on Rabies. WHO Technical Report Series 982. World Health Organization, Geneva.

Wunner, W.H., 2007. Rabies Virus. in: Jackson, AC. Wunner, WH. (Eds.), Rabies, 2nd ed. Elsevier/Academic, Amsterdam, pp. 23- 68. 
Chapter 4 
Chapter 5

Cost-effectiveness of mass dog vaccination campaigns against rabies in Flores Island, Indonesia

Ewaldus Wera, Monique C.M. Mourits, Maria M. Siko, Henk Hogeveen

Published in Transboundary and Emerging Diseases (In press).

doi:10.1111/tbed.12590 


\begin{abstract}
A dynamic deterministic simulation model was developed to determine the cost-effectiveness of different mass dog vaccination strategies against rabies in a dog population representative of a typical village on Flores Island. Cost-effectiveness was measured as public cost per averted dog-rabies case. Simulations started with the introduction of one infectious dog into a susceptible dog population of 399 dogs, and subsequently ran for a period of 10 years. The base scenario represented a situation without any control intervention. Evaluated vaccination strategies were: annual vaccination campaigns with short-acting vaccine (immunity duration of 52 weeks) (AV_52), annual campaigns with long-acting vaccine (immunity duration of 156 weeks) (AV_156), biannual campaigns with short-acting vaccine (BV_52), and once-in-twoyears campaigns with long-acting vaccine $\left(\mathrm{O} 2 \mathrm{~V} \_156\right)$. The effectiveness of the vaccination strategies was simulated for vaccination coverages of $50 \%$ and $70 \%$.

Cumulative results were reported for the 10-year simulation period. The base scenario resulted in three epidemic waves, with a total of 1274 dog-rabies cases. The public cost of applying AV_52 at a coverage of 50\% was US\$5342 for a village. This strategy was unfavourable compared to other strategies, as it was costly and ineffective in controlling the epidemic. The costs of AV_52 at a coverage of 70\% and AV_156 at a coverage of $70 \%$ were, respectively, US\$3646 and US\$3716, equivalent to US\$3.00 and US\$3.17 per averted dograbies case. Increasing the coverage of AV_156 from 50\% to 70\% reduced the number of cases by $7 \%$, and reduced the cost by US\$1452, resulting in a cost-effectiveness ratio of US\$1.81 per averted dog-rabies case.

This simulation model provides an effective tool to explore the public cost-effectiveness of mass dog vaccination strategies in Flores Island. Insights obtained from the simulation results are useful for animal health authorities to support decision making in rabies-endemic areas, such as Flores Island.
\end{abstract}




\subsection{Introduction}

Flores Island has one of the highest incidence rates of rabies in humans of all the affected islands in Indonesia, with an average annual human rabies incidence of 72 per 100000 head of population (HDENT, 2016). Fatalities can be reduced by mass vaccination of the dog population or by appropriate post-exposure treatment (PET) of humans bitten by suspected rabid dogs. PET consists of wound cleaning, rabies immunoglobulin injection and a series of rabies vaccine injections. In Flores Island, the government provides PET for free to bite victims exposed to suspected rabid dogs, which costs the government approximately \$US0.39 million per year (Wera et al., 2013). However, the PET provided by the government is not always available in the medical centres (JakartaPost, 2008). In this case, dog-bite victims have to obtain PET from private rabies-clinics in the capital regencies of Flores Island, at a cost of \$US178 per patient, which is approximately 41 times the average daily wage in Flores Island (Wera et al., 2013). Furthermore, PET is not a permanent solution to prevent rabies in humans, as it does not prevent virus transmission from rabid dogs to other humans or dogs. Elimination of rabies in the dog population through mass dog vaccination programmes is, therefore, seen as a more cost-effective approach to prevent rabies in humans (WHO, 2005; Vallat, 2011).

The local government of Flores Island has been applying annual mass dog vaccination campaigns since 2000. Most of the campaigns have used short-acting vaccines, with an immunity duration of one year, and have had coverage of less than 50\% (Wera et al., 2013; Wera et al., 2015). To date, these campaigns have not effectively controlled rabies in the dog population of Flores Island. An evaluation of alternative vaccination strategies is needed to identify vaccination campaigns that effectively control rabies in the dog population and prevent rabies cases in the human population.

The success of a dog vaccination strategy depends on two main factors: the coverage (proportion of dogs vaccinated) in relation to the turnover rate of the dog population, and the period of immunity induced by the vaccine in relation to the campaign frequency. The proportion of dogs vaccinated during annual campaigns should be high enough to maintain the population immunity between campaigns (Hampson et al., 2007; Conan et al., 2015) above the threshold immunity of 20\%-40\% (Hampson et al., 2007). Population immunity declines over time because of births, deaths, migration and voluntary culling of dogs for consumption, which is common practice in Flores (Wera et al., 2015). Hampson et al. (2009) estimated that annual vaccination campaigns should cover at least $70 \%$ of the dog population to maintain population immunity in dog populations with high turnover rates. The success of a dog vaccination strategy also depends on the reintroduction rate of infected dogs (i.e. dogs in incubation period) due to immigration of dogs into the local dog population on the island. 
However, in the context of Flores, the risk of reintroduction due to immigration of infected dogs is expected to be low.

The period of immunity is determined by the type of vaccine used and the frequency of application: short-acting vaccines applied more frequently than long-acting vaccines can induce the same period of immunity. Repeated annual vaccination using a long-acting vaccine is widely recognized as effective in reducing the incidence of dog rabies. In Bali, two consecutive years of dog vaccination with an approximate coverage of $70 \%$ resulted in an 87\% decrease in dog-rabies cases in 2010-2011 (Putra et al., 2013). Similarly, two consecutive years of dog vaccination campaigns with a coverage of $60 \%-70 \%$ in Tanzania resulted in a $97 \%$ decrease in the incidence of dog rabies (Cleaveland et al., 2003).

Mass vaccination of the dog population has also been demonstrated as a cost-effective strategy to prevent rabies in the human population (Zinsstag et al., 2009; Fitzpatrick et al., 2014). Zinsstag et al. (2009) showed that a single vaccination campaign using long-acting vaccine with a coverage of $70 \%$ in combination with PET was more cost-effective than PET alone to prevent human rabies in an urban area of Chad. Fitzpatrick et al. (2014) demonstrated that a repeated annual dog vaccination campaign with a coverage of $25 \%-90 \%$ was a costeffective strategy to prevent human rabies in rural areas of Tanzania. The results of both studies indicate the feasibility of cost-effective vaccination campaigns, but are not representative enough for extrapolation to Flores Island. The long-term cost-effectiveness of the current dog vaccination campaign and alternative strategies has not yet been studied for Flores Island. Vaccination coverage of $70 \%$ is hard to obtain in Flores Island because of its specific dog demographics, geography and limited availability of resources and socio-cultural factors specific for the local community in which dogs are left free roaming. The dog population is characterised by a high turn-over rate (>45\%) (Siko, 2011) and most of the villages are located in remote areas with poor road infrastructure (Wera et al., 2015). These characteristics in combination with limited resources, reflected by an insufficient veterinary infrastructure for dog vaccination (Bingham, 2001), make it difficult to obtain high vaccination coverage and this has implications for the cost-effectiveness of mass vaccination. Thus, an evaluation of the cost-effectiveness of different dog vaccination strategies for Flores Island is of relevance to support decision making on rabies control in the future.

The objective of this study was, therefore, to evaluate the cost-effectiveness of different mass vaccination strategies of dogs in Flores Island. Cost-effectiveness was defined as the public cost per averted dog-rabies case. Evaluated strategies varied according to the frequency of vaccine application, type of vaccine and vaccination coverage. The effectiveness of the strategies was estimated by simulating the impact of the strategy on the course of the disease through time in a dog population representative of a typical village in Flores Island. 


\subsection{Materials and Methods}

To evaluate the cost-effectiveness of alternative mass vaccination strategies to control rabies in Flores Island, we developed a deterministic simulation model that incorporates the dynamics of a dog population in a representative village and the dynamics of rabies virus transmission. The model uses a week as the basic time unit and runs over a 10-year simulation period. Model inputs were derived from data obtained from literature and expert knowledge, and from field data on dog demographics.

\subsubsection{Simulation at village level}

Simulation focused on the dynamics of an average dog population at the level of a village. A village was chosen as the epidemiological unit of interest as dogs in Flores Island live closely with their owners within the village area and are isolated from dogs from other villages. A village in Flores Island reflects an area in which a group of households or local communities live together based on the same cultural and ancestral background. An average village in Flores Island has a length of $3.4 \mathrm{~km}$ and a width of $0.5 \mathrm{~km}$. The majority of villages are surrounded by natural barriers, such as mountains or rivers, and are therefore separated from each other. A village contains, on average, 308 households (1500 humans) and 400 dogs (human to dog ratio; 3.75:1), representing a dog density of $233 \mathrm{dogs} / \mathrm{km} 2$ (Siko, 2011). Houses within a village are located close to each other and there are no fences that limit the movement of dogs. Although most dogs in Flores Island are free-roaming, they are owned and fed regularly by their owners (Hutabarat et al., 2003). A village has at least one public area located in the centre. This public area is commonly used as a playground for children and as a place to perform traditional events. Although dogs are primarily used to guard property and to chase wildlife that destroys farmers' crops (Wera et al., 2015), dogs also have cultural and economic values for the local community. As they are a popular menu item in certain traditional ceremonies of the island, dogs are also culled for consumption within the village or in the absent of rabies outbreak, dogs are sold to other villages for consumption.

\subsubsection{Dynamics of the dog population}

We used unpublished data from a dog ecology study on Flores Island to model the dynamics of an average village dog population; the study was conducted from October 2009 to April 2010 (Siko, 2011). During the dog ecology study, dog demographics were measured four times with two months between each measurement in seven villages. In the simulation model, population dynamics depend on the rates of birth (b), death (d), and voluntary culling/removal (c). The values for these variables were derived from the results of the dog ecology study. Migration of dogs was not included in the model, as we assumed that the local veterinary authority would prohibit the movement of dogs between villages during an outbreak (Manggarai regency law number 6, year 2003). The modelled birth rate reflects the number of 
live-born puppies that enter the population within a week per dog present at the beginning of the week (0.01891 puppy per dog per week). The modelled death rate indicates the number of dogs that died within a week, given the number of dogs present at the beginning of the week (0.00865 dog per dog per week). We assumed birth and death rates to be constant over time, whereas voluntary culling altered over time. In the model, voluntary culling (consumption) was directly related to the level of over-population. As a response to over-population, dog owners will sell or cull some of their dogs. In this context, over-population is regulated by dog owners and not by the availability of feed (natural carrying capacity). We modelled this by defining the maximum capacity of dogs within the village, Nmax, equal to the average dog population size in a village of 400 dogs. The voluntary culling rate in each time period $t$ (ct) subsequently depended on the difference between Nmax and the initial number of dogs at time $\mathrm{t}(\mathrm{Nt})$, plus the number of puppies born alive $(\mathrm{Nb}(\mathrm{t}))$ minus the number of natural deaths $(\mathrm{Nd}(\mathrm{t}))$ and rabies deaths (It), as shown in Equation 1 :

$$
c_{t}=\left\{\begin{array}{l}
N_{t}+N_{b(t)}-N_{d(t)}-I_{t} \leq N_{\max } \rightarrow 0 \\
N_{t}+N_{b(t)}-N_{d(t)}-I_{t}>N_{\max } \rightarrow \frac{N_{t}+N_{b(t)}-N_{d(t)}-I_{t}-N_{\max }}{N_{t}+N_{b(t)}-N_{d(t)}-I_{t}}
\end{array}\right.
$$

The parameters used for the simulated dog population are shown in Table 5.1.

\subsubsection{Dynamics of rabies virus transmission}

The rabies virus transmission among the dog population in an average village in Flores Island was simulated using a state-transition modelling approach, following the transmission principles described by Hampson et al. (2007) and Zinsstag et al. (2009). The model divides the dog population into five disease states: Susceptible (S), Exposed (E), Infectious (I), Vaccinated (V), and Immune (R). In each time step (one week), the number of dogs in each state is determined based upon a set of transition rates.

In state $\mathrm{S}$, an individual dog is susceptible for infection by the rabies virus. The number of susceptible dogs changes over time due to the entry of live-born puppies, the loss of dogs due to natural death and over-population, exposure to the virus, and the development or loss of immunity after vaccination. The number of live-born puppies is derived from the total number of dogs at time $\mathrm{t}$ minus the number of infectious dogs at time $\mathrm{t}$, as puppies born from infectious dogs die soon after birth (Fitzpatrick et a., 12014). Susceptible dogs are exposed to the rabies virus when bitten by a furious infectious dog, assuming a $100 \%$ transmission. The dynamics of newly exposed dogs at time $t$, therefore, depend only on the number of susceptible dogs and infectious dogs at time $\mathrm{t}-1$.

Newly exposed dogs remain in state E for three weeks (Hampson et al., 2009). We therefore defined an exposed state for each week of exposure: E1, E2, and E3. Exposed dogs are assumed not to spread the virus to other dogs, as the virus is considered to be absent in saliva 
at this stage. The number of dogs in state E2 and E3 depends on the number of dogs in the previous exposed stage, corrected for natural deaths and voluntary culling during the weekly interval. A proportion of dogs in state E3 becomes infectious and moves to state I, while the remaining proportion moves back to state $S$. In the model, infected dogs are considered to show clinical signs in either furious or paralytic forms (WHO, 2013). The furious form is characterised by aggression, attacking of other dogs, humans or any moving objects, and frequent wandering throughout the village (Merck Veterinary Manual, 2014). The paralytic form is characterised by paralysis of the throat and masseter muscles, caused by peripheral nerve dysfunction (David et al., 1982; Merck Veterinary Manual, 2014), resulting in death without biting any other dogs. Therefore, only dogs in the furious form were assumed to be able to spread the virus to susceptible dogs (David et al., 1982). In addition, it was assumed that all infectious dogs die from the rabies infection within a week, assuming an infectious period of one week. When a dog is vaccinated, it is assumed that the dog reaches the immune state, $\mathrm{R}$, five weeks after vaccination. Therefore, vaccination is represented by four different states: V1, V2, V3, and V4. The number of dogs in V1 depends on the vaccination coverage (vc) of the susceptible dogs within the village during a simulated vaccination campaign. The number of dogs in V2, V3, and V4 depends only on the number of vaccinated dogs in the previous stage, corrected for natural deaths and voluntary culling due to over-population occurring between consecutive stages. Dogs in state V1, V2, and V3 can still be infected by the rabies virus as they are still susceptible. Dogs in state V4 transit partly to immune state R (immune dogs) and partly back to susceptible state $S$, as a proportion of the dogs fails to become immune after vaccination. In state $\mathrm{R}$, an individual dog has enough immunity to protect itself from rabies virus infections. However, a proportion of the vaccinated dogs will not become immune because of a suppression of the immune response, caused by the presence of other diseases related to parasites and bacteria, and due to malnutrition (Zinsstag et al., 2009; Morters et al., 2014). Thus, the number of immune dogs at time $\mathrm{t}$ (e.g. week 5 after vaccination) depends on the number of dogs in state V4, the vaccine potency (vp) (proportion of vaccinated dogs with complete protection), and the proportion of immune dogs becoming susceptible again $(\delta)$.

The transitions between the described epidemiological states are given by the following equations:

$$
\begin{aligned}
S_{t}= & S_{t-1}+b\left(S_{t-1}+E_{t-1}+V_{t-1}+R_{t-1}\right)-S_{t-1}\left(d+c_{t-1}\right) \\
& -\left(\beta S_{t-1} f I_{t-1}-E 3_{t-1}(1-\sigma)+v c S_{t-1}-V 4_{t-1}(1-v e)-\delta R_{t-1}\right)\left(1-d-c_{t-1}\right)
\end{aligned}
$$




$$
\begin{aligned}
& E 1_{t}=\beta\left(S_{t-1}+V 1_{t-1}+V 2_{t-1}+V 3_{t-1}\right)\left(1-d-c_{t-1}\right) f I_{t-1} \\
& E 2_{t}=E 1_{t-1}\left(1-d-c_{t-1}\right) \\
& E 3_{t}=E 2_{t-1}\left(1-d-c_{t-1}\right) \\
& I_{t}=\sigma E 3_{t-1}\left(1-d-c_{t-1}\right) \\
& V 1_{t}=v c S_{t-1}\left(1-d-c_{t-1}\right) \\
& V 2_{t}=\left(V 1_{t-1}-\beta V 1_{t-1} f I_{t-1}\right)\left(1-d-c_{t-1}\right) \\
& V 3_{t}=\left(V 2_{t-1}-\beta V 2_{t-1} f I_{t-1}\right)\left(1-d-c_{t-1}\right) \\
& V 4_{t}=\left(V 3_{t-1}-\beta V 3_{t-1} f I_{t-1}\right)\left(1-d-c_{t-1}\right) \\
& R R_{t}=\left(R_{t-1}(1-\delta)+v e V 4_{t-1}\right)\left(1-d-c_{t-1}\right)
\end{aligned}
$$

Where St-1, E1-3t-1, V1-4t-1, and Rt-1 are respectively the number of susceptible, exposed, vaccinated, and immune dogs at time $\mathrm{t}-1 ; \mathrm{b}$ and $\mathrm{d}$ are the birth and natural death rates; $\delta$ the proportion of immune dogs becoming susceptible again; $\sigma$ the proportion of exposed dogs becoming infectious; $\beta$ the probability of a susceptible dog being bitten by an infectious dog and becoming exposed; $\mathrm{f}$ the proportion of furious rabid dogs; and ct-1 is the voluntary culling rate due to over-population at time t. Full details on transmission parameters used in the simulation are shown in Table 5.1.

\subsubsection{Simulation of outbreak and vaccination interventions}

The simulation of an outbreak of rabies in the dog population of a village in Flores Island starts with the introduction of one infectious dog into a fully susceptible population of 399 dogs. We assumed the outbreak would be recognised by the local community when the number of infectious dogs reaches two or more cases within the same time step. Once the outbreak is recognised, we assumed that a reactive vaccination campaign is initiated one week after recognition, followed by preventive vaccinations in subsequent years. The effectiveness of these strategies in reducing the number of dog-rabies cases is calculated by subtracting the cumulative rabies cases within the individual strategies from the cumulative rabies cases resulting in the base scenario (without any reactive or preventive vaccination campaigns). Furthermore, we assumed that there is no re-introduction of virus into the village. In the 
absence of re-introduction of the virus, the simulation stops when the number of cases is less than 0.50 dogs for 26 consecutive weeks or when a simulation period of 10 years is reached. The simulated vaccination strategies differed according to the frequency and coverage of vaccination and the immunity duration of the vaccine used. Only strategies that are realistic for Flores Island and a strategy without any intervention to reflect a baseline scenario were simulated. Settings for these strategies were based on the current governmental rabies vaccination campaigns in Flores Island (Wera et al., 2015). Vaccines licensed and currently used in Indonesia vary in their immunity duration. The short-acting vaccine Rabivet Supra $92 \AA$, (Pusvetma, Surabaya) is effective in providing immunity for three months, after which a booster is needed to induce an additional year of immunity. Long-acting vaccines, such as Rabisin ${ }^{\circledR}$ (Merial Paris), Defenzor 3® (Pfizer, Incorporated, USA) and Rabvac 3® (Fort Dodge Animal Health, USA), provide immunity for one year after primary vaccination, and an additional three years of immunity can be obtained by administering a booster one year after primary vaccination. In this study, we categorised rabies vaccines according to their immunity duration as either short-acting vaccines (immunity duration of 52 weeks) or longacting vaccines (immunity duration of 156 weeks). The hypothetical vaccination strategies evaluated in the present study were:

1) Without vaccination intervention (Baseline),

2) Annual vaccination campaigns using a short-acting vaccine (AV_52),

3) Annual vaccination campaigns using a long-acting vaccine (AV_156),

4) Biannual vaccination campaigns using a short-acting vaccine (BV_52),

5) Once-in-two-years vaccination campaigns using a long-acting vaccine (O2V_156).

The first strategy was chosen as the baseline scenario. The second strategy was based on the compulsory annual vaccination strategy that is currently applied in Flores Island, in which dogs are vaccinated using a short-acting vaccine (Rabivet Supra 92®, Pusvetma, Surabaya). The third strategy was based on the current vaccination strategy applied in some FAO (Food and Agriculture Organization of the United Nations) pilot project areas in Flores Island, in which a long-acting vaccine (Rabisin ${ }^{\circledR}$, Merial Paris) is used. The fourth strategy was based on the current practice in the Sikka Regency of Flores Island, consisting of a biannual vaccination campaign using a short-acting vaccine, in which all dogs are vaccinated during the second round regardless of their previous vaccination status. The fifth strategy was based on our expectation that vaccination once every two years using a long-acting vaccine might be sufficient to prevent rabies outbreaks. Each vaccination strategy was simulated assuming vaccination coverage of $50 \%$ and $70 \%$. Coverage of $50 \%$ is based on our previous field study, which showed that not all dog owners participated in the vaccination campaigns (Wera et al., 2015), whereas $70 \%$ is based on the recommendation by World Health Organization (WHO, 2013). 


\section{Table 5.1}

Model parameters for the dynamics of the dog population and rabies transmission

\begin{tabular}{|c|c|c|c|}
\hline $\begin{array}{l}\text { Para- } \\
\text { meters }\end{array}$ & Value & Reference & Description \\
\hline$N \max$ & 400 & Siko 2011 & Maximum dog population size within a village \\
\hline$b$ & 0.018910 & Siko, 2011 & Birth rate per dog per week \\
\hline$d$ & 0.008654 & Siko 2011 & $\begin{array}{l}\text { Death rate per dog per week (death due to } \\
\text { rabies excluded) }\end{array}$ \\
\hline$\beta$ & 0.0100251 & Estimation $^{\mathrm{a}}$ & $\begin{array}{l}\text { Probability of a susceptible dog being exposed } \\
\text { to an infectious dog }\end{array}$ \\
\hline$\sigma$ & 0.49 & $\begin{array}{l}\text { Hampson et al., } \\
2009\end{array}$ & $\begin{array}{l}\text { Probability of an exposed dog becoming } \\
\text { infectious }\end{array}$ \\
\hline$f$ & 0.7 & Assumption $^{\mathrm{b}}$ & $\begin{array}{l}\text { Proportion of furious rabid dogs among } \\
\text { infectious dogs }\end{array}$ \\
\hline ve & 0.8 & $\mathrm{AHHD}^{\mathrm{c}}$ & Vaccine efficacy \\
\hline \multirow[t]{2}{*}{$\delta^{d}$} & 0.0192308 & Calculated $^{\mathrm{e}}$ & $\begin{array}{l}\text { Loss-of-immunity rate of short-acting vaccine } \\
\text { per week }\end{array}$ \\
\hline & 0.0064103 & Calculated $^{\mathrm{e}}$ & $\begin{array}{l}\text { Loss-of-immunity rate of long-acting vaccine } \\
\text { per week }\end{array}$ \\
\hline \multicolumn{4}{|c|}{$\begin{array}{l}{ }^{\mathrm{a}} \text { Calculated based on the assumption that } 4 \text { susceptible dogs are bitten by an infectious dog }\left(\mathrm{N}_{\text {bite }}\right) \\
\text { during the infectious period of } 1 \text { week }\left(\mathrm{I}_{\mathrm{p}}\right) \text { (expert opinion in Flores Island), within a village with a } \\
\text { population of } 399 \text { dogs }\left(\beta=\left(\mathrm{N}_{\text {bite }} / \mathrm{N}_{\mathrm{s}}\right) * \mathrm{I}_{\mathrm{p}}\right) \text {. } \\
{ }^{\mathrm{b}} \text { Assumption based on WHO }(2013) \text {. } \\
{ }^{\mathrm{c}} \text { AAHD=Animal Health and Husbandry Department of Sikka Regency (unpublished data). } \\
{ }^{\mathrm{d}} \text { Depending on the type of vaccine used in the campaign strategy. } \\
{ }^{\mathrm{e}} \text { Loss-of-immunity rate was calculated based on the equation: } \delta=1 / \text { immunity duration of vaccine } \\
\text { (Hampson et al., 2007); in which the immunity duration of short- and long-acting vaccines was } \\
\text { respectively } 52 \text { and } 156 \text { weeks. }\end{array}$} \\
\hline
\end{tabular}

\subsubsection{Cost-effectiveness of evaluated rabies vaccination strategies}

The cost of rabies vaccination strategies was based on the actual expenditures in Flores Island (Wera et al., 2013). The costs considered in this study pertain to the public financial costs, i.e. the cost of a vaccination campaign for the government. The vaccination cost per dog (C_dv) was based on the use of a 'house to house' vaccination approach (Wera et al., 2013). The vaccination cost per dog is the sum of the price of the vaccine (pv), the price of syringes and needles (psn) and disinfectant swabs (pds), transportation costs of vaccines from manufacturer to each regency (tva), and the operational costs (ovc) (e.g. cost of vaccinators, cost of the information campaign, and capital costs, such as costs for cool bags, refrigerators, motorcycles, and muzzles). The vaccination cost per dog is shown in Equation 6:

$C_{-} d v=p v+p s n+p d s+t v a+o v c$ 
The total cost of a vaccination strategy was calculated as the product of the vaccination coverage and the number of dogs present in the village, and the vaccination cost per dog. We assumed that there is a linear relationship between vaccination coverage and cost. The input values used in the cost calculation are shown in Table 5.2.

\section{Table 5.2}

Parameters for the estimation of the public cost of vaccination strategies

\begin{tabular}{|c|c|c|c|}
\hline $\begin{array}{l}\text { Cost } \\
\text { parameters }\end{array}$ & $\begin{array}{l}\text { Value } \\
\text { (US\$) }\end{array}$ & Source & Description \\
\hline$P s v$ & 0.77 & Market price $^{\mathrm{a}}$ & Price of short-acting vaccine per dose \\
\hline$P l v$ & 1.38 & Wera et al., 2015 & Price of long-acting vaccine per dose \\
\hline Psn & 0.24 & Wera et al., 2013 & $\begin{array}{l}\text { Price of syringes and needles per } \\
\text { vaccinated dog }\end{array}$ \\
\hline$P d s$ & 0.03 & Wera et al., 2013 & $\begin{array}{l}\text { Price of disinfectant swabs per vaccinated } \\
\text { dog }\end{array}$ \\
\hline$T v a$ & 0.19 & Wera et al., 2013 & $\begin{array}{l}\text { Transportation cost of vaccines per } \\
\text { vaccinated dog }\end{array}$ \\
\hline$O v c$ & 2.32 & Wera et al., 2013 & Operational costs ${ }^{\mathrm{b}}$ per vaccinated dog \\
\hline
\end{tabular}

${ }^{\mathrm{a}}$ Market price of vaccine as indicated by the distributor in Java Island, year 2015.

${ }^{\mathrm{b}}$ Operational costs included costs of vaccinators, costs to train the temporary vaccinators, costs of the information campaign, and capital costs such as costs for cool bags, refrigerators, motorcycles, and muzzles.

The effectiveness of the rabies vaccination control strategies was represented by the number of averted dog-rabies cases. The number of averted dog-rabies cases was calculated by subtracting the cumulative number of rabies cases for a vaccination strategy from the cumulative number of rabies cases estimated in the baseline scenario; the cumulative numbers were calculated for the simulation period of 10 years. The cost-effectiveness of each vaccination strategy was expressed as public cost per averted dog-rabies case and calculated by dividing the total discounted vaccination cost of a strategy by the number of averted dograbies cases. All costs were expressed in 2015 US\$ using a discount rate of $6 \%$.

\subsubsection{Sensitivity analysis}

A univariate sensitivity analysis was performed, in which each default setting of the input parameters of the transmission model was altered by $+/-10 \%$, while the other parameters were held constant. The model outcomes for the changes in parameters were compared with the model outcomes in the default situation to assess the impact of each parameter on the costeffectiveness of vaccination strategies. 


\subsection{Results}

\subsubsection{Costs and effectiveness of rabies vaccination strategies}

In the absence of mass dog vaccination campaigns and without re-introduction of the virus, the model showed that the introduction of one infectious dog into an isolated village with 399 dogs results in 1274 cases of dog rabies (Table 3) and three epidemic waves during the 10year simulation period (Figure 5.1; A). Figure 1 shows that as the epidemic develops, the number of susceptible dogs decreases because these dogs become infectious, given a basic reproduction ratio at the start of the epidemic (R0start) of $1.37\left(\mathrm{R} 0 \mathrm{start}=\beta^{*} \mathrm{St}=0 * \mathrm{It}=0 * \mathrm{f}^{*} \sigma\right)$. Over time, the number of susceptible dogs becomes too low for the infectious dogs to produce at least one secondary infectious dog, resulting in a reproduction ratio less than one. The epidemic, as reflected by the number of infectious dogs, then starts to decrease. Due to the influx of live-born dogs, the number of susceptible dogs increases again, resulting in a population demography that enables the development of a new epidemic wave and the propagation of the epidemic.

\section{Table 5.3}

Simulated number of dog-rabies cases, public costs, cost-effectiveness ratios and duration of the simulated epidemic for the evaluated vaccination strategies over a 10 -year simulation period

\begin{tabular}{|c|c|c|c|c|c|c|c|c|}
\hline \multicolumn{2}{|l|}{ Strategy } & \multirow{2}{*}{$\begin{array}{c}\text { Number of } \\
\text { cases }^{\mathrm{a}} \\
(\mathrm{N}) \\
1628\end{array}$} & \multirow{2}{*}{$\begin{array}{c}\text { Reduction } \\
\text { in cases } \\
\text { (Eff) }\end{array}$} & \multicolumn{2}{|r|}{$\begin{array}{l}\text { Costs } \\
\left(\mathrm{C}_{\mathrm{v}}\right)\end{array}$} & \multicolumn{2}{|c|}{$\begin{array}{c}\text { Cost/effectiveness } \\
\left(\mathrm{C}_{\mathrm{v}} / \text { Eff }\right)\end{array}$} & \multirow{2}{*}{$\begin{array}{c}\text { Duration }^{c} \\
\text { (weeks) }\end{array}$} \\
\hline AV_52 & $50 \%{ }^{\mathrm{d}}$ & & & $\$$ & 5,342 & & - & \\
\hline & $70 \%$ & 59 & 1215 & $\$$ & 3,646 & $\$$ & 3.00 & 207 \\
\hline \multirow[t]{2}{*}{$A V_{-} 156$} & $50 \%$ & 100 & 1174 & $\$$ & 3,716 & $\$$ & 3.17 & 263 \\
\hline & $70 \%$ & 26 & 1248 & $\$$ & 2,264 & $\$$ & 1.81 & 103 \\
\hline \multirow[t]{2}{*}{ BV_52 } & $50 \%$ & 43 & 1232 & $\$$ & 3,348 & $\$$ & 2.72 & 123 \\
\hline & $70 \%$ & 22 & 1252 & $\$$ & 2,893 & $\$$ & 2.31 & 75 \\
\hline \multirow[t]{2}{*}{$\mathrm{O} 2 \mathrm{~V} \_156$} & $50 \%$ & 1392 & -118 & $\$$ & 2,984 & & - & nc \\
\hline & $70 \%$ & 783 & 491 & $\$$ & 4,605 & $\$$ & 9.38 & nc \\
\hline
\end{tabular}

AV_52: Annual vaccination campaigns using a short-acting vaccine.

AV_156: Annual vaccination campaigns using a long-acting vaccine.

BV_52: Biannual vaccination campaigns using a short-acting vaccine.

O2V_156: Once-in-two-years vaccination campaigns using a long-acting vaccine.

${ }^{a}$ Cumulative number of dog-rabies cases during a 10 -year simulation period.

${ }^{\mathrm{b}}$ Effectiveness of the campaigns in a 10-year simulation $\left(\mathrm{Eff}=\mathrm{N}_{\text {vaccinats }}-\mathrm{N}_{\text {no vaccination }}\right) ; \mathrm{N}_{\text {no vaccination }}=1,274$.

Negative signs (-) indicate an increased number of cases compared to base strategy without vaccination $(\mathrm{N}>1,274)$.

An epidemic is considered to be controlled when the number of dog-rabies cases $<0.5$ for 26 consecutive weeks.

${ }^{\mathrm{d}}$ Vaccination coverage.

$\mathrm{nc}=$ Ineffective in controlling the epidemic. 
Assuming disease recognition occurs once there are two or more infectious dogs, the reactive vaccination campaign starts 13 weeks after the virus introduction into the village. At that moment the cumulative number of exposed and infectious dogs is 16 and 6 dogs. The implementation of a reactive vaccination campaign combined with annual mass preventive vaccination campaigns with a coverage of 50\% using short-acting vaccine (AV_52) resulted in 354 more cases than the baseline scenario (Table 3). As the average number of dogs surviving per week is $20 \%$ (65 dogs) higher in the AV-52 scenario than in the baseline scenario, AV_52 results in a higher cumulative number of infectious dogs than the 1274 cases in the baseline scenario (Table 3 ). In addition, AV_52 with a coverage of 50\% tends to result in an endemic situation (Figure 5.1; B). However, AV_52 could bring the disease under control after four consecutive annual campaigns if the coverage is increased to $70 \%$. The cumulative total cost of AV_52 with a coverage of $70 \%$ is US\$3646, or US\$3.00 per averted dog-rabies case. Furthermore, the implementation of a reactive vaccination campaign combined with annual mass preventive vaccination campaigns with a coverage of $50 \%$ using long-acting vaccine (AV_156) prevented 1174 dog-rabies cases in comparison to the baseline scenario. This AV_156 scenario leads to control of the disease ( $<0.5$ cases) at week 263 after five annual vaccination campaigns and results in a total of 100 cases of dog rabies. Increasing the vaccination coverage from $50 \%$ to $70 \%$ shortens the period until the disease is controlled by 160 weeks (Figure 5.1; B). The cumulative cost of AV_156 with 50\% coverage is US\$3716, or US\$3.17 per averted dog-rabies case. Increasing the vaccination coverage using a long-acting vaccine (AV_156) from 50\% to $70 \%$ decreases the number of dog-rabies cases by $7 \%$ and reduces the total cost by US $\$ 1452$ as it shortens the period until the disease is controlled after 160 weeks, resulting in a cost-effectiveness ratio of US $\$ 1.81$ per averted dograbies case (Table 3 ).

If the frequency of campaigns is increased from annual to biannual, the cost-effectiveness of vaccination strategies using short-acting vaccine increases. The cost-effectiveness ratio of biannual vaccination campaigns using short acting-vaccine (BV_52) was lower than for an annual campaign (Table 3). The biannual campaign with a coverage of $50 \%$ decreases the cumulative number of cases by $97 \%$, and controls the disease (number of cases $<0.5$ ) at week 123 after five vaccination campaigns (Figure 5.1; C). Increasing the vaccination coverage from $50 \%$ to $70 \%$ reduces the cost of BV_52 by $14 \%$, as it shortens the period until the disease is controlled by 48 weeks (Figure 5.1 ; C). As a result, BV_52 with a coverage of 70\% (\$2.31 per averted dog-rabies case) was more cost-effective than a coverage of $50 \%(\$ 2.72$ per averted dog-rabies case). Vaccination once every two years with a long acting vaccine $\left(\mathrm{O} 2 \mathrm{~V} \_156\right)$ was unfavourable at both $50 \%$ and $70 \%$ vaccination coverage; this strategy is unable to control the disease in both situations (Figure 5.1; D). 


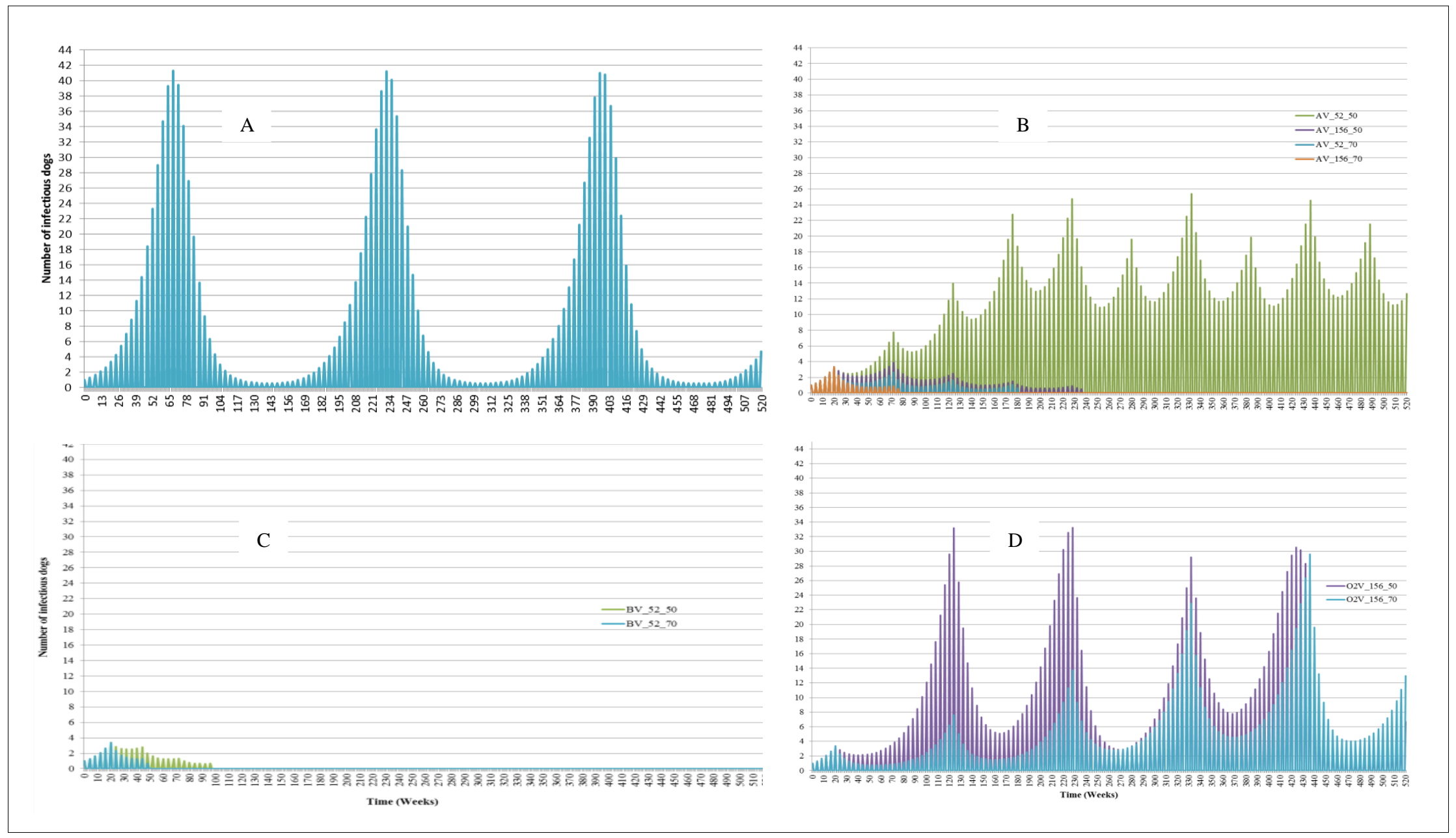

Figure 5.1 The number of infectious dogs over a 10-year simulation period for different vaccination strategies with coverage of 50\% (_50) and $70 \%$ (_70), assuming no re-introduction of virus into the village. A: no vaccination (Base), B: annual vaccination campaigns using short- $\left(A V \_52\right)$ and long-acting (AV_156) vaccines, C: biannual vaccination campaigns using short-acting vaccine (BV_52), and D: once- in-two-years vaccination campaigns using long-acting vaccine $\left(\mathrm{O} 2 \mathrm{~V} \_156\right)$. 


\subsubsection{Sensitivity analysis}

The cost-effectiveness ratio was most sensitive to changes in the following parameters: the probability of a susceptible dog being bitten by an infectious dog, the proportion of furious dogs, and the potency of the vaccine. For example, increasing the probability of a susceptible dog being bitten by an infectious dog and the proportion of furious rabid dogs by $10 \%$ increases the cost-effectiveness ratio of AV_156_70 by 54\%, whereas increasing the potency of vaccine by $10 \%$ decreases the cost-effectiveness ratio AV_156_70 by $49 \%$. A $10 \%$ change in the other transmission parameters has only minor effects (less than 10\%) on the costeffectiveness ratio.

\subsection{Discussion}

We developed a dynamic deterministic model to evaluate the cost-effectiveness of different mass dog-vaccination strategies in a representative village in Flores Island. The model results show that an outbreak is recognised 13 weeks after the introduction of the rabies virus. This is consistent with field observations in Flores Island (Wera, 2001). Our model results show that, without any intervention, the introduction of one infectious dog would result in three epidemic waves within a village during the 10 -year simulation period; a rabies epidemic wave once every three years. This pattern is consistent with reported patterns in Africa, which have been characterised by epidemic cycles with a period of three to six years (Hampson et al., 2007).

The estimated annual cost of an annual vaccination strategy using a short-acting vaccine with a coverage of $50 \%$ is US\$534 at the village level, assuming a dog population of 400 . Extrapolation of this cost to a vaccination campaign for the whole island, with a dog population of more than 0.2 million (Wera et al., 2013), suggests an annual cost of more than \$US267 000.

Our results show that the annual cost of vaccination campaigns at village level could be reduced by $58 \%$ (from \$US534 to \$US226 per year) by shifting from a short-acting vaccine with low coverage (50\%) to a vaccination campaign using a long-acting vaccine and a higher coverage of $70 \%$; this is equivalent to a saved budget of US\$154 000 per year for an islandwide campaign. Moreover, the implementation of an annual mass dog vaccination campaign with $70 \%$ coverage using a long-acting vaccine also results in a shorter epidemic period, compared to the short-acting vaccine ( 2 versus 4 years). In the absence of re-introduction, our model indicates that the cost-effectiveness ratio of an annual vaccination campaign with a vaccination coverage of $70 \%$ using a long-acting vaccine is US\$1.81 per averted dog-rabies case. A vaccination campaign using long-acting vaccine and 50\% coverage results in a slightly higher cost-effectiveness ratio (US\$3.17 per averted dog-rabies case) compared to $70 \%$ coverage with a short-acting vaccine (US\$3.00 per averted dog-rabies case). Both ratios 
are much higher than the ratio for the long-acting vaccine with $70 \%$ coverage. These findings suggest that a vaccination campaign with $70 \%$ coverage using long-acting vaccine is expected to give the most efficient use of resources for the situation in Flores Island.

An island-wide annual vaccination campaign using long-acting vaccine is a large investment for the veterinary authority, as long-acting vaccine is more expensive (US\$1.38 per dose) than short-acting vaccine (US\$0.77 per dose). The cost of an island-wide vaccination campaign using long-acting vaccine with a coverage of 70\% would cost approximately US\$193 200 per year, whereas using short-acting vaccine would cost approximately US\$107 800 per year. This may discourage the veterinary authority from purchasing long-acting vaccine. However, our model indicates that the effectiveness of an annual vaccination campaign using longacting with a coverage of $70 \%$ would compensate the initially higher vaccine costs in the long run.

The annual mass vaccination campaigns with 50\% coverage using short-acting vaccine, which are currently applied in Flores Island, appear to be unable to eradicate rabies in Flores Island (Wera et al., 2013; Wera et al., 2015). Whereas the results show that even with 50\% coverage, annual vaccination campaigns using long-acting vaccines or biannual vaccination campaigns using short-acting vaccines appear to be able to bring the epidemic under control. Our model shows that the biannual vaccination campaigns using short-acting vaccine with $50 \%$ coverage would be able to bring the disease under control faster (week 123 versus week 263) and more cost-effectively than annual vaccination campaigns using long-acting vaccine with $50 \%$ coverage (US\$2.72 versus US\$3.17 per averted dog-rabies case). However, when increasing the coverage from $50 \%$ to $70 \%$, the biannual vaccination campaigns using short-acting vaccine would be less cost-effective than annual vaccination campaigns using long-acting vaccine (US\$2.31 versus US\$1.81 per averted dog-rabies case). Our findings indicate that preference should be given to the use of long-acting vaccines with a high coverage (at least $70 \%$ ) to eradicate rabies in Flores Island.

The simulated number of rabies cases in the baseline scenario (without intervention) is not comparable with any field observation, as in practice, local people within a village will not allow an epidemic to develop without any intervention. As in other developing countries (Hampson et al., 2009; Fitzpatrick et al., 2014), killing of suspected rabid dogs is common practice in Flores once the presence of the disease has been recognised. This practice would reduce the infectious period of possibly infected dogs (Hampson et al., 2009), and consequently reduce the probability of a susceptible dog being bitten by an infectious $\operatorname{dog}(\beta)$ (see footnote to Table 5.1; $\beta=(\mathrm{Nbite} / \mathrm{Ns})^{*} \mathrm{Ip}$ )), the number of cumulative infected dogs, and the size of the epidemic. For example, if the culling of infectious dogs would result in a reduction in the infectious period by $27 \%$ or more, it would decrease $\beta$ by the same relative amount, resulting in a simulated basic reproduction ratio at the start of epidemic of less than 
one. As a result, our model shows that epidemic would fade out without vaccination intervention. These findings and the results of the sensitivity analysis indicate that the probability of a susceptible dog being bitten by an infectious dog has a significant role in rabies epidemics. Encouraging the local community to recognise the clinical signs of rabies in dogs at an early stage and to euthanize these dogs is therefore an important factor in reducing the length and size of epidemics. In this context, World Health Organization and World Organization for Animal Health recommend euthanizing dogs with clinical signs of rabies as an essential part of rabies control measures to prevent rabies in humans (Vallat, 2011; WHO, 2013).

The estimation of vaccination campaign costs in our study is based on the assumption that there is a linear relationship between vaccination coverage and costs. In practice, increasing coverage, for example from $50 \%$ to $70 \%$, will result in increased campaign costs per vaccinated dog (Fitzpatrick et al., 2014) due to additional efforts that are needed, for instance to handle/restrain unmanageable dogs (Wera et al., 2015; Wera et al., 2016). Wera et al. (2015) reported that the majority of Flores dog owners that did not join the vaccination campaign of 2012 was not aware of the campaign schedule or experienced difficulty in handling dogs during the campaigns. In order to increase the current coverage (from $50 \%$ to $70 \%$ ), additional activities such as training vaccinators in handling dogs and intensified campaign information distributions are needed. In this context the additional costs are primarily due to the necessity of vaccinators with expertise to handle the free-roaming dogs and the necessity of a systematic information campaign distribution to reach dog owners in the more remote village. As a consequence, the operational costs will be higher in situations aiming for an improved vaccination coverage, resulting in increased cost effectiveness ratios (CER). For example, if the additional operational costs to increase the coverage from $50 \%$ to $70 \%$ would be equal to US\$1.16 per dog (which is equivalent to $50 \%$ of the current operational costs of US\$2.32 per dog (Wera et al., 2013)), the costs of AV_156_70 would increase with $7 \%$ ( from US\$2,264 to US\$2,432), resulting in an increase of CER by $7 \%$ (from $\$ 1.81$ to $\$ 1.95$ per averted rabid dog). However, even when accounting for these additional operational costs, the rank of cost effectiveness ratios among the different dog vaccination strategies did not change, indicating the robustness of the results of this study.

The results of this study do not account for variability in the input parameters. Therefore there is no information available about the uncertainty in the calculated cost-effectiveness ratios. The use of booster vaccination campaigns were also not considered in the model. Although these factors might alter the outcomes of the model, we believe that the ranking of strategies according to the cost-effectiveness ratios would not be influenced.

The results of this study are considered to be representative for Flores despite the applied simulation context of an isolated village. The assumption of isolation is related to the fact that 
in Flores dogs within a village are isolated from dogs from other villages in the sense that the distances between the villages are too large for dogs to come in contact with each other just by wandering off. So, in this context the migration of dogs only occurs by humans and not unintentionally. Similarly, the assumption of the absence of re-introduction of virus during the outbreaks is related to the fact that the movement restriction during the outbreak was regulated by Manggarai Regency law number 6, 2003. However, as there is no check point between villages, there is an opportunity for dog owners to bring dogs in or out. Given the movement restriction, the probability of movement of dogs during the outbreak is low. In practice, the re-introduction of rabies virus into a remote village is expected to occur, for example 1 or 2 years after the outbreak was declared under control. This re-introduction may lengthen the time period to bring an epidemic of rabies under control or lead to new epidemics and eventually increase the costs and cost-effectiveness ratios of vaccination strategies (data not shown). For example, if the re-introduction of virus occurred at year 4 after the first introduction (equal to 1 year after the outbreak under control by strategy annual dog vaccination campaign using long acting vaccine with a coverage of $70 \%$ ), the costs and cost-effectiveness ratio of the vaccination strategy using long acting vaccine with a coverage of $70 \%$ increases by $84 \%$ (from US\$ 2264 to US\$ 4165) and 88\% (from \$US 1.81 to US\$ 3.41 per averted rabid dog), respectively (Data not shown). However, overall it would not change the conclusion with regards to the most cost effective control strategy.

Positive side effects of vaccination, such as potential benefits for dog owners due to protecting dogs from rabies and an increase in dog production, were not included in the model. However, our analysis indicates that the number of dogs that are culled or sold differs between vaccination strategies. For example, an annual vaccination strategy using a shortacting vaccine with $50 \%$ coverage results in only 473 dogs that could be culled or sold in the 10-year simulation period. Whereas more than 2000 dogs could be culled or sold if vaccination is carried out using long-acting vaccine. As a result, dog owners would receive financial benefits of more than US\$61 000 under the latter strategy (assuming the price of dogs is US\$30.80 per dog, unpublished data). Communication of the monetary benefits of a vaccination campaign for dog owners may motivate dog owners to better co-operate with governmental officials to vaccinate their dogs, which may increase the vaccination coverage. The benefits for public health due to saved human lives and reduced PET were not accounted for in the current model, although a large correlation is expected between the number of dog rabies cases averted as well as human lives saved. Further studies that incorporate stochastic processes and evaluate the benefits of dog vaccination campaigns in saved human life-years and PET costs are therefore needed, in order to fully appreciate the impact of dog-rabies control measures as part of a one-health approach. As a follow-up study, this approach has been performed as well and will be discussed in a separate paper that will be submitted soon to a peer review journal. 


\subsection{Conclusion}

The developed simulation model provides an effective tool to explore the public costeffectiveness of mass dog vaccination strategies against rabies in Flores Island. Insights obtained from the simulation results can easily be used by decision makers in rabies-endemic areas, such as Flores Island. Of the evaluated mass vaccination strategies, repeated annual mass vaccination of $70 \%$ of the total number of dogs using a long-acting vaccine was the most cost-effective strategy in reducing rabies cases in dogs. Annual vaccinations using shortacting vaccines with a coverage of $50 \%$ failed to eliminate rabies from the dog population within a village, suggesting that the current practice in Flores Island is inadequate to eradicate rabies.

\section{Acknowledgements}

The authors would like to acknowledge Directorate General of Human Resource for Science, Technology and Higher Education of Indonesia for funding this research. 


\section{References}

Bingham, J., 2001. Rabies on Flores Island, Indonesia: is eradication possible in the near future? In: Dodet B., and Meslin F.X. (Eds.), Rabies Control in Asia. John Libbey eurotext, Paris, pp. 148 -155 .

Cleaveland, S., Kaare, M., Tiringa, P., Mlengeya, T., Barrat, J., 2003. A dog rabies vaccination campaign in rural Africa: impact on the incidence of dog rabies and human dog-bite injuries. Vaccine 21, 1965-1973.

Conan, A., Akerele, O., Simpson, G., Reininghaus, B., van Rooyen, J., Knobel, D., 2015. Population Dynamics of Owned, Free-Roaming Dogs: Implications for Rabies Control. PLoS Negl. Trop. Dis. 9, e0004177.

David, J. M., Andral, L., and Artois, M., 1982. Computer simulation model of the EPI-enzootic disease of vulpine rabies. Ecol. Model. 15, 107-125.

Dürr, S. and Ward, M.P., 2015. Development of a novel rabies simulation model for application in a non-endemic environment. PLoS Negl. Trop. Dis. 9, e0003876.

Fitzpatrick, M. C., Hampson, K., Cleaveland, S., Mzimbiri, I., Lankester, L., Lembo, T., Meyers, L.A., Paltiel, A.D., and Galvani, A.P., 2014. Cost-effectiveness of canine vaccination to prevent human rabies in rural Tanzania. Ann. Intern.. Med. 160, 91-100.

Hampson, K., Dushoff, J., Bingham, J., Brückner, G., Ali, Y.H, and Dobson, A., 2007. Synchronous cycles of domestic dog rabies in sub-Saharan Africa and the impact of control efforts. Proc. Natl. Acad. Sci. USA. 104, 7717-7722.

Hampson, K., Dushoff, J., Cleaveland, S., Haydon, D.T., Kaare, M., Packer, C., and Dobson, A., 2009. Transmission dynamics and prospects for the elimination of canine Rabies. PLoS Biol. 7, 0462-0471.

HDENT, 2016. Kasus gigitan dan kematian akibat rabies di Flores dan Lembata. Dinas Peternakan Provinsi Nusa Tenggara Timur, Kupang, Indonesia.

JakartaPost, 2008. Flores Runs Out of Rabies Vaccine. Available at: http://www.thejakartapost.com/news/2008/11/15/flores-runs-out-rabies-vaccine.html (accessed on 13.11.15.).

Putra, A. A. G., K. Hampson, K., Girardi, J., Hiby, E., Knobel, D., Mardiana, I.W., Townsend, S. and H. Scott-Orr, 2013. Response to a rabies epidemic, Bali, Indonesia, 2008-2011. Emerg. Infect. Dis. 19, 648-651.

Siko, M.M., 2011: Dog population dynamic and its impact to rabies vaccination coverage in rural and urban Sikka regency, East Nusa Tenggara province period October 2009 - April 2010. M.Sc. Thesis, Gadjah Mada University, Yogyakarta, Indonesia.

Merck Veterinary Manual, 2014: Overview of rabies. Available at: http://www.merckvetmanual.com/mvm/nervous_system/rabies/overview_of_rabies.html (accessed on 13.11.15.).

Vallat, B., 2011. The OIE's commitment to fight rabies worldwide. Rabies: a priority for humans and animals. OIE Bull. 3, 1-2.

Wera, E, 2001. Epidemiologi dan usaha pemberantasan penyakit Rabies di Kabupaten Flores Timur, Provinsi Nusa Tenggara Timur periode November 1997- April 2000. Skripsi. Fakultas 
Kedokteran Hewan, Institut Pertanian Bogor. Available at: http://repositoryipbacid/bitstream/handle/123456789/21527/B01ewepdf;jsessionid=3C23983E 3FB5A771643967D5C4340EE2?sequence=2 (accessed on 6.06.14.).

Wera, E., Velthuis, A.G., Geong, M., Hogeveen, H., 2013. Costs of Rabies Control: An Economic Calculation Method Applied to Flores Island. PLoS One 8, e83654.

Wera, E., Mourits, M.C.M., and Hogeveen, H., 2015. Uptake of rabies control measures by dog owners in Flores Island, Indonesia. PLoS Negl. Trop. Dis. 9, e0003589.

Wera, E., Mourits, M.C.M., and Hogeveen, H., 2016. Intention of dog owners to participate in rabies control measures in Flores Island, Indonesia. Prev. Vet. Med. 126, 138-150.

WHO, 2005: WHO expert Consultation on Rabies, first report. In: WHO Technical Report Series 931. World Health Organisation, Geneva, Switzerland.

WHO, 2013: WHO Expert Consultation on Rabies. Second report. WHO technical report series 982. World Health Organisation, Geneva, Switzerland.

Zinsstag, J., S. Durr, M. Penny, R. Mindekem, F. Roth, S. Gonzalez, S. Naissengar and J. Hattendorf, J., 2009. Transmission dynamics and economics of rabies control in dogs and humans in an African city. Proc. Natl. Acad. Sci. USA. 106, 14996 - 15001. 
Chapter 5 
Chapter 6

Cost-effectiveness of mass dog rabies vaccination strategies to reduce human health burden in Flores Island, Indonesia

Ewaldus Wera, Monique C.M. Mourits, Henk Hogeveen

Under review by the Journal of Vaccine 


\begin{abstract}
The cost-effectiveness of different mass dog rabies vaccination strategies, defined as the costs per year of life lost (YLL) averted was evaluated by means of a dynamic simulation study for a typical village on Flores Island.

In the base strategy (no dog vaccination and no post-exposure treatment (PET) of human bite cases), the model showed that the introduction of the virus by one infectious dog into an isolated village with 1,500 inhabitants and 400 dogs resulted in 776 YLLs during a 10-year simulation period, which is equivalent to 26 human rabies cases. An annual dog vaccination campaign with a coverage of $70 \%$ using a short-acting vaccine saved 733 YLLs, while the cumulative costs for the public sector were US\$3,646 or US\$4.98 per YLL averted. Switching to a long-acting vaccine, the annual vaccination strategies with a coverage of $50 \%$ $\left(\mathrm{AV} \_156 \_50\right)$ or $70 \%\left(\mathrm{AV} \_156 \_70\right)$ reduced the baseline YLLs from 776 to respectively 69 and 23 YLLs with cumulative costs of US\$3,716 and US\$2,264 or US\$5.25 and US\$3.01 per YLL averted, respectively. In general, dog vaccination was more cost-effective than PET alone (US\$3.01-5.25 per YLL averted versus US\$26.43 per YLL averted). Although a combination of PET with AV_156_70 was less cost-effective compared to AV_156_70 alone, this strategy was able to prevent any human deaths by rabies. A combination of PET with annual vaccination using a short-acting vaccine at a coverage of $50 \%$ was far from being costeffective, suggesting that the currently applied rabies control in Flores Island is not an efficient investment in reducing human rabies burden. An increased investment in either an increase in the current coverage or in a switch from the short-acting vaccine to the long-acting vaccine type would certainly pay off.
\end{abstract}




\subsection{Introduction}

Since its introduction in 1998 rabies has posed a serious public health threat to the inhabitants of Flores Island. Annually, more than 2,500 persons are exposed to suspected rabid dogs (Wera et al., 2013). Around $86 \%$ of these persons receive post-exposure treatment (PET), which is provided free of charge to dog-bite victims by the local government, resulting in a serious financial burden for public health authorities (Wera et al., 2013). The annual costs for PET in Flores Island have been estimated to be US\$0.6 million (Wera et al., 2013). PET is, however, not a structural solution of rabies as it does not prevent the recurrent occurrence of rabies cases in humans (Zinsstag et al., 2009). Elimination of rabies in the dog population through mass dog vaccination programs is, therefore, seen as a better approach to prevent rabies in humans (Vallat, 2011; WHO, 2005).

Wera et al. (In press) evaluated the costs of various mass dog vaccination campaigns in Flores Island in relation to the number of rabid dog cases averted by means of a simulation study on the expected virus transmission among dogs within a village. Results showed that repeated annual mass vaccination using a long-acting vaccine at a coverage of $70 \%$ was the most costeffective strategy in reducing dog rabies cases. Rabies was not eliminated from the dog population with annual vaccinations using short-acting vaccines at a coverage of $50 \%$, as is the current practice in Flores.

The study of Wera et al. (In press) did not evaluate the benefits of dog vaccination campaigns on saved human life and prevented PET. In order to fully appreciate the impact of dog rabies control measures these benefits need to be evaluated as well. This study aimed to evaluate the cost-effectiveness, defined as the costs per year of life lost (YLL) averted, of mass dog vaccination strategies using a dynamic simulation model representative for the situation in Flores Island.

\subsection{Materials and Methods}

To evaluate the impact of different rabies vaccination campaigns on reducing human rabies cases, we extended our previously developed SEIVR (susceptible, exposed, infectious, vaccinated, and immune) model (Wera et al., In press) reflecting the rabies transmission dynamics among dogs with the transmission dynamics of rabies from dogs to humans.

\subsubsection{General outline of the dog SEIVR model}

The SEIVR model of Wera et al. (In press) simulates the transmission of rabies in the dog population of an average village in Flores, characterised by a population of 1,500 people owning a total of 400 dogs. The village was chosen as the epidemiological unit as dogs on Flores Island are living closely with their owners within the village area and are rather isolated from dogs of other villages. In the context of an isolated village, the migration of 
dogs only occurs by humans and not unintentionally as the distances between the villages are too large for dogs to come in contact with each other just by wandering off. Simulation started with the introduction of one infectious dogs into the village (Wera et al., In press). Transmission was subsequently simulated for a period of 10 years by time steps of a week. Detection triggered a reactive vaccination campaign followed by preventive vaccination campaigns until the rabies epidemic was under control (defined as a situation where the number of infected dogs was less than 0.50 for 26 consecutive weeks). See for a detailed description on the model and the used dog rabies transition rates Wera et al. (In press).

\subsubsection{Transmission of rabies from dogs to human}

Infected dogs show clinical signs in either furious or paralytic forms (WHO, 2013). The furious form is characterised by aggression and frequently wandering throughout the village . The paralytic form is characterised by paralysis of the throat and masseter muscles due to peripheral nerve dysfunction (David et al., 1982; Merck Veterinary Manual, 2014), resulting in death without biting any other dogs or humans. Therefore, only dogs in the furious form were considered to be able to spread the virus (David et al., 1982). Thus, the number of human rabies at time $\mathrm{t}(\mathrm{Nt})$ is based on the number of infectious dogs in time t-1 (It-1), the proportion of furious infectious dog $(\mathrm{F})$, the proportion of furious infectious dogs that bites a human (FBH), the proportion of bite-victims receiving PET (PPET), and the probability of a bite-victim developing rabies if there is no PET (PRH) (Table 6.1):

$$
N_{t}=I_{t-1} \times F \times F B H \times(1-P P E T) \times P R H
$$

PPET was estimated on the 2012 field survey results among 450 dog owners in two regencies, Manggarai and Sikka, in Flores Island which showed that not all dog-bite victims received PET due to the low accessibility to the health center (Cleaveland et al., 2002). PRH was estimated by multiplying the proportion of different bite locations on the body with their probability of developing rabies (Table 6.1), with the proportions of bite locations based on the 2011 PET registration records of the Health Department in Sikka, Flores Island and the probability of developing rabies following a bite to a certain body location by a rabid dog on Shim et al. (Shim et al., 2009). Moreover, it was assumed that the probability of a bite-victim developing rabies is $100 \%$ prevented by PET.

\subsubsection{Estimation of years of life lost (YLLs)}

As the life expectancy of human worldwide differs between genders, for example in Indonesia life expectancy is higher in female (Lf) than male (Lm) (72.8 vs 68.8 years) (WHO, 2014), the total YLLs at time $\mathrm{t}\left(\mathrm{YLL}_{(\mathrm{t})}\right)$ (time steps of a week) were estimated by cumulating the YLLs of victims at age $\mathrm{a}$ and time $\mathrm{t}\left(\mathrm{YLL}_{\mathrm{a}(\mathrm{t})}\right)$ by gender $(\mathrm{f}=\mathrm{female}, \mathrm{m}=\mathrm{male})$ : 


$$
\begin{aligned}
& Y L L_{(t)}=\sum_{a=0}^{72} \frac{\left(Y L L_{f a(t)}+Y L L_{m a(t)}\right)}{(1+r w)^{t}}, \text { with } \\
& Y L L_{f a(t)}=\frac{P_{f a} \times N_{(t)} \times C \times e^{(r a)}}{(\beta+r)^{2}} \times\left[e^{-(\beta+r)\left(L_{f a t}+a\right)}\left(-(\beta+r)\left(L_{f a}+a\right)-1\right)-e^{-(\beta+r) a}(-(\beta+r) a-1)\right] \\
& Y L L_{m a(t)}=\frac{P_{m a} N_{(t)} \times C \times e^{(r a)}}{(\beta+r)^{2}} \times\left[e^{-(\beta+r)\left(L_{m a}+a\right)}\left(-(\beta+r)\left(L_{m a}+a\right)-1\right)-e^{-(\beta+r) a}(-(\beta+r) a-1)\right]
\end{aligned}
$$

Equations 3 and 4 were adapted from WHO (WHO, 2001), where rw and $\mathrm{r}$ are, respectively, the discount rate per week and per year, $\mathrm{P}_{\mathrm{fa}}$ and $\mathrm{P}_{\mathrm{ma}}$ the proportion of female and male that died due to rabies at age a $(0,1,2,3, \ldots, 72+), \mathrm{C}$ age-weighting correction constant, $\beta$ age-weighting function constant, and $\mathrm{L}$ the duration of time lost due to premature death which is equal to the standard life expectancy at the age of death. We used the standard life expectancy of Indonesia for year 2013 from WHO life tables (WHO, 2014). It was assumed that the age distribution of people who died due to rabies in Flores (i.e. $\mathrm{P}_{\mathrm{fa}}$ and $\mathrm{P}_{\mathrm{ma}}$ ) is represented by the age distribution of dog-bite victims, as recorded by the Health Department in Sikka, Flores Island for the year 2011 (Figure 6.1).

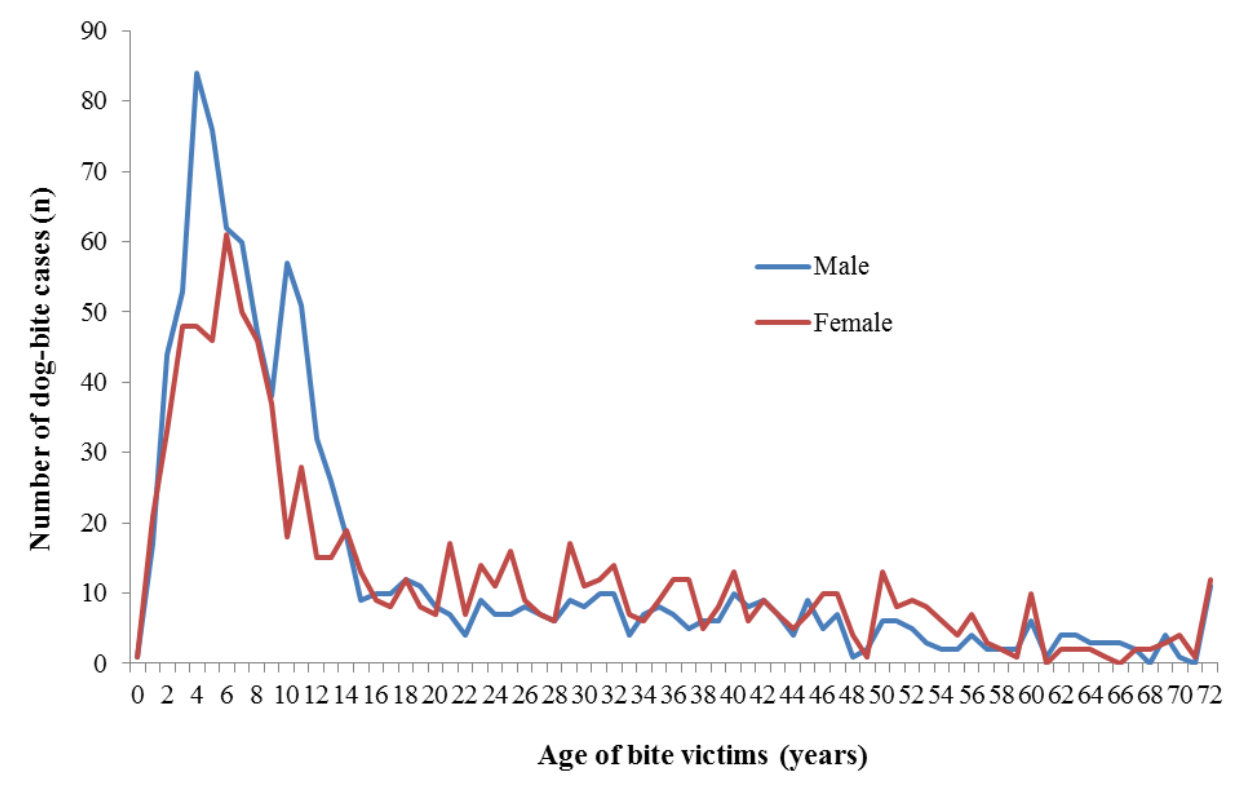

Figure 6.1 Age distribution of dog-bite victims (female and male) in Flores Island in 2011 (source: Bite/PET registration records for year 2011 provided by the Department of Health in Sikka, Flores Island). 


\section{Table 6.1}

Model parameters used in the prediction of human life years lost (YLL) due rabies infection.

\begin{tabular}{|c|c|c|c|}
\hline Parameters & Value & Reference & Description \\
\hline $\mathrm{F}$ & 0.7 & Assumption $^{\mathrm{a}}$ & $\begin{array}{l}\text { Proportion of furious rabid dogs among } \\
\text { infectious dogs }\end{array}$ \\
\hline FBH & 0.20 & Experts $^{\mathrm{b}}$ & Proportion of furious rabid dogs bite human \\
\hline PPET & 0.56 & Wera et al. (2015) & Proportion of bite-victims receiving PET \\
\hline $\mathrm{P} 1$ & 0.07 & $\mathrm{PHD}^{\mathrm{c}}$ & Probability of a bite to the head or neck \\
\hline $\mathrm{P} 2$ & 0.21 & $\mathrm{PHD}^{\mathrm{c}}$ & $\begin{array}{l}\text { Probability of a bite to the upper extremity (arm } \\
\text { or hand) }\end{array}$ \\
\hline P3 & 0.06 & $\mathrm{PHD}^{\mathrm{c}}$ & Probability of a bite to the trunk of the body \\
\hline P4 & 0.66 & $\mathrm{PHD}^{\mathrm{c}}$ & $\begin{array}{l}\text { Probability of a bite to the lower extremity (leg of } \\
\text { foot) }\end{array}$ \\
\hline P5 & 0.55 & Shim et al. (2009) & $\begin{array}{l}\text { Probability of developing rabies following a bite } \\
\text { to the head by a rabid dog }\end{array}$ \\
\hline P6 & 0.22 & $\begin{array}{l}\text { Shim et al. (Shim et al., } \\
\text { 2009) }\end{array}$ & $\begin{array}{l}\text { Probability of developing rabies following a bite } \\
\text { to the upper extremity by a rabid dog }\end{array}$ \\
\hline P7 & 0.09 & Shim et al. (2009) & $\begin{array}{l}\text { Probability of developing rabies following a bite } \\
\text { to the trunk by a rabid dog }\end{array}$ \\
\hline P8 & 0.12 & Shim et al. (2009) & $\begin{array}{l}\text { Probability of developing rabies following a bite } \\
\text { to the lower extremity by a rabid dog }\end{array}$ \\
\hline PRH & 0.15 & Calculated $^{\mathrm{d}}$ & $\begin{array}{l}\text { Probability of developing rabies following a bite } \\
\text { by a rabid dog }\end{array}$ \\
\hline $\mathrm{C}$ & 0.1658 & WHO (2001) & Age-weighting correction constant \\
\hline B & 0.04 & WHO (2001) & Age-weighting function constant \\
\hline A & Varies & & Age of death \\
\hline $\mathrm{L}$ & Varies & & Duration of time lost due to premature death \\
\hline $\mathrm{R}$ & 0.03 & WHO (2001) & Discount rate per year \\
\hline Rw & 0.000569 & Calculated $^{\mathrm{e}}$ & Discount rate per week \\
\hline
\end{tabular}

${ }^{a}$ Assumption based on WHO (2013) stated that rabies clinic manifestation was dominated by forms of furious rabid dogs.

${ }^{\mathrm{b}}$ Derived from expert knowledge of public servants/veterinarians involved in rabies control measures in the past.

${ }^{c}$ PHD $=$ Public Health Department of Sikka Regency (unpublished data).

${ }^{\mathrm{d}}$ Calculated based on the equation: $\mathrm{PRH}=(\mathrm{P} 1 * \mathrm{P} 5)+(\mathrm{P} 2 * \mathrm{P} 6)+(\mathrm{P} 3 * \mathrm{P} 7)+(\mathrm{P} 4 * \mathrm{P} 8)$.

${ }^{\mathrm{e}} \mathrm{rW}=(1+\mathrm{r})^{\wedge^{(1 / 52)}-1}$ 


\subsubsection{Evaluated control strategies}

The evaluated vaccination strategies were those that resulted in the previous simulation study [5] in an effective control of the dog rabies epidemic, i.e. annual vaccination campaigns using a short-acting vaccine with a duration of immunity of 52 weeks (AV_52) at a coverage of $70 \%$, annual vaccination campaigns using a long-acting vaccine with a duration of immunity of 156 weeks (AV_156) at a coverage of 50\% and 70\%, and bi-annual vaccination campaigns using a short-acting vaccine with a duration of immunity of 52 weeks (BV_52)at a coverage of $50 \%$ and $70 \%$. The strategy of AV_52 with a coverage of $50 \%$ was also evaluated (even it was not an effective control of the dog rabies epidemic) as this strategy represents the current practice of rabies control in Flores Island. The cost-effectiveness of each of these strategies was evaluated separately and in combination with the application of PET. The costeffectiveness of a strategy based on PET alone was also considered.

The effectiveness of the strategies was expressed by the YLLs averted. The number of YLLs averted was calculated by subtracting the simulated YLLs under a given vaccination strategy from the YLLs as estimated in the base scenario "do nothing" (no dog vaccination and no PET)

\subsubsection{Costs of vaccination measures and PET}

The cost calculation of the various vaccination strategies was similar to Wera et al. (In press) who assumed a linear relationship between vaccination coverage and costs. The total costs of a vaccination campaign were calculated by multiplying the vaccination coverage and number of dogs present with the costs of vaccination per dog (short-acting vaccine $=$ US\$3.55 per dog; long-acting vaccine $=$ US $\$ 4.16$ per dog). As the results of the present study are reported from a public financial perspective, the private costs such as opportunity costs for the owner of vaccinated dogs and the opportunity costs for the patient and anyone accompanying the patient to get treatment and their transportation costs to a medical center for each treatment were not included in the analysis. Thus costs of PET per dog-bite victim were based on the costs of the vaccine, needles, syringes, disinfectant swabs, physicians' fees, and the number of doses of vaccine for PET. As in Flores Island the Zagreb schedule is applied during the PET (Wera et al., 2013), we assumed that the PET consisted of four doses of vaccine injected intramuscularly in three visits on days 0,7 , and 21 (IHM, 2000). The total public costs of PET at time $\mathrm{t}\left(\mathrm{PCPET}_{(\mathrm{t})}\right)$ were calculated by multiplying costs of PET per dog-bite victim $(\mathrm{CPET}=$ US\$131 (Wera et al., 2013)) with the number of humans bitten by rabid dogs and receiving PET:

$$
\operatorname{PCPET}_{(t)}=\frac{C P E T \times I_{(t)} \times F \times F B H \times P P E T}{(1+r w)^{t}}
$$


The cost-effectiveness ratio of the evaluated strategies was estimated by dividing the costs of each strategy applied by the number of YLLs averted as derived from the comparison to the base strategy (no vaccination and no PET).

\subsubsection{Sensitivity analysis}

An univariate sensitivity analysis was performed to identify the influence of uncertainty in input parameters related to the rabies transmission dynamics from dogs to humans on the cost-effectiveness ratios (CERs). Parameters considered in the analysis included: proportion of furious rabid dogs among infectious dogs, proportion of furious rabid dogs that bite humans, proportion of bite-victims receiving PET, probability of developing rabies following a bite by a rabid dog (Table 6.1), costs of dog vaccination and costs of PET. Each parameter was increased and reduced by $25 \%$ of the default input value, while keeping the other variables constant. The results of the change in a parameter were compared with the results of the model outcome in the default situation to assess the impact of each parameter on the CER of vaccination strategies. We did not perform a sensitivity analysis on parameters related to the rabies transmission dynamics among dogs as it has been performed in our previous costeffectiveness study Wera et al. (In press).

\subsection{Results}

\subsubsection{Effectiveness of control measures}

The results of the evaluated strategies are shown in Table 6.2. In the base strategy (no mass dog vaccination campaigns and no PET), the model showed that the introduction of the virus into an isolated village resulted in 776 YLLs, equivalent to 26 cases of human rabies during the 10-year simulation period. Dog vaccination strategies were, in general, more effective than PET alone except for the annual vaccination strategy with a coverage of $50 \%$ using a short-acting vaccine (AV_52_50). Under AV_52_50 the YLLs increased to 974 (34 human rabies cases) (Table 6.2), due to an increase in the average weekly survival of dogs by $20 \%$ in comparison to the base scenario, resulting in a higher cumulated number of infectious dogs (Wera et al., In press). However, increasing the coverage of AV_52 from 50\% to $70 \%$ saved 931 YLLs (Table 6.2). Switching to a long-acting vaccine, the annual vaccination strategies with a coverage of 50\% (AV_156_50) and 70\% (AV_156_70) reduced the number of YLLs from the default 776 YLLs to, respectively, 69 and 23 YLLs (Table 6.2). Similarly, bi-annual vaccination strategies using short-acting vaccine with a coverage of 50\% (BV_52_50) or 70\% (BV_52_70) reduced the YLLs to 34 and 21 YLLs, respectively. Nearly all combined strategies (dog vaccination and PET) were more effective in reducing YLLs compared to dog vaccination or PET alone. Except for PET+AV_52_50, all other combinations of dog vaccination strategies with PET resulted in $>95 \%$ reduction in the YLLs of human (Table $6.2)$. 


\subsubsection{Costs and economic benefits of control measures}

Table 6.2 provides an overview of public costs per evaluated strategy cumulated over the simulated period of 10 years. Of all strategies, PET+AV_52_50 resulted in the highest total public costs of US\$19,468 (Figure 6.2) of which $73 \%$ was related to PET (Table 6.2). With an increase in coverage from 50\% to $70 \%$ (PET+AV_52_70) the total public costs decreased to US\$4,225 as the cumulative costs of PET were reduced to US\$579 and vaccination costs were lower due to the need of only 4 consecutive annual campaigns (at cumulative costs of US $\$ 3,646)$ to bring the disease under control (Wera et al., In press).

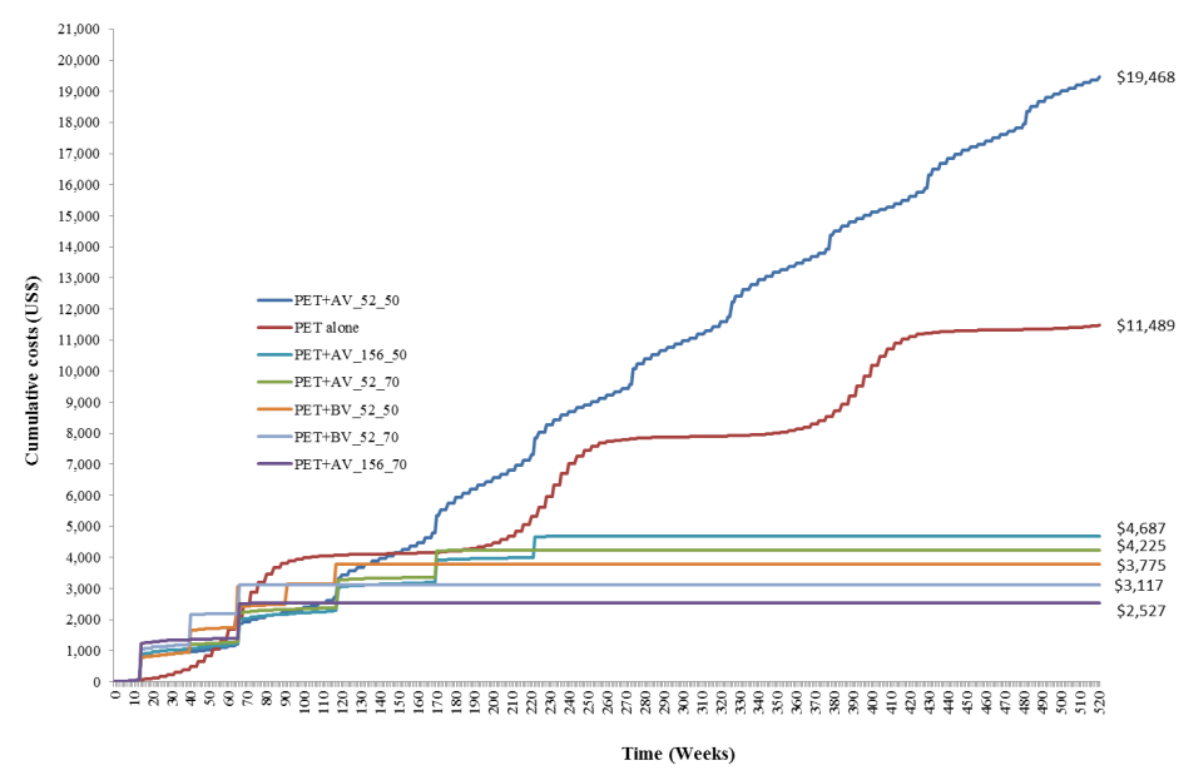

Figure 6.2 Cumulative costs per control strategy over 10-years simulation period. PET= postexposure treatment; AV_52 and AV_156 = annual vaccination campaign using short- and long-acting vaccine, respectively; $\mathrm{BV}_{-}=$biannual vaccination campaign; _50 and _70= vaccination coverage of $50 \%$ and $70 \%$, respectively. 


\section{Table 6.2}

Public costs, effectiveness in reducing number of life lost (LL), years of life lost (YLL) and cost-effectiveness ratio of evaluated vaccination strategies resulting in a 10 -year simulation period.

\begin{tabular}{|c|c|c|c|c|c|c|c|c|c|}
\hline \multicolumn{2}{|l|}{ Strategy } & $\begin{array}{l}\text { Number } \\
\text { of bite } \\
\text { cases by } \\
\text { furious } \\
\text { dogs }\end{array}$ & $\begin{array}{l}\text { Number } \\
\text { of life } \\
\operatorname{lost}^{\mathrm{a}} \\
(\mathrm{N})\end{array}$ & $\begin{array}{c}\text { Costs dog } \\
\text { vaccination } \\
(\mathrm{CD})(\$)\end{array}$ & $\begin{array}{c}\text { Costs } \\
\text { PET } \\
\text { (PCPET) } \\
(\$)\end{array}$ & $\begin{array}{c}\text { Total cost } \\
(\mathrm{CD}+\mathrm{PCPET}) \\
(\$)\end{array}$ & YLL & YLL averted $^{0}$ & $\begin{array}{l}\text { Total cost/YLL } \\
\text { averted (\$) }\end{array}$ \\
\hline \multicolumn{2}{|c|}{$\begin{array}{l}\text { I. No vaccination and no } \\
\text { PET }\end{array}$} & 178.37 & 26.49 & & & & 776.32 & & \\
\hline \multicolumn{10}{|c|}{ I. Vaccination in dog population (without PET) } \\
\hline \multirow[t]{2}{*}{ AV_52 } & $50 \%$ & 227.96 & 33.86 & 5,342 & & 5,342 & 974.49 & -198.17 & - \\
\hline & $70 \%$ & 8.22 & 1.22 & 3,646 & & 3,646 & 43.47 & 732.85 & 4.98 \\
\hline \multirow[t]{2}{*}{ AV_156 } & $50 \%$ & 13.94 & 2.07 & 3,716 & & 3,716 & 68.82 & 707.50 & 5.25 \\
\hline & $70 \%$ & 3.64 & 0.54 & 2,264 & & 2,264 & 23.10 & 753.22 & 3.01 \\
\hline \multirow[t]{2}{*}{ BV_52 } & $50 \%$ & 5.95 & 0.88 & 3,348 & & 3,348 & 33.52 & 742.81 & 4.51 \\
\hline & $70 \%$ & 3.08 & 1.00 & 2,893 & & 2,893 & 20.58 & 755.74 & 3.83 \\
\hline \multicolumn{10}{|c|}{ II. PET in human (without dog vaccination) } \\
\hline PET & & 178.37 & 11.66 & & 11,489 & 11,489 & 341.58 & 434.74 & 26.43 \\
\hline \multicolumn{10}{|c|}{ III. Combination PET in human and dog vaccination } \\
\hline \multirow[t]{2}{*}{ PET + AV_52 } & $50 \%$ & 227.96 & 14.90 & 5,342 & 14,127 & 19,468 & 428.78 & 347.54 & 56.02 \\
\hline & $70 \%$ & 8.22 & 0.54 & 3,646 & 579 & 4,225 & 19.13 & 757.19 & 5.58 \\
\hline \multirow[t]{2}{*}{ PET + AV_156 } & $50 \%$ & 13.94 & 0.91 & 3,716 & 971 & 4,687 & 30.28 & 746.04 & 6.28 \\
\hline & $70 \%$ & 3.64 & 0.24 & 2,264 & 263 & 2,527 & 10.17 & 766.15 & 3.30 \\
\hline \multirow[t]{2}{*}{ PET + BV_52 } & $50 \%$ & 5.95 & 0.39 & 3,348 & 427 & 3,775 & 14.74 & 761.58 & 4.96 \\
\hline & $70 \%$ & 3.08 & 0.20 & 2,893 & 223 & 3,117 & 9.06 & 767.26 & 4.06 \\
\hline
\end{tabular}

PET : Post-exposure treatment.

AV -156: Annual vaccination campaigns using a long-acting vaccine.

$\mathrm{BV}=52$. Bi-annual vaccination canpaigns using a short-acting vaccine.

vaccine.

byears of life lost averted in a 10-year simulation (YLS=YLL

in a 10 -year simulation (YLS=YLL vaccination $-\mathrm{YLL}_{\text {vaccination }}$ ); $\mathrm{YLL}_{\text {no vaccination }}=776.32$

\section{4}




\subsubsection{Cost-effectiveness of control measures}

The total public costs of a strategy, as cumulated over the simulation period of 10 years, varied between US\$2,264 and US\$19,468, while the number of lives lost averted ranged from -7 to 26 . In the absence of re-introduction of rabies virus into the village, results showed that a vaccination intervention at dog population level (without PET in humans) is more costeffective than PET alone (US\$3.01-5.25 per YLL averted versus US\$26.43 per YLL averted, respectively) (Table 6.2). Overall, the most cost-effective strategy in reducing YLL due to rabies is based on the strategy AV_156_70 (US\$3.01 per YLL averted) (Table 6.2). Combined strategies of dog vaccination with PET were less cost-effective in reducing YLLs compared to dog vaccination alone. However, dog vaccination alone was not able to prevent all of YLLs due to rabies (Table 6.2).

\subsubsection{Sensitivity analysis}

In the univariate sensitivity analysis, the impact of increasing or decreasing input parameters on the CERs varied among strategies. In general, the most sensitive variables to the CERs are the dog vaccination costs and the probability of an individual bitten by a furious rabid dog receiving PET (PPET). For example, an increase of $25 \%$ in the costs of long-acting vaccine resulted in the same relative increase of the CER of AV_156_70 (from US\$3.01 to US\$3.76 per YLL averted). Similarly, an increase of PPET by $25 \%$ reduced YLLs by $57 \%$ for strategy PET+AV_52_50 (from 429 to 185 YLLs) and PET+AV_156_50 (from 30 to 13 YLLs). As a result, the CERs of the PET+AV_52_50 and PET+AV_156_50 decreased by 22\% (from US\$56.02 to US\$43.60 per YLL averted) and $-7 \%$ (from US\$6.28 to US\$6.71 per YLL averted), respectively. Other parameters (the proportion of furious rabid dogs among infectious dogs, proportion furious rabid dogs bite human, and probability of developing rabies following a bite by a rabid dog) showed only limited impacts on the CERs $(<2 \%)$.

\subsection{Discussion}

Our study highlights the relevant influence of vaccine type used and its coverage on the CERs of the defined vaccination campaigns. In the absence of virus re-introduction, the model results show that the most cost-effective strategy in reducing YLL due to rabies is based on the strategy AV_156_70. However, AV_156_70 alone appears to be unable to prevent all lives lost due to rabies. A combination of PET with AV_156_70 (PET+ AV_156_70) resulted in a slightly higher cost-effectiveness ratio (US\$3.30 per YLL averted) compared to AV_156_70 (US\$3.01 per YLL averted), but this strategy would be able to prevent any human deaths by rabies. Furthermore, the implementation of PET+AV_156_70 would be more cost-effective than the combination of PET with an annual vaccination strategy using a short-acting vaccine with a coverage of 50\% (PET+AV_52_50) which represents the current rabies control strategies in Flores Island. It should be noted that the strategy of 
PET+AV_52_50 is not only unable to bring epidemic under control (Wera et al., In press) but also far from being cost-effective. This highlights the need for an increase in the current coverage of dog vaccination and/or a switch in the type of dog vaccine used.

Our results show that the implementation of AV_156_70 would need higher up-front investment compared to AV_52_50. On yearly basis the costs of AV_156_70 were larger than of AV_52_50 (US\$1,165 versus US\$709 per year-campaign, undiscounted) (Figure 6.2). Extrapolating these costs to island level with a dog population of 0.2 million, the implementation of AV_156_70 would cost the veterinary authorities US $\$ 582,500$ per yearcampaign, which would be $64 \%$ higher than the costs based on the implementation of AV_52_50 (US $\$ 354,500$ per year). However, these higher implementation costs in the first two years are a sound investment in the long run as the implementation of AV_156_70 results in lower total public costs for both PET and dog vaccination than AV_52_50. Compared to PET+AV_52_50, the implementation of PET+AV_156_70 at village level with a dog population of 400 dogs (Wera et al., In press) saved US\$13,800 on PET costs and US\$3,000 on dog vaccination costs during a period of 10 years (Table 6.2). It means that the implementation of PET+AV_156_70 at island level would save over a period of 10 years US\$6.9 million on PET and US\$1.5 million on vaccination costs compared to the current situation (PET+AV_52_50). These cost savings are due to the fact that the implementation of AV_156_70 needs less campaigns to bring the epidemic under control than AV_52_50 (2 versus 10-year campaigns) (Wera et al., In press), resulting in a larger number of dogs and humans saved from exposure to rabies and eventually less people seeking PET. These findings are in agreement with other studies (Glosser et al., 1970; Cleaveland et al., 2003) indicating that providing budget to vaccinate a larger proportion of the dogs with a longacting vaccine to reach a high coverage in short period (e.g. 2-3 year campaigns) could be seen as an efficient investment in reducing the burden of rabies in humans in the long run (over 10 years). However, a vaccination coverage of $70 \%$ may be hard to obtain in Flores Island. Recent studies on the real uptake of annual rabies vaccination campaigns have estimated the realised coverage at less than $55 \%$ of total dog population in Flores Island (Wera et al., 2013; Wera et al., 2015). Main reasons for this low participation level are related to the specific geography of the island with most villages located in remote areas with poor accessibility as well as to the culture of having the dogs roam freely in the general area of the local community (village) which makes it difficult to handle the dogs during vaccination campaigns (Wera et al., 2015). These reasons in combination with limited capacity resources, reflected by an insufficient veterinary infrastructure for dog vaccination (Bingham, 2001), make it difficult to obtain a high vaccination coverage. Switching the short-acting vaccine to the long-acting vaccine type without increasing the current coverage $(50 \%)$ is therefore a more realistic strategy in reducing the burden of rabies in Flores Island in the near future. The implementation of annual mass vaccination campaigns with a coverage of $50 \%$ using long- 
acting vaccine in combination with PET (PET+AV_156_50) would reduce the cumulative costs of the current strategy (PET+AV_52_50) by $76 \%$ (from US $\$ 19,468$ to US $\$ 4,687$ per village) (Figure 6.2), resulting in a decrease of CER by $89 \%$ (from $\$ 56.02$ to $\$ 6.28$ per YLL averted on village level) (Table 6.2).

Our results also found that the cost-effectiveness ratio of PET alone is US\$774 per life lost averted. In Tanzania, the cost-effectiveness ratio from a health care perspective was estimated by Shim et al. (2009) at US\$555 per life lost averted. The disparity is mainly caused by differences in prices of human rabies vaccine. Although both Indonesia and Tanzania used a cell culture vaccine for PET (Wera et al., 2013; Shim et al., 2009), the price of rabies human vaccine in Tanzania was lower (US\$10 per dose) (Shim et al., 2009) than in Flores Island (\$US28 per dose) (Wera et al., 2013). It is interesting to note that despite the higher costs per life saved, the costs per YLL averted are comparable with the study of Shim et al. (Shim et al., 2009) (US\$26.43 per YLL averted versus US\$27 per QALY gained, assuming 1 QALY gained equal to 1 YLL averted as Shim et al. (2009) assumed the contribution of disability due to rabies negligible). This will primarily be due to the lower life expectancy in Tanzania (51 years) (Shim et al., 2009) than in Indonesia (71 years), resulting in higher YLLs per life lost in the present study than in the study of Shim et al. (2009).

As in other cost-effectiveness models (Hampson et al., 2011; Fitzpatrick et al., 2014), the simulated number of bite cases in our model was not considering the bites of non-rabid dogs for which people also might receive PET. Extending the model, by taking into account the PET related to bites of non-rabid dogs, would increase the costs of PET and increase the CERs of the strategies involving PET. For example, if we assume an additional $25 \%$ in the number of bite victims as a result of the bites of non-rabid dogs (Ly et al., 2009), the PET costs in the strategy PET+AV_156_70 would increase by 33\% (from US\$263 to US\$350 on village level), resulting in an increase of CER by $3 \%$ (from US\$3.30 to US\$3.41 per YLL averted). Moreover, increasing the PET accessibility or compliance proved to be effective in reducing YLLs but it would increase the CER. For example, increasing PET accessibility or compliance from $56 \%$ to $81 \%$ as indicated by sensitivity analysis would increase YLLs saved by $57 \%$ for strategy PET+AV_156_70 (from 10 to 4 YLLs), whereas the CER would increase by $4 \%$ (from US\$3.30 to US\$3.43 per YLL averted). However, the increased PET accessibility as well as the inclusion of PET costs related to bite cases resulting from nonrabid dogs did not impact the ranking of the evaluated dog vaccination campaigns by their CERs, indicating the robustness of the rank presented in this study.

This study did not account for a re-introduction of virus into the village during the 10-year simulation period for two reasons. First reason is related to the fact that the dogs within a village are rather isolated from dogs from other villages as a result of the large distances between the villages which makes it hard for dogs to come in contact with each other just by wandering off. Second reason is related to the enforcement of a movement restriction during 
the outbreak as regulated by Manggarai Regency law number 6, 2003. However, as there is no formal check point between villages, the opportunity remains for dog owners to bring their dogs in or out the village. Given the enforced movement restriction as well as the high level of awareness of dog owners with respect to the risk of spreading the disease by dogs (Wera et al., 2016), the probability of movement of dogs during an outbreak is expected to be low. A re-introduction of rabies virus after an outbreak has been declared to be under control remains, however, a realistic risk. This could lengthen the time period to bring an epidemic of rabies under control or lead to new epidemics and eventually increases the costs and CERs of the vaccination strategies (Wera et al., In press). For example, if the re-introduction of virus occurred two years after the outbreak was declared to be controlled by strategy AV_156_70 (i.e. re-introduction occurred in the first week of year five after the first introduction), the total costs and CER of strategy PET+AV_156_70 increased by $79 \%$ (from US $\$ 2,527$ to US $\$ 4,532$ ) and $81 \%$ (from $\$$ US3.30 to US\$5.96 per YLL averted), respectively (data not shown). In contrast, the costs as well as the CER of the strategy PET+AV_52_50 did not change much (costs reduced by $0.3 \%$; from US $\$ 19,468$ to US $\$ 19,406$ and CER reduced by $0.4 \%$ from \$US56.02 to US\$55.79 per YLL averted) as the re-introduction occurred when the epidemic was not under control yet. The higher the frequency of a virus re-introduction, the more the CER of PET+AV_52_50 decreases, while on the other hand the CER of PET+AV_156_70 increases. For example, compared to a single introduction, a yearly re-introduction of the virus into the village (which is expected to reflect a worst case scenario in practice; (Sikko, personal communication)) would reduce the CER of PET+AV_52_50 by 64\% (from \$US56.02 to US\$20.39 per YLL averted) and increase the CER of PET+AV_156_70 by 58\% (from \$US3.30 to US\$5.22 per YLL averted). Similarly, a yearly re-introduction of the virus into the village would reduce the CER of PET+AV_156_50 by $24 \%$ (from $\$$ US6.28 to US\$4.78 per YLL averted), resulting in a higher cost-effectiveness than PET+AV_156_70. This is due to the fact that the annual costs to implement AV_156_70 are always higher than AV_156_50 (US\$1,165 versus 832 per year-campaign, undiscounted). In general, with an increase in the possibility of virus re-introduction the use of the long-acting vaccine remains more effective than short acting-vaccine but the relevance of increasing vaccination coverage is reducing.

\subsection{Conclusion}

The results of this study showed that annual vaccination using long-acting vaccine at a coverage of $70 \%$ was the most cost-effective strategy in reducing the YLLs due to rabies in the long run (over 10-year period campaigns). However, annual vaccination using long-acting vaccine at a coverage of $70 \%$ alone appears to be unable to prevent all lives lost due to rabies. A combination of PET with annual vaccination using long-acting vaccine at a coverage of $70 \%$ results in a slightly higher cost-effectiveness ratio compared to annual vaccination using 
long-acting vaccine at a coverage of $70 \%$ alone, but this strategy would be able to prevent any human deaths by rabies. A combination of PET with annual vaccination using short-acting vaccine at a coverage of $50 \%$ is far from being cost-effective, suggesting that the currently applied rabies control in Flores Island is not an efficient investment in reducing human rabies burden. It would certainly pay off to increase the investment in the annual mass vaccination campaigns by either increasing the current level of vaccination coverage or switching the currently applied short-acting vaccine for the long-acting vaccine type.

\section{Acknowledgements}

The authors would like to acknowledge Directorate General of Human Resource for Science, Technology and Higher Education of Indonesia for funding this research. 


\section{References}

Bingham, J., 2001. Rabies on Flores Island, Indonesia: is eradication possible in the near future? In: Dodet B., and Meslin F.X. (Eds.), Rabies Control in Asia. John Libbey eurotext, Paris, pp. 148 -155 .

Cleaveland S., Fevre E., Kaare M., Coleman P., 2002. Estimating human rabies mortality in the united republic of Tanzania from dog bite injuries. Bull. World Health Org. 80, 304 - 310.

Cleaveland S., Kaare M., Tiringa P., Mlengeya T., Barrat J., 2003. A dog rabies vaccination campaign in rural Africa: impact on the incidence of dog rabies and human dog-bite injuries. Vaccine 21, 1965-1973.

David JM., Andral L., Artois M., 1982. Computer simulation model of the EPI-enzootic disease of vulpine rabies. Ecol. Model. 15, 107-125.

Fitzpatrick, M.C., Hampson, K., Cleaveland, S., Mzimbiri, I., Lankester, F., Lembo, T., Meyers, L.A., Paltiel, A.D., Galvani, A.P., 2014. Cost-effectiveness of canine vaccination to prevent human rabies in rural Tanzania. Ann. Intern. Med. 160, 91-100.

Glosser, J.W., Hutchins, Lr., Rich, A.B., Huffaker, R.H., Parker, R.L., 1970. Rabies in El-Paso, Texas, before and after Institution of a new rabies control program. J. Am. Vet. Med. Assoc. 157, 820.

Hampson, K., Cleaveland, S., Briggs, D., 2011. Evaluation of cost-effective strategies for rabies postexposure vaccination in low-income countries. PLoS Negl. Trop. Dis. 5 (3), e982.

IHM, 2000. Petunjuk perencanaan dan penatalaksanaan kasus gigitan hewan tersangka/rabies di Indonesia. Cetakan VI. Jakarta.

Ly, S., Buchy, P., Heng, N.Y., Ong, S., Chhor, N., Bourhy, H., Vong, S., 2009. Rabies situation in Cambodia. PLoS Negl. Trop. Dis. 3, e511.

Merck Veterinary Manual. 2014. Overview of rabies. Available at: http://www.merckvetmanual.com/mvm/nervous system/rabies/overview of rabies.html (accessed on 13.11.15.).

Shim, E., Hampson K., Cleaveland S., Galvani AP., 2009. Evaluating the cost-effectiveness of rabies post-exposure prophylaxis: A case study in Tanzania. Vaccine 27, 7167- 7172.

Vallat, B., 2011. The OIE's commitment to fight rabies worldwide. Rabies: a priority for humans and animals. OIE Bull. 3, 1-2.

Wera, E., Mourits MCM., Hogeveen H. Cost-effectiveness of mass dog vaccination campaigns against rabies in Flores Island, Indonesia. Transbound. Emerg. Dis. In press.

Wera, E., Mourits MCM., Hogeveen H., 2016. Intention of dog owners to participate in rabies control measures in Flores Island, Indonesia. Prev. Vet. Med.126, 138-50.

Wera, E., Mourits, M.C.M., Hogeveen, H., 2015. Uptake of rabies control measures by dog owners in Flores Island, Indonesia. PLoS Negl. Trop. Dis. 9 (3), e0003589.

Wera, E., Velthuis, A.G., Geong, M., Hogeveen, H., 2013. Costs of Rabies Control: An Economic Calculation Method Applied to Flores Island. PLoS One 8 (12), e83654.

WHO, 2001. National burden of disease studies: A practical guide. Edition 2.0. World Health Organization. Geneva.

WHO, 2005. WHO expert Consultation on Rabies. WHO Technical Report Series 931. World Health Organisation, Geneva. 
WHO, 2013. WHO Expert Consultation on Rabies. WHO Technical Report Series 982. World Health Organization, Geneva.

WHO, 2014. Life expectancy: Life Expectancy Data Based on Country. Available at: http://apps.who.int/gho/data/node.main.688?lang=en (accessed on 17.06.14.).

Zinsstag, J., Durr, S., Penny, M., Mindekem, R., Roth, F., Gonzalez, S., Naissengar, S., Hattendorf, J., 2009. 2009. Transmission dynamics and economics of rabies control in dogs and humans in an African city. Proc. Natl. Acad. Sci. USA. 106, 14996 - 15001. 
Chapter 6 
Chapter 7

General discussion 
The main objective of this dissertation was to support decision making on the control of rabies in Flores Island, Indonesia by providing insight into the role of socio-demographic and psychological factors of dog owners in the uptake of rabies control measures and analysing the cost-effectiveness of dog vaccination strategies. As described in Chapter 1, the overall objective was split into five sub-objectives, each of which was addressed in a separate chapter (Chapters 2-6).

Chapter 2 assessed the economic impact of rabies in Flores Island as experienced during the period 2000-2011. Chapters 3 and 4 described a survey that investigated which sociodemographic and psychological factors of dog owners were associated with the current uptake of rabies control measures and with the future intention to participate in rabies control measures. Chapter 5 presented a SEIVR model (Susceptible, Exposed, Infectious, Vaccinated and Immune) in combination with a discounting cost model; these models were developed to estimate the cost-effectiveness of vaccination strategies in the dog population. Costeffectiveness was defined in this chapter as the costs per averted case of dog rabies. Chapter 6 focused on the impact of rabies control measures on human health. This chapter described an extension of the SEIVR model to evaluate the cost-effectiveness of different vaccination strategies in the dog population in combination with human post-exposure treatment (PET). Cost-effectiveness was defined as the costs per averted year of human life lost.

This concluding chapter synthesises the results of the different chapters (section 7.1), reflects on the applied research approach and methods (sections 7.2 and 7.3), discusses the possible implications of the results for future rabies control in Flores (section 7.4), elaborates on the implications for future research (section 7.5), and ends with the main conclusions of this dissertation (section 7.6).

\subsection{Synthesis of the results}

The work described in this dissertation is a good example of the "One Health" approach. The importance of this approach is described by Degeling et al. (2015): "A One Health approach emphasizing inter-disciplinary co-operation is increasingly seen as necessary for effective emerging and re-emerging infectious diseases control and prevention”. In this dissertation, different science perspectives (e.g. epidemiology, social psychology and economics) were integrated to support decision making by veterinary and public health authorities on rabies control in rural areas with a high dog density, such as Flores Island. In this section, the results from these different science perspectives are synthesised to draw conclusions with respect to the overall objective of the study.

\subsubsection{Economics of rabies and its control measures}

Control of rabies in dogs is an important means to prevent rabies in humans. Possible control measures include mass vaccination of dogs and culling of roaming dogs in infected villages. 
Dog culling can be very effective in controlling rabies in endemic areas, as demonstrated in the studies of Tenzin et al. (2010) and Shone (1962, as cited by Knobel et al., 2013). For example, Tenzin et al. (2010) reported that a timely dog culling measure in Bhutan led to the eradication of rabies in a short period (seven months after the virus introduction). In Flores, however, the culling measure failed because of a low participation rate among dog owners. Chapter 4 showed that the majority (60\%) of dog owners did not intend to cull their dogs if there was an incidence of rabies in the dog population in their village. This was because dogs have an economic value and therefore culling dogs is costly for dog owners (Chapter 2). The private costs of culling roaming dogs during the period 2000-2011 were estimated at US\$31.70 per dog culled (Chapter 2), this is equivalent to $2.8 \%$ of the GDP of Flores Island for 2014 (US\$1,147 per capita (Wikipedia, 2016)). These costs are high for dog owners, as the majority of people on Flores have a daily income of less than US\$2 per day (Chapter 3). A further explanation for the low level of intention to cull dogs is found in the belief held by most respondents that culling dogs does not reduces rabies cases in humans (Chapter 4).

Understanding the economic aspects of rabies is necessary to design a cost-effective rabies control policy. Chapter 2 therefore devoted extra attention to the economic impact of rabies control during the period 2000-2011. We showed that the economic impact on the local government was largely $(51 \%)$ due to the provision of vaccines free of charge to dog owners and human bite victims (PET). Although the costs of controlling rabies in the dog population were considerable in this period, the costs of PET were even higher because the applied strategy was unable to reduce rabies transmission from dogs to humans. This finding was confirmed by the simulated results (Chapter 6) for the strategy that reflects the current rabies control strategy in Flores Island. This strategy consists of annual vaccination campaigns using a short-acting vaccine with a coverage of $50 \%$ in combination with PET. For this strategy, the cumulative cost of PET (US\$14,127) was much higher than the cumulative cost of dog vaccination (US\$5,342) over a 10-year simulation period for a typical village of 1,500 inhabitants owning 400 dogs (Table 6.2).

The high expenditure on PET could be minimised by improving the dog vaccination strategy. Chapter 6 clearly demonstrated that, for a rabies outbreak controlled using dog vaccination, the PET costs were affected by the type of dog vaccine used, in combination with the frequency of application and the level of vaccination coverage. When the duration of vaccineinduced immunity at dog population level increased, either by the use of a long-acting vaccine or a higher coverage, the cumulative costs of PET decreased under the same campaign frequency. For example, for an annual vaccination campaign with a coverage of $50 \%$, increasing the duration of immunity of dog vaccines from 52 to 156 weeks by switching to a long-acting vaccine at an additional cost of US\$0.61 per dose (in total US\$122 per campaign; equivalent to US\$1,220 in a 10 -year simulation period) reduced the cumulative PET costs 
from US\$14,127 to US\$971 in the case of a single virus introduction into a typical village of 1,500 inhabitants owning 400 dogs. Using a short-acting vaccine but increasing the coverage from $50 \%$ to $70 \%$ at an additional cost of US\$284 per annual campaign per village (or an additional US $\$ 2,840$ for a 10 -year simulation period) reduced the cumulative PET costs even more, from US $\$ 14,127$ to US $\$ 579$ per village for a 10 -year simulation period.

Improving the vaccination strategy requires the allocation of extra resources in the first two years of an outbreak to achieve and maintain a sufficiently high level of vaccination coverage (Chapter 6). This is also demonstrated by the results in Chapter 5. Although the cumulative costs in the first two years were much higher (US\$2,264 versus US\$1,376 for a typical village) for the improved vaccination strategy (using long-acting vaccine with a coverage of $70 \%$ ) compared to the current strategy, the total public costs were lower in the long run (US\$2,527 versus US\$19,468) (Table 6.2). Moreover, the initially more expensive approach appeared effective in controlling the epidemic, resulting in more dogs and humans saved from exposure to rabies and eventually less people seeking PET. In Bali, investing in safe and effective rabies vaccines (vaccine with an immunity duration of three years) at a vaccination coverage of $70 \%$ made it possible to control rabies in less than three years (Putra et al., 2013). These findings indicate that eradication of rabies from Flores Island should be technically feasible and will depend on the combination of coverage and vaccine quality.

Chapter 6 showed that annual mass dog vaccination campaigns using a long-acting vaccine with a coverage of $70 \%$ were the most cost-effective strategy to reduce the health burden of rabies at the village level in Flores. This is in line with the findings of previous studies (Fiztpatrick et al 2014; Zinsstag et al., 2009). In comparison to the current strategy, this approach could save island-wide US\$13,800 and 418 human years of life lost during a 10year period. The saved costs are due to a reduction in PET. The long-acting vaccine remains favourable even with an increase in the likelihood of virus re-introduction. However, as the likelihood of virus re-introduction increases, the marginal effect of an increase in vaccination coverage on the cost-effectiveness decreases (Chapter 6).

\subsubsection{The impact of socio-demographic factors on the uptake of rabies control}

Knowledge of the factors associated with dog owners' decisions to vaccinate their dogs is important for policy makers to design future policy on mass vaccination campaigns. Chapter 3 showed that the uptake of the 2012 vaccination campaign was relatively low (52\%). This level of dog vaccination uptake is too low to maintain a dog population immunity that prevents rabies circulating among dogs (Hampson et al., 2009).

Chapter 3 showed that limited geographical accessibility and low income levels were important socio-demographic factors associated with the low level of participation in the Flores vaccination campaign of 2012. Dog owners living in villages with poor accessibility 
are likely to have less exposure to campaign information. These results indicate that interventions that target dog owners living in poorly accessible villages and interventions that target dog owners with a low income can be effective in increasing the level of dog vaccination uptake in the future. As discussed in Chapter 3, the majority of dog owners who did not participate in the vaccination campaign were not at home during the campaign as they were not informed by the veterinary authorities in time. It is common practice on Flores Island for dog owners with a low income to be at the field during daylight hours. To increase participation, vaccination campaigns should become more community-based. This could include discussing the campaign approach with the local community and providing an effective system for distributing information on the vaccination schedule, for instance through elementary school teachers, and church and village leaders.

\subsubsection{Dog owners' intentions and perceptions about rabies control measures}

Chapter 4 identified the socio-psychological factors associated with the intention of dog owners to participate in rabies control measures on Flores Island. The results showed that most (96\%) dog owners intended to participate in a free-of-charge vaccination campaign. This finding conflicts with the realised vaccination uptake by dog owners in Flores Island in 2012, which was only $52 \%$ even though the vaccination was free of charge (Chapter 3). This conflict suggests that constraints, such as accessibility and communication, may have prevented dog owners from implementing their intended behaviour. Measures that address these constraints, such as the community-based interventions proposed in Chapter 3, are therefore likely to be effective in changing actual behaviour.

The implementation of vaccination campaigns using a long-acting vaccine with a coverage of at least $70 \%$ (as recommended in Chapters 5 and 6) requires a substantial investment in vaccine and labour. For instance, Chapter 5 showed that the annual cost of the vaccine for an island-wide vaccination campaign using long-acting vaccine with a coverage of $70 \%$ was approximately US\$185,400 higher than for the current vaccination campaign. Limited financial resources may discourage the veterinary authorities from purchasing long-acting vaccine.

One potential solution to overcome the limited financial resources of veterinary authorities is for dog owners to participate in funding the vaccination campaigns, which can ensure the sustainability of the campaign (Meslin and Briggs, 2013). Potential synergic funding for mass dog vaccination has been successfully implemented in the Philippines, where dog owners contributed approximately $10 \%$ of the total funding of the vaccination campaign in 2010-2012 (Miranda et al., 2015). However, charging dog owners on Flores Island with a vaccination fee is likely to lead to a lower uptake of vaccination. This is supported by the results in Chapter 4: the stated intention of dog owners to participate in the vaccination campaign decreased substantially under a charged vaccination campaign (from $96 \%$ when the vaccine was free of 
charge to $24 \%$ when a fee was charged for the vaccine). The lower level of intention was associated with the perception of dog owners about their ability to pay; dog owners who perceived that they had sufficient financial resources tended to have a higher intention to participate in a charged vaccination campaign. In the context of Flores Island, charging dog owners with a fee for vaccination is likely to be ineffective. Other potential alternatives to overcome limited financial resources and achieve successful and sustainable implementation of an improved vaccination strategy include subsidising the vaccine for dog owners with a low income, involving non-governmental organisations in the funding of dog vaccination or sharing the funding between public and veterinary authorities.

\subsection{Methodological approach}

A number of methodological approaches have been used to model rabies. Bogel and Meslin (1990) developed a static, deterministic model to evaluate the cost-effectiveness of different dog vaccination strategies. They claimed that such an approach is user friendly and useful to support the decision-making process. However, such a model does not incorporate the dynamics of rabies transmission and dog demography. Therefore the results of a static deterministic model provide limited information to decision makers. The general outline of the dynamic deterministic model used in our work (SEIVR; Chapters 5 and 6) is similar to models used to evaluate the cost-effectiveness of dog vaccination strategies in Tanzania (Fitzpatrick, et al., 2014) and Chad (Zinsstag, et al., 2009), although these two studies used a stochastic approach. Limited data availability meant that a stochastic approach was not feasible for our work. A stochastic model has advantages over a deterministic model because it generates useful insights into the range of outcomes arising from natural variation and uncertainty in input parameters. Differences in the range of outcomes of the alternative vaccination strategies indicate differences in risk levels, which is relevant information to support the decision-making process.

The data used to parameterise the model, for example the virus transmission rate, were based on the knowledge of field experts and literature. Ideally, the specific estimation of the virus transmission rate should be based on observational data (e.g. occurrence of rabies in dogs and humans) (Fitzpatrick, et al. 2014; Zinsstag, et al., 2009) as it would then capture the stochastic process of rabies transmission among dogs and from dogs to humans. As discussed in Chapters 5 and 6 , the outcome of the current model was very sensitive to certain inputs, particularly the inputs related to the transmission rates (the probability of a susceptible dog being bitten by an infectious dog and the proportion of furious dogs). Although the range of uncertainty around the average results was not captured by our study, the deterministic model developed in this dissertation provides a simple and effective tool to explore the public costeffectiveness of different vaccination strategies and could easily be used by decision makers in rabies endemic areas, such as Flores Island. 
In contrast to the study of Fitzpatrick et al. (2014), the dynamics of the dog population and virus transmission were simulated over time at the level of a village (instead of the level of a square kilometre) and without accounting for spatial aspects of the spread and control of rabies outbreaks. The spatial aspects such as differences in accessibility of villages, dog density and dog movements between villages were not included in our work because of limited data. The spread of rabies among villages with good accessibility may be faster than among villages with poor accessibility. Moreover, the control of rabies in villages with lower dog densities could be achieved with lower vaccination coverage than in villages with higher dog densities. Fitzpatrick et al. (2014) compared rabies control between pastoral and agropastoral districts in Tanzania, where the dog density was nearly seven times higher in the agro-pastoral district than in the pastoral district. They found that the coverage at which rabies would no longer persist in the dog population (i.e. the herd immunity threshold) was around $10 \%$ in pastoral districts and $30 \%$ in agro-pastoral districts. This indicates that the spread and control of a rabies outbreak could vary between settings, due to different densities and contact patterns among dogs (Fitzpatrick et al., 2014).

In this study, the vaccination strategy was triggered by the detection of rabid dogs after the introduction of the virus, and stopped as soon as the outbreak was under control, reflecting a reactive approach. The current vaccination campaigns in Flores Island mostly reflect a preventive approach; application is not driven by a specific disease condition but simply by structural planning. A reactive vaccination campaign may be less effective than a structural preventive campaign, but could also save vaccination costs in the period after an outbreak has been declared to be under control (Chapters 5 and 6), while the costs of a preventive vaccination campaign remain. This is assuming that the analysis is conducted for a specific time period, such as the 10-year simulation period in this dissertation. As a consequence, the cost-effectiveness ratios of the evaluated campaigns may differ between the reactive and preventive approaches, but the ranking of the evaluated campaigns based on the costeffectiveness ratios is expected to remain the same, if the risk of virus re-introduction is taken into account (Chapter 5).

In Chapter 4, the theory of planned behaviour (TPB) (Ajzen, 1991) was used to identify the factors associated with dog owners' intention to participate in rabies control measures. The TPB is a framework that has been widely applied in veterinary science in recent years (e.g. Bruijnis et al., 2013; Delgado et al., 2012; Lind et al. 2012) to obtain insight into the socialpsychological factors (attitudes, subjective norm and perceived behavioural control) that influence intentions. However, the TPB is not the only framework that provides insight into the social-psychological factors behind behaviour with regard to animal health. For instance, the health belief model (HBM) is an alternative framework to identify the factors associated with intention. However, the HBM does not include the subjective norm. Subjective norm in 
our context refers to the influence of a group of people (e.g. religious leaders, village leaders, teachers and public health officers) whose opinions might affect the intention to participate in rabies control measures. As discussed in Chapters 3 and 4, the involvement of these groups of people is important to effectively implement rabies control measures in a regency. Their encouragement is expected to stimulate dog owners to participate in dog vaccination campaigns, as dog owners perceived the opinion of these groups as relevant in their decision to participate in rabies control measures (Chapter 4). The TPB framework only captures the intention of dog owners and the factors associated with this intention; it is unable to capture actual behaviour. Knowledge of the level of intention and the associated factors, however, already provides valuable information for decision makers to design measures and policy to increase the future uptake of rabies control measures.

\subsection{Type of economic evaluation and unit of measurement of the rabies burden}

Decision makers involved in rabies control constantly face budget constraints and must therefore allocate resources efficiently. An economic evaluation of potential rabies control measures provide decision makers with information to support efficient resource allocation. Drummond et al. (2005) identified three types of full economic evaluation of health programs: cost-effectiveness analysis (CEA), cost-utility analysis (CUA) and cost-benefit analysis (CBA). CEA is an economic evaluation method where the ratio of costs to health effects are compared across alternative strategies (Drummond et al., 2005); the strategy with the lowest cost-effectiveness ratio is considered as the favourable strategy from an economic point of view. CEA differs from CBA by measuring the effect in a non-monetary unit, and is useful in situations where it is not feasible or desirable to express the effect in a monetary unit. The outcomes of CEA are measured in programme-specific units, such as percentage of prevalence decreased, life years gained, cases cured or lives saved (Drummond et al., 2005). CEA is useful when comparing disease control strategies aimed at a specific disease. In CUA, the different outcomes (e.g. quality and quantity of life gained) are incorporated into a single composite summary outcome, such as quality-adjusted life years (QALYs) gained. This makes CUA especially useful when comparing disease control strategies for different diseases. CEA is an appropriate evaluation method for this dissertation because we consider a single disease and the effects of different vaccination strategies are measured in non-monetary units: averted dog-rabies cases (Chapter 5) and averted years of life lost (Chapter 6). Chapters 5 and 6 show that a CEA can provide valuable information for decision makers who have to determine where to allocate limited veterinary resources.

In Chapter 6 we used years of life lost as the unit to measure the burden of rabies in humans. This is in contrast to the current estimate of the global burden of rabies, which uses disabilityadjusted life years (DALYs) as the unit for measuring the burden of disease (Hampson et al., 
2015). We assumed that no years are lost due to disability because rabies has a fatality rate of almost $100 \%$ (Briggs, 2007) and because the current PET vaccine in Flores Island is a modern cell culture vaccine without any side effects. Our results for years of life lost are therefore almost identical to DALYs, unlike in some other endemic rabies countries that still use nerve tissue vaccines for PET, which have negative side effects for human health.

\subsection{Policy Implications}

The current rabies control programme in Flores Island is a combination of annual dog vaccination campaigns using short-acting vaccine with an estimated coverage of $50 \%(52 \%$ in 2012; Chapter 3) and free-of-charge PET for people bitten by a suspected rabid dog. This programme has a large economic impact on the government of Flores Island (Chapter 2) and is far from being cost-effective, as indicated by the results of the simulation model developed in this dissertation (Chapters 5 and 6). The current dog vaccination practice in Flores Island must be improved to eradicate rabies from the island. Decision makers should consider switching from the current short-acting vaccine to a long-acting vaccine and increasing the annual vaccination coverage (from $\sim 50 \%$ to at least $70 \%$ ). A combination of high coverage (70\% of the total dog population) and long-acting vaccine is expected to be the most efficient way to reduce the years of life lost due to rabies in the long run (over a 10-year period) for the situation in Flores Island (Chapter 6). However, the operational costs of increasing vaccination coverage (from $\sim 50 \%$ to $70 \%$ ) and replacing the short-acting vaccine with longacting vaccine are expected to be high for the veterinary authorities (Chapter 5).

Given the high potential economic benefits for the public health authorities due to reduced PET costs, a realistic option is to share resources between veterinary and human health authorities to conduct mass dog vaccination campaigns, reflecting the "One Health" approach. The involvement of the public health sector enabled some countries in Latin America to control and eliminate rabies disease (Vigilato et al., 2012).

Limited resources may mean that it is not feasible to implement the most efficient strategy across the entire island. In this case, differentiated campaigns could be considered whereby the intensified vaccination campaign is initially applied in those regencies that pose a high risk for human health (as indicated by the number of registered cases) or by moving the intensified campaign gradually from one side of the island to the other.

As discussed in Chapter 6, a re-introduction of the rabies virus remains a realistic risk after an outbreak has been declared to be under control, and this can lead to new epidemics. Therefore other control measures, such as quarantine of dogs entering the island and establishing joint checkpoints at the borders of regencies, are required to prevent and control human-mediated dog movement between regencies. 
Vaccination campaigns should pay more attention to dog owners in remote villages, as these dog owners were less likely to participate in control measures (Chapter 3). How much effort should be targeted towards this group is unclear. Although these dogs are less likely to be vaccinated, they may also have a lower risk of exposure to rabies and be less likely to be a source of transmission to other villages. It is vital that dog vaccination campaigns achieve uniformly high coverage in all villages within a regency regardless of their accessibility, to ensure that no villages have a lower vaccination coverage that enables the rabies virus to persist. This could be achieved through community-based interventions by involving religious leaders, village leaders, teachers and public health officers at village level to encourage dog owners to participate actively in dog vaccination campaigns. The involvement of these groups of people in rabies control activities, as discussed in Chapters 3 and 4, is likely to be important to effectively implement rabies control measures in a regency.

\subsection{Future research}

Chapter 2 of this dissertation focused on the costs of current rabies control measures in dogs and humans. Other costs, such as costs arising from rabies in livestock (e.g. cattle, pigs and horses), may also contribute to the total costs of rabies. Suspected cases of rabies in livestock have been frequently reported in Flores Island during the last two years (Siko, personal communication). Tenzin et al. (2012) reported that the total cost of direct losses of livestock due to rabies in Bhutan during the period 2001-2008 was US\$0.8 million, equivalent to $3.6 \%$ of the total costs of rabies control. Although economic losses from rabies in livestock represent only a small percentage of the total costs of rabies, the economic impact at the household level is extensive (Jibat et al., 2016). Investigating the economic impact of rabies in livestock is therefore important to obtain an accurate estimate of the net benefits of improved rabies control.

Chapters 3 and 4 considered the role of socio-demographic and psychological factors of dog owners in the uptake of rabies control measures in Flores Island. However, dog ecology factors, such as age, sex and confinement status of dogs, may also be associated with the uptake of rabies control measures. It is well documented that dogs younger than one year, female dogs and unconfined dogs are less likely to be vaccinated by their dog owners (FloresIbarra and Estrella-Valenzuela, 2004; Suzuki et al., 2008; Kaare et al., 2009; Davlin et al., 2012). Hence, additional research on the role of dog ecology factors in the uptake of rabies control measures in Flores Island is needed to provide information that can be used to design targeted interventions and thereby increase the uptake of control measures. Chapter 4 showed that an improvement in the items of dog owners' perceived behavioural control increased the intention to participate in control measures However, we did not investigate the effect of an improvement in perceived behavioural control items on the actual uptake of control measures. This should be investigated in future studies. 
The model developed in Chapters 5 and 6 did not consider either the stochasticity of input parameters or the spatial aspects of the spread and control of rabies outbreaks. As already discussed in section 7.2, incorporating stochastic characteristics of input parameters in the model is important to indicate the variability around the expected means of the outcomes. This information is useful for the decision-making process to compare risk estimates (reflected by the likelihood of bad outcomes) of different rabies control strategies. For instance, in the deterministic approach of Chapters 5 and 6, the rabies epidemic was defined to be under control when the number of infected dogs was less than 0.50 for 26 consecutive weeks. In a stochastic approach, the end of a rabies epidemic is determined by a stochastic process indicating that the epidemic is under control or not (i.e., number of infected dogs $=0$ or $>0$ ). Multiple replications subsequently result in a probability distribution that provides insight in the range of possible durations of an epidemic. A stochastic approach would add to the complexity of the model and require additional data, but could improve the understanding of the variability of the outcomes. Hence, future research should extend the current model to include the stochasticity of input parameters and the effects on the cost-effectiveness of rabies control measures.

Future research should also focus on improving the current model by incorporating spatial aspects of rabies outbreaks. Spatial aspects, such as differences in dog density, accessibility of villages and dog movements between villages, influence the spread and control of rabies outbreaks. Extending the model to capture these spatial aspects can provide insight into the dynamic of rabies and its control measures in different villages (e.g. villages with good accessibility versus villages with poor accessibility) in Flores Island. This provides decision makers with extra information to tailor the control strategy and improve the efficiency of resource allocation.

Movement of dogs between villages was not considered in Chapters 5 and 6. These movements are important because they spread the rabies virus between villages or regencies. For example, a situation recently occurred in Sikka Regency where a number of dogs and humans were bitten by a rabid dog that moved from East Flores Regency a week before clinical signs appeared (Siko, personal communication). As discussed in Chapters 5 and 6, the likelihood of dog movements between villages or regencies during an outbreak is relatively low. However, during a non-outbreak situation, the likelihood of dog movements may increase resulting in a higher likelihood for new outbreaks. It is therefore important that dog movements between villages or between regencies and the effects on rabies transmission and control are explored in more detail. Extending the simulation model to capture spatial aspects should facilitate the analysis of dog movements.

A related aspect that deserves further consideration is the impact of seasonality on the costeffectiveness of vaccination campaigns. It is common practice in Flores to trade dogs between 
villages, especially before the traditional celebrations that take place between June and August and during the Christmas and New Year season. After these events, there are fewer adult susceptible dogs. Vaccination campaigns carried out shortly after the traditional festivities are therefore expected to require less resources because fewer animals need to be vaccinated. On the other hand, a higher degree of dog movement before the festivities will also mean a higher risk of rabies transmission between villages. Further research is needed to investigate how these effects influence the cost-effectiveness of vaccination campaigns.

\subsection{Main conclusions}

Based on the research described in this dissertation, the following conclusions can be drawn:

- Rabies has a large economic impact on both the government (US\$0.6 million per year) and the dog owners (US\$0.5 million per year) of Flores Island (Chapter 2).

- Compared to other control measures, controlling rabies by culling dogs is relatively costly for dog owners because of the lost value of the dog (Chapter 2).

- Preventing rabies in humans by providing PET to exposed humans is costly for the government ( $71 \%$ of total public costs) and does not provide a permanent solution to rabies in the future (Chapter 2).

- Overall, the uptake of the 2012 vaccination campaign by dog owners was relatively low (52\%) (Chapter 3).

- Uptake of the vaccination campaign was four times more likely for dog owners living in a village with good infrastructure than for those living in more remote villages with poor road infrastructure (Chapter 3).

- Dog owners' attitudes and perceived behavioural control were significantly associated with the intention to participate in the free-of-charge vaccination campaign (Chapter 4).

- The intention to participate in the charged vaccination campaign was mainly explained by the dog owners' financial resources (Chapter 4).

- A combination of PET and annual dog vaccination campaigns using a short-acting vaccine at a coverage of 50\% was unable to bring an epidemic under control (Chapter 5) and also far from being cost-effective (Chapter 6). This suggests that the current rabies control programme in Flores Island is not an efficient investment to reduce the human rabies burden. A clear gain can be achieved by increasing the level of vaccination coverage, switching from the current short-acting vaccine to a long-acting vaccine, or both. 
- Repeated annual mass vaccination using a long-acting vaccine and with a coverage of $70 \%$ of the total number of dogs was the most cost-effective strategy to reduce rabies cases in both dogs and humans (Chapters 5 and 6). 


\section{References}

Ajzen, I., 1991. The theory of planned behavior. Organ. Behav. Hum. Decis. Process. 50, 179 - 211.

Bogel, K., Meslin, F.X., 1990. Economics of Human and Canine Rabies Elimination - Guidelines for Program Orientation. Bull. World Health Organ. 68, 281-291.

Briggs, D.J., 2007. Human Rabies Vaccine In. Elsevier/Academic Rabies. 2nd ed. Amsterdam. The Netherlands.

Bruijnis, M., Hogeveen, H., Garforth, C., Stassen, E., 2013. Dairy farmers' attitudes and intentions towards improving dairy cow foot health. Livest. Sci. 155, 103-113.

Davlin, S., Lapiz, S.M., Miranda, M.E., Murray, K., 2012. Factors Associated with Dog Rabies Vaccination in Bohol, Philippines: Results of a Cross-Sectional Cluster Survey Conducted Following the Island-Wide Rabies Elimination Campaign. Zoonoses Public Health 60, 494503.

Degeling, C., Johnson, J., Kerridge, I., Wilson, A., Ward, M., Stewart, C., Gilbert, G., 2015. Implementing a One Health approach to emerging infectious disease: Reflections on the socio-political, ethical and legal dimensions. BMC Public Health 15.

Delgado, A.H., Norby, B., Dean, W.R., McIntosh, W.A., Scott, H.M., 2012. Utilizing qualitative methods in survey design: Examining Texas cattle producers' intent to participate in foot-andmouth disease detection and control. Prev. Vet. Med. 103, 120-135.

Drummond, M.F., O'Brien, B., Stoddart, G.L., Torrance, G.W., 2005. Methods for the Economics Evaluation of Health Care Programmes. Oxford University Press. New york.

Fitzpatrick, M. C., K. Hampson, S. Cleaveland, I. Mzimbiri, F. Lankester, T. Lembo, L. A. Meyers, A. D. Paltiel and A. P. Galvani, 2014: Cost-effectiveness of canine vaccination to prevent human rabies in rural Tanzania. Ann. Intern. Med. 160, 91-100.

Flores-Ibarra, M., Estrella-Valenzuela, G., 2004. Canine ecology and socioeconomic factors associated with dogs unvaccinated against rabies in a Mexican city across the US-Mexico border. Prev. Vet. Med. 62, 79-87.

Hampson, K., Coudeville, L., Lembo, T., Sambo, M., Kieffer, A., Attlan, M., et al. 2015. Estimating the global burden of endemic canine rabies. PLoS Negl. Trop. Dis. 9 (4), e0003709.

Hampson, K., J. Dushoff, S. Cleaveland, D. T. Haydon, M. Kaare, C. Packer and A. Dobson, 2009: Transmission dynamics and prospects for the elimination of canine Rabies. PLoS Biol. 7, 0462-0471.

Jibat, T., Mourits, M.C.M., Hogeveen, H., 2016. Incidence and economic impact of rabies in the cattle population of Ethiopia. Prev. Vet. Med. 130, 67-76.

Kaare, M., Lembo, T., Hampson, K., Ernest, E., Estes, A., Mentzel, C., Cleaveland, S., 2009. Rabies control in rural Africa: evaluating strategies for effective domestic dog vaccination. Vaccine $27,152-160$.

Knobel, D.L., Lembo, T., Morters, M., Townsend, S.E., Cleaveland, S., et al., 2013. Dog Rabies and Its Control. Rabies: Elsevier Inc. pp. 591-615.

Lind, A.-K., Thomsen, P., Rintakoski, S., Espetvedt, M., Wolff, C., Houe, H., 2012. The association between farmers' participation in herd health programmes and their behaviour concerning treatment of mild clinical mastitis. Acta Vet. Scand. 54, 1-9. 
Miranda, L.M., Miranda, M.E., Hatch, B., Deray, R., Shwiff, S., Roces, M.C., Rupprecht, C.E., 2015. Towards Canine Rabies Elimination in Cebu, Philippines: Assessment of Health Economic Data. Transbound. Emerg. Dis. (in Press).

Putra, A.A.G., Hampson, K., Girardi, J., Hiby, E., Knobel, D., Wayan Mardiana, I., Townsend, S., Scott-Orr, H., 2013. Response to a rabies epidemic, Bali, Indonesia, 2008-2011. Emerg. Infect. Dis. 19, 648-651.

Suzuki, K., Pereira, J.A.C., Frías, L.A., López, R., Mutinelli, L.E., Pons, E.R., 2008. Rabiesvaccination Coverage and Profiles of the Owned-dog Population in Santa Cruz de la Sierra, Bolivia. Zoonoses Public Health 55, 177-183.

Tenzin, Sharma, B., Dhand, N.K., Timsina, N., Ward, M.P., 2010. Re-emergence of rabies in Chhukha district, Bhutan, 2008. Emerg. Infect. Dis. 16, 1925-1930.

Tenzin, Wangdi, K., Ward, M.P., 2012. Human and animal rabies prevention and control cost in Bhutan, 2001-2008: The cost-benefit of dog rabies elimination. Vaccine 31, 260-271.

Vigilato, M.A.N., Clavijo, A., Knobl, T., Silva, H.M.T., Cosivi, O., Schneider, M.C., Leanes, L.F., Belotto, A.J., Espinal, M.A., 2013. Progress towards eliminating canine rabies: Policies and perspectives from Latin America and the Caribbean. Phil. Trans. R. Soc. B. 368, 20120143.

Zinsstag, J., S. Durr, M. Penny, R. Mindekem, F. Roth, S. Gonzalez, S. Naissengar and J. Hattendorf, 2009: Transmission dynamics and economics of rabies control in dogs and humans in an African city. Proc. Natl. Acad. Sci. USA. 106, 14996 - 15001. 
Chapter 7 
Summary 
Rabies is a viral disease that can cause encephalomyelitis both in animals and humans. With a fatality rate of almost $100 \%$, rabies has the highest case fatality rate of any infectious human disease. Recent global estimate of annually human rabies deaths is 61,000 cases with $45 \%$ of these cases occurring in the South East Asia region. In this region domestic dogs are the major transmitters of the disease to humans. Since its introduction in 1984, rabies has been a serious health threat in Indonesia with 150-300 fatal human rabies cases reported annually. Among all islands of Indonesia, Flores Island has one of the highest incidences of rabies with approximately 19 fatal human cases a year.

A structural approach to prevent rabies in human is the elimination of rabies in the dog population through mass dog vaccination campaigns. Since 2000, the local government of Flores has been offering annual mass dog vaccination campaigns for free. Despite these campaigns, rabies is still endemic in Flores indicating that the current vaccination strategy has not been effective in controlling the disease. The success of a dog vaccination strategy in controlling the disease depends on the vaccination coverage (proportion of dogs vaccinated) in relation to the turnover rate of the dog population, and on the period of immunity induced by the type of vaccine used in relation to the campaign frequency. The proportion of dogs vaccinated during annual campaigns should be high enough to maintain the population immunity between campaigns. In practice, this proportion depends on the extent by which dog owners participate in the offered vaccination campaigns as well as the available resources to finance the vaccination campaigns; application of long acting vaccine and or higher campaign frequencies require higher investments from the animal health authorities.

The main objective of this dissertation was to support decision making on the control of rabies in Flores Island, Indonesia by providing insight into the role of socio-demographic and psychological factors of dog owners in the uptake of rabies control measures and analysing the cost-effectiveness of dog vaccination strategies. This objective was addressed by the following five sub-objectives:

1. To estimate the costs of rabies control measures currently applied in both dogs and humans (Chapter 2).

2. To identify the role of socio-demographic factors of dog owners associated with the uptake of rabies control measures (Chapter 3).

3. To identify the role of psychological factors of dog owners (attitude, subjective norm, and perceived behavioral control) in the intention to participate in future rabies control measures (Chapter 4).

4. To evaluate the cost-effectiveness of different dog vaccination strategies in reducing dog rabies cases (Chapter 5).

5. To evaluate the cost-effectiveness of different dog vaccination strategies in reducing human rabies cases (Chapter 6). 
Chapter 2 developed a deterministic economic model to calculate the costs of the currently applied rabies control measures. Total costs of rabies control measures were estimated at US\$1.12 million (range: US\$0.60-1.47 million) per year. The costs of culling roaming dogs resulted in the highest cost portion (39\%), followed by the costs of post-exposure treatment (35\%), mass vaccination costs $(24 \%)$, costs for pre-exposure treatment $(1.4 \%)$, and remaining costs $(1.3 \%)$ (dog-bite investigation, diagnostic testing of suspected rabid dogs, trace-back investigation of human contact with rabid dogs, and quarantine of imported dogs). Of the total costs of rabies control measures during the study period (2000-2011) of US\$13.4 million, public costs were higher (US\$6.8 million) than private costs (US\$6.6 million). Control of rabies by culling dogs was relatively costly for the dog owners (5.1 million; $77 \%$ of the total private costs) in comparison with other applied control measures. Providing post-exposure treatment for humans is, in general, an effective way to prevent rabies, but is costly for government ( $71 \%$ of total public costs on Flores) and does not provide a permanent solution to rabies in the future. Vaccination of dogs against rabies, on the other hand, is recognized as an effective means to control rabies in dogs and eventually in humans. However, Chapter 2 showed that the uptake level of vaccination of dogs against rabies during 2000-2011 was lower $(52 \%)$ than the recommended level by WHO (70\%) to prevent rabies circulating within dog population.

Dog owners' decisions in the uptake of rabies control measures are significantly influenced by socio-demographic and psychological factors. Therefore, an understanding of these factors is essential to support policy decisions about rabies control in the future and were elaborated in detail in Chapters 3 and 4.

Chapter 3 identified risk factors associated with the uptake level of rabies control measures on Flores Island, by describing the results of an extensive survey among 450 dog-owners from 44 randomly selected villages in the regencies of Sikka and Manggarai. Specific emphasize was given to the analysis of socio-demographic factors and the knowledge level of the dog owners associated with the uptake of the vaccination campaign of 2012. The results showed that the majority of dog owners surveyed (>90\%) knew that rabies is a fatal disease and that it can be prevented by proper post-exposure treatment. Moreover, 68\% of the dog owners had a high level of knowledge about available rabies control measures. Fifty-two percent of the dog owners had had at least one of their dogs vaccinated during the 2012 vaccination campaign. Vaccination uptake was significantly higher for dog owners who resided in Sikka, kept female dogs for breeding, had an income of more than one million rupiah, and had easy access to their village. The most important reasons not to join the vaccination campaign were lack of information about the vaccination campaign schedule (40\%) and difficulty to catch the dog during the vaccination campaign (37\%). Targeted distribution of information on vaccination schedules and methods to catch and restrain dogs in 
those villages with poor accessibility may, therefore, increase vaccination uptake in the future.

Chapter 4 used the Theory of Planned Behaviour to identify the psychological factors, which are associated with the intention of dog owners to participate in rabies control measures by face to face questionnaires administered to the 450 selected dog owners in the regencies Manggarai and Sikka. Ninety-six percent of the surveyed dog owners indicated to have the intention to participate in a free-of-charge vaccination campaign. This intention level decreased to $24 \%$ when dog owners were asked to pay a vaccination fee equal to the market price of the vaccine (Rp 18.000 per dose=US\$2). Approximately $81 \%$ of the dog owners intended to keep their dogs inside their house or to leash them day and night during a period of at least three months in case of an incidence of rabies in the dog population within their village. Only $40 \%$ intended to cull their dogs in case of a rabies incident in their village. Using multivariable logistic regression analysis, the attitude item 'vaccinating dogs reduces rabies cases in humans', and the perceived behavioural control items 'availability of time' and 'ability to confine dogs' were shown to be significantly associated with the intention to participate in a free-of-charge vaccination campaign. The attitude item 'culling dogs reduces rabies cases in humans' was significantly associated with the intention to participate in a culling measure. The attitude item 'leashing of dogs reduces human rabies cases' and perceived behavioural controls 'availability of time' and 'money to buy a leash' were associated with the intention to leash dogs during a rabies outbreak. As the attitude variables were often significantly associated with intention to participate in a rabies control measure, an educational rabies campaign focusing on the benefit of rabies control measures is expected to increase the intention of dog owners to participate in future rabies control measures. The significant association between perceived behavioural controls and intention to participate, points to other relevant policy interventions, like providing dog owners with a skill to confine dogs and creating a subsidy program to cover the vaccine and leash costs. Moreover appropriate time management, such as implementing vaccination campaigns during the weekend, could improve the current coverage in the future, by relaxing the constraints on the availability of dog owners' time.

Given the limited resources available in Flores Island, integrated analyses on the efficiency and effectiveness of the improved control measures in the long term are important to support the decision making process. In this context Chapters 5 and 6 of this dissertation gave special attention on the cost-effectiveness analysis of different mass dog vaccination strategies against rabies in a dog population.

Chapter 5 presented a dynamic deterministic simulation model to determine the costeffectiveness of different mass dog vaccination strategies against rabies in a dog population representative of a typical village on Flores Island with 1,500 inhabitants and 400 dogs. Costeffectiveness was measured as public cost per averted dog-rabies case. Simulations started 
with the introduction of one infectious dog into a susceptible dog population of 399 dogs, and subsequently ran for a period of 10 years. The base scenario represented a situation without any control intervention. Evaluated vaccination strategies consisted of annual vaccination campaigns with short-acting vaccine (immunity duration of 52 weeks) (AV_52), annual campaigns with long-acting vaccine (immunity duration of 156 weeks) (AV_156), biannual campaigns with short-acting vaccine (BV_52), and once-in-two-years campaigns with longacting vaccine (O2V_156). The effectiveness of the vaccination strategies was simulated for vaccination coverages of $50 \%$ and $70 \%$. Cumulative results were reported for the 10 -year simulation period. The base scenario resulted in three epidemic waves, with a total of 1274 dog-rabies cases. The cumulated public cost of applying AV_52 at a coverage of 50\% was US\$5342. This strategy was unfavorable compared to other strategies, as it was costly and ineffective in controlling the epidemic. The costs of AV_52 at a coverage of $70 \%$ and AV_156 at a coverage of $70 \%$ were, respectively, US\$3646 and US\$3716, equivalent to US\$3.00 and US\$3.17 per averted dog-rabies case. Increasing the coverage of AV_156 from $50 \%$ to $70 \%$ reduced the number of rabies cases by $7 \%$, and reduced the cost by US\$1452, resulting in a cost-effectiveness ratio of US\$1.81 per averted dog-rabies case. The simulation model presented in Chapter 5 provides an effective tool to explore the public costeffectiveness of mass dog vaccination strategies in Flores Island. Insights obtained from the simulation results are useful for animal health authorities to support decision making in rabies-endemic areas, such as Flores Island.

Chapter 6 subsequently evaluated the cost-effectiveness of different mass dog rabies vaccination strategies defined as the costs per year of life lost (YLL) averted by extending the developed simulation model with a module reflecting the transmission between dogs and humans. In the base strategy (no dog vaccination and no post-exposure treatment of human bite cases), the model showed that the introduction of the virus by one infectious dog into an isolated village with 1,500 inhabitants and 400 dogs resulted in 776 YLLs during a 10-year simulation period, which is equivalent to 26 human rabies cases. An annual dog vaccination campaign with a coverage of $70 \%$ using a short-acting vaccine saved 733 YLLs, while the cumulative costs for the public sector were US\$3,646 or US\$4.98/YLL averted. Switching to a long-acting vaccine, the annual vaccination strategies with a coverage of 50\% (AV_156_50) or 70\% (AV_156_70) reduced the baseline YLLs from 776 to respectively 69 and 23 YLLs with cumulative costs of US\$3,716 and US\$2,264 or US\$5.25 and US\$3.01 per YLL averted, respectively. In general, dog vaccination was more cost-effective than post-exposure treatment alone (US\$3.01-5.25 per YLL averted versus US\$26.43 per YLL averted). Although a combination of post-exposure treatment with AV_156_70 was less cost-effective compared to AV_156_70 alone, this strategy was able to prevent any human deaths by rabies. A combination of post-exposure treatment with annual vaccination using a short-acting vaccine at a coverage of $50 \%$ was far from being cost-effective, suggesting that the currently 
applied rabies control in Flores Island is not an efficient investment in reducing human rabies burden. An increased investment in either an increase in the current coverage or in a switch from the short-acting vaccine to the long-acting vaccine type would certainly pay off.

Finally, Chapter 7 synthesised the results of this dissertation to draw conclusions with respect to the overall objective of the dissertation. This chapter also reflected on the integrated research approach and methods applied, discussed implications of the results for future rabies control in Flores Island and outlined directions for future research.

Based on the research described in this dissertation, the following conclusions can be drawn:

- Rabies has a large economic impact on both the government (US\$0.6 million per year) and the dog owners (US\$0.5 million per year) of Flores Island (Chapter 2).

- Compared to other control measures, controlling rabies by culling dogs is relatively costly for dog owners because of the lost value of the dog (Chapter 2).

- Preventing rabies in humans by providing PET to exposed humans is costly for the government ( $71 \%$ of total public cost) and does not provide a permanent solution to rabies in the future (Chapter 2).

- Overall, the uptake of the 2012 vaccination campaign by dog owners was relatively low (52\%) (Chapter 3).

- Uptake of the vaccination campaign was four times more likely for dog owners living in a village with good infrastructure than for those living in more remote villages with poor road infrastructure (Chapter 3).

- Dog owners' attitudes and perceived behavioural control were significantly associated with the intention to participate in the free-of-charge vaccination campaign (Chapter 4).

- The intention to participate in the charged vaccination campaign was mainly explained by the dog owners' financial resources (Chapter 4).

- A combination of PET and annual dog vaccination campaigns using a short-acting vaccine at a coverage of $50 \%$ was unable to bring an epidemic under control (Chapter 5) and also far from being cost-effective (Chapter 6). This suggests that the current rabies control programme in Flores Island is not an efficient investment to reduce the human rabies burden. A clear gain can be achieved by increasing the level of vaccination coverage, switching from the current short-acting vaccine to a long-acting vaccine, or both.

- Repeated annual mass vaccination using a long-acting vaccine and with a coverage of $70 \%$ of the total number of dogs was the most cost-effective strategy to reduce rabies cases in both dogs and humans (Chapters 5 and 6). 


\section{Acknowledgements}


Writing this thesis is not something I did alone. Many people have played an important role. Therefore, it is a pleasure to thank those who made this thesis possible. First of all, I would like to express my sincerest appreciation and gratitude to my promotor and co-promotor, Prof. dr ir Henk Hogeveen and Dr ir Monique Mourits. Henk, thank you for your advice, guidance, and support. Your scientific insight and support were very valuable for writing this thesis. Your words of encouragement: "Ewaldus, you are on the track..." really motivated me to finalize this thesis. I have learnt a lot from you and I am grateful to you for that. Dear Monique, I was privileged to do my $\mathrm{PhD}$ under your close supervision. You have never complained although we had a regular weekly meeting and bi-weekly skype meeting when I was in Indonesia. You were always available whenever needed, even during your family time and your overwhelming periods of work. Your critical remarks really challenged me to think and write critically. I learned a lot from you and I really appreciate you for that. My gratitude goes also to Dr Annet Velthuis and Dr Maria Geong for their extensive assistance during the first year of my $\mathrm{PhD}$ journey. Annet, thank you for carrying me passed that critical time of my $\mathrm{PhD}$ journey and thank you for all the support throughout the process of writing the proposal and Chapter 2 of this thesis. Ibu Maria, even though we never worked together directly, your encouragement and support brought me to the topic of rabies. Chapter 2 of this thesis could not have been written without the data that you provided. I really appreciate you for that.

This $\mathrm{PhD}$ journey would be never started without supporting from the Business Economics group (BEC). I am immensely grateful to the chair of the group, Prof. dr ir Alfons Oude Lansink for accepting me as a PhD student in his group. Alfons, thank you for the 'letter of acceptance' that you provided me to obtain a scholarship from the Indonesian Government. Without the letter, it would not be impossible for me to be in Wageningen. I would also like to acknowledge the support and help from the support staff of BEC (Anne, Jeannette, Ilona) and the international office of WASS (Nalini, Ineke) for taking care of all administration and immigration matters. Furthermore, I do not want to forget to thank my paranymphs, Dikky Indrawan and Nurul Suhaimi, and all $\mathrm{PhD}$ colleagues and staff at BEC for creating the atmosphere that made my study in Wageningen so pleasant.

I am grateful to the Directorate General of Human Resource for Science, Technology and Higher Education of Indonesia for the financial support for this $\mathrm{PhD}$ project and to Director/former Directors of Politeknik Pertanian Negeri Kupang: Ir Blasius Gharu, M.Si; Ir Jacobus S. Oematan M.Si, and Ir Joseph P. Ticoalu, M.Si for granting me a study permit to conduct this $\mathrm{PhD}$ project. My sincere recognition is extended to the staff of Dinas Peternakan dan Kesehatan Hewan Kabupaten Sikka and Manggarai where this research was carried out. A special thanks to Maria Margaretha Siko, DVM, MSc and Severinus Jani Hadir, SST for facilitating the field work. Special thanks also go to all Indonesian colleagues in Wageningen 
especially mba Arita, mas Agung, and mas Dipo for the friendship and the hospitality during the years of my study.

I would like to dedicate this thesis to my father, Nikolaus Marus (Alm) and my mother, Berta Cea. Papa Niko and ende (mama) Berta, your loving care and the freedom you created for me have largely made me what I am today. Ende Berta, you are a super woman. You teached me how to survive in difficult situations. Thanks for the continuous support, blessing and love. Papa Niko, you were the first who learned me how to live with integrity, hard work and respect for each other, wherever we are. You are not with me now, but I do believe your promise that you will always pray for me and my family wherever we are.

Last but not least, I would like to thank all my family members for their unconditional support, especially to my beloved wife, Velomena Marjelija Murung (Bunda) and my son, Alfonsus Nederlando Wera (Derlan), and my daughter Maria Aliana Kennocha Wera (Alin). Bunda, thank you for being a strong mom for our son and daughter during the several hard periods of my absence. Thank you also for your trust, sacrifice and whole-hearted support especially in the very stressful moments I had during the completion of this $\mathrm{PhD}$ journey. Now, I am a DOCTOR, let us celebrate it!

\section{Ewaldus Wera}

April, 2017

Wageningen, The Netherlands 


\section{About The Author}

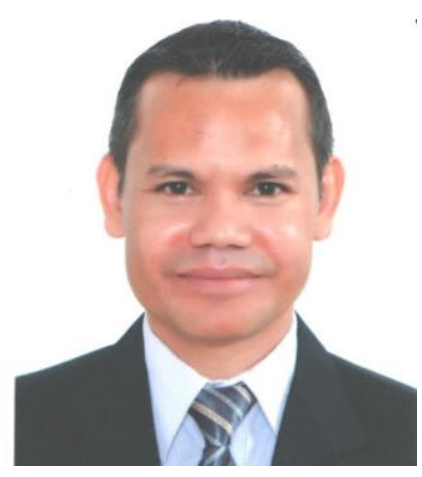

Ewaldus Wera was born on April 25, 1978 in Bung Manggarai, Flores Island, Indonesia. He completed his senior high school at SMUN 1 Ruteng, Flores in 1997 and his Doctor of Veterinary Medicine (DVM) education at Bogor Agricultural University (Institut Pertanian Bogor) in 2003. He then worked some time at PT Tekad Mandiri Citra as a technical support for poultry farmers in Bandung, Indonesia before joining Kupang State Agricultural Polytechnic (Politeknik Pertanian Negeri Kupang) in 2004. He contributed as a lecturer to the Animal Health Study Program and expanded his skill and knowledge by participating in various trainings in Indonesia as well as abroad. Amongst others, he was selected to join a short course 'Modern Broiler Management' at Massey University, New Zealand in 2007. In 2008, he joined the master program Veterinary Epidemiology and Economics at the Faculty of Veterinary Medicine, Utrecht University, Netherlands. He graduated in 2010 after which he joined the Business Economics group of the Wageningen University and Research, Netherlands to obtain his $\mathrm{PhD}$ on the socioeconomic modelling of rabies control in Flores Island. During his $\mathrm{PhD}$ work he was involved in tutoring practical sections in the courses 'Decision Science II' and 'Food Safety Economics'. He attended several international conferences and has published various original research papers in peer reviewed international journals. He has been a reviewer for scientific journals such as Preventive Veterinary Medicine, Vaccine, Frontiers in Veterinary Science, and Journal of Wildlife Diseases. Together with two other junior scientists, on March 9, 2017, he was given the opportunity to present his $\mathrm{PhD}$ research at the $99^{\text {th }}$ Dies Natalis of Wageningen University \& Research within the theme 'Towards a Global One Health'.

Ewaldus' research interest focuses on the epidemiological and socio-economic impacts of zoonotic infectious diseases and their control. After his $\mathrm{PhD}$ graduation he will rejoin the Politeknik Pertanian Negeri Kupang as a lecturer. For more information, he can be reached through his email: nanawaldi@yahoo.com. 


\section{Publications}

\section{Refereed scientific journals}

1. Wera, E., Velthuis AGJ., Geong M., Hogeveen H., 2013. Costs of Rabies Control: An Economic Calculation Method Applied to Flores Island. PLoS ONE 8(12): e83654. doi:10.1371/journal.pone.0083654.t002

2. Wera, E., Monique MC. Mourits, Hogeveen H., 2015. Uptake of rabies control measures by dog owners in Flores Island, Indonesia. Plos Neglected Tropical Disease 9(3): e0003589. doi:10.1371/journal.pntd.0003589

3. Wera, E., Monique MC. Mourits, Hogeveen H., 2016. Intention of dog owners to participate in rabies control measures in Flores Island, Indonesia. Preventive Veterinary Medicine. doi:10.1016/j.prevetmed.2016.01.029

4. Wera, E., Monique MC. Mourits, Hogeveen H., 2016. Cost-effectiveness of mass dog vaccination campaigns against rabies in Flores Island, Indonesia. Transboundary and Emerging Diseases (in press). doi:10.1111/tbed.12590

5. Wera, E., Monique MC. Mourits, Hogeveen H., 2016. Cost-effectiveness of mass dog rabies vaccination strategies to reduce human health burden in Flores Island, Indonesia. Under review by the Journal of Vaccine.

\section{Contributions to conferences and seminars}

1. Wera, E., Velthuis AGJ., Geong M., Hogeveen H., 2012. Costs of the current rabies control strategies on Flores Island; Presented at the 13th International Symposium on Veterinary Epidemiology and Economics (ISVEE). Maastricht, The Netherlands, 2024 August 2012. (Oral presentation).

2. Wera, E., Velthuis AGJ., Geong M., Hogeveen H., 2012. Framework to Evaluate the cost-effectiveness of rabies control on Flores Island. Presented at the 13th International Symposium on Veterinary Epidemiology and Economics (ISVEE). Maastricht, The Netherlands, 20-24 August 2012. (Poster presentation).

3. Wera, E., Velthuis AGJ., Hogeveen H., 2012. The economic impact of rabies control programs on Flores Island, Indonesia. Presented at the 8th International Workshop held at Research Centre Foulum, Denmark, 5 October 2012. (Oral presentation).

4. Wera, E., Monique MC. Mourits, Hogeveen H., 2014. Adoption of dog vaccination program in Flores Island. Presented at the Annual Conference of The Society for Veterinary Epidemiology and Preventive Medicine (SVEPM). Dublin, Ireland, 26-28 March 2014. (Poster presentation). 
5. Wera, E., Monique MC. Mourits, Hogeveen H., 2015. The intention of dog owners towards vaccination program in Flores Island. Presented at the Annual Conference of The Society for Veterinary Epidemiology and Preventive Medicine (SVEPM). Ghent, Belgium, 25-27 March 2015. (Poster presentation).

6. Wera, E., Monique MC. Mourits, Hogeveen H., 2015. The uptake of vaccination campaign in Flores Island, Indonesia. Presented at the 3rd INTERNATIONAL ONE HEALTH Conference. Amsterdam, the Netherlands, 15-18 March 2015. (Poster presentation).

7. Wera, E., Monique MC. Mourits, Hogeveen H., 2015. Cost-effectiveness of mass dog vaccination campaigns against rabies in Flores Island, Indonesia; Presented at the 14th International Symposium of Veterinary Epidemiology and Economics (ISVEE). Merida, Yucatan, Mexico, 3-7 November 2015. (Oral presentation).

8. Wera, E., Monique MC. Mourits, Hogeveen H., 2017. Socio-economic modelling to support zoonotic diseases control: The example of rabies in Flores Island, Indonesia. Presented at the $99^{\text {th }}$ Dies Natalis of Wageningen University \& Research within the theme 'Towards a Global One Health'. Wageningen, 9 March 2017. (Oral presentation). 


\section{Ewaldus Wera}

Wageningen School of Social Sciences (WASS)

\section{Completed Training and Supervision Plan}

Wageningen School

of Social Sciences

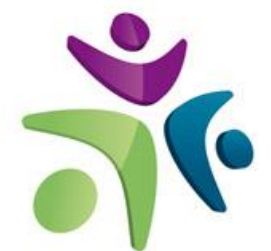

\begin{tabular}{llcc}
\hline Name of the learning activity & Department/Institute & Year & ECTS $^{\mathbf{2}}$ \\
\hline $\begin{array}{l}\text { A) Project related competences } \\
\begin{array}{l}\text { Agricultural Business Economics, } \\
\text { BEC 51806 }\end{array}\end{array}$ & WUR & 2011 & 6.0 \\
$\begin{array}{l}\text { Applied Economic Modelling for the } \\
\text { Veterinary Sciences }\end{array}$ & $\begin{array}{l}\text { Graduate School of Life } \\
\text { Science, Utrecht University }\end{array}$ & 2012 & 3.0 \\
$\begin{array}{l}\text { Advanced Agricultural Economics, } \\
\text { BEC 30306 }\end{array}$ & WUR & 2012 & 6.0 \\
$\begin{array}{l}\text { Quantitative Risk Analysis in Animal Health } \\
\text { and Food Safety }\end{array}$ & $\begin{array}{l}\text { EpiX Analytics; Pre-ISVEE } \\
\text { 13 Workshop Course, }\end{array}$ & 2012 & 1.0 \\
$\begin{array}{l}\text { Methodology in Health Economic Evaluation } \\
\text { Ghent, Belgium }\end{array}$ & $\begin{array}{l}\text { Graduate School of Life } \\
\text { Science, Utrecht University }\end{array}$ & 2012 & 1.5 \\
$\begin{array}{l}\text { Generalized Linear Model } \\
\text { Introduction to R }\end{array}$ & $\begin{array}{l}\text { PE\&RC, WUR } \\
\text { PE\&RC, WUR }\end{array}$ & 2012 & 0.6 \\
\hline
\end{tabular}

\section{B) General research related competences}

\begin{tabular}{|c|c|c|}
\hline $\begin{array}{l}\text { Research Methodology: From Topic to } \\
\text { Proposal }\end{array}$ & WASS & 2011 \\
\hline WASS Introduction Course & WASS & 2012 \\
\hline Writing PhD proposal & BEC, WUR & 2011-2012 \\
\hline BEC PhD Meetings & BEC, WUR & 2012-2015 \\
\hline $\begin{array}{l}\text { 'The economic impact of rabies control } \\
\text { programs on Flores Island, Indonesia' }\end{array}$ & IWFAHE, Foulum, Denmark & 2012 \\
\hline $\begin{array}{l}\text { 'Costs of the current rabies control } \\
\text { strategies in Flores Island' }\end{array}$ & $\begin{array}{l}\text { The } 13^{\text {th }} \text { ISVEE, Maastricht, } \\
\text { The Netherlands }\end{array}$ & 2012 \\
\hline $\begin{array}{l}\text { 'Framework to Evaluate the cost- } \\
\text { effectiveness of rabies control in Flores } \\
\text { Island' }\end{array}$ & $\begin{array}{l}\text { The } 13^{\text {th }} \text { ISVEE, Maastricht, } \\
\text { The Netherlands }\end{array}$ & 2012 \\
\hline $\begin{array}{l}\text { 'Adoption of dog vaccination program in } \\
\text { Flores Island' }\end{array}$ & SVEPM. Dublin, Ireland & 2014 \\
\hline $\begin{array}{l}\text { 'The intention of dog owners towards } \\
\text { vaccination program in Flores Island' }\end{array}$ & SVEPM, Ghent, Belgium & 2015 \\
\hline $\begin{array}{l}\text { 'The uptake of vaccination campaign in } \\
\text { Flores Island, Indonesia' }\end{array}$ & $\begin{array}{l}\text { The } 3^{\text {rd }} \text { INTERNATIONAL } \\
\text { ONE HEALTH Conference. } \\
\text { Amsterdam, The }\end{array}$ & 2015 \\
\hline
\end{tabular}


Netherlands

'Factors associated with the dog owners'

WASS Multidisciplinary

2015

intention to participate in rabies control in

Seminar (PhD day),

Wageningen

Flores Island, Indonesia'

The $14^{\text {th }}$ ISVEE, Merida,

2015

1.0

campaigns against rabies in Flores Island,

Yucatan, Mexico

Indonesia'

\section{C) Career related competences/personal development}

Techniques for Writing and Presenting a

Wageningen Graduate

2012

Scientific Paper

School, WUR

Information Literacy Including EndNote

WUR Library

2012

0.6

Introduction (ILP)

Voice Matters-Voice and presentation Skills

WASS

2012

Training

Efficient Writing Strategies

Wageningen in'to

2014

1.2

Languages

Tutoring practical sections in the course

BEC, WUR

2014,2015

1.0

'Decision Science II'

Tutoring practical sections in the course

BEC, WUR

2014

0.5

'Food Safety Economics'

Total

${ }^{1} \mathrm{BEC}=$ Business Economics Group; WUR=Wageningen University and Research Centre; ISVEE= International Symposium on Veterinary Epidemiology and Economics; PE\&RC=Graduate School for Production Ecology and Resource Conservation; WASS = Wageningen School of Social Sciences; IWFAHE=International Workshop on Farm Animal Health Economics; SVEPM= Society for Veterinary Epidemiology and Preventive Medicine.

${ }^{2}$ One credit according to ECTS is on average equivalent to 28 hours of study load 
The research described in this thesis was financially supported by The Directorate General of Human Resource for Science, Technology and Higher Education of Indonesia.

Financial support from Business Economics Group, Wageningen University for printing this thesis is gratefully acknowledged.

Cover design by Ewaldus Wera

Printed by Proefschriftmaken.nl || Uitgeverij BOXPress 